TESORO ELENA DEL CARPIO HUAYLLAS

\title{
MICRO-REDES ELÉTRICAS: ESTADO DA ARTE E CONTRIBUIÇÃO PARA O DIMENSIONAMENTO, APLICAÇÃO E COMERCIALIZAÇÃO DA ENERGIA PRODUZIDA
}

Tese apresentada à Escola Politécnica da Universidade de São Paulo para obtenção do título de Doutor em Ciências. 


\section{MICRO-REDES ELÉTRICAS: ESTADO DA ARTE E CONTRIBUIÇÃO PARA O DIMENSIONAMENTO, APLICAÇÃO E COMERCIALIZAÇÃO DA ENERGIA PRODUZIDA}

Tese apresentada à Escola Politécnica da Universidade de São Paulo para obtenção do título de Doutor em Ciências.

Área de Concentração:

Sistemas de Potência

Orientador:

Prof. Dr. Dorel Soares Ramos 
Este exemplar foi revisado e alterado em relação à versão original, sob responsabilidade única do autor e com a anuência de seu orientador.

São Paulo, 12 de Agosto de 2015.

Assinatura do autor

Assinatura do orientador

Catalogação na publicação

Del Carpio Huayllas, Tesoro Elena

Micro-redes elétricas: estado da arte e contribuição para o dimensionamento, aplicação e comercialização da energia produzida / T.E. Del Carpio Huayllas. -- ed. rev.--São Paulo, 2015. p.162

Tese (Doutorado) - Escola Politécnica da Universidade de São Paulo. Departamento de Engenharia de Energia e Automação Elétricas.

1.Distribuição de energia elétrica 2.Micro-redes elétricas 3.Negociação de energia, Operação de Sistemas Ilhados

I.Universidade de São Paulo. Escola Politécnica. Departamento de Engenharia de Energia e Automação Elétricas II.t. 


\section{AGRADECIMENTOS}

Ao Professor Dr. Dorel Soares Ramos, pela orientação, confiança e sugestões realizadas durante o desenvolvimento do trabalho. Por estar sempre do meu lado, nos piores e melhores momentos, proporcionando todo o suporte e apoio que foi preciso.

Aos Profs. Dr's Carlos Marcio Vieira Tahan e Eliane Aparecida F. A. Fadigas pelas sugestões e comentários feitos na fase de qualificação do trabalho.

Ao Prof. Dr. Marciano Morozowski Filho, pelas sugestões e importante contribuição na revisão da tese na sua edição final.

À CAPES e ao Departamento de Engenharia de Energia e Automação Elétricas (PEA), pelo apoio financeiro que tornou possível a realização deste trabalho. 


\section{Resumo}

As conseqüências e repercussões do recente blecaute de grande escala ocorrido no Brasil em 2009, que afetou as regiões Sudeste, Sul, Centro-Oeste e Nordeste além do Paraguai todo; assim como aqueles que afetaram a região do Norte e Nordeste dos Estados Unidos (2003) e toda Itália, também em 2003, mostraram mais uma vez que na atualidade a sociedade tem uma dependência quase total da energia elétrica. Em todos os casos, a falta de energia elétrica atingiu de forma significativa vários setores da economia, ao passo que sistemas de transporte elétrico, indústrias e hospitais sem sistemas de geração emergencial, instituições acadêmicas, iluminação pública e residencial e, inclusive, sistemas de comunicação, ficaram praticamente inoperantes. Após esses eventos, houve uma busca por algumas alternativas que ofereçam maior confiabilidade no fornecimento de energia elétrica ou, pelo menos, alternativas que ajudem a minimizar o seu impacto. O estabelecimento de sistemas baseados em micro-redes elétricas mostrou-se como uma alternativa que poderia ser utilizada para tal finalidade, de tal forma que não apenas cargas críticas, mas também boa parte das atividades mencionadas poderia continuar operando durante períodos de contingência. Por outro lado, o conceito das micro-redes elétricas tem ganho recentemente maior atenção em virtude da crescente penetração de fontes de geração distribuída e dos incentivos providos pelos governos para promover a geração de energia através de fontes renováveis como por exemplo a energia eólica, solar, biomassa, hidrelétrica, e outras. Nos mais diversos países do mundo, atualmente, populações assentadas em regiões remotas utilizam esquemas baseados em micro-redes elétricas para o suprimento de energia elétrica. Assim, neste trabalho serão apresentados os resultados referentes ao estudo da tecnologia das micro-redes elétricas, especificamente o seu desempenho diante de condições operativas como o modo de operação ilhado e o modo conectado com a rede elétrica. Particularmente, a transição para o modo de operação ilhado demandou um estudo, através das simulações, mais dedicado. No que se refere à negociação da energia entre a micro-rede e a rede principal, quando da disponibilidade de energia excedente nos períodos de carga reduzida na micro-rede, será apresentada uma análise crítica dos possíveis métodos de tarifação, os quais até agora são apenas utilizados na forma de incentivos governamentais. Será também apresentada uma análise referente à viabilidade econômica de micro-redes, já que para que estas tenham atratividade econômica, os custos de aquisição de equipamentos e operação devem também ser competitivos.

Palavras Chave: Geração distribuída, Micro-redes, Negociação de energia, Operação de Sistemas Ilhados. 


\begin{abstract}
After the occurrence of some major blackouts like the one that affected the Northern and Northeastern part of the United States in 2003, the one that affected the Southeast, Midwest and Northeastern part of Brazil including Paraguay, in 2009; and the blackout that affected the whole Italy in 2003, to mention a few a few of them, there was a rush for seeking some alternatives to deal with such events or at least find out feasible solutions that can contribute to diminish their impact. The lack of electric power, for whatever reason it was, unveiled one common fact, our modern society is so dependent on electricity that during the blackouts areas like the electrical transport system, financing activity, academic institutions, industries, health centers with no emergency or standby generation, public and residential lighting and even some communication systems failed to operate. The establishment of microgrid systems proved to be an alternative that could be used for this purpose; thus, not only critical loads, but also some of the activities mentioned earlier on could continue their operation during such emergency periods. In addition, the concept of micro-grid systems has recently gained particular attention due to the increasing penetration of distributed generation and also due to the incentives provided by the governments to promote the generation of electricity from renewable sources such as wind power, solar, biomass, small hydroelectric schemes, etc. At present, countless settlements located in remote areas worldwide use microgrid systems to generate and distribute electricity. In this work, the results related to the microgrid technology, specifically its performance towards system conditions such as the islanding mode and grid connected mode of operation will be presented. Particularly, the transition to the islanded mode of operation demanded a more dedicated study during the simulations performed. As for the energy trading between the microgrid and the utility, which can occur when the microgrid generators are lightly loaded, it will be presented a critical analysis about the possible tariff methods to be applied. Such tariffs are so far only applied in the form of government subsidies to promote the use of renewable energy sources. Additionally, an analysis of a microgrid economic feasibility to show how competitive or complimentary this technology is with the utility will be presented herein.
\end{abstract}

Index Terms: Distributed Generation, Energy trading, Microgrid Islanded and Grid Connected Mode of Operation. 


\section{Lista de Abreviaturas}

\begin{tabular}{|c|c|}
\hline ANEEL & Agência Nacional de Energia Elétrica \\
\hline CA & Corrente Alternada \\
\hline CC & Corrente Continua \\
\hline CDM & Customer Driven Microgrid \\
\hline CERTS & Consortium for Electric Reliability Technology Solutions \\
\hline CHP & Combined Heat and Power \\
\hline DERs & Distributed Energy Resources \\
\hline DMS & Distribution Management System \\
\hline DOE & Department of Energy ( EUA) \\
\hline EPE & Empresa de Pesquisas Energéticas \\
\hline FACTS & Flexible AC Transmission Systems \\
\hline FiT & Feed-in Tariff \\
\hline GD & Geração Distribuída \\
\hline IEEE & Institute of Electronic and Electrical Engineers \\
\hline LC & Load Controller \\
\hline MC & Migrogrid Controller \\
\hline MGCC & Microgrid Central Controller \\
\hline MME & Ministério de Minas e Energia \\
\hline MMS & Microgrid Management System \\
\hline MR & Micro-rede \\
\hline MT & Media Tensão \\
\hline ONS & Operador Nacional do Sistema Elétrico \\
\hline PCC & Point of Common Coupling \\
\hline $\mathrm{PCH}$ & Pequenas Centrais Hidrelétricas \\
\hline PLC & Power Line Comunication \\
\hline PRODIST & Procedimento de Distribuição de Energia Elétrica no Sistema Elétrico Nacional \\
\hline PROINFA & Programa de Incentivo às Fontes Alternativas de Energia Elétrica \\
\hline PSCAD & Power System Computer Aided Design \\
\hline PSS & Power System Stabilizer \\
\hline PV & Photo Voltaic Systems \\
\hline REC & Renewable Energy Certificates \\
\hline RoCoF & Rate of Change of Frequency \\
\hline RPS & Renewable Portfolio Standard \\
\hline SBPE & Sociedade Brasileira de Planejamento Energético \\
\hline SCADA & Supervisory Control and Data Acquisition \\
\hline STATCOM & Static Compensator \\
\hline TIR & Taxa Interna de Retorno \\
\hline TMA & Taxa Mínima de Atratividade \\
\hline VPL & Valor Presente Líquido \\
\hline
\end{tabular}




\section{Lista de Símbolos}

$\begin{array}{ll}\triangle \mathrm{f} & \text { Variação da freqüência } \\ \triangle \mathrm{V} & \text { Variação da Tensão } \\ \triangle \Phi & \text { Diferença do ângulo de fase } \\ i & \text { Taxa de juros } \\ \mathrm{rpm} & \text { Revoluções por minuto } \\ d f / d t & \text { Variação da frequência no tempo }\end{array}$




\section{Lista de Figuras}

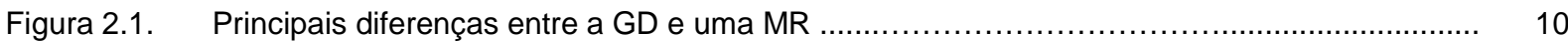

Figura 2.2. Principais componentes de uma micro-rede .................................................... 12

Figura 2.3. Conjunto habitacional (MR) com alimentação: (a) individual, (b) centralizada ...................... 17

Figura 2.4. Esquema de uma micro-rede simples (apenas um usuário) ....................................... 19

Figura 2.5. Esquema de uma MR constituída por um conjunto de usuários ..................................... 19

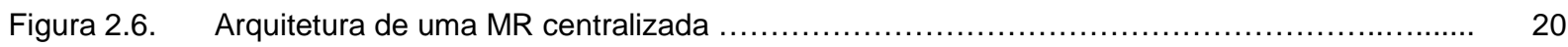

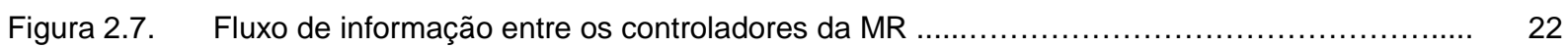

Figura 2.8. Capacidade em MW e porcentagem de participação das MRs por região (2014) no mundo... 30

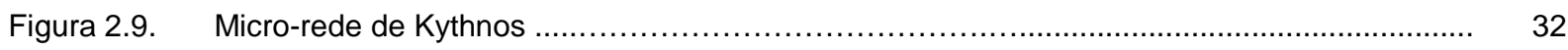

Figura 2.10. (a) Micro-rede de Bronsbergen, (b) Esquema unifilar da micro-rede ............................... 33

Figura 2.11. Configuração da Micro-rede CESI RICERCA DER .................................................

Figura 2.12. Esquema geral do projeto piloto DeMoTec …........................................................

Figura 2.13 Esquema da micro-rede de Hachinohe .............................................................. 36

Figura 2.14 Esquema do projeto de micro-rede de Kyotango ........................................................ 37

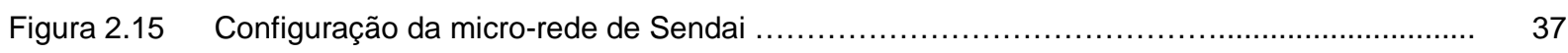

Figura 2.16 Configuração da micro-rede de Huatacondo .............................................................. 40

Figura 2.17 Localização dos principais sistemas isolados no SIN ........................................... 42

Figura 2.18 Previsão de Mercado de Micro-redes remotas no Brasil ................................................. 42

Figura 2.19 Resumo das premissas básicas da proposta ANEEL 482/2012 .................................. 44

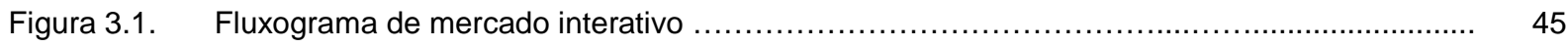

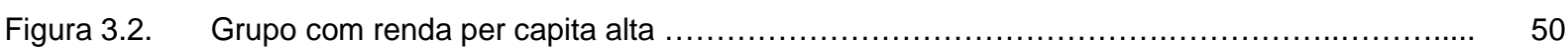

Figura 3.3. Grupo com renda per capita média-alta........................................................... 50

Figura 3.4. Países com renda per capita média-baixa.................................................................. 50

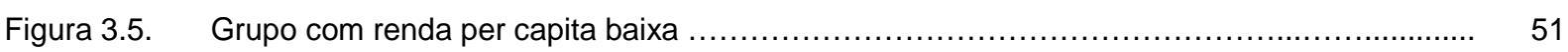

Figura 3.6. Micro-rede formada por fontes renováveis e não renováveis............................................ 53

Figura 3.7. Proposta da resolução 482/2012 da ANEEL............................................................. 53

Figura 4.1. Perfil diário da radiação solar (média) e curva típica do consumo residencial ...................... 56

Figura 4.2. Arranjo dos painéis fotovoltaicos adotados ................................................................. 59

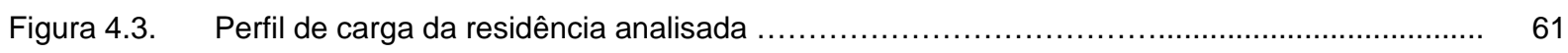

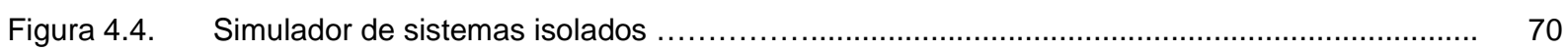

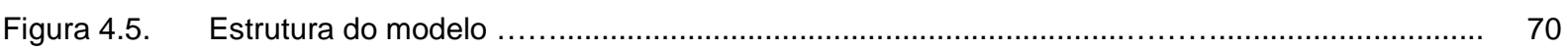

Figura 4.6. Fluxograma de entradas e saídas da análise econômica .................................................... 72

Figura 4.7. Fluxograma do modelo geral de otimização ................................................................. 73

Figura 4.8. Fluxograma de reconstrução de histórico de radiação solar ............................................... 75

Figura 4.9. Micro-rede proposta para a análise de viabilidade econômica .......................................... 76

Figura 4.10. Tela principal mostrando a saída da simulação para o Caso 1 ...................................... 88

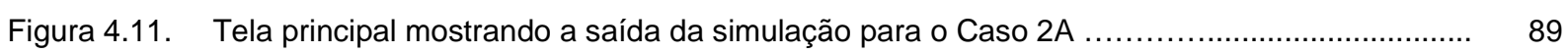

Figura 4.12. Tela principal mostrando a saída da simulação para o Caso 2B ….................................. 90

Figura 4.13. Tela principal mostrando a saída da simulação para o Caso 3A ............................................ 91

Figura 4.14. Tela principal mostrando a saída da simulação para o Caso 3B ........................................ 92

Figura 4.15. Tela principal mostrando a saída da simulação para o Caso 4A ........................................ 93 
Figura 4.16 Tela principal mostrando a saída da simulação para o Caso 4B ....................................... 94

Figura 4.17. Tela principal mostrando a saída da simulação para o Caso 4C ..................................... 95

Figura 4.18. Tela principal mostrando a saída da simulação para o Caso 5A ...................................... 96

Figura 4.19. Tela principal mostrando a saída da simulação para o Caso 5B .................................... 97

Figura 4.20. Tela principal mostrando a saída da simulação para o Caso 5C ........................................ 98

Figura 4.21. Tela principal mostrando a saída da simulação para o Caso 6A ......................................... 99

Figura 4.22. Tela principal mostrando a saída da simulação para o Caso 6B ....................................... 100

Figura 4.23. Tela principal mostrando a saída da simulação para o Caso 7A .......................................... 101

Figura 4.24. Tela principal mostrando a saída da simulação para o Caso 7B ....................................... 102

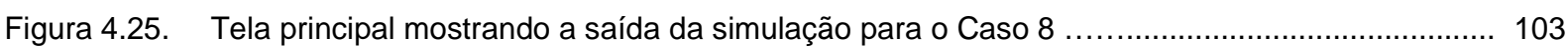

Figura 5.1. Efeito de freio (stall) devido à turbulência criada na própria pá ............................. 107

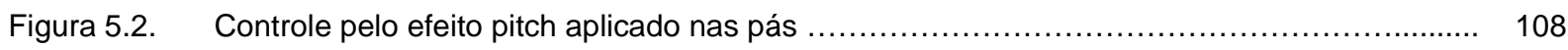

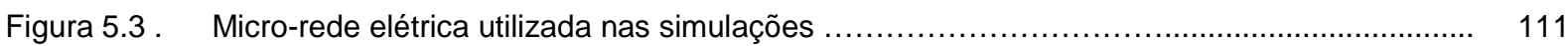

Figura 5.4. (a) Potência do gerador diesel, (b) Tensão na Barra 2, (c) Freqüência do gerador diesel ...... 114

Figura 5.5. Potências: (a) do gerador eólico, (b) da carga no gerador eólico ......................................... 114

Figura 5.6. Ilhamento pré-planejado: (a) Potência do gerador diesel, (b) Tensão na barra 2, (c) Velocidade do

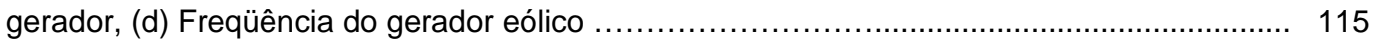

Figura 5.7. Ilhamento forçado bem sucedido: (a) Potência do gerador diesel, (b) Tensão na barra 2, (c) Frequencia do gerador diesel, (d) Potência do gerador eólico, (e) Frequência do gerador eólico

Figura 5.8. Ilhamento forçado (com sucesso) graças a desconexão da carga 2: (a) Potência do gerador diesel, (b) Tensão na barra 2, (c) Frequência do gerador diesel, (d) Potência do gerador eólico, (e) Frequência do gerador eólico

Figura 5.9. Colapso da MR devido à excessiva carga conectada: (a) Potência do gerador diesel, (b) Tensão na barra 2, (c) Frequência do gerador diesel ........................................................ 120

Figura 5.10. Micro-rede implementada no programa PSCAD .................................................... 121

Figura 5.11. (a) Componentes de controle do gerador (síncrono) diesel, (b) Diagrama do regulador de tensão

Figura 5.12. Gerador de indução duplamente alimentado (DIFG) utilizado ...................................... 125

Figura 5.13. Principais blocos de controle implementados no gerador da $\mathrm{PCH}$.................................. 126

Figura 5.14. (a) Potência alimentada à carga do gerador diesel, (b) Valor eficaz (pu) da tensão, (c) Torque elétrico e mecânico, (d) Frequência do gerador diesel

Figura 5.15. (a) Potência do gerador na PCH, (b) Valor eficaz (pu) da tensão, (c) Torque elétrico e mecânico, (d) Frequência do gerador

Figura 5.16. (a) Potência do gerador DFIG, (b) Valor eficaz (pu) da tensão, (c) Frequência do DFIG 130

Figura 5.17. (a) Potência do gerador diesel, (b) Valor eficaz (pu) da tensão, (c) Torque elétrico e mecânico, (d) Frequência do gerador

Figura 5.18. (a) Potência do gerador na PCH, (b) Valor eficaz (pu) da tensão, (c) Torque elétrico e mecânico, (d) Frequência do gerador

Figura 5.19. (a) Potência do gerador DFIG, (b) Valor eficaz (pu) da tensão 134

Figura 5.20. Gerador diesel: (a) Potência nos terminais, (b) Torque elétrico e mecânico, (c) Frequência do gerador

Figura 5.21. Gerador na PCH: (a) Potência nos terminais, (b) Valor eficaz (pu) da tensão, (c) Torque 
elétrico e mecânico, (d) Frequência do gerador 136

Figura 5.22. Micro-rede ilhada utilizada na análise de sobretensões .............................................. 138

Figura 5.23. (a) Detalhe do cabo utilizado, (b) dimensões da linha aérea utilizada ................................. 139

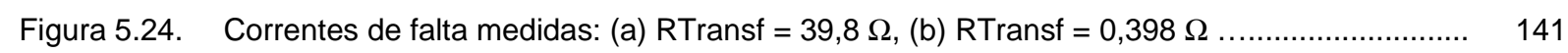

Figura 5.25. Tensões medidas na Barra 1 (fases A e B) durante a falta fase-terra ............................ 142

Figura 5.26. Tensões medidas na Barra 1 (fase A) durante a falta dupla fase-terra ............................. 142

Figura 5.27. Tensões medidas próximas da linha aérea (rompimento de condutor) ............................. 143

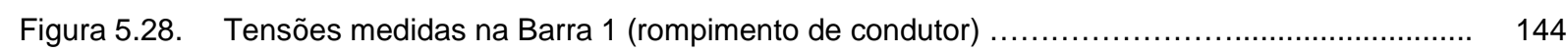

Figura 5.29. Tensões medidas na Barra 1 durante a falta fase-terra sem carga ............................. 144 


\section{Lista de Tabelas}

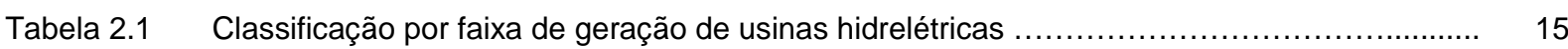

Tabela 2.2 Principais fontes de geração em MRs e GD ........................................................... 23

Tabela 2.3 Características das fontes de GD e compatibilidade com as MRs ....................................... 24

Tabela 2.4 Visão geral de alguns benefícios que as MRs podem oferecer ..................................... 26

Tabela 2.5 Límites dos parâmetros de sincronização (Norma IEEE-1547) dirigidos à interconexão síncrona entre a GD e o sistema ........................................................................................ 27

Tabela 2.6 Resposta do sistema de interconexão para freqüências anormais ................................. 27

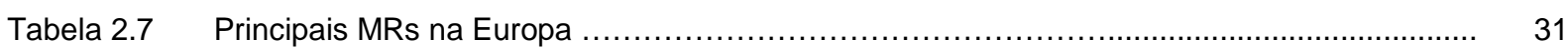

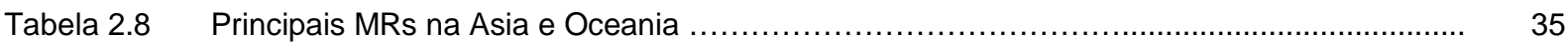

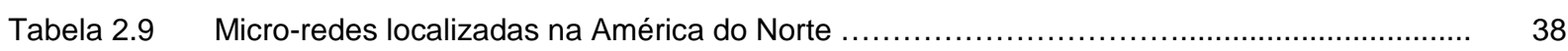

Tabela 2.10 Principais exemplos de MRs remotas no mundo ..................................................

Tabela 3.1 Principais políticas de incentivo em alguns países para a promoção de energia proveniente de fontes renováveis

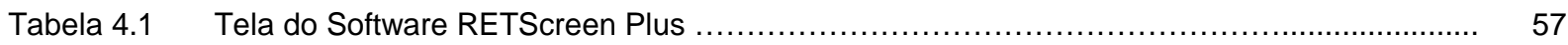

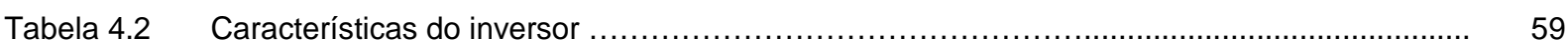

Tabela 4.3 Custo Referencial do conjunto de Painel Solar para Aplicação Residencial......................... 60

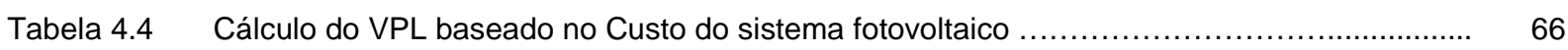

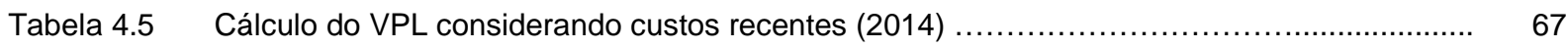

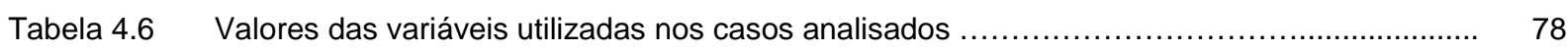

Tabela 4.7 Resumo dos custos CMM, CET, CV@R e custo médio sazonal ........................................... 86

Tabela 4.8 Melhor configuração encontrada via Algorítmos Genéticos (Caso 4) .................................. 104

Tabela 4.9 Melhor configuração encontrada via Algorítmos Genéticos (caso otimizado) ......................... 105

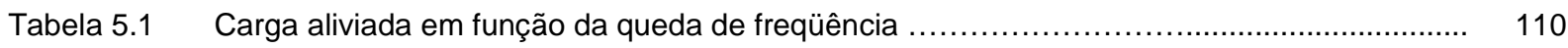

Tabela 5.2 Carga aliviada em função do método RoCoF ....................................................... 110

Tabela 5.3 Tensões do BSL e BIL em sistemas de baixa tensão ................................................... 140

Tabela 5.4 Comparação das sobretensões medidas na Barra 1 para cargas com potência constante

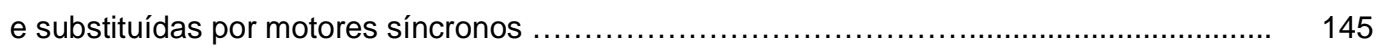

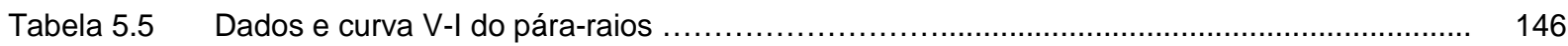




\section{SUMÁRIO}

Resumo

Abstract

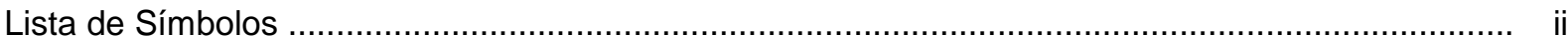

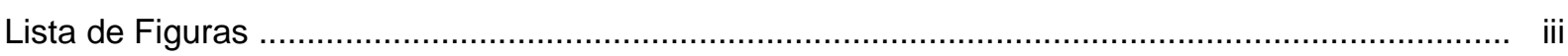

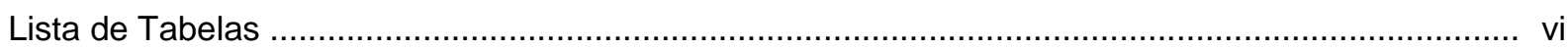

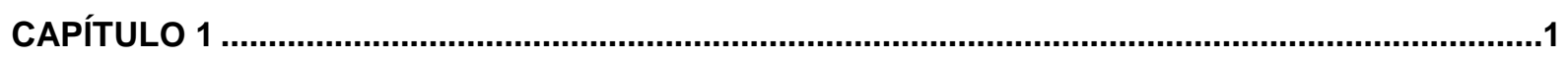

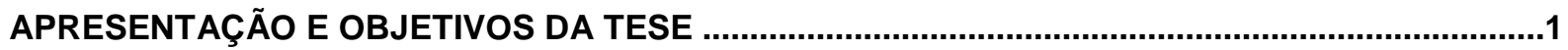

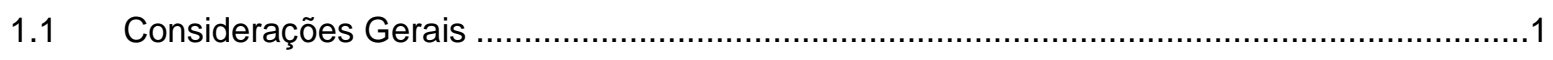

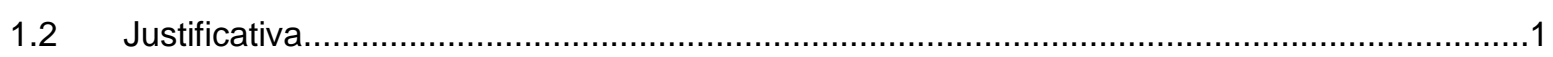

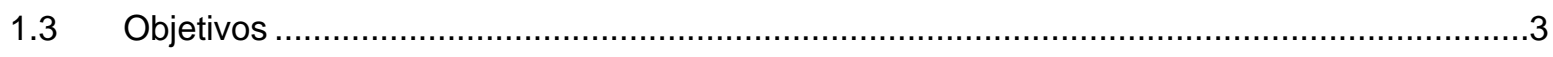

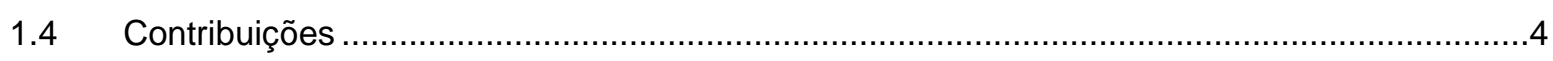

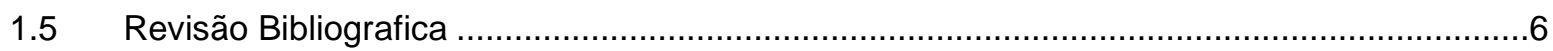

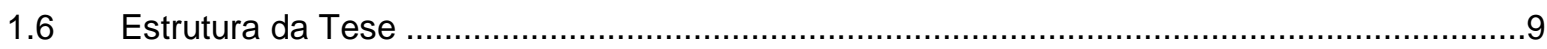

CAPÍTULO 2

ESTRUTURA E TIPOS DE MICRO-REDES ELÉTRICAS ...................................................... 10

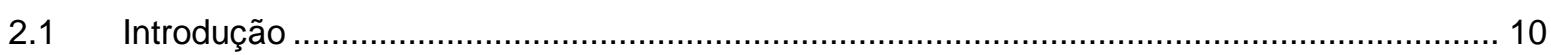

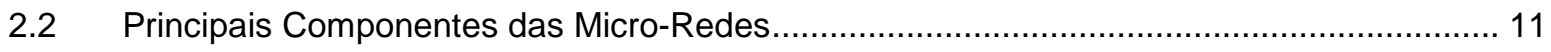

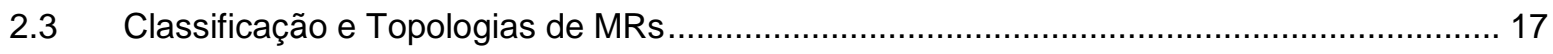

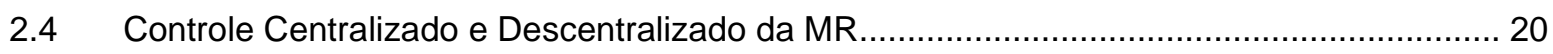

2.4.1 Controle da Operação durante o Modo Normal .................................................. 22

2.5 Principais Fontes de Geração Utilizadas em MRs e Interface com a Rede........................... 23

2.6 Características das Fontes de GD e Compatibilidade com as MRs.................................... 23

2.7 Vantagens e Desvantagens oferecidas pelas MRs ...................................................... 25

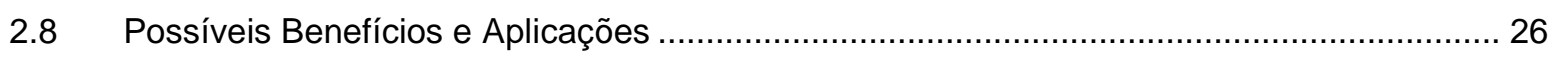

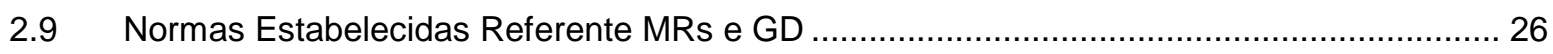

2.9.1 Condições para a Conexão entre a Rede Principal e a GD ................................... 26

2.9.2 Limites de Freqüência durante Perturbações na Rede......................................... 27

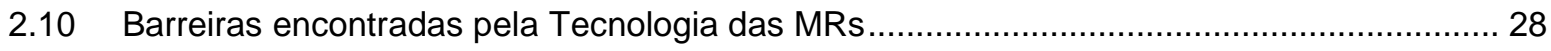

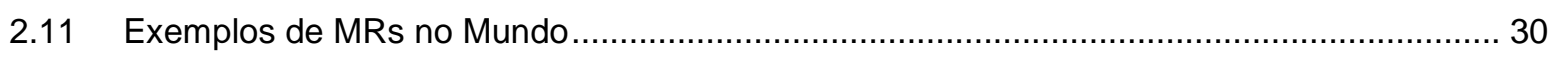

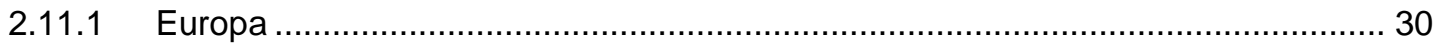

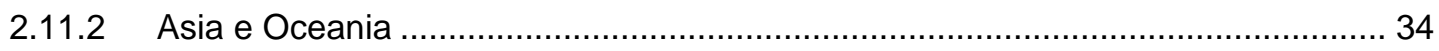

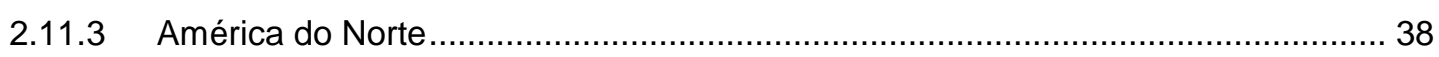

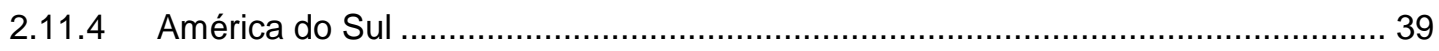

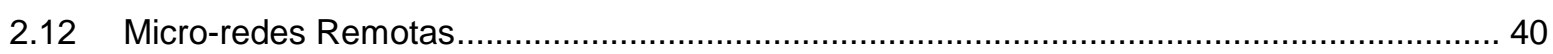




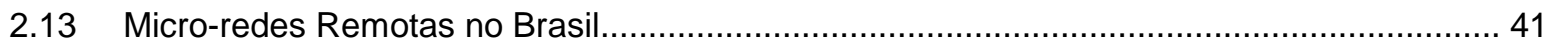

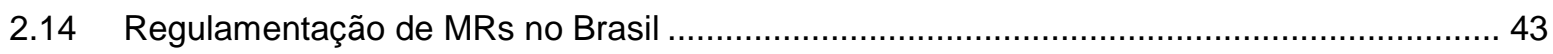

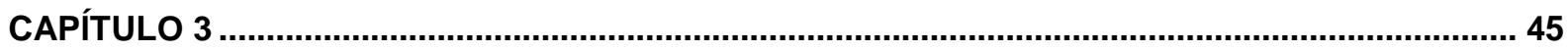

PRINCIPAIS MECANISMOS DE INCENTIVO E TENDÊNCIAS COMERCIAIS ............................ 45

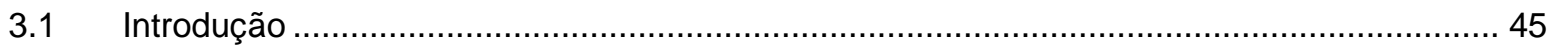

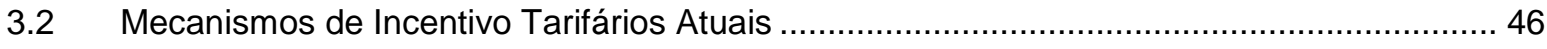

3.2.1 Política de Quota ou Renewable Portfolio Standard (RPS) ................................. 46

3.2.2 Certificados de Energia Renovável ou Renewable Energy Certificates (REC) ..... 46

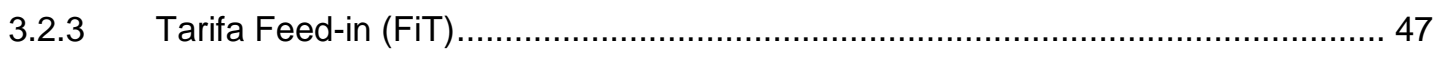

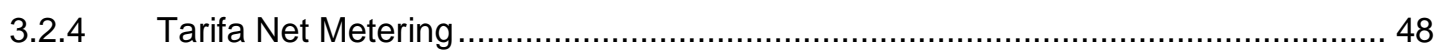

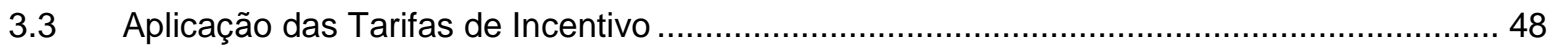

3.4 Análise Comparativa entre a Tarifa Feed-in e Net Metering e Possível Aplicação em MRs 51

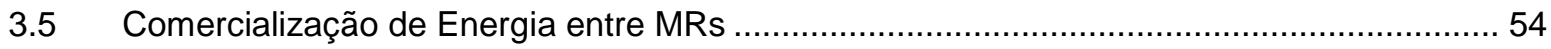

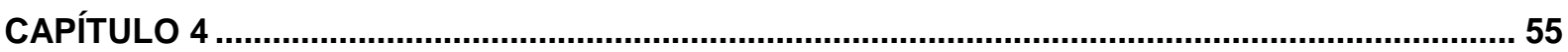

DIMENSIONAMENTO DE MICRO-REDES ELÉTRICAS: ESTUDOS ECONÔMICOS E

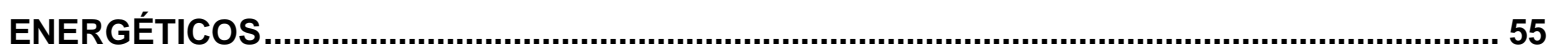

4.1 Análise Econômica de uma MR Solar conectada à Rede de Distribuição ............................ 55

4.1.1 Taxa de Radiação Solar Diária por Metro Quadrado …………………............... 56

4.1.2 Cálculo da Energia Produzida por um Painel Solar Fotovoltaico Simples............. 56

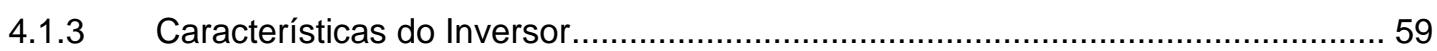

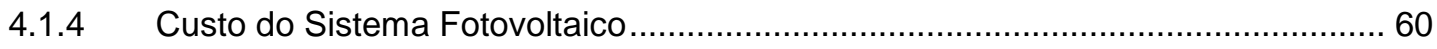

4.1.5 Cenários Considerados para avaliação do Sistema Solar Fotovoltaico ................. 60

4.1.5.1 Suprimento de Energia à Residência pela Concessionária e pelo Sistema

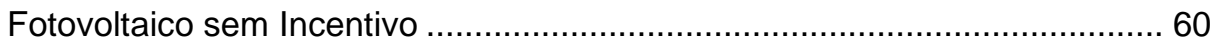

4.1.5.2 Exportação da Energia Gerada à Rede Considerando a Tarifa Net Metering 62

4.1.5.3 Utilização da Tarifa Feed-in ..................................................................... 63

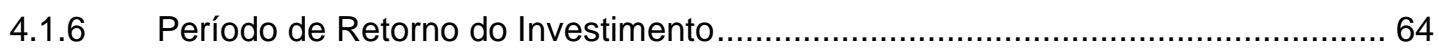

4.1.7 Análise dos Fatores Incidentes na Viabilidade Econômica...................................... 65

4.1.7.1 Incidência do Preço do Equipamento .......................................................... 65

4.1.7.2 Incidência dos Níveis de Radiação............................................................. 67

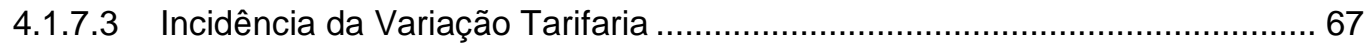

4.2 Viabilidade Econômica de uma Micro-Rede Híbrida em Sistemas Isolados......................... 69

4.2.1 Desenvolvimento do Modelo para Simulação ..................................................... 70

4.2.2 Análise Econômica e Otimização dos Investimentos ............................................. 71

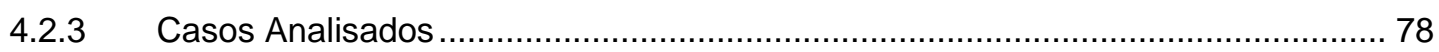

4.2.3.1 MR suprida apenas pelo gerador diesel (Caso 1) ...................................... 79

4.2.3.2 MR conectada com a rede e simultaneamente com a PCH, o gerador eólico e

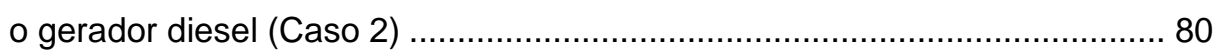


4.2.3.3 MR conectada com a rede e simultaneamente com a PCH e o Gerador eólico (Caso 3)

4.2.3.4 MR ilhada constituída por um gerador diesel, a PCH, o gerador eólico e gerador solar (Caso 4)

4.2.3.5 Similar ao Caso 4, porém, conectada com a rede, com limite de exportação de 3,0 MW (Caso 5)

4.2.3.6 MR ilhada constituída por um gerador diesel, o gerador eólico, o painel solar, sem PCH (Caso 6)

4.2.3.7 MR ilhada constituída apenas pelo gerador eólico e painel solar (Caso 7) ... 84

4.2.3.8 MR alimentada exclusivamente pela rede elétrica (Caso 8) .......................... 85

4.2.4 Portfólio Ótimo (Caso Exemplo) …................................................................ 104

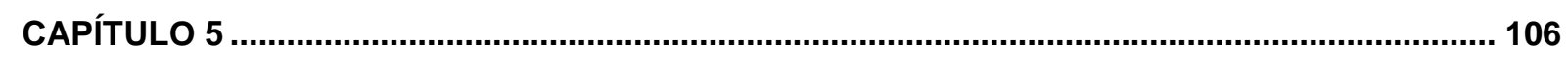

DIMENSIONAMENTO DE MICRO-REDES: ESTUDOS ELÉTRICOS........................................ 106

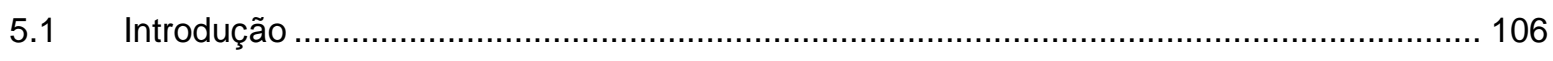

5.2 Principais Conceitos Vinculados ao Controle de Aerogeradores ........................................ 106

5.2.1 Métodos de Controle de Potência .................................................................... 106

5.2.1.1 Controle do Stall ............................................................................. 107

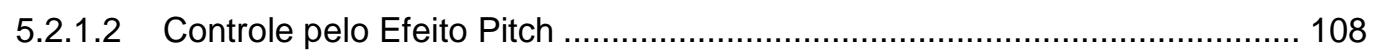

5.2.1.3 Controle Simultâneo Pitch e Stall .......................................................... 108

5.2.2 Necessidade de uma Carga Dissipadora .......................................................... 108

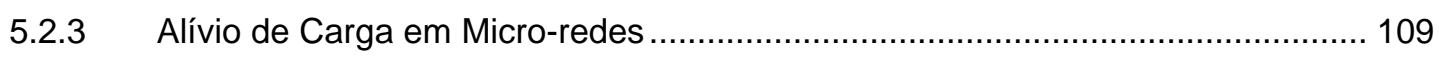

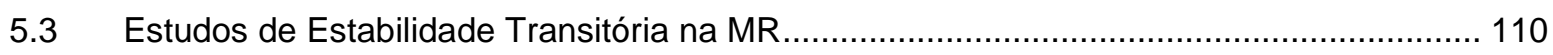

5.3.1 Análise de Desempenho e Illhamento da Micro-rede utilizando o Programa Matlab 111

5.3.1.1 Operação da Micro-rede no Modo Conectado com a Rede ........................ 113

5.3.1.2 Modo de Ilhamento Planejado ou Intencional........................................... 115

5.3.1.3 Modo de Illhamento Forçado ou Não-Intencional ...................................... 116

5.3.1.3.1 Ilhamento Bem Sucedido ..................................................... 116

5.3.1.3.2 Sucesso no Ilhamento devido à Saída do Motor Assíncrono .. 118

5.3.1.3.3 Colapso da MR devido a Sobrecarga ................................... 119

5.3.2 Avaliação de Condições Críticas de operação da MR utilizando o Programa

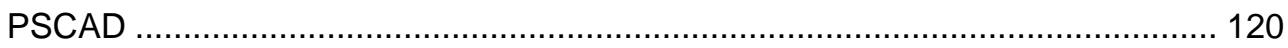

5.3.2.1 Principais Caracteristicas dos Componentes Utilizados ............................ 122

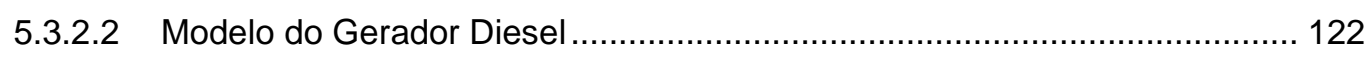

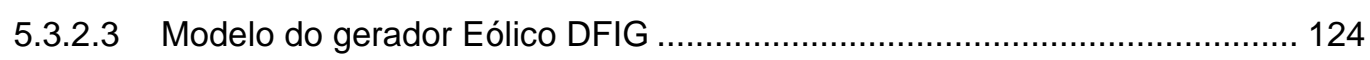

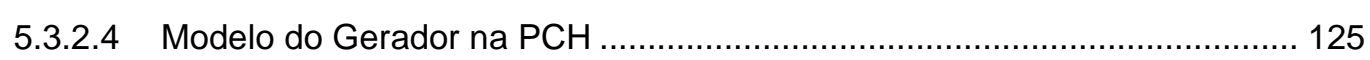

5.3.3 Resultados das Simulações ...................................................................... 126

5.3.3.1 Ilhamento Planejado .................................................................... 126

5.3.3.1.1 Gerador Diesel ............................................................ 127 
5.3.3.1.2 Gerador PCH.......................................................... 128

5.3.3.1.3 Gerador Eólico DFIG ........................................................ 128

5.3.3.2 Alívio de Carga logo após o Ilhamento .................................................. 130

5.3.3.2.1 Gerador Diesel ............................................................... 130

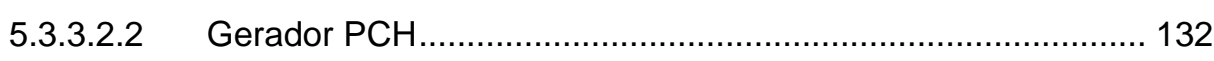

5.3.3.2.3 Gerador Eólico DFIG ........................................................ 132

5.3.3.3 Perda de um Gerador ........................................................................... 134

5.3.3.3.1 Gerador Diesel .................................................................. 134

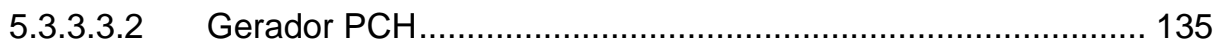

5.3.3.4 Falha na Desconexão da Carga não Prevista .......................................... 136

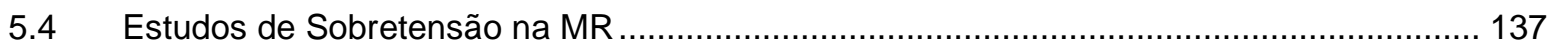

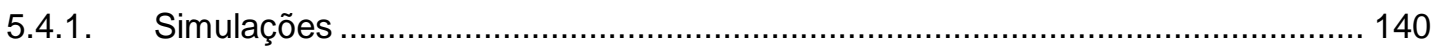

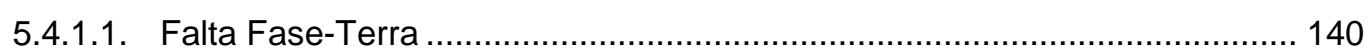

5.4.1.2. Falta Fase-Fase ........................................................................ 142

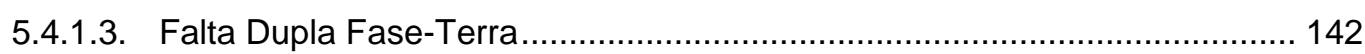

5.4.1.4. Rompimento de Condutor ...................................................................... 143

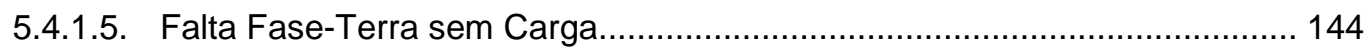

5.4.1.6. Substituição das Cargas Lineares por Motores Equivalentes ..................... 145

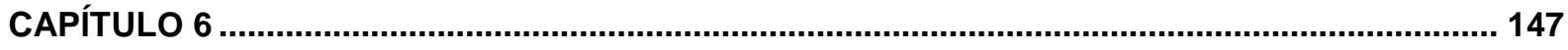

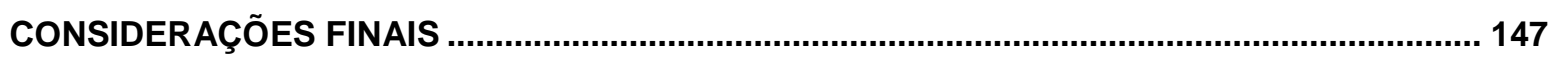

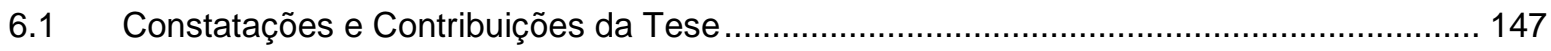

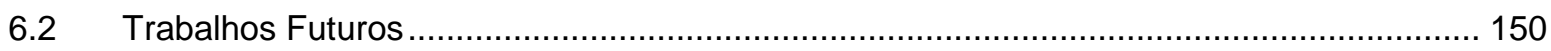

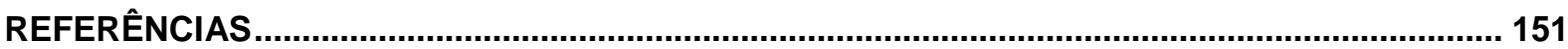

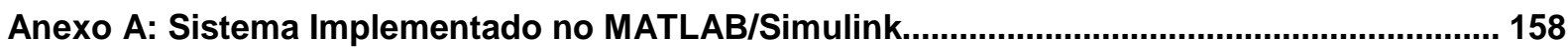

Anexo B: Sistema Implementado no Programa PSCAD/EMTDC …...................................... 160

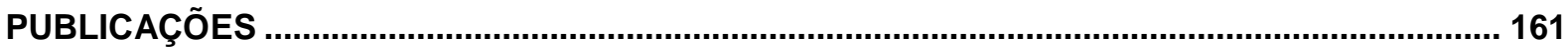




\section{CAPÍTULO 1}

\section{APRESENTAÇÃO E OBJETIVOS DA TESE}

\subsection{Considerações Gerais}

As alterações regulatórias na indústria de energia e o desenvolvimento de sistemas geradores de pequeno porte (geração distribuída) como por exemplo sistemas fotovoltaicos e de micro-cogeração, oferecem aos consumidores a possibilidade de gerar energia no local de consumo. Embora essa oportunidade possa ser considerada benéfica para o meio ambiente, uma vez que a geração distribuída pode utilizar fontes de energia renováveis, de outro lado representa também um grande desafio para os operadores da rede.

Uma micro-rede elétrica é composta por uma ou mais fontes de energia associadas a uma carga, e pode operar de forma independente ou conectada à rede principal, sendo vista pelo resto do sistema como uma unidade controlada individualmente. Do ponto de vista do consumidor, uma micro-rede elétrica pode ser projetada de forma a reforçar a confiabilidade, aumentar a eficiência do sistema e melhorar a qualidade da tensão, entre outros. Assim, a estrutura de uma micro-rede pode variar em função do tipo de carga e da fonte de energia a ser utilizada.

\subsection{Justificativa}

A sociedade de hoje tem uma dependência quase total da energia elétrica. Este fato foi comprovado através dos recentes apagões de grande escala ocorridos em alguns paises. Em 2003, a região Norte e Nordeste dos Estados Unidos, assim como parte do Canadá, foram afetados por um destes blecautes.

Um evento similar ocorreu no Brasil em 2009, afetando varias cidades das regiões Sudeste, Sul, Centro-Oeste e Nordeste. O Paraguai teve afetado aproximadamente $90 \%$ de seu território por este blecaute (Itaipu binacional). Esta falta de energia atingiu de forma significativa vários setores da economia, ao passo que sistemas de transporte elétrico, indústrias e hospitais sem sistemas de geração emergencial, instituições acadêmicas, iluminação pública e residencial, e inclusive sistemas de comunicação, ficaram praticamente inoperantes.

$\mathrm{Na}$ Europa ocorreu um fato similar, também em 2003, quando cerca de $100 \%$ do sistema elétrico Italiano e parte da Suíça ficou sem energia durante aproximadamente 9 horas. Em 
2005, cerca de 100 milhões de pessoas na Indonésia (quarto país com maior população no mundo) ficaram sem energia durante quase 12 horas. O mais recente "apagão" ocorreu na India em Julho de 2012, deixando mais de 600 milhões de pessoas sem eletricidade durante dois dias.

Após a ocorrência desses eventos, houve uma busca por algumas alternativas que ofereçam maior confiabilidade no fornecimento de energia elétrica, ou pelo menos, alternativas que ajudem a minimizar o seu impacto. O governo americano, por exemplo, após o supracitado "apagão", aumentou substancialmente a alocação de investimentos para o desenvolvimento de mais micro-redes..

O estabelecimento de sistemas baseados em micro-redes elétricas mostrou-se como uma alternativa que poderia ser utilizada para tal finalidade, de tal forma que não apenas cargas críticas, mas também boa parte das atividades mencionadas, pudessem continuar operando durante períodos de contingência.

Atualmente, as micro-redes (MRs) elétricas estão sendo investigadas devido a seu potencial para lidar com determinados problemas como:

i) Evitar a perda total de energia durante distúrbios e blecautes em sistemas e redes contendo cargas críticas e cargas normais, desta forma aumentando a confiabilidade do suprimento, tanto para o consumidor, como para o sistema.

ii) Otimizar e incentivar o uso de fontes de geração de energia renováveis como a energia solar, eólica, PCHs (Pequenas Centrais Hidrelétricas), etc, que possuem capacidades de geração menores aos das usinas convencionais.

iii) Em paises nos quais o sistema de distribuição é descentralizado, o estabelecimento das micro-redes visa também compensar parte dos custos do consumidor, gerando sua própria energia durante períodos nos quais a tarifa da concessionária de distribuição é maior o custo da energia gerada pela micro-fonte de energia (proteção contra a volatilidade dos preços).

iv) Aumento da segurança no sistema contra ataques terroristas e desastres naturais pelo fato de utilizar e promover o uso de fontes de energia dispersa.

v) Outra vantagem adicional da produção de energia local é a otimização de sistemas de co-geração térmicos. O calor liberado ao ambiente a partir destes centros de produção pode ser re-utilizado por um lado, por exemplo, para o aquecimento de 
água, e posterior uso e, por outro, para ser utilizado em pequenas usinas termelétricas dotadas de tecnologia de ciclo combinado.

Observa-se que em face dos problemas e necessidades existentes na atualidade há uma demanda para tornar a rede elétrica mais confiável, através de diversas alternativas, entre as quais o uso das micro-redes aparece com uma opção promissora. O potencial de aplicação das micro-redes vem sendo alavancado pela utilização de recursos tecnológicos atualmente disponíveis, como por exemplo, o grau de maturidade alcançado pela Eletrônica de Potência, os Sistemas Inteligentes (smart grids), e a tecnologia wireless, entre outros.

No Brasil existe um grande potencial para o desenvolvimento de micro-redes baseadas em PCH's (Pequena Central Hidrelétrica), como também deve-se considerar o potencial da radiação solar para o estabelecimento de fazendas solares e a possibilidade de minigeração eólica. O estabelecimento de micro-redes eletricas próximos dos centros de carga (edifícios e prédios residências e/ou comercias), mesmo não sendo baseadas em fontes não renováveis, pode oferecer vantagens para seus proprietários, bem como para o sistema elétrico nacional. Daí a importância para o desenvolvimento da presente pesquisa.

Por outro lado, no Brasil, assim como em outros países, existem barreiras geograficas que naturalmente impõem o estabelecimento de MRs, particularmente no caso dos assentamentos e populações, localizadas em áreas remotas, aos quais a rede elétrica do SIN não pode chegar de forma econômica.

\subsection{Objetivos}

Com base nas justificativas apresentadas no item anterior, a presente tese tem como objetivos:

(a) Estudo dos possíveis métodos de negociação de energia entre a rede principal e a micro-rede elétrica, visto que até o momento não existe uma consolidação de entendimento sobre o sistema de comercialização de energia mais adequado para o intercâmbio de energia entre uma micro-rede e o sistema principal.

(b) Implementação e simulação de alguns sistemas de micro-redes elétricas, mostrando as diferentes respostas e desempenho frente a condições operativas críticas, como por exemplo:

- Operação da micro-rede no "modo ilhado". 
- Comportamento durante a transição do modo conectado com a rede principal ao modo ilhado.

- Reconexão da micro-rede à rede principal após o ilhamento.

- Contribuição no controle de reativos e suporte de tensão local à rede principal pela micro-rede.

Estas tarefas e funcionalidades deverão ser realizadas com moderada complexidade e, ainda assim, oferecer boa confiabilidade e flexibilidade da operação considerando a localização estratégica das fontes de geração distribuída.

(c) Analisar e responder questões ligadas à operabilidade e ao marco regulatório das micro-redes, como por exemplo quais os incentivos regulatórios para alavancar a implementação de micro-redes.

(d) Analisar e buscar soluções para situações em que a MR possa enfrentar sobrecarga durante o processo de transição do modo conectado com a rede para o modo ilhado, por exemplo, devido a possíveis erros no chaveamento dos circuitos, avaliando a resposta dos geradores dentro da MR perante esta condição, ou seja, de forma mais específica, analisar o alivio automático e controlado de carga.

(e) Realizar uma análise da viabilidade econômica de dois casos: (i) uma MR residencial simples constituída por um sistema fotovoltaico e, (ii) uma MR híbrida composta de um gerador diesel, uma $\mathrm{PCH}$, um gerador eólico e ainda um sistema fotovoltaico, para o atendendimento de uma determinada carga.

\subsection{Contribuições}

Entre as principais contribuições desta tese, produto da pesquisa desenvolvida, podem ser mencionadas as seguintes:

- Foi realizado um levantamento bibliográfico e análise sistematizada dos principais mecanismos para possível negociação da energia, que tem correlação com os incentivos governamentais e que poderiam ser aplicados em micro-redes elétricas. Entre estes mecanismos estão: a tarifa feed-in e a tarifa net metering. Recentemente, a ANEEL propôs a aplicação desta ultima tarifa em mini-redes e micro-redes existentes, corroborando a ideia inicial considerada no trabalho. Na tese podem também ser encontrados outros mecanismos que, embora não estejam dentro da categoria de incentivo, poderiam ser aplicados em micro-redes compostas 
por geração não renovável. Dessa forma buscou-se evidenciar os prós e contras das alternativas para comercialização de energia de uma MR, de tal forma a indicar a melhor solução de compromisso entre incentivos e investimentos e os custos a serem suportados pelo consumidor final.

- Foram realizadas simulações em programas como o MATLAB/Simulink e PSCAD/EMTDC, na vertente dos estudos necessários para o dimensionamento elétrico de uma micro-rede, que permitem estudar a operação de uma instalação específica diante de várias condições operativas e perturbações consideradas mais comuns neste tipo de redes, sendo que a consolidação desses estudos permitiu a publicação de Artigo em periódico indexado internacional de reconhecida reputação e bastante seletivo nas propostas submetidas (elevada taxa de rejeição) [92]:

- A transição da micro-rede do modo conectada com a rede (concessionária) para o modo ilhado. Neste estudo foram mostradas as respostas de ilhamento bem sucedido e ilhamento sem sucesso.

- Comportamento de micro-rede diante de faltas internas como curto-circuitos, sobrecargas e funcionamento de esquema de alívio de carga, como também comportamento diante da perda de um gerador.

- Adicionalmente, foi realizado um estudo referente à sobretensões nas fases sãs de uma micro-rede quando da ocorrência de faltas fase-terra. Para isso foi utilizado o programa ATP (Alternative Transients Program)

- Foi analisada a viabilidade econômica de uma micro-rede solar residencial utilizando conceitos econômicos clássicos como a TIR (Taxa Interna de Retorno) e VPL (Valor Presente Líquido), com formulação adequada para tratar o problema de dimensionamento econômico de micro-redes elétricas. Isto em resposta ao questionamento de consumidores residenciais referente às vantagens de sua aquisição.

- Foram analisados e simulados os custos operacionais e a viabilidade de uma microrede híbrida (composta por fontes renováveis e não renováveis) diante de diferentes cenários operativos, considerando as curvas de carga diária, condições climáticas favoráveis a um ou outro tipo de geração, assim como os custos de combustível e tarifas de importação/exportação de energia com a concessionária. Maiores detalhes referentes à ferramenta utilizada para este fim e as diferentes condições impostas à micro-rede utilizada, estão sendo apresentados no Capítulo 4. 
Com o objetivo de dar sequência ao estudo e análise dessa Tese nos estudos de caso ilustrativos e que foram inseridos de forma associada aos diferentes tópicos abordados, no possível foi utilizada a mesma micro-rede constituida por um gerador diesel, uma PCH um gerador eólico, um sistema fotovoltaico e respectivas cargas.

\subsection{Revisão Bibliografica}

Nos últimos anos, um crescente interesse pelas MRs tem sido observado na literatura especializada. As publicações que abordam este assunto e que foram consultadas para a elaboração desta tese incluem tópicos como a definição de micro-redes, as estratégias de controle, estudos que analisam a forma de operação e desempenho, os distintos projetospiloto desenvolvidos até agora, os mecanismos de incentivo, alivio de carga e outros tópicos avançados.

Por exemplo, em [1]-[5], [97], são apresentados estudos sobre o estado da arte das microredes bem como das barreiras encontradas durante sua integração à rede principal. São também apresentados aspectos básicos relacionados às normas regulatórias, a condição de operação autônoma e as estratégias de controle, entre outros.

Nas referencias [6] e [7] mostra-se a crescente participação da microgeração em redes elétricas, isto é feito através da exploração e extensão do conceito de micro-rede, envolvendo a investigação de alternativas de controle de carga (centralizadas ou descentralizadas) para fornecer um funcionamento eficiente.

Em [8] e [9] é apresentado o sistema de controle centralizado denominado de MGCC Microgrid Central Control (Controlador Central da Micro-rede) para aplicação numa microrede composta por vários agentes. Apresenta-se também as funções que desempenham outros controladores automáticos dentro da micro-rede.

Em [10] são descritas as barreiras encontradas pela tecnologia das MRs, como tambem propõe-se a existência de cinco modelos que poderiam ser utilizados para categorizar as MRs segundo o tipo de proprietário e as práticas comercias.

Em [11] é apresentado uma proposta de um marco regulatório orientado à aplicabilidade e integração de sistemas contendo fontes de micro-geração e micro-redes ao sistema de distribuição.

Também são definidos modelos para a avaliação dos benefícios alcançados com a microgeração e as micro-redes, entre os quais: segurança no abastecimento, redução de perdas elétricas, deferimento nos investimentos, redução na emissão de gases à atmosfera e aumento da confiabilidade nos sistemas de distribuição. 
O desenvolvimento de programas de pesquisa práticos sobre MRs foi iniciado em alguns países da União Européia, Japão e os EUA. Mais recentemente, países como a China, Coréia do Sul e Singapura têm apresentado também um interesse crescente sobre esta tecnologia [12]-[14], [15].

Considerando que as micro-redes remotas se constituem no principal mecanismo para o atendimento de boa parte da população mundial que vive em áreas onde o suprimento de energia elétrica é precário, em [60] são apresentados exemplos de algumas MRs remotas, bem como o tipo de controle utilizado nestas.

No que se refere às micro-redes elétricas no Brasil, existem algumas propostas que se enquadrariam no contexto desta forma de tecnologia. Por exemplo, no recente relatório apresentado pela ANEEL no âmbito da Resolução Normativa № 482 de 17/04/2012, publicada em 19/04/2012 [16], propõe-se aos consumidores a utilização de fontes renováveis, como mini-turbinas eólicas e painéis fotovoltaicos. Pela proposta da ANEEL, seria criado um Sistema de Compensação de Energia, por meio do qual os consumidores com geração distribuída, poderiam trocar energia com a distribuidora. Este mecanismo, porém, não prevê nenhuma transação do tipo financeiro. Caso um consumidor gere mais energia do que consumiu, o montante extra pode ser acumulado e abatido nos meses seguintes. Esse crédito teria validade de trinta e seis meses.

No que concerne à existencia de Normas para a interconexão de fontes de geração distribuída com a rede elétrica, o comité técnico do IEEE (Institute of Electronic and Electrical Engineers) disponibilizou através das referências [17], [18], um instrumento normativo chamado de Norma IEEE 1547 (Standard for Interconnecting Distributed Resources with Electric Power Systems). Esta Norma, em constante processo de atualização, possui outras seis normas complementares, também disponibilizadas, destinadas a esclarecer ou expandir o padrão inicial, e que são as seguintes:

- IEEE P1547.1 - Procedimentos para os testes de conformidade de equipamentos que interconectam fontes de geração distribuída com a rede elétrica (Standard for Conformance Tests Procedures for Equipment Interconnecting Distributed Resources with Electric Power Systems).

- IEEE P1547.2 - Guia de aplicação da norma IEEE 1547 para a interconexão de fontes de geração distribuída com a rede elétrica (Draft Application Guide for IEEE 1547 Standard for Interconnecting Distributed Resources with Electric Power Systems). 
- IEEE 1547.3 - Guia para o monitoramento, intercâmbio de informação e controle de fontes de geração distribuida interconectados com a rede elétrica (Guide For Monitoring, Information Exchange, and Control of Distributed Resources Interconnected with Electric Power Systems).

- IEEE P1547.4 - Guia para o projeto, operação e integração de fontes de geração distribuida interconectados com a rede elétrica (Draft Guide for Design, Operation, and Integration of Distributed Resource Island Systems with Electric Power Systems).

- IEEE P1547.5 - Diretrizes técnicas para a interconexão de fontes de geração distribuída maiores a 10 MVA com a rede elétrica (Draft Technical Guidelines for Interconnection of Electric Power Sources Greater than 10MVA to the Power Transmission Grid).

- IEEE P1547.6 - Práticas recomendadas para a interconexão de fontes de geração distribuída com a rede secundária do sistema de distribuição (Draft Recommended Practices for Interconnecting Distributed Resources With Electric Power Systems.

No trabalho, foram consideradas estas normas com intuito de se obter resultados e efetivar análises sob a égide de tais instrumentos normativos.

Quanto às tendências comerciais em MRs, existem algumas propostas que incluem funcionalidades, tais como a obtenção do preço da energia em tempo real e o fluxo bilateral em função do aumento da demanda em uma ou outra MR. Esses aspectos não são ainda aplicados rigorosamente e poderiam ser implementados após consolidação da tecnologia das MRs. Estas propostas e abordagens relacionados à comercialização de energia em MRs são apresentados em [19] - [22].

Por outro lado, a adoção de um mecanismo de remuneração que incentive a geração de energia elétrica a partir de uma fonte renovável constitui-se em uma força motriz que permite potencializar a aceitação e promoção das micro-redes. Entre os mecanismos adotados por diversos países para incentivar a geração de energia a partir de fontes renováveis, destacam-se os apresentados em [23].

Uma análise comparativa entre a tarifa feed-in e net metering e a sua possível aplicação em MRs é apresentada em [24], [73]. Outra tendência comercial está relacionada com a comercialização de energia entre MRs. Nas referências [25], [26], considera-se que a comercialização de energía entre micro-redes pode incorrer em custos mais baixos do que a 
comercialização com a rede da concessionária, devido à eliminação das perdas devido à transmissão.

Ressalta-se que, no decorrer e desenvolvimento da tese, serão citadas e analisadas outras referências em função de sua relevância e para fins de comparação com os casos aqui apresentados.

\subsection{Estrutura da Tese}

O presente trabalho está estruturado em mais seis capítulos, além deste introdutório.

No Capítulo 2 são abordados os principais conceitos, a estrutura e tipos de micro-redes elétricas, além de se apresentar uma revisão sobre os principais projetos desenvolvidos até o presente. São também apresentadas as principais vantagens de sua conexão com a rede elétrica, questões regulatórias e outras referentes a sua operação.

No Capítulo 3 apresentam-se os principais mecanismos de incentivo e tendências comerciais estabelecidas atualmente para promover o crescimento e desenvolvimento das micro-redes.

No Capitulo 4 apresenta-se uma análise econômica e de viabilidade de micro-redes cujo objetivo é mostrar se essas opções de conexão à rede de distribuição poderiam ser economicamente atrativas para o consumidor final. Dito estudo é realizado utilizando inicialmente um sistema fotovoltaico residencial e na sequência uma micro-rede híbrida, que inclui fontes renováveis e um gerador diesel.

No Capítulo 5 são apresentados os resultados das simulações realizadas com uma microrede nos vários modos de operação como por exemplo: quando esta (micro-rede) encontrase conectada com a concessionária e ilhada desta. Foram também realizados, neste capítulo, estudos referentes ao comportamento da micro-rede diante de faltas internas como curto-circuitos, sobrecargas e respectivo alívio de carga, entre outros. Adicionalmente, apresentam-se os resultados do estudo referente às sobretensões nas fases sãs na microrede, produto da ocorrência de faltas fase-terra.

Finalmente, no Capítulo 6, são apresentadas as principais conclusões e propostas de trabalhos futuros relacionadas às MRs. 


\section{CAPÍTULO 2}

\section{ESTRUTURA E TIPOS DE MICRO-REDES ELÉTRICAS}

\subsection{Introdução}

Uma micro-rede elétrica (MR) é uma versão em pequena escala da rede elétrica com possibilidade de operar de forma ilhada ou conectada à rede principal de baixa tensão (BT) ou de média tensão (MT), através de um único ponto intermediário chamado de ponto de aclopamento comum ou PCC (Point of Common Coupling); assim, a MR pode ser vista pelo resto do sistema como uma unidade controlada [27].

Dentro da tecnologia das MRs são comumente utilizados termos como a geração distribuída (GD) e cogeração. A GD consiste da aplicação de geradores de pequeno porte chamados de fontes de energia distribuídas que são instalados próximos do consumidor final para o suprimento de energia. Entre as fontes de energia que podem ser enquadradas como GD estão: geradores hídricos, geradores eólicos, painéis solares, pilhas de célula combustível, geradores diesel e turbinas a gás (com porte compatível à geração distribuída).

Já a cogeração refere-se ao fato de gerar de forma simultânea, e em sequência, mais de uma modalidade de energia ( $p$. ex. elétrica e térmica) a partir de uma mesma fonte de combustível (p. ex. gás natural). Assim, pode-se dizer que todo sistema de cogeração é um tipo de GD, mas nem toda GD é um sistema de cogeração. Na referência [28] são estabelecidas as características que diferenciam a GD de uma MR (Figura 2.1).

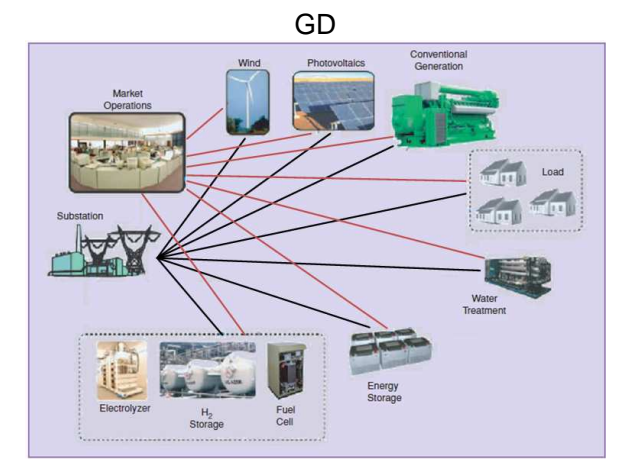

- Muitos pontos de acoplamento.

- Falta de coordenação do sistema GD para obtenção de benefício máximo.

- Complexidade na interconexão com a rede.

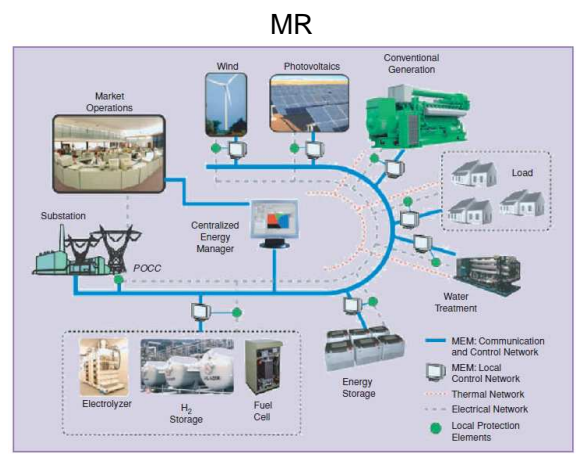

- Um único ponto de acoplamento com a rede (PCC).

- Coordenação e otimização na MR para obtenção de benefício máximo dos ativos (assets).

- Conectada com a rede ou ilhada desta para aumentar sua confiabilidade e economia.

- Oferece benefícios à concessionária e usuário final.

Figura 2.1. Principais diferenças entre a GD e uma MR [28]. 
Uma das características particularmente interessantes de uma MR é a sua flexibilidade durante sua operação com a rede principal; assim, em função das condições existentes no sistema, esta poderia operar nos seguintes modos:

a) Modo de operação normal (conectada com a rede principal). Nesta condição operativa a micro-rede pode oferecer suporte de reativos à rede, controlando assim a tensão local, além de injetar potência ativa na mesma.

b) Modo de ilhamento planejado (intencional). Normalmente, este modo de operação resulta na geração de pequenos transitórios de tensão. A micro-rede ilhada pode enfrentar problemas de desequilíbrio entre a carga e a geração. Em alguns casos, a fim de eliminar estas conseqüências, incluindo um possível colapso de tensão, pode ser necessária a aplicação do respectivo alívio de carga (load shedding). Do ponto de vista econômico (tarifário) este modo de operação pode ser atrativo para os consumidores.

c) Modo de ilhamento "forçado" (não intencional). Este modo de operação ocorre devido principalmente à presença de faltas no sistema ou devido à presença de outras perturbações na rede principal tais como quedas de tensão severas, blecautes, etc. Idealmente, a transição para o modo ilhado deve ser realizada mantendo determinados níveis de tensão e freqüência. Porém, não se descarta a ocorrência de transitórios de maior intensidade que os mencionados no modo de ilhamento planejado, inclusive a ocorrência de interrupções momentâneas durante a transição ao modo ilhado.

\subsection{Principais Componentes das Micro-Redes}

As MRs têm sido apresentadas como uma opção atraente para integrar a GD com a rede principal e este fato motiva a introdução de mudanças operacionais no mercado elétrico, entre estas: mudança nas estratégias de controle, que diferem dos sistemas convencionais de controle utilizados, mudança nos aspectos relacionados ao gerenciamento das cargas, sincronização com a rede principal, etc. Conforme ilustrado na Figura 2.2, várias são as tecnologias atualmente envolvidas nas MRs, entre as quais podem-se mencionar: microgeradores, sistemas de armazenamento de energia, inversores, cargas, etc. 


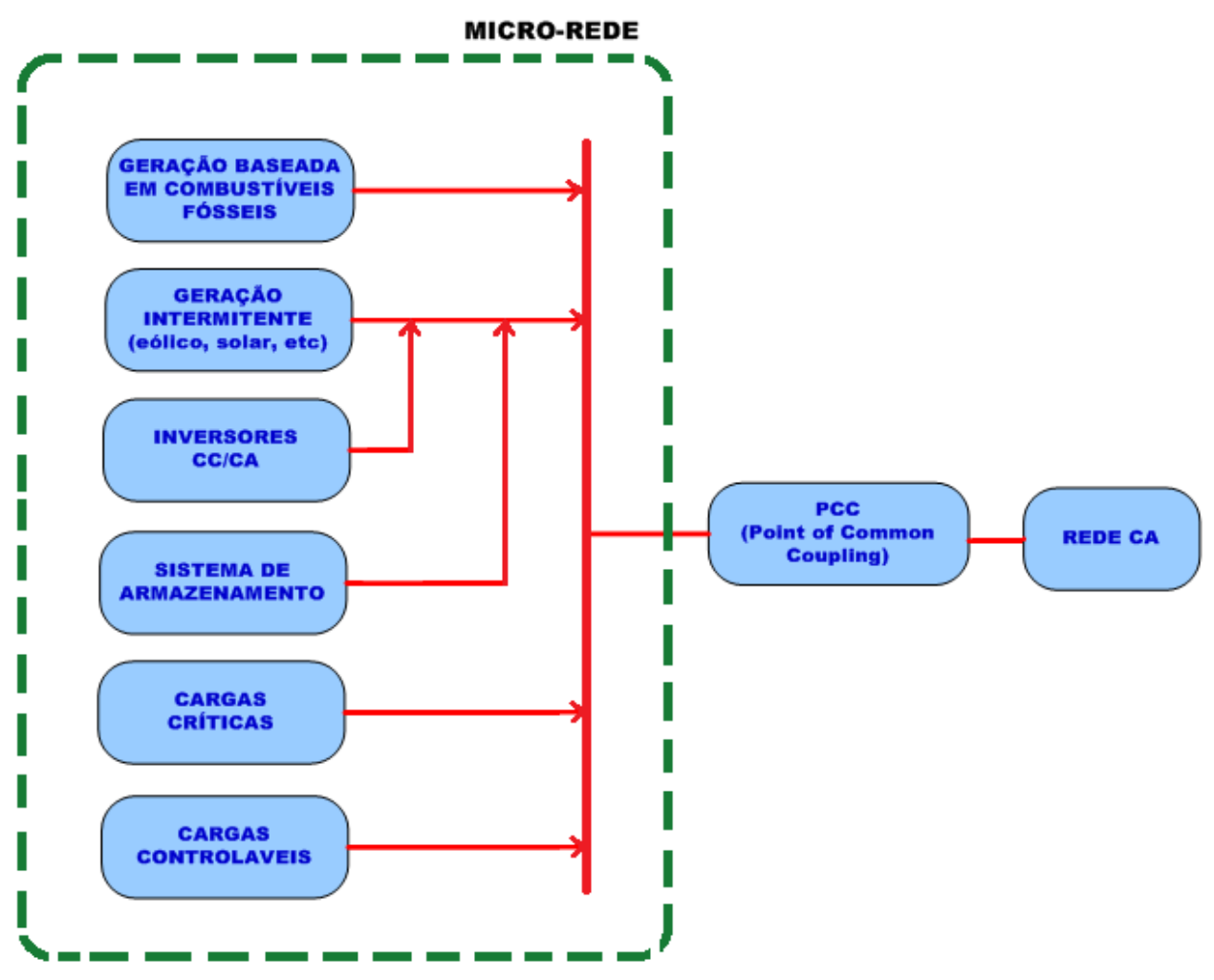

Figura 2.2. Principais componentes de uma micro-rede.

\subsubsection{Mini e Microgeração}

As fontes de energia distribuida utilizadas em micro-redes são fontes alternativas ou renováveis e fontes baseada em combustiveis fósseis. A seguir descrevem-se os principais tipos de geradores utilizados em MRs:

- Grupo motor-gerador diesel

Neste tipo de geração, os motores de combustão interna são associados mecanicamente com os geradores elétricos que podem ser do tipo síncrono ou de indução, formando um grupo motor-gerador que utiliza combustiveis fósseis, geralmente o diesel, como fonte primária. A eficiência deste tipo de geração é de aproximadamente $30 \%$ a $40 \%$ [29]. Boa parte da geração baseada em motores de combustão interna está associada a sistemas de co-geração, operando em centros comerciais, hospitais, instituições de pesquisa, hotéis e shopping centers. 
- Turbinas a Gás Convencionais

São também utilizadas na GD, geralmente em usinas termelétricas e em sistemas de co-geração. As usinas termelétricas podem ser de ciclo simples ou de ciclo combinado. As termelétricas de ciclo simples utilizam a energia térmica proveniente de gases quentes ou a energia térmica do vapor de água para a produção de energia elétrica. Quando a energia térmica dos gases de escape não é recuperada a planta chama-se de ciclo aberto. Utiliza como combustível gás natural ou biogás. Basicamente, o gás quente em alta pressão produzido durante a combustão aciona a turbina e esta, pelo acoplamento mecânico, gira o gerador, produzindo-se assim energia elétrica [30]. Uma usina a ciclo combinado (CCPS - Combined Cycle Power Station] usa turbinas a gás e a vapor associadas em uma única planta, ambas geram energia elétrica a partir da queima do mesmo combustível. Para isto, o calor existente nos gases de exaustão das turbinas a gás é recuperado, produzindo o vapor necessário ao acionamento da turbina a vapor. A eficiência deste tipo de geração está na faixa de $42 \%$ a $58 \%$ Contudo, recentes avanços tecnológicos, redução de custos unitários, etc, neste tipo de geração poderíam aumentar ainda mais esta eficiência [31].

- Célula Combustível

É uma forma de geração de energia elétrica a partir da energia química (processo eletroquímico). O principal combustível utilizado é o hidrogênio. Pelo fato desse dispositivo não utilizar uma etapa térmica intermediária, a sua eficiência de conversão de energia elétrica atinge aproximadamente $50 \%$, além de ser pouco poluente. A célula combustível pode ser utilizada em sistemas de emergência, em zonas onde não existe rede elétrica, em aparelhos portáteis e veículos e outras aplicações. A sua principal desvantagem é o custo ainda elevado, pelo fato de tratar-se de uma tecnologia relativamente nova que não é produzida em grande escala [29].

\section{- Geração Eólica}

A geração eólica constitui-se um dos tipos de geração mais promissores em MRs elétricas. Diferentemente das outras tecnologias, a geração eólica (similarmente à geração fotovoltaica) depende diretamente das condições da fonte primária (vento) e do tipo de turbina. Toda turbina eólica têm sua própria curva de eficiência que varía segundo a velocidade do vento, sendo que em média esta eficiência não supera $60 \%$. Uma das principais dificuldades 
apresentadas pela geração eólica para sua integração à rede elétrica foi a sua contínua variação de tensão e frequência. Contudo, recentes estudos e avanços sobre a qualidade de energia de geradores eólicos e suas interfaces (inversores) mostram que este problema pode ser superado. Com os últimos avanços tecnologicos, a redução do custo da tecnologia disponível no mercado, associada aos incentivos governamentais de cada país, um novo cenário foi desenhado para esta forma de energia, visando alavancar sua competitividade em relação às outras fontes de geração de eletricidade.

Hoje em dia, as torres e estrutura de suporte dos aerogeradores são mais altas, atingindo alturas de 120 metros, onde os ventos são mais fortes. Com isso, a geração de energia teria melhorado e o volume de investimento, que antes era de aproximadamente $R \$ 6.500 / \mathrm{kW}$ instalado teria-se reduzido para $R \$ 3.400 / \mathrm{kW}$ instalado [32].

- Fotovoltaica

É obtida através da conversão direta da luz em eletricidade (efeito fotovoltaico). As células fotovoltaicas são formadas por placas de material semicondutor, geralmente de silício, uma dopada positivamente $(P)$ e a outra dopada negativamente $(\mathrm{N})$, formando uma junção $\mathrm{PN}$. Quando a luz do sol incide sobre esta junção, o campo elétrico entre as duas placas permite o fluxo eletrônico na forma de corrente contínua. A eficiência da conversão das células solares é medida pela proporção da radiação solar incidente sobre a superfície da célula que é convertida em energia elétrica. Atualmente, as melhores células apresentam um índice de eficiência de 25\% [33]. Comumente, os painéis solares requerem acumuladores ou baterias para o armazenamento de energia para que estas (baterias) supram de energia à carga nos períodos em que não há sol. A sua conexão com a rede elétrica requer inversores $\mathrm{CC} / \mathrm{CA}$.

- Pequenas Centrais Hidrelétricas (PCHs)

São usinas hidrelétricas de pequeno porte que geralmente operam sem a necessidade de grandes reservatórios ou diretamente a fio de água. Geralmente estão localizadas próximas dos centros de carga. A eficiência deste tipo de geração está em torno de $70 \%$ a 90\%. Na Tabela 2.1 apresenta-se a classificação das faixas de geração hidro estabelecidas na referência [34] segundo sua capacidade de geração. 
Tabela 2.1. Classificação por faixa de geração de usinas hidrelétricas.

\begin{tabular}{|c|l|}
\hline $\begin{array}{c}\text { Tipo de geração } \\
\text { hidrelétrica }\end{array}$ & \multicolumn{1}{|c|}{ Faixa } \\
\hline Pico & $0 \mathrm{~kW}-5 \mathrm{~kW}$ \\
\hline Micro & $5 \mathrm{~kW}-100 \mathrm{~kW}$ \\
\hline Mini & $100 \mathrm{~kW}-1 \mathrm{MW}$ \\
\hline Pequena & $1 \mathrm{MW}-10 \mathrm{MW}$ \\
\hline Média & $10 \mathrm{MW}-100 \mathrm{MW}$ \\
\hline Grande & $100 \mathrm{MW}+$ \\
\hline
\end{tabular}

No Brasil, são consideradas PCHs aquelas instalações que operam em uma faixa de geração de 1 a $30 \mathrm{MW}$ e com um reservatório de área inferior a 3 km². $\mathrm{Na}$ referência [35] podem ser encontradas informações mais detalhadas sobre este tipo de geração.

- Biomassa

Biomassa é toda matéria orgânica não fóssil, de origem animal ou vegetal, que pode ser utilizada na produção de calor, seja para uso térmico industrial, seja para geração de eletricidade e/ou que pode ser transformada em outras formas de energias sólidas (carvão vegetal, etc), líquidas (etanol, biodiesel) e gasosas (biogás de lixo).

Atualmente, a biomassa vem sendo bastante utilizada na geração de eletricidade, principalmente em sistemas de co-geração e no suprimento de eletricidade de comunidades isoladas da rede elétrica. A sua eficiência está em torno de $7 \%$ a $27 \%$. Prevê-se que com o advento de novas tecnologias, tais como o acoplamento de sistemas de gaseificação a turbinas a gás e outros, a eficiência deste tipo de geração possa atingir valores de até 35\%.

\section{- Geração Geotérmica}

A energia geotérmica é produzida através de fontes que expelem vapor subterrâneo de gêiseres e áreas vulcânicas, e cujo aproveitamento em usinas termelétricas gera eletricidade, principalmente através de vapor denominado "vapor seco", em que a pressão é alta o suficiente para movimentar turbinas com excepcional força. Os paises com maior número de usinas geotérmicas são os Estados Unidos, Filipinas e a Indonésia. A eficiência térmica de usinas geotérmicas é baixa, em torno de 10-23\%, isto porque o vapor geotérmico possui uma temperatura relativamente menor quando comparada com o vapor gerado nas usinas termelétricas convencionais. 


\subsubsection{Sistemas de Armazenamento}

Com a finalidade de utilizar a energia renovável de maneira mais eficiente, frente a problemas inerentes à sua operação (variabilidade e intermitência na geração assim como questões de instabilidade na rede elétrica) é comum o uso de banco de baterias, supercondutores magnéticos e volantes de inércia (flywheels) como elementos de armazenamento de energia [36].

- Os volantes de inércia funcionam através da aceleração de um volante a uma velocidade muito alta mantendo a energia no sistema na forma de energia rotacional. Este sistema tem sido recentemente considerado como meio viável para o suporte de cargas críticas durante interrupções no sistema elétrico por apresentarem respostas mais rápidas que os sistemas de armazenamento eletroquímicos [37].

- Os bancos de baterias, comumente constituídos por um conjunto de células eletroquímicas, armazenam energia elétrica sob a forma de energia química. O seu uso é comum em centros com cargas críticas, já que bancos de baterias podem ser inseridos no sistema de forma instantânea. A desvantagem desta alternativa é o período de duração da produção de energia que, em função da carga conectada, pode ser curto. Sistemas de geração fotovoltaica e eólica, assim como outras fontes de geração intermitentes, comumente precisam de banco de baterias para o armazenamento da energia que logo será utilizada durante períodos pouco favoráveis (tempo sem sol e vento, respectivamente). São particularmente essenciais para a alimentação a sistemas de controle e/ou proteção. As baterias de chumboácido, seguido das baterias de enxofre de sódio, estão entre as mais usadas devido a seu baixo custo e propriedades estáveis em MRs [38].

\subsubsection{Inversores}

Tem a função de converter a corrente contínua (CC), gerada na fonte CC, em corrente alternada (CA). É o caso da geração através de sistema fotovoltaicos e a sua posterior utilização em diversos tipos de carga. Segundo Normas, como a IEEE-1547 [17], com o objetivo de evitar a operação ilhada de redes que não sejam planejadas para este propósito, o inversor deve ser desconectado do painel quando a rede elétrica estiver fora de operação. Porém, dentro do conceito das MRs, a nova geração de inversores deve permanecer conectada a MR quando esta se desconecte da rede principal, mantendo a MR operando no modo ilhado [42]. Atualmente, através desta Norma (IEEE-1547), estão 
sendo desenvolvidos protocolos para que o ilhamento ou separação da MR da rede principal seja realizada de forma mais segura.

\subsubsection{Cargas}

As MRs podem oferecer energia elétrica a diferentes tipos de cargas, principalmente as denominadas cargas críticas (que devido à sua importância não admitem interrupção do fornecimento de energia), assim como a determinadas cargas controláveis (não críticas). Atualmente $o$ atendimento a cargas normais (residencial, industrial e rural) pelas MRs vem sendo mais estudados e/ou aprimorados.

\subsection{Classificação e Topologias de MRs}

Existem diversos critérios que poderiam ser considerados para a classificação de MRs elétricas.

- Uma das primeiras formas de classificação considera as MRs pela sua forma de alimentação em: "individual" e "centralizada", conforme mostrado na Figura 2.3 [39].

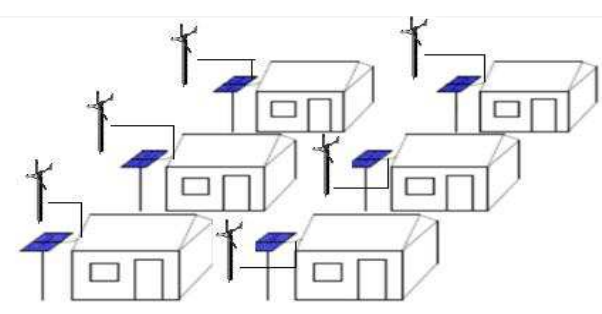

(a)

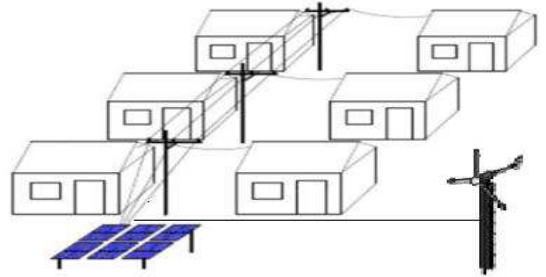

(b)

Figura 2.3. Conjunto habitacional (MR) com alimentação: (a) individual, (b) centralizada [39].

- Outra forma de classificação está relacionada a seu modo de operação, sendo estas: (a) "conectada" com a rede elétrica, (b) "ilhada" desta.

- Segundo a sua topologia, uma micro-rede pode ser classificada em: (a) rede "radial", (b) "malhada" e, (c) em "anel" [40]. Cada uma desta MRs apresenta diferentes requisitos operacionais e de proteção.

- A MR radial está baseada numa linha tronco, onde as cargas e as possíveis fontes de geração estão ligadas em paralelo com a linha tronco. Esta configuração de MR é a mais comum em áreas rurais. 
- A MR malhada tem como principal vantagem a flexibilidade na operação, porém requer um sistema de proteção mais complexo.

- MRs em anel requerem vários pontos ou subestações secundárias com duas rotas para o fluxo da energia. Este tipo de configuração apresenta ainda uma melhor estabilidade de tensão e perdas de energia mais baixas.

- Segundo seu modo de controle, uma MR pode ser classificada em: "centralizada" e "descentralizada" [40], de forma análoga ao mostrado na Figura 2.3.

- Em função do tipo de corrente as MRs podem ser classificadas em CA ou CC, ou "mistas". Neste último caso (MRs mistas), tanto a rede CC como a rede CA coexistem dentro da MR. Os componentes da área CC estarão conectados à rede CA através de um conversor [41]. Atualmente, as redes CC podem ser concebidas para operar de forma autônoma, já que boa parte das fontes de geração, tais como a fotovoltaica, células de combustível e a maioria das cargas digitais operam com alimentação CC. Diante disso, as MRs CC podem dispensar de conversores CC/CA. Isto oferece certa vantagem em termos de custo, tamanho e eficiência do sistema.

- Dentro de sua classificação podem ainda ser considerados aspectos relacionados a [43]:

- Número de clientes a serem atendidos (um único cliente ou mais de um) de forma análoga ao mostrado na Figura 2.3.

- Tipo de cliente (residencial, comercial ou industrial).

- Tempo de funcionamento (integral ou parcial).

- Nível de tensão utilizado.

- Tipo de geração distribuída utilizada, entre outros.

A seguir são descritos alguns dos tipos de MRs mencionados neste último item.

a) Micro-rede Simples (apenas um usuário).

É considerada como a forma mais simples de MR. Está formada por um gerador de emergência e um único interruptor de conexão (Figura 2.4). A partir da incorporação de sistemas de controle e sincronização, além de um sistema de detecção automática das condições de ilhamento, é possível configurar uma MR que opere de forma sincronizada com a rede elétrica ou ilhada desta. 


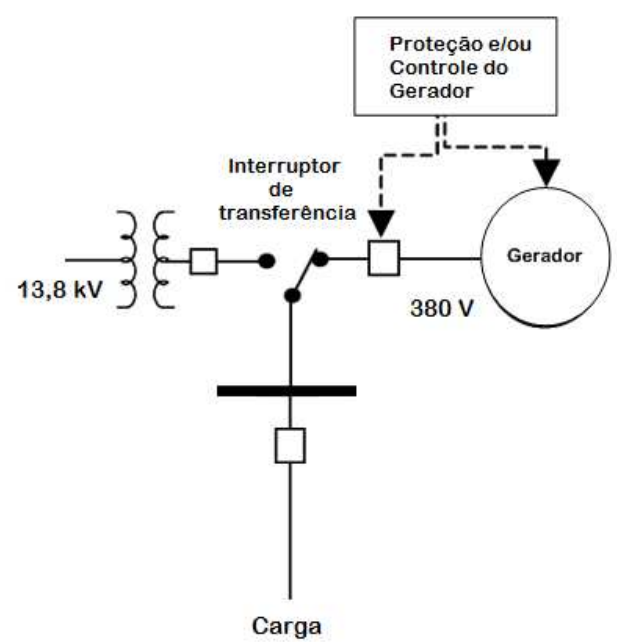

Figura 2.4. Esquema de uma micro-rede simples (apenas um usuário) [43].

b) Micro-rede constituída por um conjunto de usuários

Atende um grupo de consumidores que normalmente encontram-se conectados à rede elétrica (Figura 2.5). Além de fontes de geração distribuída, a MR pode incorporar dispositivos de armazenamento de energia e geração de calor residual para calefação a cada um dos usuários isto a fim de incrementar a eficiência energética da MR. Nesta figura não está sendo representada a fonte primária de geração, mas apenas o banco de baterias alimentado por estas.

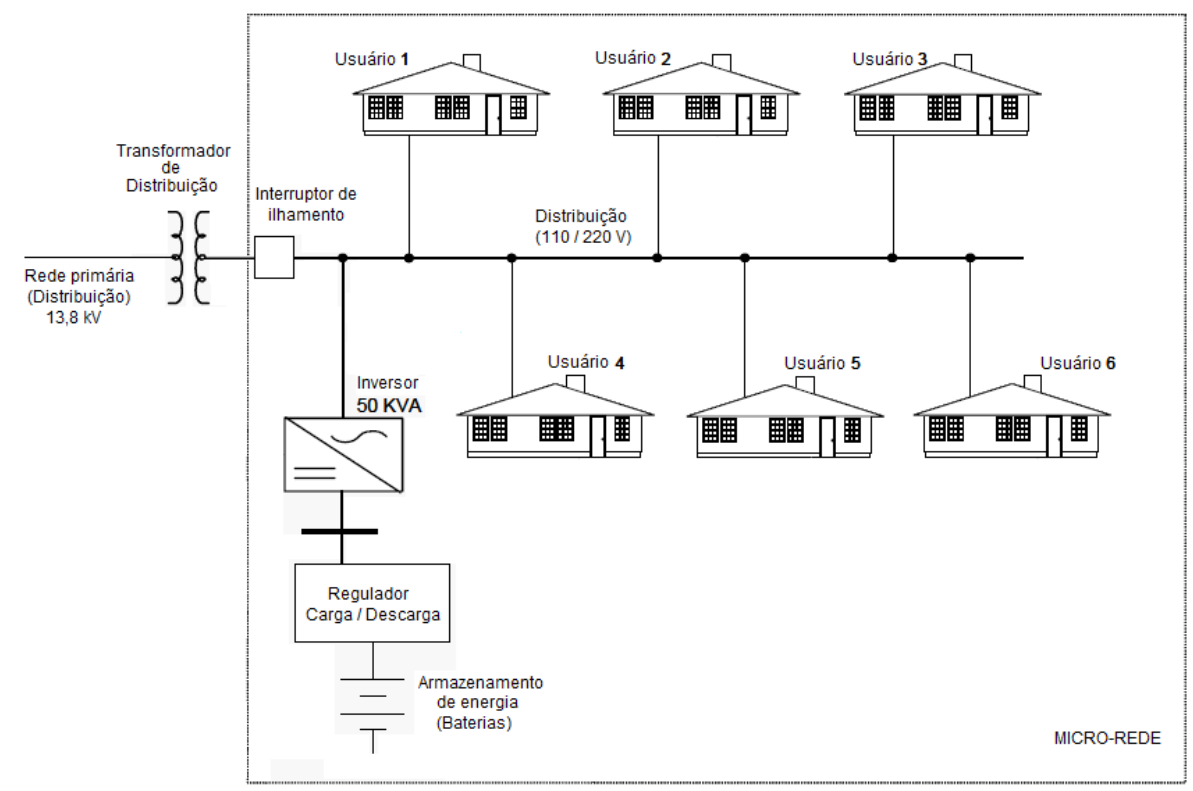

Figura 2.5. Esquema de uma MR constituída por um conjunto de usuários [43]. 
c) Micro-rede com múltiplas fontes de geração distribuída

Considerada como um conceito mais sofisticado de MR, onde se busca principalmente utilizar a geração de diferentes pontos na rede (geração solar, eólica, micro-turbina a gás, mini-turbinas hidráulicas, etc.). O uso de múltiplas fontes de geração dispersa requer uma mudança significativa na proteção e metodologias de controle. Neste caso, a proteção padrão radial e abordagens de seletividade comuns poderiam não ser as mais adequadas. Os geradores terão de se comunicar uns com outros de forma que seja garantida uma distribuição adequada da carga. Deverão também ser analisadas questões de estabilidade, controle de tensão e melhor desempenho do sistema (MR) em relação à sua eficiência e ao custo de produção de energia, entre outros.

\subsection{Controle Centralizado e Descentralizado da MR}

No tipo de controle chamado de "centralizado" ou hierárquico, como o apresentado na Figura 2.6, podem ser identificados quatro tipos de controladores [44], [45], sendo estes:

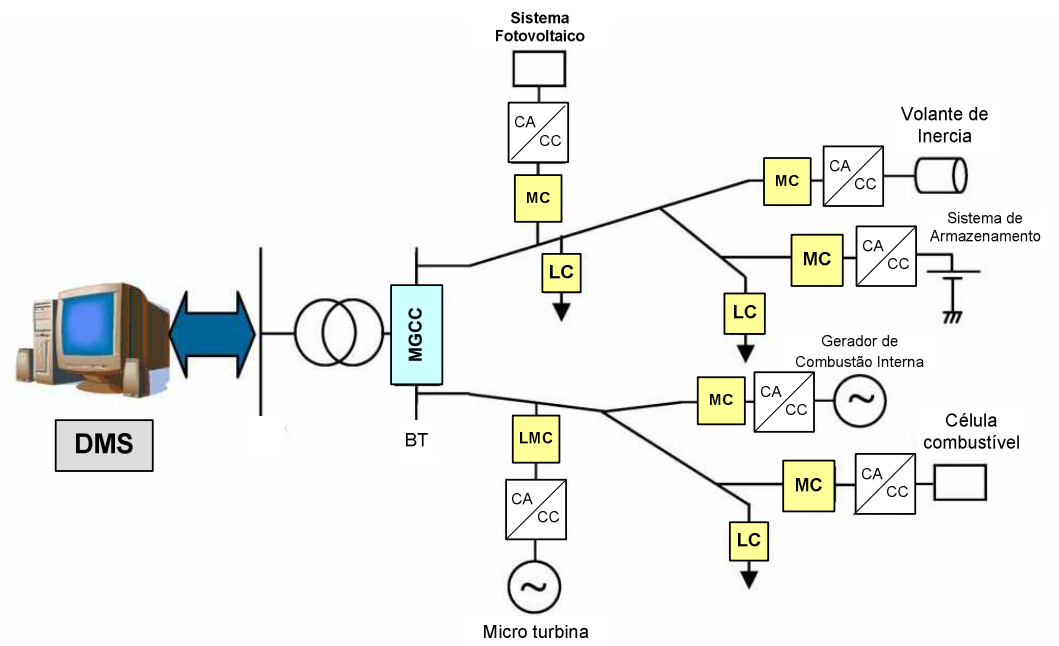

Onde:

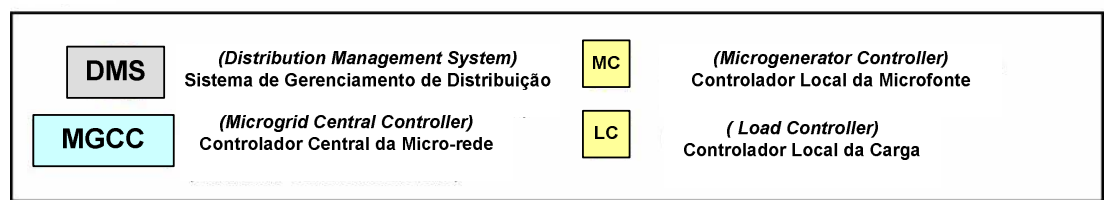

Figura 2.6. Arquitetura de uma MR centralizada [7].

a) Controlador da micro-fonte (MC - Microsource Controller), utilizado para controlar a tensão e a frequência da MR. 
b) Controlador da carga (LC - Load Controller), sendo na realidade uma chave que opera em coordenação com a freqüência da rede. A chave desliga a carga de forma automática durante os períodos de elevada demanda e a reconecta após esta (demanda) diminuir.

c) Controlador Central da MR (MGCC - Microgrid Central Controller) ou MMS (Microgrid Management System). Controlador que monitora a potência ativa e reativa da MR além de ser responsável pela transmissão de informação de/para os MCs e LCs.

As funções básicas do MGCC são [8]-[6]:

- Comunicação bi-direcional em tempo real.

- Sistema de gerenciamento da distribuição.

- Sistema de armazenamento de energia.

- Disjuntor de interconexão com a MR e com outros dispositivos de proteção.

- $\quad$ Intercâmbio de informação com as unidades de geração distribuída e as cargas.

- Condição e estado das unidades.

- Comando de controle com as unidades de GD.

- Estabelecer as bases para condições como:

- Transição para o modo de operação normal.

- Transição ao modo de operação ilhada.

- Operação no modo ilhado.

- Capacidade de restabelecimento da MR ou blackstart ${ }^{1}$.

- Gerenciamento de faltas e religamento sincronizado.

d) Sistema de gerenciamento da distribuição (DMS - Distribution Management System), que gerencia a interligação entre a MR e a rede principal.

Ainda não foram disponibilizadas informações referentes ao desempenho real do sistema de controle acima descrito, mas na teoria, o LC e MC intercambiam informação de forma contínua com o MGCC (controle centralizado) que devolve informação dos set-points mais adequados dos geradores (potência ativa e reativa) por meio do MC.

1 No caso das MRs, esta característica se refere à capacidade de restabelecimento o fornecimento da energia pelos geradores, após a ocorrência de um blecaute, sem que estes (geradores) estejam conectados ao sistema ou a um sistema de geração auxiliar (p.ex. gerador diesel ou banco de baterias). 
A MR poderá oferecer ao operador de rede principal informações como tensão, fluxo de potência ativa e reativa que for intercambiada com esta (rede de distribuição).

O controle descentralizado apresenta características similares ao sistema de controle centralizado, com a diferença que no primeiro a responsabilidade principal é dada aos MCs que, visando satisfazer a demanda e exportar a máxima potência possível considerando os preços atuais do mercado, competem para maximizar sua produção. Este tipo de controle (descentralizado) constitui-se em uma forma de maximizar a autonomia dos micro-geradores e cargas [6], [45].

\subsubsection{Controle da Operação durante o Modo Normal}

Durante a operação no modo normal (conectada com a rede), o MGCC pode lidar com a gestão técnica e econômica da MR atuando como um operador de mercado [8], [7]. Na Figura 2.7 apresenta-se de forma esquemática a interação (fluxo de informação) do MGCC com o MC e com o LC. Além das funcionalidades acima descritas, o MGCC é responsável de fornecer às MCs informações sobre os preços de mercado, possíveis limites (set points) da geração, além dos lances de preço ao mercado. A responsabilidade do MGCC dentro da MR é crítica e, por isso, a sua operação deverá ser ininterrupta e com bom desempenho.

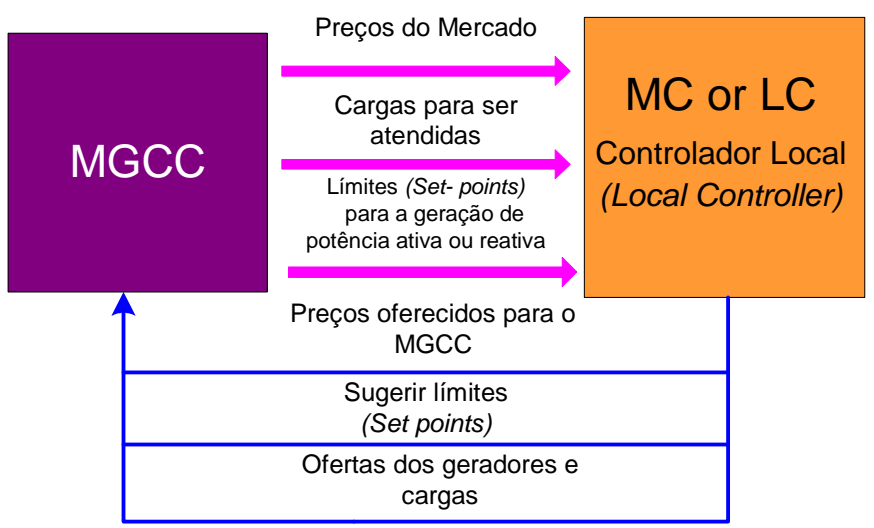

Figura 2.7. Fluxo de informação entre os controladores da MR [7].

Neste contexto, prevê-se que as redes inteligentes (smart grids) contribuam com a leitura remota de variáveis e condições em tempo real, a fim de realizar de forma segura a transição, por exemplo, da conexão e/ou outras tarefas como as mencionadas anteriormente, de um estado de operação para outro. 


\subsection{Principais Fontes de Geração Utilizadas em MRs e Interface com a Rede}

Conforme apresentado na Tabela 2.2, as fontes de geração utilizadas em MRs elétricas e GD podem ser classificadas segundo a fonte de combustível utilizado, o tipo de conexão com o sistema atendido, e segundo a capacidade de geração [46]. A eleição do tipo de tecnologia de geração numa micro-rede dependerá de alguns fatores como, por exemplo: os custos de investimento, custo de operação e manutenção, disponibilidade do combustível, emissões de ruído, emissões de gases de efeito estufa e maturidade da tecnologia, entre outros [47].

Tabela 2.2. Principais fontes de geração em MRs e GD.

\begin{tabular}{|c|c|c|c|c|c|}
\hline Tecnología & Fonte de Energia & $\begin{array}{l}\text { Interface } \\
\text { (conexão) }\end{array}$ & $\begin{array}{l}\text { Pequeno } \\
<100 \mathrm{~kW}\end{array}$ & $\begin{array}{c}\text { Médio } \\
100 \mathrm{~kW}-1 \mathrm{MW}\end{array}$ & $\begin{array}{l}\text { Grande } \\
>1 \mathrm{MW}\end{array}$ \\
\hline $\begin{array}{l}\text { Motores a combustão com } \\
\text { geradores síncronos ou } \\
\text { assíncronos }\end{array}$ & $\begin{array}{c}\text { Combustível fóssil } \\
\text { e biogás }\end{array}$ & Direta & $x$ & $x$ & $x$ \\
\hline Pequenas turbinas a gás & $\begin{array}{c}\text { Combustível fóssil } \\
\text { e biogás }\end{array}$ & Direta & & & $x$ \\
\hline Micro-turbinas & $\begin{array}{c}\text { Combustível fóssil } \\
\text { e biogás }\end{array}$ & Inversor & $x$ & $x$ & \\
\hline Células combustíveis & $\begin{array}{c}\text { Combustivel fóssil } \\
\text { e renovável }\end{array}$ & Inversor & $x$ & $x$ & $x$ \\
\hline Geotérmico & Renovável & Direta & & $x$ & $\mathrm{X}$ \\
\hline $\mathrm{PCH}$ & Renovável & Direta & & $x$ & $x$ \\
\hline Eólica & Renovável & Inversor & $x$ & $x$ & $x$ \\
\hline Fotovoltaíco & Renovável & Direta & $x$ & $\mathrm{X}$ & $x$ \\
\hline Solar Térmico & Renovável & Direta & $x$ & $x$ & $x$ \\
\hline $\begin{array}{l}\text { Armazenamento em } \\
\text { baterías }\end{array}$ & Rede elétrica & Inversor & $x$ & $x$ & $x$ \\
\hline $\begin{array}{l}\text { Armazenamento em } \\
\text { volantes de inércia }\end{array}$ & Rede elétrica & Inversor & & $x$ & $x$ \\
\hline $\begin{array}{l}\text { Armazenamento em } \\
\text { supercondutores } \\
\text { (sistemas SMS - } \\
\text { Superconducting Magnetic } \\
\text { Energy Storage) }\end{array}$ & Rede elétrica & Inversor & & $x$ & $x$ \\
\hline
\end{tabular}

Fonte: [46].

\subsection{Características das Fontes de GD e Compatibilidade com as MRs}

Na Tabela 2.3 apresenta-se um resumo das principais fontes de geração distribuída e sua compatibilidade com as MRs elétricas [48]. Segundo esta tabela, o motor de combustão interna é considerado a melhor tecnologia para trabalhar de forma contínua com cargas relativamente pequenas, bem como lidar com possiveis perturbações que ocorram no sistema. Por sua vez as tecnologias que consideram o uso de fontes renováveis, por exemplo, eólica e fotovoltaica, não são adequadas para despacho contínuo; isto pela natureza da sua geração (dependência das condições climáticas). 
No caso da geração das MRs, estas não poderiam ser consideradas como fontes primárias, a menos que disponham de dispositivos de armazenamento de energia de tamanho considerável.

Tabela 2.3. Características das fontes de GD e compatibilidade com as MRs.

\begin{tabular}{|c|c|c|c|c|c|}
\hline $\begin{array}{l}\text { Fonte de } \\
\text { Geração }\end{array}$ & $\begin{array}{c}\text { Conversor } \\
\text { de potência } \\
\text { comumente } \\
\text { utilizado }\end{array}$ & $\begin{array}{l}\text { Eficiência } \\
\text { relativa } \\
\text { (potência } \\
\text { de ponta) }\end{array}$ & $\begin{array}{l}\text { Corrente } \\
\text { de falta em } \\
\text { relação á } \\
\text { nominal }(x)\end{array}$ & $\begin{array}{l}\text { Confiabilidade/ } \\
\text { Disponibilidade }\end{array}$ & Comportamento em MRs \\
\hline $\begin{array}{l}\text { Motor de } \\
\text { combustão } \\
\text { interna }\end{array}$ & \multirow{2}{*}{$\begin{array}{l}\text { Gerador } \\
\text { Síncrono }\end{array}$} & $35-40 \%$ & $\begin{array}{l}\text { Inicialmente } \\
5-10 x\end{array}$ & $\begin{array}{l}90-96 \% \text { em } \\
\text { função da } \\
\text { manutenção }\end{array}$ & $\begin{array}{l}\text { Satisfaz tanto a carga base } \\
\text { como a carga variável. Tida } \\
\text { como a melhor de todas as } \\
\text { fontes de geração para MRs }\end{array}$ \\
\hline $\begin{array}{l}\text { Turbina de } \\
\text { combustão } \\
\text { convencional }\end{array}$ & & $\leq 40 \%$ & $\begin{array}{l}\text { Inicialmente } \\
5-10 x\end{array}$ & $\begin{array}{l}90-96 \% \text { em } \\
\text { função da } \\
\text { manutenção }\end{array}$ & $\begin{array}{l}\text { Diante de cargas variáveis não } \\
\text { é tão boa quanto o motor de } \\
\text { combustão interna. Atende } \\
\text { melhor a carga base. }\end{array}$ \\
\hline Micro turbina & \multirow[t]{2}{*}{ Inversor } & $<40 \%$ & $\begin{array}{l}\text { Depende do } \\
\text { inversor } \\
(<4 \mathrm{x})\end{array}$ & -- & $\begin{array}{l}\text { Pouco efetivo para cargas } \\
\text { variáveis. Satisfaz melhor à } \\
\text { carga base. Tecnologia em } \\
\text { desenvolvimento. }\end{array}$ \\
\hline $\begin{array}{l}\text { Fotovoltaico } \\
\text { (PV) }\end{array}$ & & & $\begin{array}{l}\text { Depende do } \\
\text { inversor } \\
(<4 x)\end{array}$ & $\begin{array}{l}\text { 8-25\% (em } \\
\text { função do tipo } \\
\text { de fonte) }\end{array}$ & \multirow{2}{*}{$\begin{array}{l}\text { Apenas conveniente para uso } \\
\text { durante períodos de ponta de } \\
\text { carga. Sem fonte de } \\
\text { armazenamento limitada } \\
\text { menos de } 20 \% \text { da capacidade } \\
\text { de geração da MR. }\end{array}$} \\
\hline Turbina eólica & $\begin{array}{l}\text { Gerador de } \\
\text { indução ou } \\
\text { síncrono } \\
\text { (inversor) }\end{array}$ & $<25 \%$ & $\begin{array}{l}5-10 x \text { para } \\
\text { o gerador } \\
\text { de indução. } \\
\text { Para o } \\
\text { Inversor }< \\
4 x\end{array}$ & $\begin{array}{l}10-40 \% \text { (em } \\
\text { função do tipo } \\
\text { de fonte) }\end{array}$ & \\
\hline $\begin{array}{l}\text { Célula } \\
\text { combustivel }\end{array}$ & Inversor & $35-40 \%$ & $\begin{array}{l}\text { Depende do } \\
\text { inversor } \\
(<4 \mathrm{x})\end{array}$ & $\begin{array}{l}\text { 90-95\%, ainda } \\
\text { em fase de } \\
\text { otimização. }\end{array}$ & $\begin{array}{l}\text { Pode ser um recurso excelente } \\
\text { tanto para carga variável como } \\
\text { para carga base. Em função } \\
\text { do projeto do inversor, pode } \\
\text { atender bem as variações de } \\
\text { carga. }\end{array}$ \\
\hline
\end{tabular}

Fonte: [48]

Outras fontes de geração, como as células de combustível e microturbinas, ainda estão sendo investigadas e aprimoradas. Espera-se que estas, além dos inversores necessários para conversão em CA, possam ser utilizadas durante variações de carga significativas.

A geração baseada em motores de combustão interna e turbinas de combustão convencional têm mostrado fatores de disponibilidade entre $90 \%$ a $98 \%$, comparado com a disponibilidade oferecida pela rede principal que está em torno de 99\%. Dessa forma, para garantir níveis exigentes de confiabilidade dentro da MR seriam necessárias fontes de geração redundantes. 


\subsection{Vantagens e Desvantagens oferecidas pelas MRs}

Existem vários fatores de interesse sob os quais as MRs, e sua implementação, tornam-se promissoras, entre estas:

- A capacidade de ilhamento durante quedas de energía ou blecautes na rede principal; idealmente, sem afetar a continuidade de suprimento aos usuários da MR.

- A injeção de potência na rede principal em períodos de ponta de carga reduzindo as perdas e evitando sobrecargas na rede da concessionária.

- Redução dos custos de energia do usuário pelo fato deste gerar sua própria energia a um custo inferior à tarifa da concessionária.

- Redução de gases poluentes (efeito estufa), caso a MR possua geração baseada em fontes de energia renovável.

- Um aspecto considerado promissor é sua capacidade de prestar serviços complementares (ancilares) dirigidos a aumentar a confiabilidade do sistema de distribuição tais como, por exemplo: suporte de tensão à rede principal, fornecimento de energía de reserva, capacidade de black start e ilhamento controlado [49], [50]

Entre as desvantagens, podem-se mencionar:

- A qualidade da tensão e freqüência geradas, principalmente se a MR utiliza conversores para se conectar com a rede principal (em função dos harmônicos que a MR pode gerar). Estas grandezas deveriam-se enquadrar nos padrões estabelecidos nas Normas, evitando assim comprometer a operação regular de determinadas cargas.

- Dependendo do tipo de fonte de geração, pode ser necessário o uso de sistemas de armazenamento de energia, o que demanda espaço adicional e manutenção.

- Em função do tipo de automação da MR (completa ou parcialmente automatizada), a sincronização com a rede elétrica durante a reconexão pode oferecer dificuldades.

- O sistema de proteção da MR e sua coordenação com o sistema da concessionária é um dos desafios atualmente em fase de investigação e aprimoramento.

- Questões regulatórias e de comercialização para sua conexão à rede elétrica representam obstáculos a serem removidos. 


\subsection{Possíveis Benefícios e Aplicações}

$\mathrm{Na}$ Tabela 2.4, adaptada da referência [51], apresenta-se uma síntese dos benefícios trazidos pelo estabelecimento de MRs elétricas em relação à concessionária, à sociedade e ao consumidor final (stakeholders).

Tabela 2.4. Visão geral de alguns benefícios diretos que as MRs podem oferecer.

\begin{tabular}{|c|c|c|c|c|}
\hline $\begin{array}{l}\text { Classe de } \\
\text { Beneficio }\end{array}$ & Beneficio Especifico & Consumidor & Concessionária & Sociedade \\
\hline \multirow{2}{*}{$\begin{array}{l}\text { Econômico } \\
\text { (direto) }\end{array}$} & $\begin{array}{l}\text { Redução de custo da } \\
\text { eletricidade e } \\
\text { combustível }\end{array}$ & $\checkmark$ & & \\
\hline & $\begin{array}{l}\text { Venda do excedente de } \\
\text { eletricidade para a rede }\end{array}$ & $\checkmark$ & $\checkmark$ & $\checkmark$ \\
\hline \multirow{2}{*}{$\begin{array}{l}\text { Econômico } \\
\text { (indireto) }\end{array}$} & $\begin{array}{l}\text { Redução de perdas na } \\
\text { distribuição }\end{array}$ & & $\checkmark$ & $\checkmark$ \\
\hline & $\begin{array}{l}\text { Reservas operacionais } \\
\text { reduzidas }\end{array}$ & & $\checkmark$ & \\
\hline \multirow{2}{*}{$\begin{array}{l}\text { Confiabilidade } \\
\text { de Energia }\end{array}$} & $\begin{array}{l}\text { Diminuição da falta de } \\
\text { energia no local }\end{array}$ & $\checkmark$ & $\checkmark$ & \\
\hline & $\begin{array}{l}\text { Capacidade de } \\
\text { blackstart. }\end{array}$ & & $\checkmark$ & $\checkmark$ \\
\hline Apoio à Rede & $\begin{array}{l}\text { Controle de reativos e } \\
\text { tensão terminal. }\end{array}$ & & $\checkmark$ & \\
\hline \multirow{2}{*}{$\begin{array}{l}\text { Ambiental } \\
\text { (com fontes } \\
\text { renováveis) }\end{array}$} & $\begin{array}{l}\text { Incremento no uso de } \\
\text { energia renovável }\end{array}$ & $\checkmark$ & $\checkmark$ & $\checkmark$ \\
\hline & $\begin{array}{l}\text { Redução de emissões } \\
\text { de efeito estufa }\end{array}$ & & & $\checkmark$ \\
\hline
\end{tabular}

Verifica-se através desta tabela que o suporte da MR aos diversos stakeholders é fundamental em termos técnicos, econômicos e ambientais.

\subsection{Normas Estabelecidas Referente MRs e GD}

Apesar de não existirem normas e diretrizes especificamente dirigidas ao caso de MRs, acredita-se que boa parte de sua filosofia de conexão estará baseada nas Normas propostas tanto pelo IEEE e CIGRÉ para a GD. Assim, a seguir são apresentadas as principais faixas e parâmetros de operação estabelecidos para este tipo de redes.

\subsubsection{Condições para a Conexão entre a Rede Principal e a GD}

Uma das principais condições refere-se aos valores de freqüência, tensão e ângulo no momento do fechamento do disjuntor entre a rede principal e a fonte (DER Distributed Energy Resource) da GD.

A Norma IEEE-1547 estabelece que durante o fechamento estas três variáveis deverão estar dentro dos valores indicados na Tabela 2.5 [17], [18]. Caso algúm dos 
parâmetros seja maior do que os valores mostrados, o DER não poderá ser conectado.

Tabela 2.5. Límites dos parâmetros de sincronização (Norma IEEE-1547) dirigidos à interconexão síncrona entre a GD e o sistema.

\begin{tabular}{|c|c|c|c|}
\hline $\begin{array}{c}\text { Capacidades dos DERs } \\
(\mathbf{k V A})\end{array}$ & $\begin{array}{c}\text { Diferença de Freqüência } \\
(\triangle \boldsymbol{f}, \mathbf{H z})\end{array}$ & $\begin{array}{c}\text { Diferença de Tensão } \\
(\triangle \mathbf{V}, \boldsymbol{\%})\end{array}$ & $\begin{array}{c}\text { Diferença do ângulo } \\
\text { de fase } \\
(\triangle \boldsymbol{\Phi}, \mathbf{g r a u s})\end{array}$ \\
\hline $0-500$ & 0,3 & 10 & 20 \\
\hline$>500-1500$ & 0,2 & 5 & 15 \\
\hline$>1500-10.000$ & 0,1 & 3 & 10 \\
\hline
\end{tabular}

\subsubsection{Limites de Freqüência durante Perturbações na Rede}

A Norma IEEE Std 1457-2003 4.2.4 [17], estabelece que, diante de uma perturbação na rede, quando a freqüência elétrica estiver na faixa mostrada na Tabela 2.6, o DER deverá desconectar-se do sistema num tempo de abertura igual ou inferior ao mostrado. O tempo de abertura é o tempo entre o início da condição anormal e o tempo de desconexão da DER do sistema. Para DERs menores ou iguais a $30 \mathrm{~kW}$ (capacidade de ponta), os valores de referência da frequência e os tempos de abertura deverão ser fixos ou ajustáveis em campo. Para DERs com potências maiores a $30 \mathrm{~kW}$ os valores de referência da freqüência deverão ser ajustáveis em campo. Os valores de disparo ajustáveis para casos de sub-frequência deverão ser coordenados com a operação do sistema de potência.

Tabela 2.6. Resposta do sistema de interconexão para frequências anormais

\begin{tabular}{|c|c|c|}
\hline Tamanho do DER & $\begin{array}{c}\text { Faixa de Freqüência } \\
\mathbf{( H z )}\end{array}$ & ${\text { Tempo de Abertura } \mathbf{( s )}{ }^{*}}^{*} \leq 30 \mathrm{~kW}$ \\
\cline { 2 - 3 } & $>60,5$ & 0,16 \\
\hline \multirow{3}{*}{$>30 \mathrm{~kW}$} & $>59,3$ & 0,16 \\
\cline { 2 - 3 } & $\begin{array}{c}>60,5 \\
\text { (set points ajustáveis) }\end{array}$ & 0,16 \\
\cline { 2 - 3 } & $<57,0$ & Ajustável entre 0,16 a 300 \\
\hline
\end{tabular}

(*) DER $\leq 30 \mathrm{~kW}$, tempos de abertura máximos; DER $>30 \mathrm{~kW}$, tempos de abertura por default, conforme especificado na norma IEEE.

A reconexão ao sistema, após eliminada a perturbação, poderá ocorrer quando a faixa de frequências estiver, por exemplo, no caso de DERs com potências iguais ou inferiores a $30 \mathrm{~kW}$, na faixa de $59,3 \mathrm{~Hz}$ a $60,5 \mathrm{~Hz}$, em coordenação com os limites de tensão estabelecidos nas Normas. Este mesmo procedimento é válido no caso de DERs com potências superiores a $30 \mathrm{~kW}$. 


\subsection{Barreiras encontradas pela Tecnologia das MRs}

Apesar das vantagens técnicas oferecidas pelas MRs ainda existem algumas dificuldades tecnológicas e regulatórias a serem resolvidas antes de serem legalmente reconhecidas como entidades elétricas. Atualmente, grande parte das MRs corresponde a projetos piloto. Entre estas dificuldades podem ser mencionadas as seguintes:

\section{i) Políticas regulatórias}

Necessárias para o estabelecimento de um sistema elétrico com participação do consumidor final como pequeno produtor. Isto porque, na atualidade, muitos dos órgãos de regulação de sistemas elétricos ainda não estão completamente familiarizados com o conceito e aplicação prática das MRs; assim, permanece a incerteza sobre como estas políticas serão aplicadas ao caso das MRs.

\section{ii) Modelos de propriedade e gerenciamento da MR}

Este assunto tem relação com a forma de gerenciamento e propriedade da MR. Em [10], propõe-se a existência de cinco modelos que poderiam ser utilizados para categorizar as MRs segundo o tipo de proprietário e as práticas comerciais, sendo estes:

a) Modelo da Concessionária de Distribuição (Utility model) - No qual, a concessionária de distribuição é proprietária da MR e também responsável pela operação das instalações.

b) Modelo do Locador (Landlord model) - Um único proprietário (locador) é o dono da MR e fornece energia elétrica através de um contrato de locação contratual.

c) Modelo Cooperativo (Co-op model) - A MR é administrada por uma cooperativa. Os clientes se juntam à MR de forma voluntária e são supridos de energia sob contrato.

d) Modelo Cliente-Gerador (Customer-generator model) - Uma única pessoa, ou empresa, é proprietária da MR, fornecendo energia elétrica a si mesmo e a seus clientes. Os clientes se juntam à MR de forma voluntária e são providos de energia sob contrato.

e) Modelo similar ao sistema de aquecimento urbano (District heating model) - Neste modelo, uma empresa independente é proprietária da MR e a administra fornecendo energia elétrica a vários clientes. 
Cada um destes modelos apresenta vantagens e desvantagens que devem ser discutidos, caso seja adotado pela MR.

\section{iii) Escolha do nível de tensão}

Por razões técnicas e de custo as MRs conectam-se preferencialmente ao nível de baixa tensão (BT) até $1 \mathrm{kV}$. Porém, nada impede destas se conectarem em média tensão (MT), em tensões na faixa $1 \mathrm{kV}$ a $35 \mathrm{kV}$.

\section{iv) Áreas de Concessão}

Comumente, as concessionárias de distribuição exercem um monopólio sobre o fornecimento de energia dento de sua área de concessão, com o objetivo de evitar a instalação de fios redundantes na área de concessão. Estas concessões reduzem o risco financeiro da concessionária diante de um mercado competitivo; em troca, esta tem o dever de oferecer energia de forma ininterrupta. Em alguns países, a posição das MRs sobre este aspecto vem sendo discutida [10].

\section{v) Tarifas}

No futuro, deverá também ser definido se o sistema de tarifação tradicional pode ser aplicado ao caso das MRs, ou, se serão necessárias modificações a este sistema tarifário. No atual estado de desenvolvimento das MRs, principalmente aquelas baseadas em fontes de geração alternativa, utilizam-se algumas políticas de incentivo, conforme descrito no Capitulo 3.

\section{vi) Procedimentos de Interconexão}

As concessionárias de distribuição mostram-se, normalmente, contrárias ou relutantes à conexão de sistemas de geração distribuída na sua rede, alegando questões de estabilidade e segurança de seu sistema. Tanto os operadores do sistema como as agências reguladoras ainda se encontram debatendo este aspecto.

\section{vii) Leis ambientais e localização}

Outro aspecto ainda a ser esclarecido é a necessidade de regulamentações relacionadas ao impacto das MRs sobre o meio ambiente. Este aspecto, assim como sua localização, são normalmente tratados pelos órgãos pertinentes. Algumas mudanças necessárias na regulamentação, que poderiam ser adotadas pelos agentes reguladores pertinentes, são apresentadas em [10]. 


\subsection{Exemplos de MRs no Mundo}

O desenvolvimento de programas de pesquisa práticos sobre MRs foi iniciado a começos da década dos 2000 [51], em alguns países da União Européia, no Japão e nos EUA. Mais recentemente, países como a China, Coréia do Sul e Cingapura têm apresentado um interesse crescente sobre esta tecnologia [14], [15].

$\mathrm{Na}$ atualidade, conforme observado na Figura 2.8, os EUA é um dos paises com maior número de MRs, seguido pelos países europeus e Asia [52]. A Antártida é a menor região com partcipação percentual do total no mundo, com apenas $0,3 \%$.

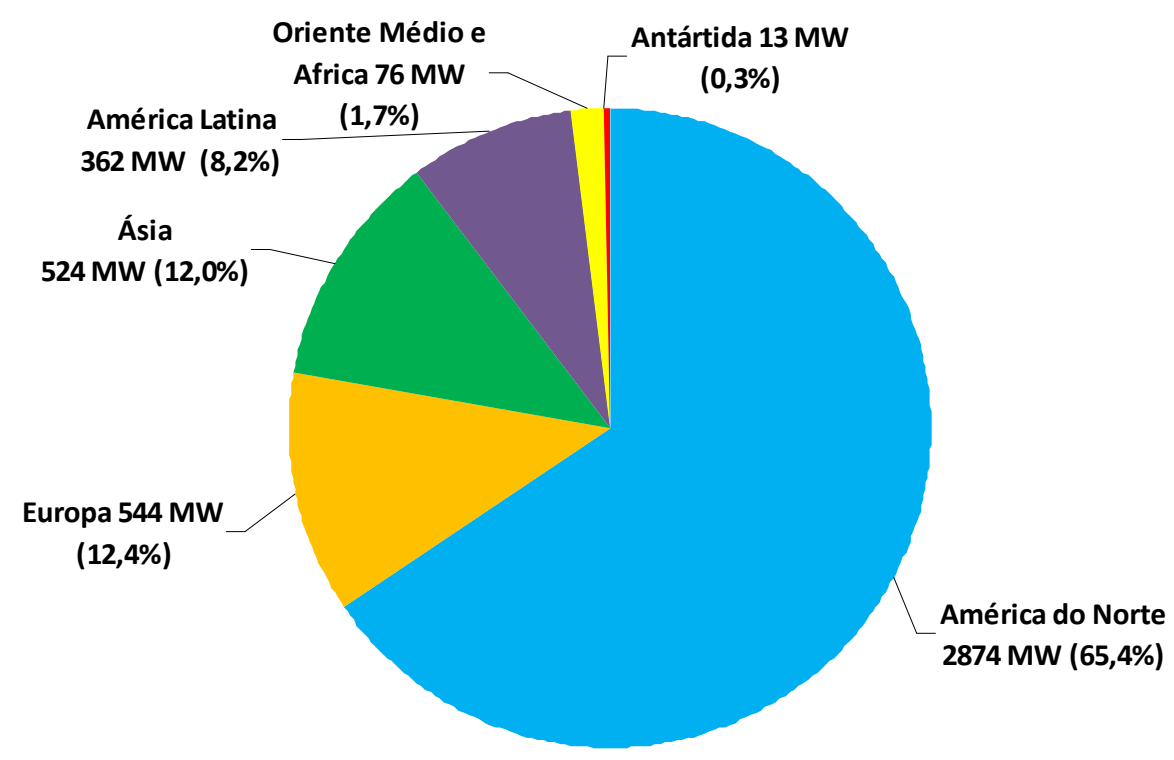

Figura 2.8. Capacidade em MW e porcentagem de participação por região (2014) no mundo [52].

\subsubsection{Europa}

Na Tabela 2.7 estão sendo apresentados os principais exemplos de MRs desenvolvidas até agora, bem como o tipo de controle (centralizado ou descentralizado), e o tipo de estrutura (CA/CC). Pode-se observar que boa parte dos projetos são redes CA comerciais com sistema de controle centralizado; o restante de projetos corresponde a prototipos experimentais. 
Tabela 2.7. Principais MRs na Europa.

\begin{tabular}{|c|c|c|c|c|c|c|c|c|}
\hline \multirow[b]{2}{*}{ Localização } & \multirow[b]{2}{*}{ País } & \multirow[b]{2}{*}{$\begin{array}{l}\text { Administrador do } \\
\text { Projeto }\end{array}$} & \multicolumn{2}{|c|}{ Tipo de Projeto } & \multicolumn{2}{|c|}{ Tipo de Controle } & \multicolumn{2}{|c|}{ Estrutura } \\
\hline & & & Comercial & Experimental & $\begin{array}{l}\text { Centra- } \\
\text { lizado }\end{array}$ & $\begin{array}{l}\text { Descentra- } \\
\text { lizado }\end{array}$ & CA & CC \\
\hline $\begin{array}{l}\text { Bornholm } \\
\text { Island }\end{array}$ & Dinamarca & Projeto Mais MRs & $\checkmark$ & & & $\checkmark$ & $\checkmark$ & \\
\hline Lyon & França & $\begin{array}{l}\text { NEDO (New Energy \& } \\
\text { Industrial Technology } \\
\text { Development } \\
\text { Organization) }\end{array}$ & & $\checkmark$ & & & $\checkmark$ & \\
\hline Kassel & Alemanha & $\begin{array}{l}\text { The Institute for Solare, } \\
\text { University of Kassel } \\
\text { Institute for Electrical } \\
\text { Energy Techonology } \\
\text { (IEE) }\end{array}$ & & $\checkmark$ & $\checkmark$ & & $\checkmark$ & \\
\hline $\begin{array}{l}\text { Mannheim } \\
\text { Wallstad }\end{array}$ & & Projeto mais MRs & $\checkmark$ & & & $\checkmark$ & & \\
\hline Stutensee & & Projeto DISPOWER & $\checkmark$ & & $\checkmark$ & & $\checkmark$ & \\
\hline Atenas & Grécia & $\begin{array}{l}\text { National Technical } \\
\text { University of Athens } \\
\text { (NTUA) }\end{array}$ & & $\checkmark$ & & $\checkmark$ & $\checkmark$ & \\
\hline Milan & Itália & $\begin{array}{l}\text { Ricerca Sistema } \\
\text { Energético (RSE) }\end{array}$ & & $\checkmark$ & $\checkmark$ & & & $\checkmark$ \\
\hline Agria pig farm & Macedonia & Projeto Mais MRs & $\checkmark$ & & & & $\checkmark$ & \\
\hline Bronsbergen & & Projeto Mais MRs & $\checkmark$ & & $\checkmark$ & & $\checkmark$ & \\
\hline Groningen & Holanda & KEMA & $\checkmark$ & & & $\checkmark$ & $\checkmark$ & \\
\hline Utsira & Noruega & $\begin{array}{l}\text { Statoil Hydro and } \\
\text { Enercon }\end{array}$ & $\checkmark$ & & $\checkmark$ & & $\checkmark$ & \\
\hline Ilhavo & Portugal & Projeto Mais MRs & $\checkmark$ & & & & $\checkmark$ & \\
\hline Barcelona & Espanha & $\begin{array}{l}\text { Instituto de Recerca en } \\
\text { Energia de Catalunya } \\
\text { (IREC) }\end{array}$ & & $\checkmark$ & & & $\checkmark$ & \\
\hline Derio & & Projeto Mais MRs & & $\checkmark$ & $\checkmark$ & $\checkmark$ & $\checkmark$ & \\
\hline Miñano & & Ikerlan & & $\checkmark$ & $\checkmark$ & & $\checkmark$ & \\
\hline $\begin{array}{l}\text { Horizon, } \\
\text { Manchester }\end{array}$ & $\begin{array}{l}\text { Grã } \\
\text { Bretanha }\end{array}$ & $\begin{array}{l}\text { Universidade de } \\
\text { Manchester }\end{array}$ & $\checkmark$ & & $\checkmark$ & & $\checkmark$ & \\
\hline
\end{tabular}

Fonte: [60]

$\mathrm{Na}$ Europa, através de programas como o Microgrids: Large Scale Integration of MicroGeneration to Low Voltage Grid, e o programa chamado de Mais Micro-redes: Arquiteturas Avançadas e Conceitos de Controle, liderado pela universidade de Atenas, foram alcançados importantes avanços no que se refere ao controle de MRs.

A seguir serão descritas algumas das MRs existentes na Europa que não necessariamente aparecem na Tabela 2.7.

- Na Inglaterra, o primeiro projeto deste gênero foi chamado de The Ashton Hayes Going Carbon Neutral Project, iniciado em 2009. Ashton Hayes é uma pequena cidade em Cheshire (Noroeste da Inglaterra), onde a administração da cidade, em parceria com a EA Tecnologia e a Universidade de Chester, iniciou este projeto inovador para o controle e uso eficiente da geração de pequena escala. Através deste projeto foi possível evidenciar que as comunidades podem assumir o controle de suas emissões de 
carbono. Este projeto está composto de fontes de geração renováveis, particularmente solar e eólica.

- Outro projeto piloto de micro-rede está localizado na ilha de Kythnos (Grécia), fornecendo energia elétrica a um pequeno vilarejo no vale de Kythnos. Está constituído por painéis solares com capacidade total de $10 \mathrm{~kW}$, um banco de baterias de $53 \mathrm{kWh}$ de capacidade, assim como um gerador diesel de 5 kVA (Figura 2.9). Há previsão de que, em longo prazo, esta micro-rede possa ser ligada à rede principal [97].

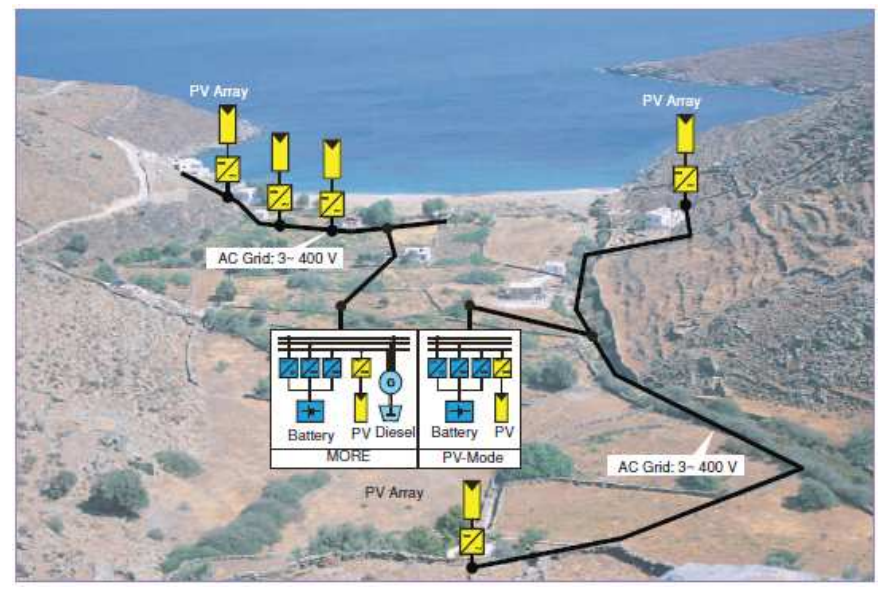

Figura 2.9. Micro-rede de Kythnos

- Outra instalação piloto, desta vez uma micro-rede especificamente do tipo residencial, está localizada na região de Bronsbergen, na Holanda. A principal característica desta micro-rede é que está constituída basicamente por sistemas fotovoltaicos instalados nos telhados residenciais, conforme mostrado na Figura 2.10(a). Esta micro-rede tem uma capacidade de geração de ponta de 315 kW e uma demanda máxima de 150 kW. Tem também dois bancos de baterias para armazenamento da energia, conforme mostrado na Figura 2.10(b). Outra característica desta micro-rede é que está composta de quatro ramos paralelos de baixa tensão, nos quais estão conectadas as residências [97]. 


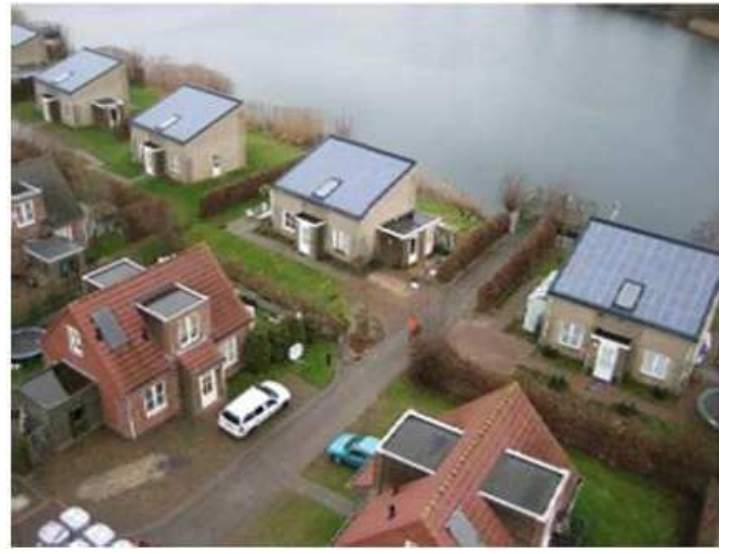

(a)

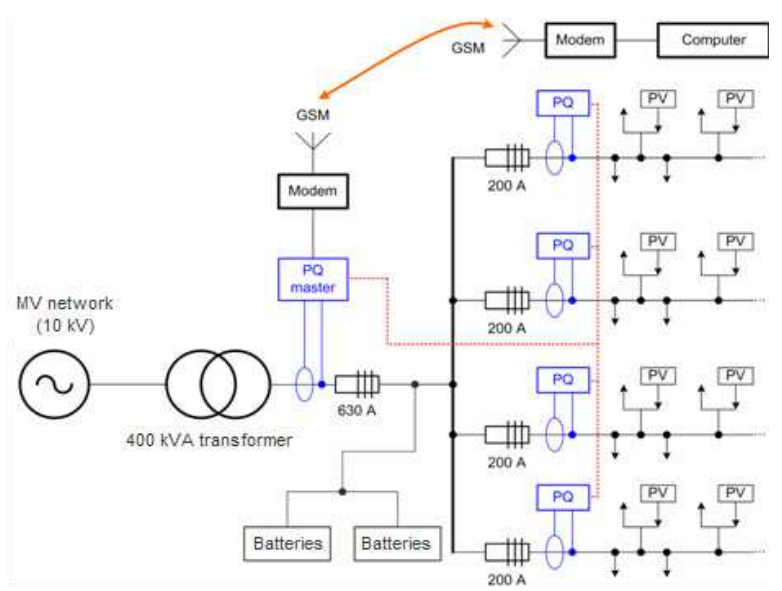

(b)

Figura 2.10. (a) Micro-rede de Bronsbergen, (b) Esquema unifilar da micro-rede.

- Na Itália se destaca a MR chamada de CESI RICERCA DER. É um projeto piloto de baixa tensão (400 V) ligada à rede de média tensão. Conforme apresentado na Figura 2.11, é um projeto relativamente grande que envolve várias fontes de GD [53].

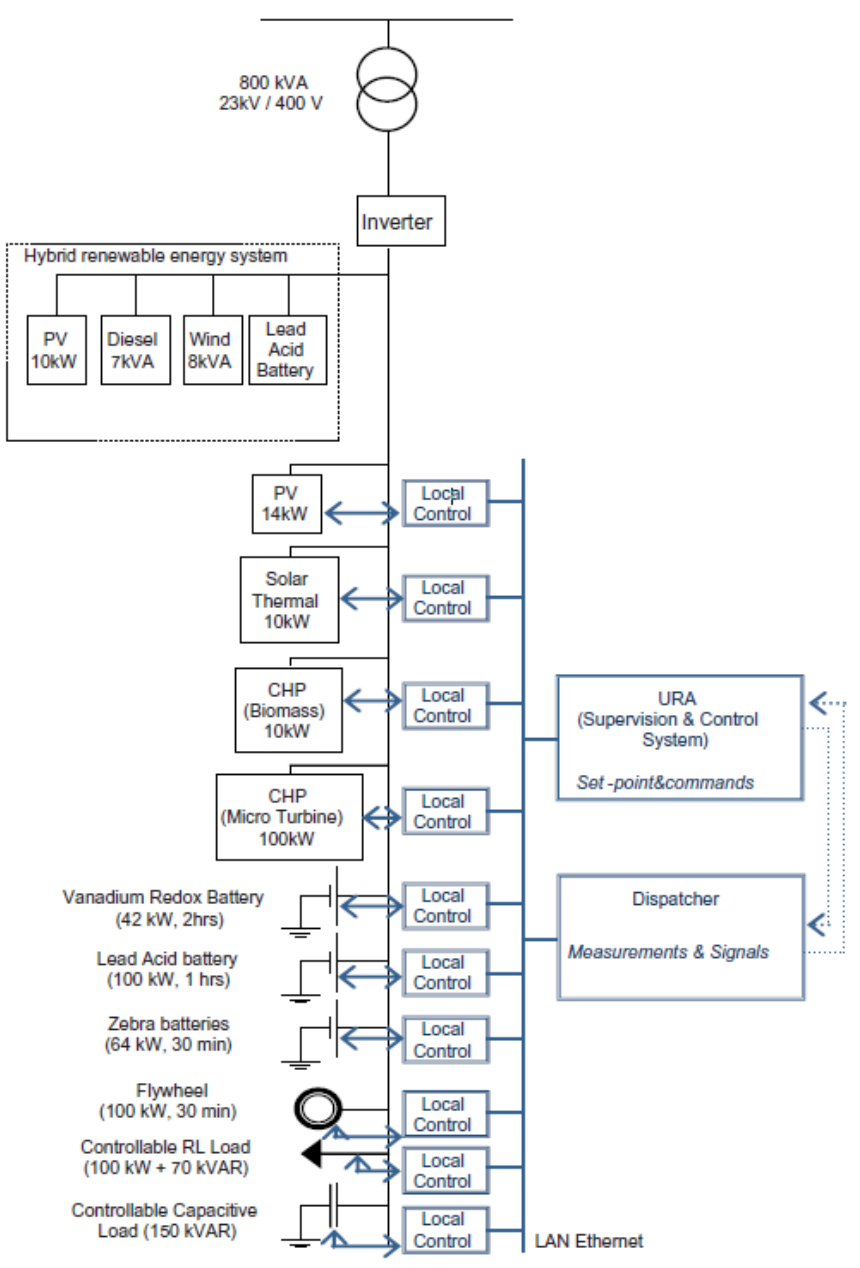

Figura 2.11. Configuração da Micro-rede CESI RICERCA DER [53]. 
- Na Alemanha, destaca-se o projeto piloto de DeMoTec. Esta micro-rede possue duas unidades de bateria, dois geradores a diesel, geradores PV e um gerador de energia eólica (Figura 2.12). A capacidade de geração total disponível é de aproximadamente 200 kW. Existem várias cargas com diferentes níveis de prioridade e vários interruptores automáticos. O sistema SCADA (Supervisory Control and Data Acquisition) é usado tanto para o controle dos geradores, como para o controle dos diferentes estados de funcionamento do sistema. O sistema de comunicação é realizado por meio de uma linha separada de Ethernet juntamente com o protocolo de comunicação XML-RPC ${ }^{2}$ [54].

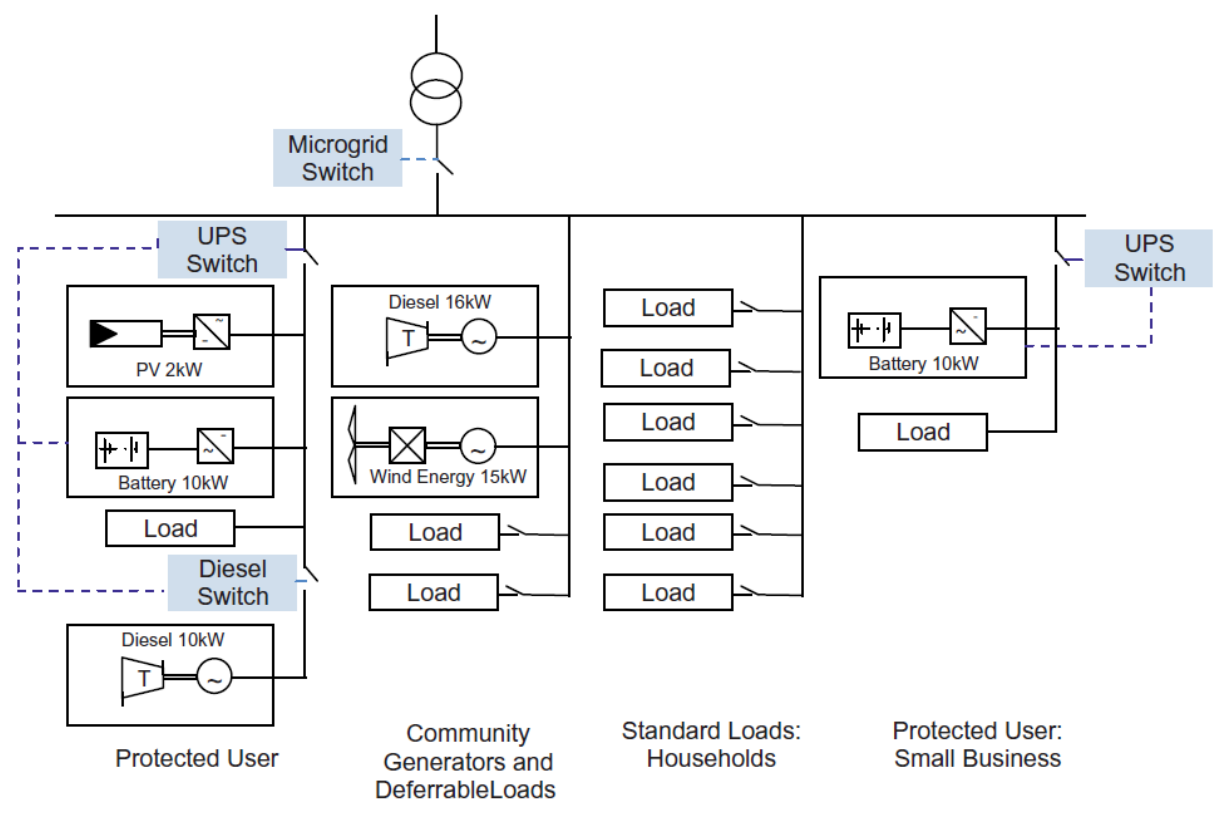

Figura 2.12. Esquema geral do projeto piloto DeMoTec.

\subsubsection{Asia e Oceania}

Recentemente, a Ásia tem experimentado uma grande demanda de MRs em função do seu rápido desenvolvimento econômico e intensa industrialização. O Japão tem fomentado pesquisas relacionadas com MRs, visando aumentar a contribuição das fontes de energia renováveis. Outros países, tais como a China, Coréia do Sul e Cingapura, vem também desenvolvendo programas de demonstração de MRs [14]. Na Tabela 2.8 apresenta-se uma síntese das características de alguns dos projetos desenvolvidos até 2011 nestes paises. Conforme observado, o Japão é o país que mais desenvolveu projetos de MRs através da New Energy and Industrial Technology Development Organization (NEDO).

2 É um tipo de protocolo RPC (Remote Procedure Call) que utiliza a linguagem XML (eXtensible Markup Language) para codificar esta comunicação, de forma análoga à ação feita pelo código HTML na web. 
Os principais projetos foram desenvolvidos nas regiões de Hachinohe, Sendai, Aichi e Kyoto. Estes projetos visam demostrar a viabilidade técnica de micro-redes com base em energias renováveis.

Tabela 2.8. Principais MRs na Ásia e Oceania.

\begin{tabular}{|c|c|c|c|c|c|c|c|c|}
\hline \multirow{2}{*}{$\begin{array}{c}\text { Nome do } \\
\text { Projeto de } \\
\text { MR }\end{array}$} & \multirow[b]{2}{*}{ País } & \multirow{2}{*}{$\begin{array}{c}\text { Administrador do } \\
\text { Projeto }\end{array}$} & \multicolumn{2}{|c|}{ Tipo de Projeto } & \multicolumn{2}{|c|}{ Tipo de Controle } & \multicolumn{2}{|c|}{ Estrutura } \\
\hline & & & Comercial & Experimental & $\begin{array}{l}\text { Centrali- } \\
\text { zado }\end{array}$ & $\begin{array}{c}\text { Descentrali- } \\
\text { zado }\end{array}$ & CA & CC \\
\hline Newcastle & Austrália & $\begin{array}{l}\text { CSIRO Energy } \\
\text { Center }\end{array}$ & & $\checkmark$ & $\checkmark$ & & $\checkmark$ & \\
\hline Hefei & \multirow[t]{2}{*}{ China } & $\begin{array}{l}\text { Hefei University of } \\
\text { Technology (HFUT) }\end{array}$ & $\checkmark$ & $\checkmark$ & & $\checkmark$ & & \\
\hline Tiajin & & Tiajin University & & $\checkmark$ & $\checkmark$ & & $\checkmark$ & \\
\hline Changwon & $\begin{array}{l}\text { Coréia } \\
\text { do Sul }\end{array}$ & $\begin{array}{l}\text { Korea } \\
\text { Electrotechnology } \\
\text { Research Institute } \\
\text { (KERI) }\end{array}$ & & $\checkmark$ & $\checkmark$ & & $\checkmark$ & \\
\hline $\begin{array}{l}\text { Uttar } \\
\text { Pradesh }\end{array}$ & India & $\begin{array}{l}\text { Mera Gao Power } \\
(\text { MGP) }\end{array}$ & & $\checkmark$ & $\checkmark$ & & $\checkmark$ & \\
\hline Aichi & \multirow{5}{*}{ Japão } & $\begin{array}{l}\text { Aichi Institute of } \\
\text { Technology (AIT), } \\
\text { NEDO. }\end{array}$ & $\checkmark$ & & & & & \\
\hline $\begin{array}{l}\text { CRIEPI, } \\
\text { Akagi }\end{array}$ & & \multirow{4}{*}{$\begin{array}{l}\text { NEDO (New Energy } \\
\text { \& Industrial } \\
\text { Technology } \\
\text { Development } \\
\text { Organization) }\end{array}$} & $\checkmark$ & $\checkmark$ & & $\checkmark$ & & \\
\hline Hachinohe & & & $\checkmark$ & & $\checkmark$ & & $\checkmark$ & \\
\hline $\begin{array}{l}\text { Kyoto Eco } \\
\text { Energy }\end{array}$ & & & & $\checkmark$ & $\checkmark$ & & $\checkmark$ & \\
\hline Sendai & & & $\checkmark$ & & $\checkmark$ & $\checkmark$ & & \\
\hline
\end{tabular}

- Micro-rede de Hachinohe

Este projeto foi desenvolvido pela Mitsubishi Electric Corporation e pelo NEDO, [55]. Este projeto entrou em funcionamento em Outubro de 2005 e teria atingido resultados satisfatórios relacionados à qualidade de serviço e redução de emissões de $\mathrm{CO}_{2}$. A energia gerada pelo sistema provém de fontes renováveis (quatro grupos de painéis fotovoltaicos com potência total de $80 \mathrm{~kW}$, três geradores eólicos com uma capacidade total de $20 \mathrm{~kW}$ e três turbinas de gás com capacidade total de 510 kW). Dispõe também de um grupo de baterias de $100 \mathrm{~kW}$ que funciona como backup instantâneo caso os geradores não consigam atender à demanda. Esta microrede está conectada à rede de distribuição em um único ponto, não sendo permitido, por acordo entre as partes, exportar energia à rede de distribuição, mas apenas importá-la. O esquema completo do projeto Hachinohe pode ser visto na Figura 2.13. 


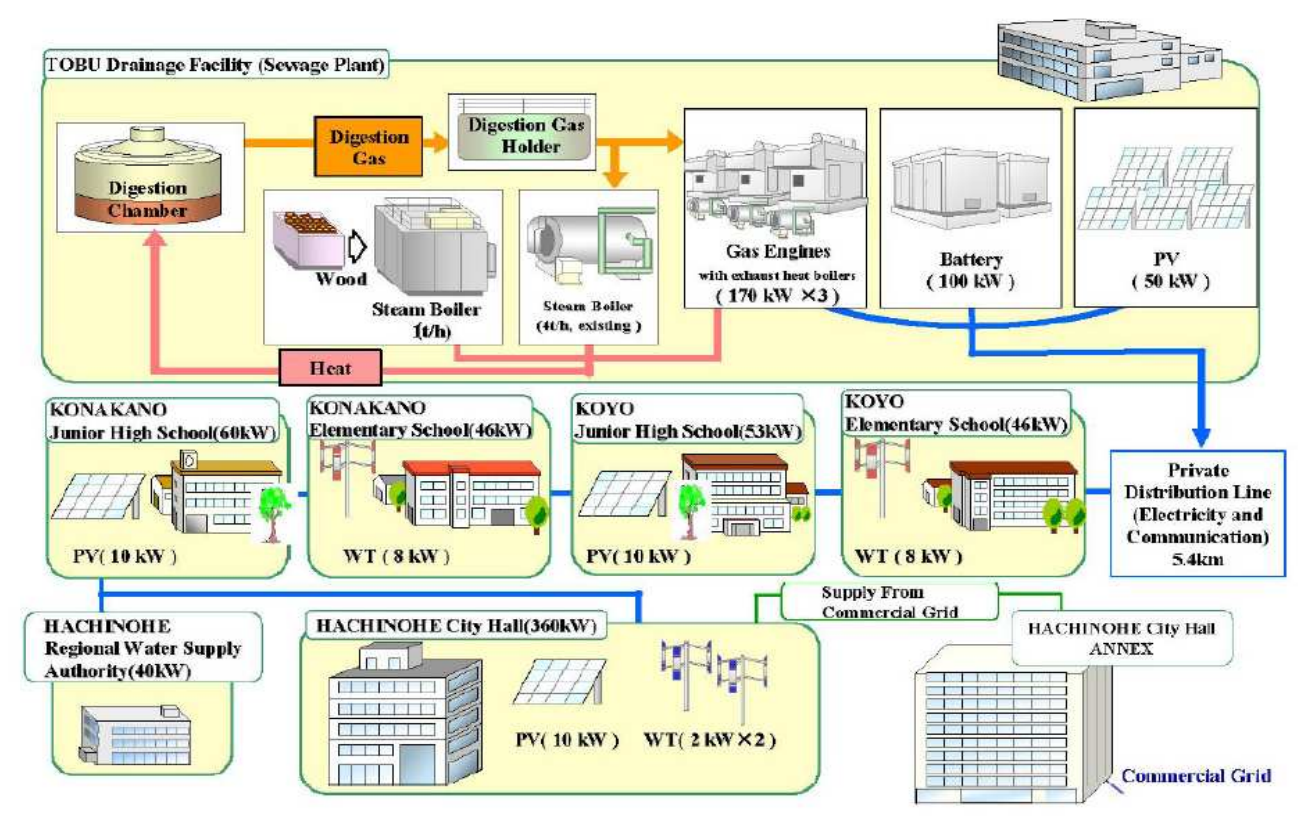

Figura 2.13. Esquema da micro-rede de Hachinohe.

- Micro-rede de Aichi

Esta MR está localizada no Instituto de Tecnologia de Aichi (AIT) e está constituída por um gerador diesel, geradores fotovoltaicas, gerador de energia eólica e um sistema de armazenamento. O sistema de geração fotovoltaica tem $330 \mathrm{~kW}$ cujo banco de baterias é de sódio-enxofre.

- Micro-rede de Kyoto

Esta MR está formada por uma pequena usina com geração a gás, cuja capacidade total é de $400 \mathrm{~kW}$, uma célula de combustível de carbonato fundido de $250 \mathrm{~kW}$ e uma bateria de chumbo-ácido de $100 \mathrm{~kW}$, além de um sistema fotovoltaico de $50 \mathrm{~kW}$ e uma pequena turbina eólica de $50 \mathrm{~kW}$, localizados em locais relativamente distantes. O centro de controle comunica-se com os DERs via protocolos de internet para equilibrar a oferta e a demanda de energia com o sistema de distribuição, conforme mostrado na Figura 2.14. 


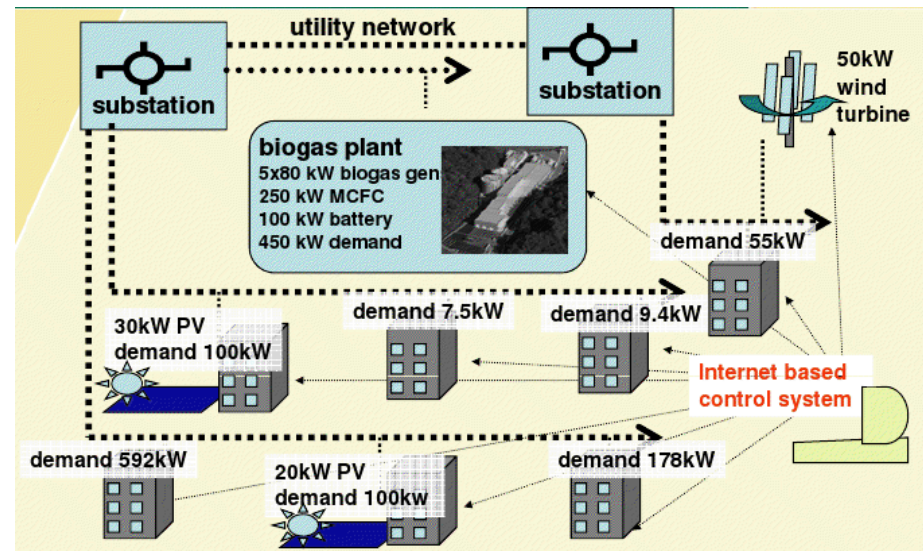

Figura 2.14. Esquema do projeto de micro-rede de Kyotango.

- Micro-rede de Sendai

Esta MR está localizada no campus da universidade de Tohoku Fukushi ao noroeste de Sendai, foi desenvovida pela New Energy and Industrial Technology Development Organization (NEDO). Está constituído por dois geradores a gás com potência instalada de $350 \mathrm{~kW}$ cada um (Figura 2.15). São também utilizadas células de combustível de $250 \mathrm{~kW}$ e painéis solares de $50 \mathrm{~kW}$ de potência. [56]. Apesar de o projeto ter sido encerrado em 2008, o mesmo continua funcionando. Durante o terremoto e tsunami ocorridos em 2011, esta MR teria mostrado um bom desempenho [57].

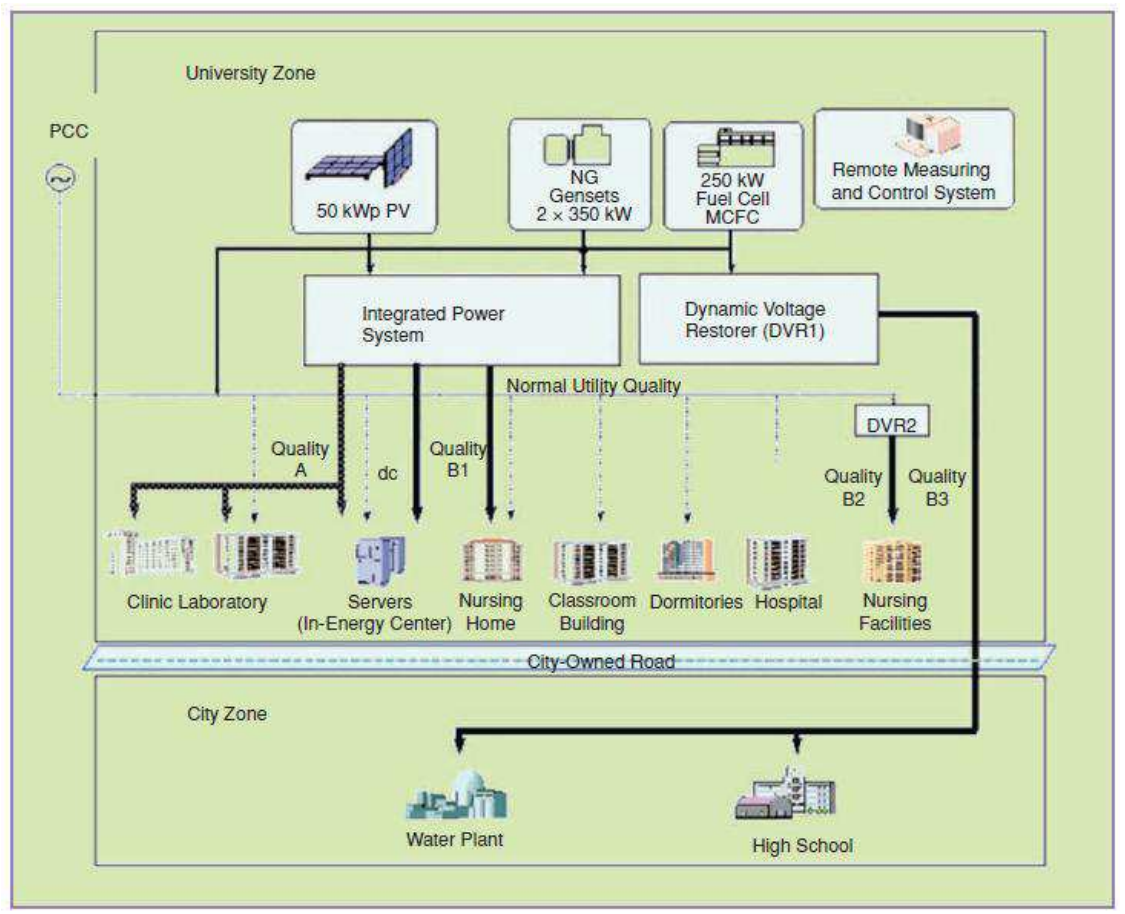

Figura 2.15. Configuração da micro-rede de Sendai. 


\subsubsection{América do Norte}

Com o objetivo de tornar o sistema elétrico menos vulnerável a interrupções prolongadas no fornecimento de energia e a ataques terroristas, o governo norte americano, através do Departamento de Energia (DOE - Department of Energy) e a Comissão de Energia da California (CEC), realizam grandes investimentos para o desenvolvimento de MRs.

$\mathrm{Na}$ Tabela 2.9 a seguir são apresentados os principais projetos de MRs desenvolvidos até 2014 [14], [15].

Tabela 2.9. Micro-redes localizadas na América do Norte [14].

\begin{tabular}{|c|c|c|c|c|c|c|c|c|}
\hline \multirow[b]{2}{*}{ Localização } & \multirow[b]{2}{*}{ País } & \multirow[b]{2}{*}{ Administrador do Projeto } & \multicolumn{2}{|c|}{ Tipo de Projeto } & \multicolumn{2}{|c|}{ Tipo de Controle } & \multicolumn{2}{|c|}{ Estrutura } \\
\hline & & & Comercial & Teste & $\begin{array}{l}\text { Centrali- } \\
\text { zado }\end{array}$ & $\begin{array}{l}\text { Descentrali- } \\
\text { zado }\end{array}$ & CA & cc \\
\hline Boston Bar & & BC Hydro & $\checkmark$ & & & $\checkmark$ & $\checkmark$ & \\
\hline Senneterre & Canada & Hydro Quebec (HQ) & $\checkmark$ & & & $\checkmark$ & $\checkmark$ & \\
\hline $\begin{array}{l}\text { Albuquerque, } \\
\text { Novo México }\end{array}$ & \multirow{13}{*}{ USA } & $\begin{array}{l}\text { NEDO (New Energy \& } \\
\text { Industrial Technology } \\
\text { Development } \\
\text { Organization), } \\
\text { Universidade de Novo } \\
\text { Mexico e Companhias } \\
\text { Japonesas }\end{array}$ & & $\checkmark$ & & & & \\
\hline $\begin{array}{l}\text { Ansonia, } \\
\text { Connecticut }\end{array}$ & & $\begin{array}{l}\text { Energía Pareto, Centro de } \\
\text { Avanço Tecnologico de } \\
\text { Connecticut (CCAT) }\end{array}$ & $\checkmark$ & & & & & \\
\hline $\begin{array}{l}\text { Borrego } \\
\text { Springs, } \\
\text { California }\end{array}$ & & $\begin{array}{l}\text { San Diego Gas \& Electric } \\
\text { Company (SDG \& E) }\end{array}$ & $\checkmark$ & & $\checkmark$ & & $\checkmark$ & \\
\hline Columbus & & Dolan Technolgy Center & & $\checkmark$ & & $\checkmark$ & $\checkmark$ & \\
\hline Washington & & Howard University & & $\checkmark$ & & & & \\
\hline Chicago & & $\begin{array}{l}\text { Illinois Institute of } \\
\text { Technology }\end{array}$ & & $\checkmark$ & & $\checkmark$ & & \\
\hline $\begin{array}{l}\text { Los Alamos, } \\
\text { New Mexico }\end{array}$ & & $\begin{array}{l}\text { NEDO (New Energy \& } \\
\text { Industrial Technology } \\
\text { Development } \\
\text { Organization) }\end{array}$ & & $\checkmark$ & & & & \\
\hline Madison & & University of Winconsin & & $\checkmark$ & & $\checkmark$ & $\checkmark$ & \\
\hline $\begin{array}{l}\text { Marin county, } \\
\text { California }\end{array}$ & & $\begin{array}{l}\text { Xantus consulting } \\
\text { International }\end{array}$ & $\checkmark$ & & & $\checkmark$ & $\checkmark$ & \\
\hline California & & Santa Clara University & & $\checkmark$ & & & $\checkmark$ & \\
\hline $\begin{array}{l}\text { Stamford, } \\
\text { connecticut }\end{array}$ & & Pareto Energy & $\checkmark$ & & & & & \\
\hline San Diego & & University of California & & $\checkmark$ & & & & \\
\hline $\begin{array}{l}\text { Twenty-nine } \\
\text { Palms, } \\
\text { California }\end{array}$ & & General Electric (GE) & $\checkmark$ & & $\checkmark$ & & $\checkmark$ & \\
\hline
\end{tabular}

Além das micro-redes mencionadas na Tabela 2.9, existem outros projetos a serem destacados, como por exemplo:

- Fort Bragg Microgrid (Carolina do Norte, USA). O objetivo desta micro-rede é aumentar o grau de confiabilidade de uma das bases do exército norte americano. 
Fort Bragg é proprietário da sua própria rede de distribuição elétrica e é capaz de monitorar várias fontes de microgeração por meio de um centro de gestão de energia. Apesar de seu porte relativamente pequeno, esta micro-rede está totalmente integrada com a rede de distribuição através de Tecnologias da Informação (TI). Segundo relatos disponíveis, resultado do seu sistema inteligente de distribuição, Fort Bragg tem reforçado a sua confiabilidade no suprimento de energia e reduzido seus custos energéticos globais.

- Beach Cities Microgrid Project (San Diego, Califórnia). Este projeto é o resultado da parceria entre a San Diego Gas and Electric, a Horizon Energy Group, Controle Advance, Motorola, IBM, Lockheed Martin, Pacific Northwest National Laboratory e a Universidade de San Diego. Juntos desenvolveram um sistema constituído por fontes de energia solar, em residências e empresas, geradores movidos a biodiesel, dispositivos de armazenamento de energia e tecnologias baseadas em medidores inteligentes (smart meters). Um dos objetivos deste sistema é reduzir a carga de ponta da rede interna em aproximadamente $15 \%$.

- Perfect Power no Illinois Institute of Technology (IIT), Chicago. Resultou da parceria entre a Galvin Power Iniciative e o DOE dos Estados Unidos para atender a demanda do campus universitário do IIT. Através deste projeto pretende-se eliminar os efeitos econômicos produzidos por blecautes, minimizar as perturbações de energia, atender a demanda interna crescente e reduzir as emissões de gases de efeito estufa.

\subsubsection{América do Sul}

Micro-rede de Huatacondo, Chile

A Universidade do Chile em Santiago desenvolveu o primeiro projeto de micro-rede inteligente localizado na comunidade de Huatacondo [58]. Este é um dos projetos mais destacados na América do Sul. Está constituído por um conjunto de paineis fotovoltaicos (22 kW), um aerogerador de $3 \mathrm{~kW}$, um banco de baterias de $170 \mathrm{kWh}$ e um gerador diesel de $150 \mathrm{~kW}$ (Figura 2.16). Esta MR é um exemplo típico de microrede remota, pois, a carga atendida pela mesma (povoado) não tem conexão com o sistema interligado nacional. 


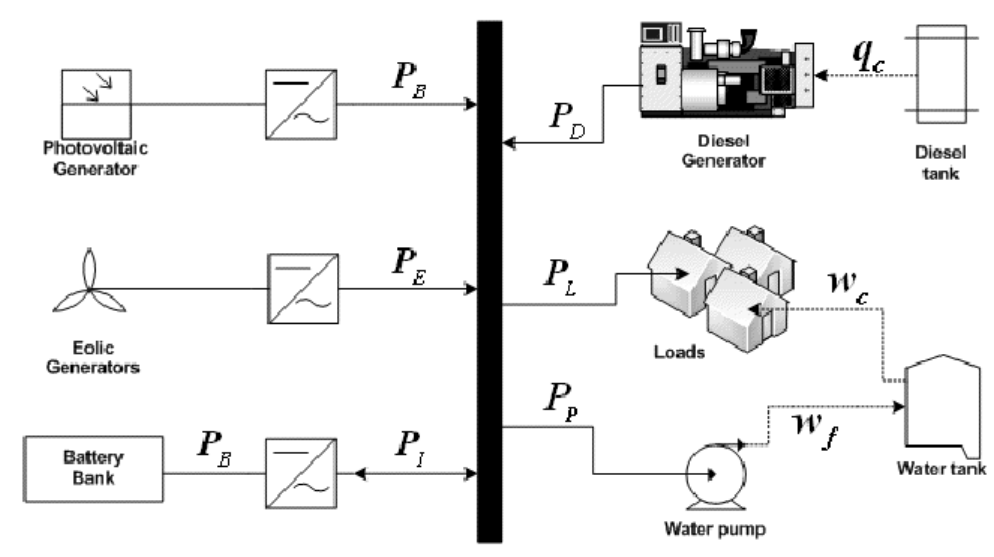

Figura 2.16. Configuração da micro-rede de Huatacondo [58].

O que torna este projeto interessante é o fato de que, no seu sistema de controle, é utilizado um Controlador Central (MMS-Microgrid Management System), descrito no início deste capítulo. O mesmo permite otimizar a operação do conjunto de unidades de geração e cargas. Esta atividade é monitorada pelo sistema SCADA. Alêm do projeto de Huatacondo existem outros projetos a serem desenvolvidos no Chile, como por exemplo: as Micro-redes de Ollague (Tarapacá) e Villa Cameron (na Patagônia).

\subsection{Micro-redes Remotas}

$\mathrm{Na}$ atualidade, boa parte da população mundial vive em áreas onde o suprimento de energia elétrica é precário. Devido a razões geográficas, o suprimento de energia a estas áreas, através da rede elétrica, é difícil; assim, o estabelecimento de MRs remotas constitui-se no principal mecanismo para o atendimento a esta demanda [59].

A título de exemplo, nas Filipinas, constituída por mais de 7.000 ilhas, há dificuldades geográficas e econômicas para a integração de seu sistema elétrico. Assim, torna-se necessário o estabelecimento de sistemas independentes (MRs remotas) para atender a demanda local.

Na Tabela 2.10 são apresentados exemplos de MRs remotas assim como o tipo de controle (centralizado ou descentralizado) e o tipo de estrutura (CA/CC) [60]. 
Tabela 2.10. Principais exemplos de MRs remotas no mundo.

\begin{tabular}{|c|c|c|c|c|c|c|c|}
\hline \multirow[b]{2}{*}{ Região } & \multirow[b]{2}{*}{ Localização } & \multirow[b]{2}{*}{ País } & \multirow[b]{2}{*}{ Administrador do Projeto } & \multicolumn{2}{|c|}{ Tipo de Controle } & \multicolumn{2}{|c|}{ Estrutura } \\
\hline & & & & $\begin{array}{l}\text { Centrali- } \\
\text { zado }\end{array}$ & $\begin{array}{l}\text { Descentrali- } \\
\text { zado } \\
\end{array}$ & CA & CC \\
\hline \multirow{3}{*}{ África } & Akkan & Marrocos & -- & $\checkmark$ & & $\checkmark$ & \\
\hline & Diaka Madina & Senegal & -- & $\checkmark$ & & $\checkmark$ & \\
\hline & Lucingweni & $\begin{array}{c}\text { África do } \\
\text { sul }\end{array}$ & $\begin{array}{c}\text { National Energy Regulator of South } \\
\text { Africa (NERSA) }\end{array}$ & & $\checkmark$ & $\checkmark$ & $\checkmark$ \\
\hline Antártida & $\begin{array}{l}\text { Princess } \\
\text { Elisabeth } \\
\text { Station }\end{array}$ & $\begin{array}{l}\text { Grã } \\
\text { Bretanha }\end{array}$ & Laborelec & $\checkmark$ & & $\checkmark$ & \\
\hline \multirow{3}{*}{ Ásia } & $\begin{array}{l}\text { Kuroshima } \\
\text { Island }\end{array}$ & Japão & Kyushu Electric Power & $\checkmark$ & & $\checkmark$ & \\
\hline & $\begin{array}{l}\text { Miyano Island } \\
\text { (Okinawa) }\end{array}$ & Japão & $\begin{array}{l}\text { Okinawa Electric Power Company } \\
\text { (OEPC) }\end{array}$ & & & & \\
\hline & Town Island & $\begin{array}{l}\text { Hong } \\
\text { Kong }\end{array}$ & Hong Kong University (HKU) & $\checkmark$ & & $\checkmark$ & \\
\hline Europa & Kythnos & Grécia & $\begin{array}{c}\text { National Technical University of } \\
\text { Athens (NTUA) }\end{array}$ & $\checkmark$ & & $\checkmark$ & \\
\hline \multirow{7}{*}{$\begin{array}{l}\text { América } \\
\text { do Norte }\end{array}$} & Bella Cola & Canadá & BC Hydro, GE, Power Tech & $\checkmark$ & & $\checkmark$ & \\
\hline & Hartley Bay & Canadá & Pulse Energy (ICE) & & $\checkmark$ & $\checkmark$ & \\
\hline & $\begin{array}{l}\text { Kasabonika } \\
\text { Lake }\end{array}$ & Canadá & $\begin{array}{c}\text { Hydro One, GE, University of } \\
\text { Waterloo }\end{array}$ & $\checkmark$ & & $\checkmark$ & \\
\hline & Nemiah Valley & Canadá & NRCan & $\checkmark$ & & $\checkmark$ & \\
\hline & Ramea Island & Canadá & $\begin{array}{l}\text { N\&L Hydro, Nalcor Energy, NRCan, } \\
\text { Frontier power }\end{array}$ & $\checkmark$ & & $\checkmark$ & \\
\hline & Colonias, Texas & USA & $\begin{array}{l}\text { Texas State Energy Conservation } \\
\text { Office (SECO), Texas Engineering } \\
\text { Experiment Station, Xtreme Power }\end{array}$ & $\checkmark$ & & $\checkmark$ & \\
\hline & Fort Bragg & USA & Encorp, Honeywell & $\checkmark$ & & $\checkmark$ & \\
\hline Oceania & Kings Canyon & Austrália & UNSW (Sydney) & $\checkmark$ & & $\checkmark$ & \\
\hline \multirow{2}{*}{$\begin{array}{l}\text { América } \\
\text { do Sul }\end{array}$} & Chico Mendes & Brasil & Eletrobras & $\checkmark$ & & $\checkmark$ & $\checkmark$ \\
\hline & $\begin{array}{l}\text { Ilha da } \\
\text { Ferradura }\end{array}$ & Brasil & Siemens, Energia Pura & $\checkmark$ & & $\checkmark$ & \\
\hline
\end{tabular}

\subsection{Micro-redes Remotas no Brasil}

No Brasil, segundo informações disponibilizadas em [61], cerca de 3\% das familias (de um total de aproximadamente 50 milhões) não tem acesso à eletricidade. Considerando que em média uma família possui quatro membros, isto equivale a cerca de 5 milhões de pessoas sem acesso à eletricidade. Boa parte dessas pessoas está localizada na região Amazônica. O Sistema Interligado Nacional compreende aproximadamente $98 \%$ das redes no país, ou seja que cerca de $2 \%$ esta composto por sistemas ilhados (Figura 2.17).

Paradoxalmente, as regiões Norte e Noroeste do país possuem o maior potencial de geração hídrico, como no caso dos projetos Madeira, Santo Antônio e Jirau; porém, até agora ainda dependem da instalação de sistemas de geração isolados (micro-redes elétricas). 


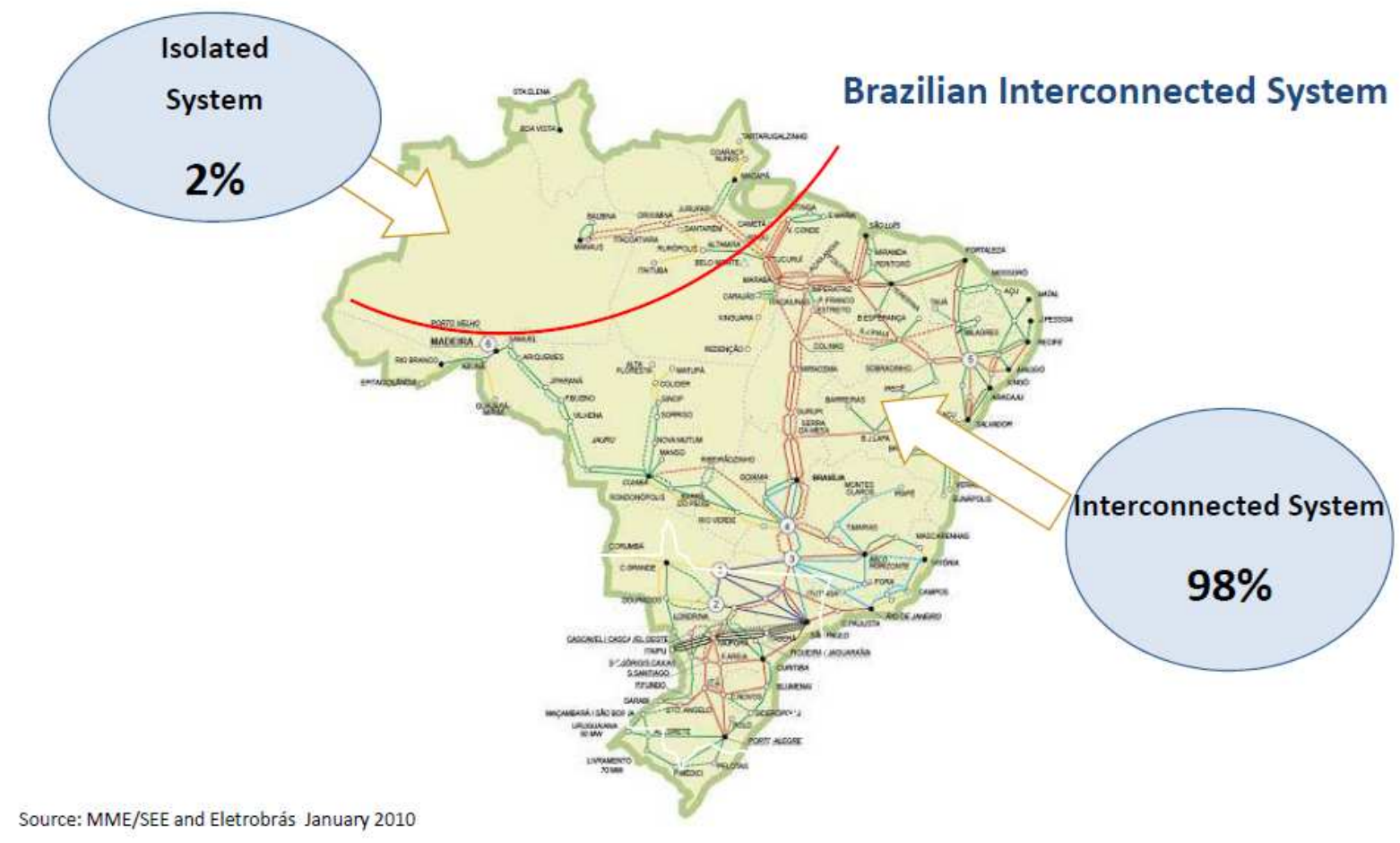

Figura 2.17. Localização dos principais sistemas isolados no SIN [63].

Segundo o relatório elaborado pela Zpryme Research \& Consulting [62], estima-se que o investimento em MRs remotas no Brasil aumentará de US\$149 milhões para 518 milhões dólares, no período de 2012 a 2020 (Figura 2.18).

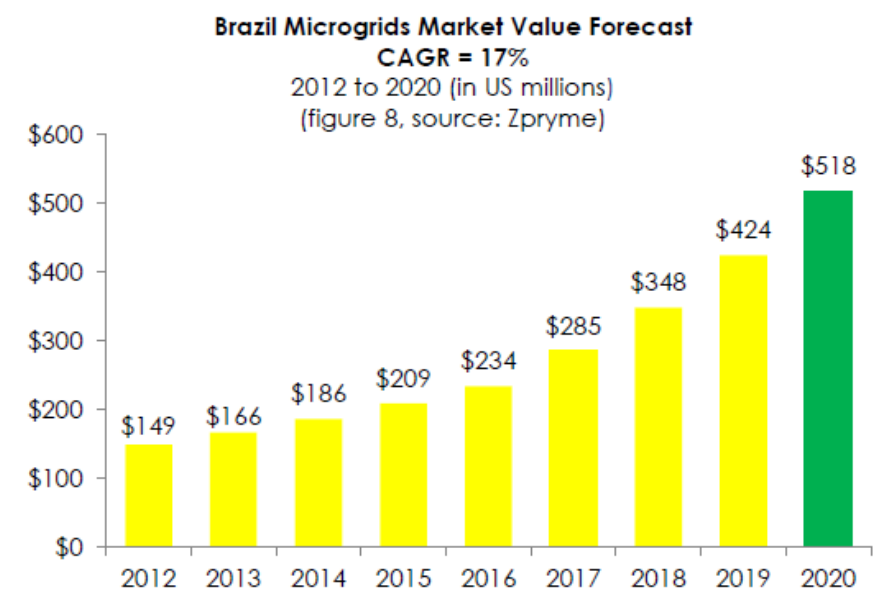

Figura 2.18. Previsão de Mercado de Micro-redes remotas no Brasil. 
Conforme [64], entre os principais exemplos de MRs remotas podem-se mencionar a:

- Ilha dos Lençóis, Cururupu (Maranhão).

- Sistema Fotovoltaico Diesel de Araras (Rondônia).

- Aplicação de sistemas fotovoltaicos no programa luz para todos da COELBA (Bahia).

- Projeto piloto de São Francisco do Aiucá (Amazonas).

Em 2012, segundo a referência [65], a ANEEL teve 178 projetos propostos no programa de Redes Inteligentes, nas sub-áreas de geração distribuída, microgeração e MRs elétricas, o que mostra o interesse no desenvolvimento desta tecnología no Brasil.

As instituições acadêmicas (universidades) e empresas privadas têm mostrado importantes avanços nesta área incluindo testes de laboratório, visando avaliar o grande suporte que as MR poderiam oferecer à rede elétrica e aos próprios usuários.

\subsection{Regulamentação de MRs no Brasil}

Em 2010, foi criado um grupo de trabalho formado pela Empresa de Pesquisas Energéticas (EPE), pelo Centro de Pesquisas de Energia Elétrica (CEPEL), pela Agência Nacional de Energia Elétrica (ANEEL) e pelo Operador Nacional do Sistema Elétrico (ONS), cujo objetivo é analisar o estabelecimento de políticas públicas para implantação do programa Brasileiro de Rede Elétrica Inteligente (smart grid), que irá também estudar a regulamentação da atuação de novos agentes que acessem o mercado elétrico, no qual se incluam as MRs [66].

Por outro lado, com o objetivo de garantir, estimular e reduzir as barreiras regulatórias existentes para conexão de geração distribuída de pequeno porte com a rede elétrica, a ANEEL realizou em 2010 a Consulta Pública 015/2010, visando receber contribuições das concessionárias e da sociedade sobre as questões apresentadas na Nota Técnica oㅡ 043/2010 - SRD/ANEEL [67]. Produto dessa consulta as fontes de geração conectadas na rede de distribuição com potência instalada menor ou igual a $100 \mathrm{~kW}$ foram denominadas de microgeração, enquanto que aquelas com potência instalada superior a $100 \mathrm{~kW}$ e menor ou igual a $1 \mathrm{MW}$ foram denominadas de mini-geração.

O sistema de compensação pela injeção desta energia seria através do sistema net metering, que permite ao consumidor instalar pequenos geradores em sua unidade consumidora e trocar energia com a distribuidora local, regra válida somente para geradores que utilizem fontes incentivadas de energia, como hidráulica, solar, biomassa, eólica e cogeração qualificada. Propõe-se também que o consumidor poderá compensar a energia 
gerada mensalmente com a concessionária em um prazo de até 36 meses. Detalhes ao respeito são apresentados no Capítulo 3.

Em 2012 foi aprovada a resolução ANEEL n 482 [16], cujo objetivo é facilitar o acesso de fontes de geração com até $1 \mathrm{MW}$ de potência instalada que esteja baseada em fontes de geração alternativa (solar, eólica, biomassa, hídrica e cogeração qualificada), conforme apresentado na Figura 2.19.

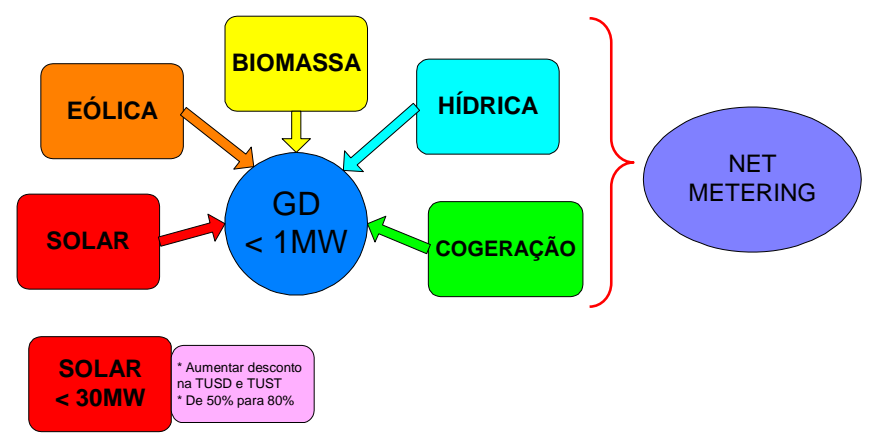

Figura 2.19. Resumo das premissas básicas da proposta ANEEL 482/2012.

Esta resolução prevê também incentivar esta forma de geração através de descontos às tarifas TUSD (Tarifa de Uso do Sistema de Distribuição) e TUST (Tarifa de Uso do Sistema de Transmissão) para potências de até $30 \mathrm{MW}$ que sejam injetadas no sistema, embora isto seja aplicável apenas ao caso da geração solar.

Recentemente, o governo brasileiro apresentou uma medida para promover a desoneração do PIS (Programas de Integração Social) e COFINS (Contribuição para Financiamento da Seguridade Social) incidentes na geração distribuída [68]. A medida tem por objetivo fomentar o estabelecimento de fontes de geração de energia renováveis, particularmente a solar. A medida faz parte da campanha pelo governo para aumentar a oferta de energia, devido à recente crise hídrica no sudeste do país. 


\section{CAPÍTULO 3}

\section{PRINCIPAIS MECANISMOS DE INCENTIVO E TENDÊNCIAS COMERCIAIS}

\subsection{Introdução}

Apesar dos avanços tecnológicos e os benefícios que as MRs podem trazer às concessionárias e ao consumidor final, a sua implementação prática ainda enfrenta diversas barreiras. A regulamentação associada às questões económicas precisa ser concebida cuidadosamente, de modo a estabelecer uma participação eficiente das micro-redes nos mercados de eletricidade, assim como no fornecimento de vários serviços ancilares. Há propostas que incluem funcionalidades como preço da energia em tempo real, possibilidade de fluxo bilateral, de acordo com o aumento da demanda em uma ou outra MR. Esses aspectos não são ainda aplicados rigorosamente e poderiam ser implementados após consolidação da tecnologia das MRs. Algumas propostas e abordagens relacionados à comercialização de energia em MRs são apresentados em [21] e [69].

\subsubsection{Possibilidade de Participação de MRs no Mercado Elétrico}

A participação de MRs no mercado de energia permitiria a participação de novos atores no papel de prosumidores ${ }^{3}$ e agregadores (intermediários). Os agregadores teriam a função de compilar as informações de oferta e procura de energia e ofertá-lo no mercado. Essas ofertas seriam sujeitas à verificação por parte dos operadores do sistema local (ou regional) e pelas concessionárias [22], [70]. Na Figura 3.1 mostra-se uma possível forma de interação entre esses agentes e as MRs e rede principal.

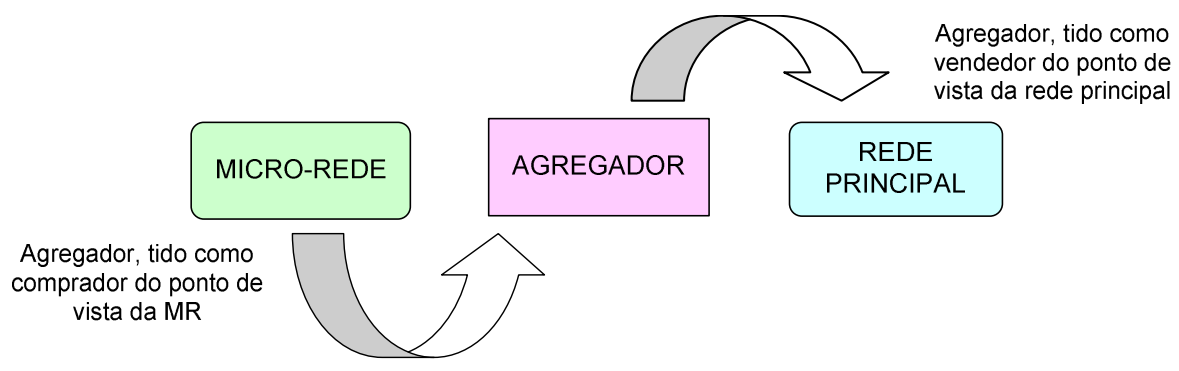

Figura 3.1. Fluxograma de mercado interativo.

\footnotetext{
${ }^{3} \mathrm{O}$ prosumidor (prosumer) é aquele consumidor que tem a capacidade de produzir energia e, eventualmente, disponibilizá-la a outros consumidores através da rede.
} 
Observa-se (Figura 3.1) que, durante a venda de energia realizada pela MR para a rede principal, o agregador cumpre o papel de vendedor, do ponto de vista da rede principal, e o papel de comprador do ponto de vista da MR.

\subsection{Mecanismos de Incentivo Tarifários Atuais}

O principal obstáculo na economia das MRs está associado aos custos de instalação e colocação em funcionamento. Para incentivar este tipo de instalações, os governos têm criado subsídios (mecanismos de remuneração), principalmente às fontes de energia renovável.

A adoção de um mecanismo de remuneração que incentive a geração de energia elétrica a partir de uma fonte renovável constitui-se em força motriz que permite potencializar a aceitação e promoção das MRs. Entre os mecanismos adotados por diversos países para incentivar a geração de energia a partir de fontes renováveis, destacam-se os apresentados a seguir [23].

- Política de Quota ou Renewable Portfolio Standard (RPS).

- Certificados de Energia Renovável ou Renewable Energy Certificates (REC).

- Tarifa Feed-in (FiT).

- Tarifa Net metering.

\subsubsection{Política de Quota ou Renewable Portfolio Standard (RPS)}

Estabelece que um percentual mínimo de toda a energia comprada pelas concessionárias de energia provenha de fontes renováveis. As empresas que cumprirem com tais objetivos recebem certificados que podem ser vendidos para aquelas que não atingem [71].

\subsubsection{Certificados de Energia Renovável ou Renewable Energy Certificates (REC)}

Nesta forma de incentivo, emitem-se certificados negociáveis como prova de que $1 \mathrm{MWh}$ de energia foi gerada a partir de uma fonte de energia renovável. Estes certificados podem ser comercializados ou trocados no mercado elétrico [72]. De forma similar ao mercado de RPSs, descrito anteriormente, existem mercados para a comercialização de CERs, já que as empresas de fornecimento de energia são obrigadas a resgatar estes certificados. 


\subsubsection{Tarifa Feed-in (FiT)}

Refere-se ao preço que as concessionárias devem pagar aos produtores de energia com fontes de geração limpa por cada kWh produzido. Oferece três principais benefícios: (a) um pagamento pela energia produzida, mesmo que seja utilizada pelo próprio produtor, (b) um pagamento adicional (bônus) pela energia exportada à rede, (c) uma redução na conta padrão do produtor de energia, por ter usado sua própria energia gerada [73].

Segundo [98], diversos países no mundo têm realizado algumas modificações à tarifa FiT para se enquadrar melhor aos cenários econômicos. Uma destas modificações refere-se aos níveis de remuneração pela tarifa FiT, de modo que o patamar de incentivos oferecidos seja coerente com o tamanho e tecnologia da instalação. A ideia desta modificação é que, normalmente, empreeendimentos de maior porte são os mais econômicos e, portanto, deveriam ser considerados dentro de faixas específicas de pagamentos. As faixas de potências propostas em [98], são:

- $0 \mathrm{~kW}<\mathrm{FiT} A \leq 30 \mathrm{~kW}$;

- $30 \mathrm{~kW}<\mathrm{FiT} B \leq 100 \mathrm{~kW}$;

- $100 \mathrm{~kW}<\mathrm{FiT} \mathrm{C}<2 \mathrm{MW}$;

- $2 \mathrm{MW}$ e superiores = FiT D.

Outro aspecto a ser analisado é a duração da aplicação da tarifa FiT. Caso um prosumidor opte por um período curto de remuneração, o nível de remuneração teria que ser alto a fim de se garantir um periodo de amortização adequado para o empreendimento. No caso de pagamentos por periodos mais longos, a taxa de inflação acumulada pode ser impactante e, portanto, deverá ser levada em conta.

O período de remuneração em varios países é, em geral, de 10-20 anos. O pagamento de até 20 anos normalmente equivale à vida média de projetos de energia renovável. Períodos de remuneração mais longos são geralmente evitados devido a que estes desincentivam a inovação tecnológica do projeto.

No caso de países nos quais a tarifa FiT já foi estabelecida há algum tempo e cujo parque gerador, baseado em fontes alternativas, alcançou um tamanho considerável, poderão ser estabelecidos e aplicados modelos de FiT mais avançados, tais como a tarifa FiT premium; remuneração pelo uso de tecnologias de geração híbrida, por exemplo, eólico e solar; entre outros. Informações adicionais a este respeito podem ser encontradas em [98]. 


\subsubsection{Tarifa Net Metering}

Consiste na medição do fluxo de energia em uma unidade consumidora dotada de pequena geração através de medidores bi-direcionais. Dessa forma, registra-se o valor líquido da energia (net metering) no ponto de conexão. Ou seja, se a energia gerada for maior que a carga, o consumidor recebe um crédito ou um desconto em energia na próxima fatura. Caso contrário, o consumidor pagará apenas a diferença entre a energia consumida e a gerada. Em [73] mostra-se uma lista dos principais países no mundo e na América do Sul que utilizam estes mecanismos de incentivo.

\subsection{Aplicação das Tarifas de Incentivo}

Deve-se ressaltar que na atualidade, dentro de um mesmo pais, podem estar sendo aplicadas mais de uma política (tarifa) de incentivo, principalmente nos países com autonomia nos seus estados. Este fato pode ser verificado na Tabela 3.1, que contém as principais políticas regulatórias (tipos de tarifas), os incentivos fiscais (redução de taxas) e se esta possui algum tipo de financiamento público para promover a geração de energia a partir de fontes renováveis.

Para isso, os países escolhidos da referência [23] foram classificados segundo sua renda per capita, obtendo-se 4 grupos denominados como: países com renda "elevada", "médiaalta", "média-baixa" e "baixa" renda per capita. Observa-se, da Tabela 3.1, que a maioria dos países pertencentes ao grupo com renda per capita "alta" realizam algum tipo de investimento público (incentivo do governo através de empréstimos), bem como oferecem subsídios de capital e redução de impostos (equivalentes ao ICMS no Brasil) para promover a geração de energia a partir de fontes de energia renovável de pequeno porte. A tarifa tipo feed-in e os certificados chamados de RECs são as formas mais comuns de incentivo neste grupo.

No grupo de países com renda per capita "média-alta", "média-baixa" e "baixa", a tarifa tipo feed-in e a redução de impostos são também as políticas de incentivo predominantes. Com base nos dados contidos na Tabela 3.1, foram elaboradas as Figuras 3.2 a 3.5 que mostram, de forma objetiva, a tendência das políticas de incentivo acima referidas. Para isso, todos os países (de cada coluna e cada grupo) marcados com $\left({ }^{* *}\right)$ e $(x)$ foram agrupados. 
Tabela 3.1. Principais políticas de incentivo em alguns países para a promoção de energia proveniente de fontes renováveis, até 2012.

\begin{tabular}{|c|c|c|c|c|c|c|c|c|c|}
\hline \multicolumn{4}{|c|}{ POLÍTICAS REGULATORIAS } & \multicolumn{4}{|c|}{ INCENTIVOS F ISCAIS } & \multicolumn{2}{|c|}{$\begin{array}{l}\text { FINANCIAMENTO } \\
\text { PÚ BLICO }\end{array}$} \\
\hline 志 & 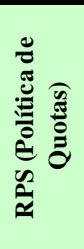 & 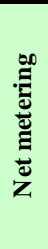 & 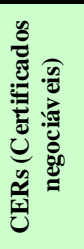 & 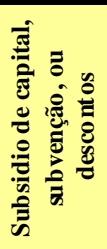 & 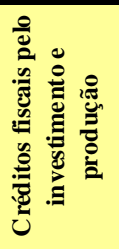 & 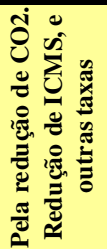 & 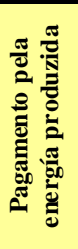 & 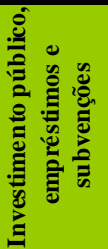 & 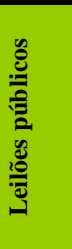 \\
\hline
\end{tabular}

Principais PAÍSES COM RENDA ALTA

\begin{tabular}{|c|c|c|c|c|c|c|c|c|c|c|}
\hline Australia & ** & & & $x$ & $x$ & & & & $x$ & \\
\hline Belgica & & ** & $x$ & $x$ & $\mathrm{x}$ & $x$ & $x$ & & & \\
\hline Canada & ** & ** & $x$ & & $x$ & $x$ & $x$ & & $x$ & $x$ \\
\hline Dinamarca & $x$ & & $x$ & $\mathrm{x}$ & $x$ & $x$ & $\mathrm{x}$ & & $x$ & $\mathrm{x}$ \\
\hline Finlândia & $x$ & & & $x$ & $x$ & & $\mathrm{x}$ & $x$ & & \\
\hline França & $x$ & & & $x$ & $x$ & $x$ & $x$ & & $x$ & $\mathrm{x}$ \\
\hline Alemanha & $x$ & & & & $x$ & $x$ & $x$ & & $x$ & \\
\hline Japão & $\mathrm{x}$ & $x$ & $x$ & $x$ & $x$ & & & & $x$ & \\
\hline Holanda & & & & $x$ & $\mathrm{x}$ & $\mathrm{x}$ & $\mathrm{x}$ & $x$ & & \\
\hline Noruega & & & & $x$ & $x$ & & $x$ & & $x$ & \\
\hline Portugal & $x$ & $x$ & $x$ & & $\mathrm{x}$ & $x$ & $x$ & & $x$ & $\mathrm{x}$ \\
\hline Espanha & $x$ & & & $x$ & ** & $\mathrm{x}$ & $\mathrm{x}$ & & $\mathrm{x}$ & \\
\hline Reino Unido & $x$ & $x$ & & $\mathrm{x}$ & . & & $x$ & $x$ & $x$ & \\
\hline
\end{tabular}

Principais PAÍSES COM RENDA ALTA-MÉDIA

\begin{tabular}{|c|c|c|c|c|c|c|c|c|c|c|}
\hline Argentina & $x$ & & & & $x$ & $x$ & $x$ & $x$ & $x$ & $\mathrm{x}$ \\
\hline Brasil & $\bar{x}$ & & $x$ & & & & $x$ & & $\bar{x}$ & $x$ \\
\hline Chile & & $x$ & $x$ & & $x$ & & $x$ & & $x$ & \\
\hline Colómbia & & & & & $x$ & & & & & \\
\hline Costa Rica & $x$ & & & & & & & & & \\
\hline Mexico & & & $x$ & & & $\mathrm{x}$ & & & $x$ & $x$ \\
\hline Perú & $x$ & & & & & $x$ & $x$ & $x$ & & $x$ \\
\hline Russia & & & & $x$ & $x$ & & & & & . \\
\hline Africa do Sul & $x$ & & & $x$ & $x$ & & & & & $x$ \\
\hline Uruguay & $x$ & & $x$ & & $x$ & & $x$ & & $x$ & $x$ \\
\hline
\end{tabular}

Uruguay

\section{Principais PAÍSES COM RENDA MÉDIA-BAIXA}

\begin{tabular}{|c|c|c|c|c|c|c|c|c|c|}
\hline Bolívia & & & & & & & $x$ & & \\
\hline Equador & $x$ & & & & & & & & \\
\hline Guatemala & & & $x$ & & & $x$ & $x$ & & $x$ \\
\hline Honduras & $x$ & & & & & $x$ & $x$ & & $x$ \\
\hline India & $x$ & $x$ & & $x$ & $x$ & $x$ & $x$ & $x$ & $x$ \\
\hline Indonesia & $x$ & & & & $x$ & $x$ & $x$ & $x$ & $x$ \\
\hline Nicaragua & $x$ & & & & & $x$ & $x$ & & \\
\hline
\end{tabular}

\section{Principais PAÍSES COM RENDA BAIXA}

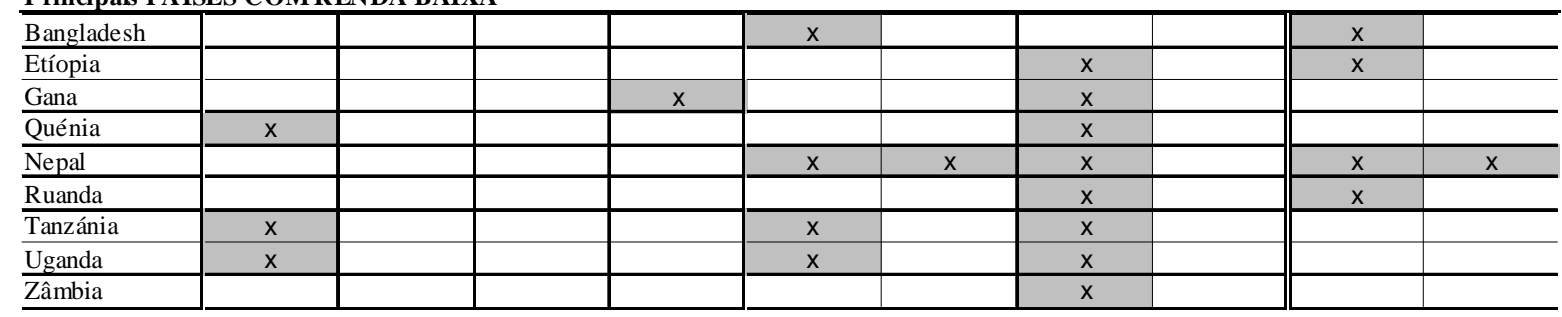

Fonte: [23].

$\left.{ }^{* *}\right)$ Aplicada apenas em alguns estados ou províncias, pois não existe uma política a nível nacional.

Nota 1: Os países foram classificados considerando a renda per capita seguinte: "alta" entre US\$12.196 ou mais, "média-alta" entre US\$ 3.946 a US\$12.195, "média-baixa"entre US\$ 996 a \$US 3.945 dólares, e "baixa" de US\$ 995 ou menores. 
A Figura 3.2, por exemplo, mostra que dos 16 países considerados no grupo com renda per capita "alta", a tarifa feed-in está em 13 países, os esquema de RPS em 7 países, o net metering em 8 países e os incentivos do tipo REC em 12 países.

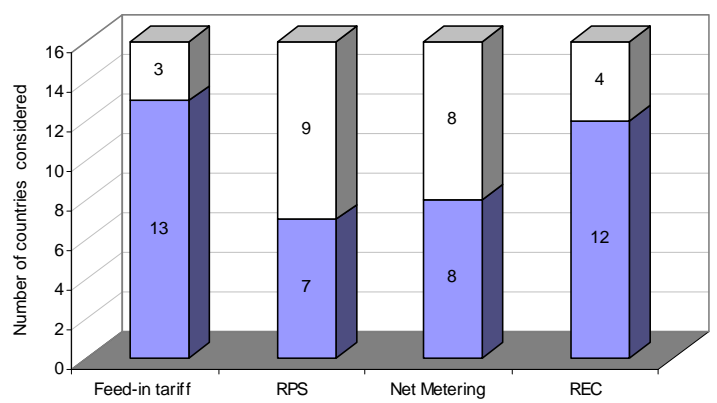

Figura 3.2. Grupo com renda per capita alta.

Na Figura 3.3 mostra-se que dos 12 países considerados no grupo de renda per capita "média-alta", a tarifa feed-in está em 6 países, o RPS em 2 países, o net metering em 1 pais, e o sistema de incentivos REC em 2 países.

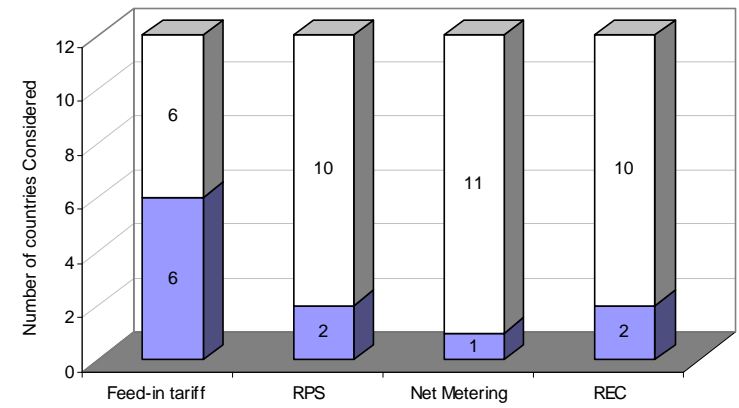

Figura 3.3. Grupo com renda per capita média-alta.

Quanto ao grupo com renda per capita "média-baixa" (Figura 3.4), a tarifa feed-in é utilizada em 7 dos 10 países considerados, o esquema RPS em 2 países, o net metering em 1 pais, e o sistema de incentivos REC em 1 país.

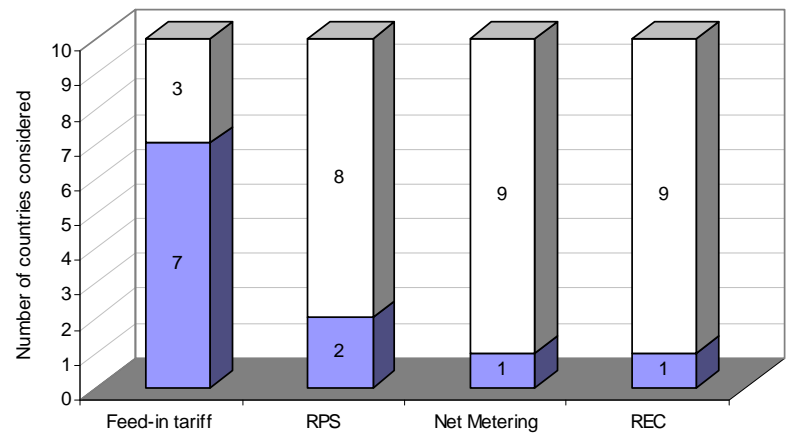

Figura 3.4. Países com renda per capita média-baixa. 
Finalmente, na Figura 3.5 mostra-se o grupo de países com renda per capita "baixa" onde a tarifa feed-in é utilizada em 3 de 9 países. Nenhum país, dos escolhidos, utiliza o RPS ou o net metering, e o incentivo REC é utilizado apenas em 1 país.

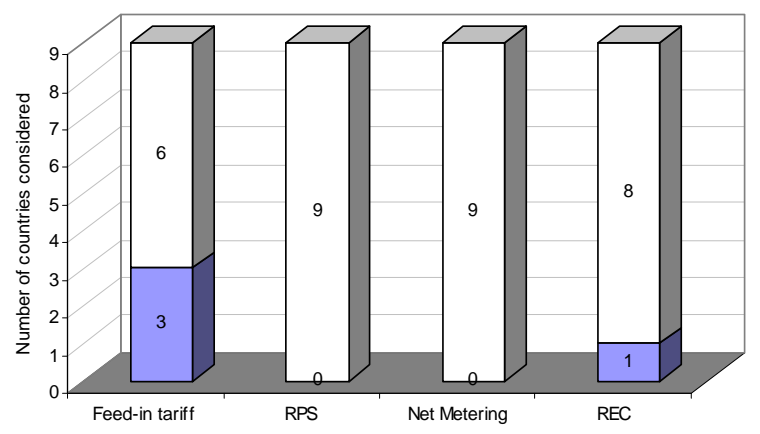

Figura 3.5. Grupo com renda per capita baixa.

Pode-se concluir que contrariamente ao grupo de países com alta renda, os países do grupo de baixa renda têm regimes tarifários com menos incentivos para promover a geração de energia a partir de fontes de energia renovável de pequeno porte.

\subsection{Análise Comparativa entre a Tarifa Feed-in e Net Metering e Possível Aplicação em MRs}

Conforme observado anteriormente, as tarifas feed-in e net metering estariam entre as formas de incentivos mais próximos a serem aplicadas em micro-redes. A tarifa net metering é, em princípio, a mais fácil de ser implementada. Isto porque apenas um medidor precisa ser usado para medir a energia líquida entre a rede e a MR. Este mecanismo pode ser usado para incentivar a micro-rede a vender eletricidade para a concessionária simplificando dessa forma os pagamentos entre a concessionária e a MR. Porém, segundo [74], nem toda MR poderia ser beneficiada por este tipo de tarifa, já que sua concepção visualizou apenas o caso de clientes individuais e não MRs que envolvam vários clientes. Assim, é provável que Micro-redes com inserção de fontes não renováveis e híbridas, ou com vários donos, sejam rejeitadas caso busquem receber estes benefícios.

Por outro lado, do ponto de vista técnico, o único inconveniente na tarifa tipo feed-in seria a necessidade de um segundo medidor (para exportação ou importação de energia) e uma instalação elétrica adicional. Porém, como mencionado anteriormente, este aspecto pode ser facilmente resolvido com a ajuda de medidores bi-direcionais, já disponíveis comercialmente. 
No entanto, feitas as adaptações específicas às atuais regulamentações e exigências, este tipo de tarifa, e possivelmente os outros esquemas tarifários, poderiam ser aplicadas em MRs em geral. Uma forma de conseguir isto seria considerando o PCC (Point of Common Coupling) da MR como o ponto de ligação no qual está conectado um cliente único (equivalente), independente do número de clientes que participam ou entidades ligadas ao PCC.

Qualquer discrepância existente dentro deste cliente equivalente deverá ser resolvida internamente. Atualmente, este aspecto não está completamente claro na regulamentação dos países que adotaram estas políticas de incentivo.

Contudo, assumindo que a MR esteja sendo operada por uma cooperativa, como mostrada na Figura 3.6, podem surgir determinadas obrigações da MR e do sistema, entre estas:

a) O gerador A, cuja geração de energia está exclusivamente baseada em energia limpa, poderia estabelecer um contrato direto com a concessionária (para se beneficiar com as tarifas de incentivo) desde que a rede de distribuição pertença a este gerador ou à concessionária. Neste caso, ele receberá todos os benefícios previstos nestas políticas de incentivo (tarifa feed-in, net metering, RPS e CERs).

b) Caso a rede (ativos) de distribuição pertença à cooperativa que administra a microrede, o gerador A teria que cumprir com as cláusulas estabelecidas pela cooperativa administrativa (por exemplo, pagar pelo aluguel da rede utilizada). Neste caso, qualquer receita recebida pela micro-rede poderá ser administrada pela cooperativa.

c) Caso a micro-rede esteja localizada em uma área remota ou opere no modo ilhado, o gerador $\mathrm{A}$ ou teria que obedecer às normas estabelecidas pela cooperativa (caso da área remota) ou ter obrigações/compensações por parte da cooperativa (se a rede pertencer à cooperativa) e pela concessionária. Neste último caso, poderia receber uma compensação da concessionária pelo apoio no fornecimento de energia às cargas críticas, normalmente alimentadas pela concessionária (é o caso do ilhamento forçado da micro-rede e sua operação). 


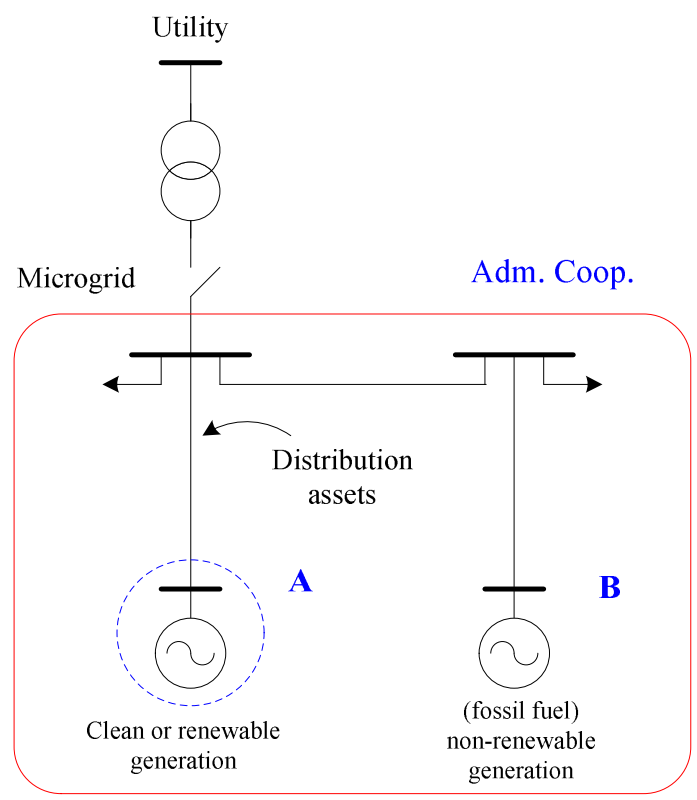

Figura 3.6. Micro-rede formada por fontes renováveis e não renováveis [73].

Ressalta-se, finalmente, que estas tarifas de incentivo e aplicação em MRs são para sistemas em corrente alternada (CA). Até agora, pouco foi discutido na literatura sobre a sua aplicação e validade para MRs em corrente contínua (CC).

No Brasil, a ANEEL, através da Norma 482/2012, estabeleceu que a geração distribuída tenha, além da pequena geração (capacidades entre $1 \mathrm{MW}$ até $5 \mathrm{MW}$ ), mais duas categorias [16] quais sejam a micro-geração e a mini-geração, conforme mencionado no item 2.14. A tarifa net metering seria a forma de compensação (econômica) pela energia gerada nestas duas últimas categorias desde que a energia gerada provenha de fontes renováveis como a hidrelétrica, solar, eólica e biomassa, incluindo a co-geração. Na Figura 3.7 apresenta-se um resumo desta proposta feita pela ANEEL.

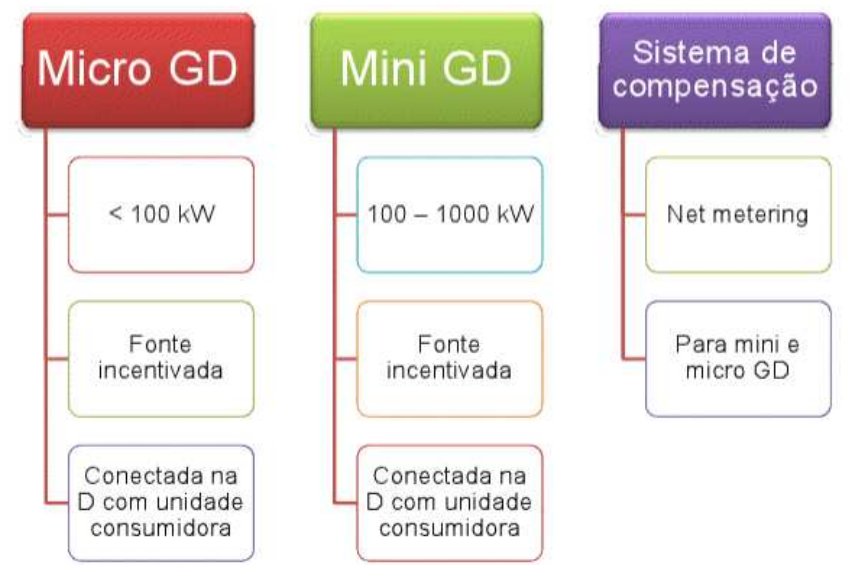

Figura 3.7. Proposta da Resolução 482/2012 da ANEEL. 
No entanto, há ainda algumas questões regulamentares e técnicas a serem definidas tais como a sua interconexão e coordenação da proteção com a rede principal. Estes regulamentos e procedimentos referentes à contribuição da "micro" e "mini-geração" ainda estão sendo analisados (2012).

\subsection{Comercialização de Energia entre MRs}

Outra tendência comercial está relacionada com a comercialização de energia entre MRs. Neste caso pode-se produzir o seguinte fenômeno: num cenário de várias MRs próximas umas das outras em determinada região, e que pela sua vez estejam desconectadas da rede principal, em um determinado momento uma MR pode produzir mais energia do que precisa. No caso de uma MR apresentar um déficit de energia, as outras MRs com excedente de energia propõem um preço; então, a MR com déficit poderá comprar a energia mais barata.

Assim, este mercado de MRs resulta em uma concorrência de preços. Esta forma de competição entre MRs vizinhas (característica de um Oligopólio) pode incorrer em custos mais baixos do que a comercialização de energia entre as MRs com a rede principal, isto devido à eliminação das perdas de energia durante a transmissão. Por conseguinte, as MRs farão todo o possível para baixar seus custos de produção com o qual as MRs poderiam tornar-se um mercado dedicado especificamente ao lucro. Assim, será necessária uma regulamentação para evitar esta situação. Contudo, diante desta tendência comercial poderiam ser aplicadas propostas e métodologias de resolução de incertezas, como por exemplo, a teoria de jogos e alguns algoritmos similares como os propostos em [26]. 


\section{CAPÍTULO 4}

\section{DIMENSIONAMENTO DE MICRO-REDES ELÉTRICAS: ESTUDOS ECONÔMICOS E ENERGÉTICOS}

Com a finalidade de se realizar uma análise da viabilidade de micro-redes elétricas para efeito de ajustar seu dimensionamento, foram desenvolvidos dois estudos distintos. $O$ primeiro, mostrando maior nível de detalhamento nos cálculos, considera uma micro-rede composta por um único gerador solar (painel) típico para aplicação residencial, mas com possibilidade de se conectar à rede de distribuição para injetar o seu excedente de geração. O segundo estudo refere-se a uma micro-rede composta por várias fontes de geração, incentivadas e não incentivadas, e uma carga equivalente conectada à mesma. O objetivo é avaliar se essas opções de conexão à rede de distribuição poderiam ser economicamente atrativas para o consumidor final, ou ente responsável pela sua administração, considerando os principais custos envolvidos.

\subsection{Análise Econômica de uma MR Solar conectada à Rede de Distribuição}

Neste primeiro estudo está sendo considerado um sistema solar fotovoltaico residencial, catalogado também como uma micro-rede simples, conectado ao sistema de distribuição. Muitos consumidores questionam se a instalação de painéis solares nas suas residências traria os benefícios econômicos que são difundidos por algumas organizações e principalmente pelos comerciantes destes produtos.

Assim, através deste exemplo, será possível mostrar as vantagens e os custos incorridos durante a aquisição deste equipamento. O sistema em estudo não considera sistemas de armazenamento de energia (baterias) o que poderia trazer ao sistema uma confiabilidade atipicamente elevada. A instalação de baterias poderia se tornar em uma vantagem em termos de desempenho técnico, embora possa desfavorecer o custo de aquisição. Os resultados aqui apresentados foram publicados num evento dirigido especificamente a micro-redes elétricas e smart grids em 2013 [75].

Considerou-se que o sistema fotovoltaico considerado para análise está instalado no telhado de uma residência localizada na região Sudeste do Brasil. Conforme mostrado na Figura 4.1, o período máximo de radiação é de aproximadamente $5 \mathrm{hr} /$ dia (10:00 a 15:00, linha segmentada). Observa-se que a produção de energia solar é maior no período de menor 
consumo residencial no dia. Esta figura foi obtida de [76], e mostra a curva de carga residencial para consumos entre $221 \mathrm{kWh} / \mathrm{mês}$ a $500 \mathrm{kWh} / \mathrm{mês}$ na região SE do Brasil.

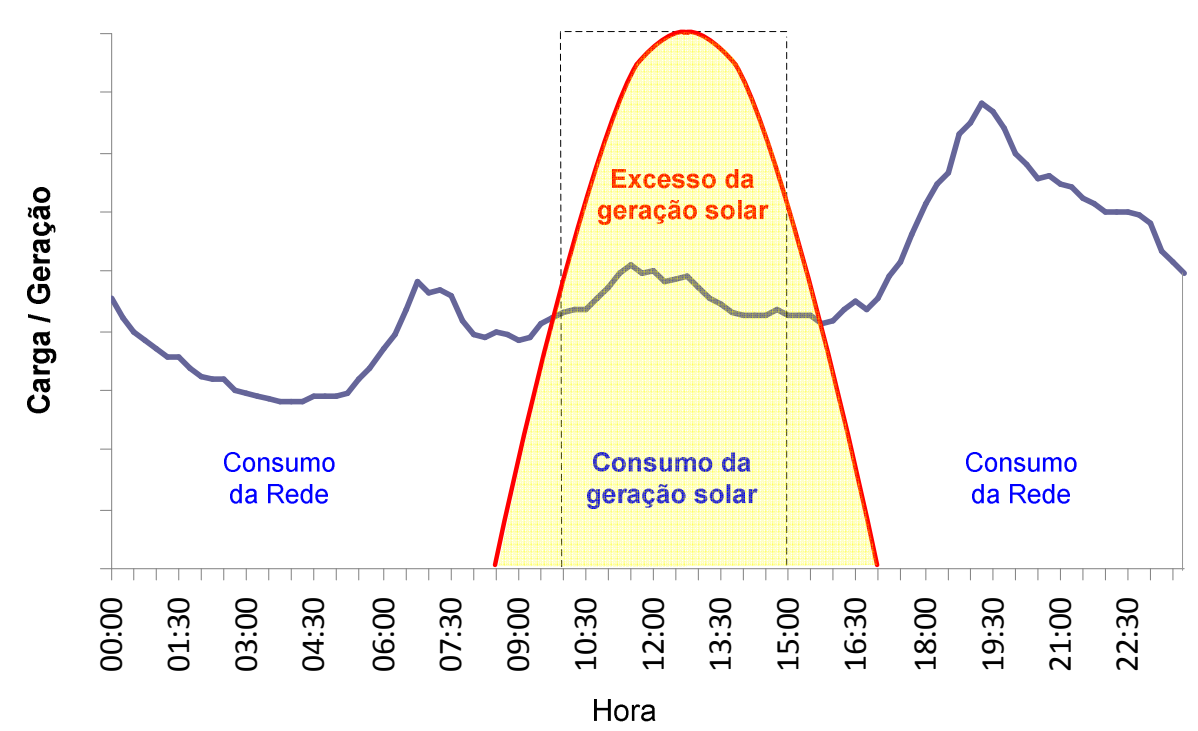

Figura 4.1. Perfil diário da radiação solar (média) e curva típica do consumo residencial (221 a 500 $\mathrm{kWh} / \mathrm{mês}$ ) na região SE do Brasil [76].

\subsubsection{Taxa de Radiação Solar Diária por Metro Quadrado}

Os valores de radiação solar diária na localidade escolhida (São Paulo), bem como outras características, foram extraídos da base de dados da RETScreen Plus [77], que é um software online aberto para consulta de dados de radiação, e outros parâmetros, em qualquer região do mundo. Neste caso o valor da radiação solar média diária obtida foi de $E_{S}=5,02 \mathrm{kWh} / \mathrm{m}^{2} / \mathrm{dia}$, conforme apresentado na Tabela 4.1. Existem atualmente outras bases de dados online que fornecem informações similares à utilizada neste trabalho. Para fins de cálculo, será assumido que a radiação máxima é de $1000 \mathrm{~W} / \mathrm{m}^{2}$.

\subsubsection{Cálculo da Energia Produzida por um Painel Solar Fotovoltaico Simples}

Considera-se que o painel solar terá uma disposição horizontal fixa. A potência máxima considerada (obtida de catálogo [78]) durante as $5 \mathrm{hr} /$ dia consideradas (10:00-15:00) é igual a $P_{\text {MAX }}=240 \mathrm{~W} /$ painel .

A área deste painel é de

$$
A p=(0,99 m \times 1,66 m)=1,6434 m^{2} \text {. }
$$

A relação para o cálculo da eficiência de conversão do painel [79], pode ser obtida através de (4.1): 


$$
\eta_{p}=\frac{P_{\text {MAX }}}{A_{P} \times 1000}
$$

Assim, tem-se ${ }^{4}$ que,

$$
\eta_{p}=\frac{240 \mathrm{~W}}{1,6434 \mathrm{~m}^{2} \times 1000 \mathrm{~W} / \mathrm{m}^{2}}=0,1460 \approx 14,6 \%
$$

Tabela 4.1. Tela do Software RETScreen Plus [77].

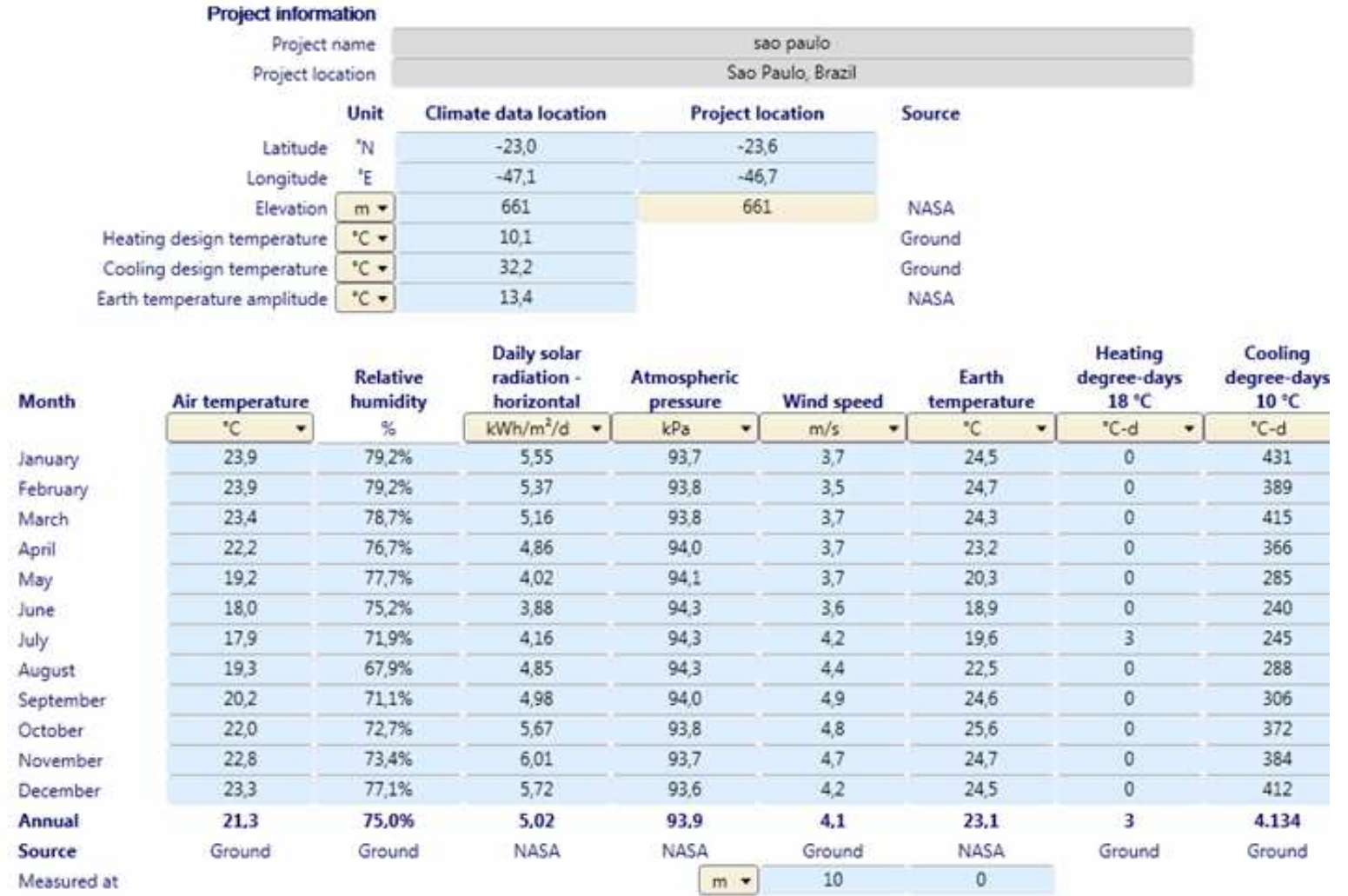

A energia produzida pelo painel solar [79], é igual a:

$$
E_{D}=E_{S} \times A_{P} \times \eta_{P} \times \eta_{i n v}
$$

Onde,

$E_{D}$ : Energia produzida pelo sistema solar ( $\left.\mathrm{kWh} / \mathrm{dia}\right)$

$E_{S}$ : Energia diária recebida do sol ( $\mathrm{kWh} / \mathrm{m} 2 /$ dia)

$A_{p}$ : Área do painel $\left(\mathrm{m}^{2}\right)$

$\eta_{p}$ : Eficiência de conversão do painel

$\eta_{\text {inv }}$ : Eficiência do inversor (em torno de 0,95).

$4 \mathrm{Na}$ expressão (4.1) o valor 1000 corresponde à taxa de radiação solar padronizada de $1000 \mathrm{~W} / \mathrm{m}^{2}$, que é usada pelos fabricantes e laboratórios de certificação para especificar e testar os painéis fotovoltaicos. A potência máxima de um painel é determinada com base nesse valor padronizado. 
Assim, a energia produzida será:

$E_{D}=5,02\left(\mathrm{kWh} / \mathrm{m}^{2} / \mathrm{dia}\right) \times 1,6434 \mathrm{~m}^{2} \times 0,146 \times 0,95=1,1443(\mathrm{kWh} / \mathrm{dia})$

A energia total suprida pelo painel em um mês será:

$E_{D_{\text {mes }}}=1,1443(\mathrm{kWh} /$ dia $) \times 30$ dias $/ \mathrm{mês}=34,33 \mathrm{kWh} / \mathrm{mês}$

Caso se deseje zerar o consumo de energia, então o número de painéis necessários será:

$$
\begin{aligned}
& N_{\text {paineis }}=\frac{E_{\text {residência }}}{E_{D \_ \text {mês_paineis }}} \\
& N_{\text {paineis }}=\frac{250(\mathrm{kWh} / \mathrm{mes})}{34,33(\mathrm{kWh} / \mathrm{mes})}=7,28 \approx 7 \text { painéis }
\end{aligned}
$$

Porém, considerando que não se pretende instalar acumuladores de energia (baterias), o que tornaria a residência independente da concessionária de distribuição, serão instalados apenas 4 painéis. A energia total mensal suprida pelos 4 painéis será,

$$
E_{D_{T}}=34,33(\mathrm{kWh} / \mathrm{mês}) \times 4=137,32(\mathrm{kWh} / \mathrm{mês})
$$

A potência total do sistema fotovoltaico será:

$P_{M A X_{T}}=4 \times 240 \mathrm{~W}=0,96 \mathrm{~kW}$

Conexão dos Painéis:

Conforme [78] e [79], neste caso podem ser utilizados painéis de silício monocristalino cuja tensão máxima de saída varia entre $21 \mathrm{~V}$ e $30 \mathrm{~V}$, e corrente no entorno de $8 \mathrm{~A}$. Será adotada uma tensão de saída de $24 \mathrm{~V}$. Em circuito aberto a tensão de saída do painel adotado é de aproximadamente $30 \mathrm{~V}$.

A conexão dos painéis solares adotados poderia ser em série ou paralelo. Painéis conectados em série possuem menor corrente e praticamente constante, enquanto que a tensão e dobrada após a conexão de cada painel solar. Este fato pode também influenciar no dimensionamento do inversor, que precisaria maior tensão (CC) na entrada. Por outro lado, este arranjo tem a desvantagem de que caso um dos painéis apresente defeito (ou desequilíbrio) a corrente total será interrompida.

Painéis conectados em paralelo possuem uma corrente relativamente maior enquanto que a tensão é mantida constante nos terminais de cada painel. Uma das vantagens da conexão em paralelo é que a tensão CC, por ser menor (por exemplo, 24 Vcc) é menos 
perigosa, fator que pode ser decisivo no caso de instalações domiciliarias, necessitando ademais menor nível de isolamento.

Por esta razão, optou-se por adotar o inversor acima descrito com os painéis conectados em paralelo, conforme mostrado na Figura 4.2.

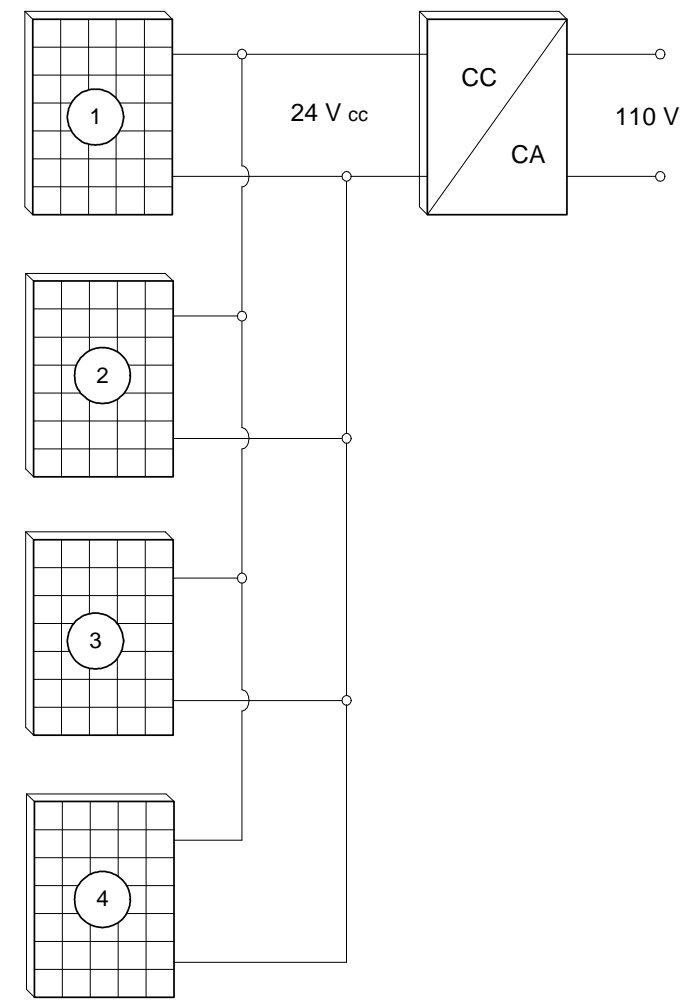

Figura 4.2. Arranjo dos painéis fotovoltaicos adotados.

\subsubsection{Características do Inversor}

Feita uma análise em relação às características do painel solar e os inversores no mercado optou-se pelo inversor modelo Grid Tie 1200W 12Vdc / 24Vdc / 48Vdc disponível no mercado [78] cujo preço, no Brasil, é de aproximadamente $R \$ 1.500$. As características deste inversor são as seguintes (Tabela 4.2):

Tabela 4.2. Características do inversor.

\begin{tabular}{|l|l|}
\hline \multicolumn{1}{|c|}{ Inversor } & \multicolumn{1}{c|}{ Especificações } \\
\hline Potência & $1200 \mathrm{~W}$ \\
\hline Entrada & $14-28 \mathrm{Vcc}$ ou 28-55 Vcc \\
\hline Saída & $110 \mathrm{Vca}$ ou 220Vca (senoidal pura) \\
\hline Freqüência & $50-60 \mathrm{~Hz}$ \\
\hline Eficiência & $90 \%$ \\
\hline Dimensões & $30 \times 20 \times 6 \mathrm{~cm}$ \\
\hline Peso & $5 \mathrm{Kg}$ \\
\hline
\end{tabular}




\subsubsection{Custo do Sistema Fotovoltaico}

Segundo [78], além de outros catálogos comerciais, foram verificados os seguintes custos unitários aproximados (Tabela 4.3):

Tabela 4.3. Custo Referencial do conjunto de Painel Solar para Aplicação Residencial.

\begin{tabular}{|l|c|c|c|}
\hline \multicolumn{1}{|c|}{ Item } & $\begin{array}{c}\text { Custo unitário } \\
\mathrm{R} \$ / \mathrm{Wp}^{(\mathrm{a})}\end{array}$ & Vida útil media & Observações \\
\hline Painel solar horizontal fixo & 5,50 & $25 \operatorname{anos}^{(\mathrm{c})}$ & \\
\hline Inversor & $1,55^{(\mathrm{b})}$ & 5 anos & (d) \\
\hline Controladores & - & - & - \\
\hline Instalação e Montagem & 1,90 & - & - \\
\hline
\end{tabular}

(a) Taxa de câmbio R\$. 2,17/US\$. em 2012; porém, será também utilizado o câmbio atual (2014) para ver a variação de preços.

(b) Preço unitário referencial de um inversor comum (12 $\left.\mathrm{V}_{\mathrm{cc}}, 110 \mathrm{~V}_{\mathrm{ca}}, 1,2 \mathrm{~kW}\right)$ para painéis solares de $1 \times 1$ $\mathrm{m}^{2}$.

(c) Na prática, este período de vida útil pode ser menor que o indicado.

(d) No caso analisado foi utilizado o inversor tipo grid-tie descrito na seção 4.1.3.

Assim, o custo total dos painéis solares será:

$\begin{array}{lll}\text { Painel }=5,50(\mathrm{R} \$ / \mathrm{Wp}){ }^{*} 960(\mathrm{Wp}) & =\mathrm{R} \$ .5 .280,0 \\ \text { Inversor }(\text { vide 4.1.3) } & \mathrm{R} \$ .1 .500,0 \\ \text { Montagem }=1,9(\mathrm{R} \$ / \mathrm{Wp})^{*} 960(\mathrm{Wp})= & \mathrm{R} \$ .1 .824,0 \\ \text { Total } & =\mathbf{R} \$ .8 .604,0\end{array}$

Não foi considerado o custo do controlador MPP (Maximum Power Point Tracking) ou Rastreador do Ponto de Máxima Potência, uma vez que o sistema fotovoltaico não tem baterias. Daí que a geração ponta do painel considera só 5 hrs.

\subsubsection{Cenários Considerados para avaliação do Sistema Solar Fotovoltaico}

Para o desenvolvimento desta análise serão considerados os seguintes cenários:

i) Suprimento de energia à residência pela concessionária e pelo sistema fotovoltaico sem nenhum incentivo.

ii) Exportação da energia gerada à rede considerando a tarifa net metering.

iii) Utilização da tarifa feed-in.

\subsubsection{Suprimento de Energia à Residência pela Concessionária e pelo Sistema Fotovoltaico sem Incentivo}

Neste caso, assume-se que a residência decide não solicitar nenhum mecanismo de incentivo (feed-in ou net metering), mas apenas compensar sua própria demanda 
através do painel solar durante o dia. Durante a noite a residência será conectada à rede de forma normal. Considera-se ainda que o custo mensal da energia aplicado pela concessionária é de $R \$ 0,3692 / k W h$ (incluídos impostos, tais como PIS e COFFINS, dentre outros).

Considerou-se ainda que a carga média da residência (das 10:00 a 15:00 hr) é de 0,49 $\mathrm{kW}$, valor obtido adotando um fator de carga $\left(f_{c}\right)$ igual a $50 \%$ e um consumo de 250 kWh/mês (Fig. 4.3), sendo a duração dos patamares de carga intermediária e de ponta de $5 \mathrm{hr}$ (10:00-15:00) e 3hr (17:00-20:00), respectivamente. Esta carga média (0,49 kW) é menor que a potência máxima do sistema fotovoltaico calculado $(0,96 \mathrm{kWp})$.

A potência média na residência é igual a:

$P_{m}=\frac{250 \mathrm{kWh} / \mathrm{mês}}{720 \mathrm{hr} / \mathrm{mês}}=0,35 \mathrm{~kW}$

Assumindo um fator de capacidade $\left(f_{\text {cap }}\right)$ igual a $50 \%$, tem-se que a potência nominal, $P_{N}$ (carga pesada entre as 17:00 e 20:00) na residência será de:

$f_{\text {cap }}=\frac{E_{m}}{P_{N}{ }^{*} T}=\frac{P_{m}}{P_{N}}$

$P_{N}=\frac{0,35 \mathrm{~kW}}{0,5}=0,7 \mathrm{~kW}($ pico $)$

Assume-se ademais que a relação entre a carga intermediaria $\left(P_{\text {interm }}\right)$ e a carga pesada é de 0,7 . Assim, tem-se que:

$P_{\text {interm }}=0,7^{*} P_{N}=0,7 * 0,7 \mathrm{~kW}=0,49 \mathrm{~kW}$

A energia média gerada pelo painel solar e consumida na residência, será igual a:

$E_{\text {solar }}=0,49 \mathrm{~kW} * 5 \mathrm{hr} / \mathrm{dia} * 30 \mathrm{dias} / \mathrm{mês}=73,5 \mathrm{kWh} / \mathrm{mês}$

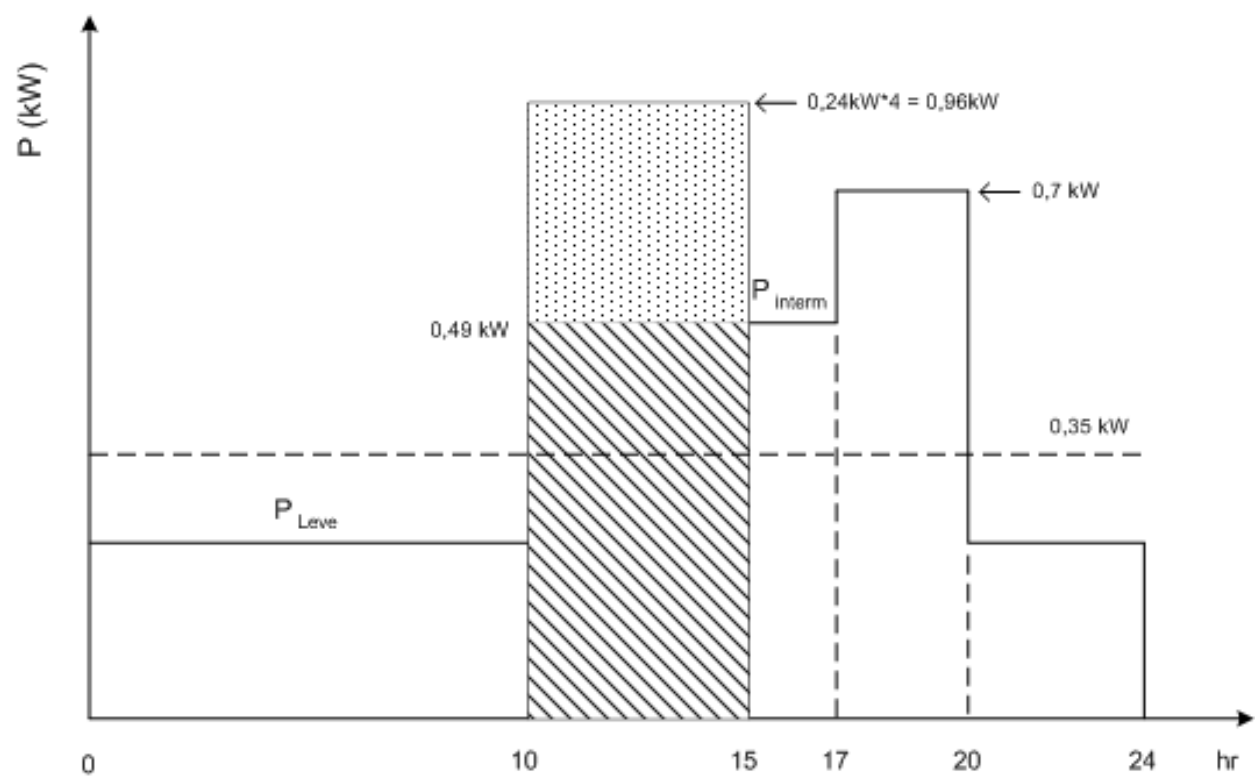

Figura 4.3. Perfil de carga da residência analisada. 
Com isso, o custo mensal a ser pago à concessionária será:

$C_{E}=(250-73,5) \frac{k W h}{m e ̂ s} \times 0,3692 \frac{R \$}{k W h}=R \$ 65,16 / m e ̂ s$

Na ausência do sistema fotovoltaico, o custo a ser pago pela residência seria de:

$C_{E}=250 \frac{\mathrm{kWh}}{\mathrm{mês}} \times 0,3692 \frac{R \$}{\mathrm{kWh} / \mathrm{mês}}=R \$ 92,3 / \mathrm{mês}$

Desta forma, a economia na fatura é de 29,40\%; ou seja, uma economia anual de (92,3$65,16) \times 12=R \$ 325,68 /$ ano. Porém, isto requer que no período de maior radiação solar (por exemplo, entre as 10:00 e 15:00) a alimentação recebida da concessionária seja desligada diariamente (assumindo tempo ensolarado). Ressalta-se que justamente no período em que a geração do painel solar poderia ser máxima, a demanda de energia da residência é reduzida (patamar de carga intermediária). Disso decorre que, como neste caso o usuário "não exporta" energia à rede, a quantidade de painéis considerados estará sobredimensionada, inviabilizando a instalação do sistema solar com esse dimensionamento.

\subsubsection{Exportação da Energia Gerada à Rede Considerando a Tarifa Net Metering}

No caso da tarifa net metering (compensação considerando consumo líquido) o usuário poderá exportar a energia excedente à rede elétrica, além de não ter que manobrar diariamente o disjuntor da entrada da concessionária no período em que utiliza sua própria geração. Assim, não haverá necessidade de discriminar os diferentes patamares na curva de carga residencial.

Como o conjunto de painéis solares está conectado de forma continua, a energia gerada será aquela calculada na Seção 4.1.2, ou seja, $E_{D T}=137,32 \mathrm{kWh} / \mathrm{mês}$. Com isso, o custo a ser pago pela residência (com sistema solar) será:

$C_{E}=(250-137,32) \frac{k W h}{m e ̂ s} \times 0,3692 \frac{R \$}{k W h}=R \$ 41,60 / m e ̂ s$

Observa-se que, em relação ao caso "sem" sistema fotovoltaico, existe uma redução de 45.07\% na tarifa. Esta compensação pela concessionária seria em energia, registrando um crédito ao consumidor, e não monetária.

No caso do Brasil, a resolução 482 da ANEEL [16] dispõe da aplicação da tarifa net metering para usuários cuja potencia máxima (micro-geração) seja menor ou igual a 100 
kW. Porém, a Resolução 482 não menciona qualquer incentivo econômico pelo custo de fontes renováveis.

\subsubsection{Utilização da Tarifa Feed-in}

No caso de se aplicar a tarifa feed-in o usuário residencial poderia ter os benefícios mencionados no Capítulo 3. Considerando o consumo médio anual da residência igual a:

$E_{\text {Res }}=250 * 12=3000 \mathrm{kWh} / \mathrm{ano}$

A energia média gerada em um ano, pelo sistema fotovoltaico, será de:

$E_{D T}=137,32 * 12=1647,84 \mathrm{kWh} / \mathrm{ano}$

- Beneficio pela energia produzida (geração): Será utilizada (assumida) a mesma tarifa de fornecimento da concessionária,

$$
G_{1}=1647,84 \mathrm{kWh} / \mathrm{ano} \times 0,3692 R \$ / \mathrm{k} W h=R \$ .608,38 / \mathrm{ano}
$$

- Beneficio pelo consumo evitado: A valoração econômica do consumo evitado deve ser feita utilizando a tarifa de fornecimento. Assim, ao invés de pagar 3000 $\mathrm{kWh} / \mathrm{ano}^{*} 0,3692 \mathrm{R} \$ / \mathrm{kWh}$ (adaptado de [80]) = R $\$ 1107,6 /$ ano será pago apenas:

$$
G_{2}=(3000-1647,84) \mathrm{kWh} / \mathrm{ano} \times 0,3692 R \$ / \mathrm{k} W \mathrm{~h}=R \$ 499,2 / \mathrm{ano}
$$

- Beneficio pela tarifa de exportação: Pode-se assumir um parâmetro de valoração desse incentivo igual ao valor do custo médio de geração da concessionária, estimado em $0,1094 \mathrm{R} \$ / \mathrm{kWh}$. Este valor aproximado é o equivalente em Reais ao considerado comumente na Europa. Assim, tem-se que:

$$
G_{3}=(1647,84-3000) \mathrm{kWh} / \mathrm{ano} \times 0,1091 R \$ / \mathrm{kWh}=R \$-147,5 / \mathrm{ano}
$$

Neste caso, o benefício não poderá ser aplicado, visto que o usuário teria que pagar ao invés de receber (pelo sinal negativo, devido a que a sua geração é menor que o seu própio consumo). Contudo, apesar do consumo global ser maior que a geração, o sistema PV exportará energia diária (período entre 10:00 e 15:00). Isto deverá ser previsto no acordo com a concessionária.

Portanto, o beneficio anual total pela aplicação da tarifa feed-in será (4.5):

$$
G=(G 1+G 2+G 3)
$$

$$
G=(608,38+499,2+0)=\mathrm{R} \$ 1107,58 / \text { ano }
$$


Conforme mencionado em [73], o período mínimo inicial de adesão com a tarifa feed-in é de 5 anos, posteriormente este período é normalmente ampliado para 15 ou 20 anos, dependendo do tipo e tamanho de geração renovável.

Em suma, apesar da energia injetada no sistema não ser significativa, o sistema PV contribui na redução dos gastos pelo consumo de energia elétrica da residência. Contudo, a vantagem técnica deste projeto deve também ser validada por meio da viabilidade econômica (retorno do investimento), conforme mostrado a seguir.

\subsubsection{Período de Retorno do Investimento}

Para a determinação do grau de atratividade econômica do sistema em análise foram utilizados como indicadores econômicos: o Valor Presente Líquido (VPL) e a Taxa Interna de Retorno (TIR). O VPL de um fluxo de caixa é obtido através da soma de todos os montantes anuais no período, descontados à data de referência econômica, conforme (4.6):

$V=\sum_{t=0}^{n} \frac{F_{t}}{\left(1+i^{t}\right.}$

Onde:

F: Valores dos fluxos de caixa

t: Anos do período considerado

$i$ : Taxa de juros adotada

Via de regra, tem-se que:

- Se o VPL > 0, o investimento é viável e terá um retorno do capital investido com uma taxa maior do que a TMA (Taxa Mínima de Atratividade) cujo valor adotado no caso em estudo é de $12 \%$.

- Se o $\mathrm{VPL}=0$, o investimento é indiferente e terá um retorno do capital investido com uma taxa igual a TIR;

- Porém se o VPL < 0 (negativo), o investimento não é viável, pois a taxa de retorno do capital investido será menor que a TMA.

Para o cálculo da $\operatorname{TIR}^{5}$ foi usada a expressão (4.7):

$$
\sum_{t=0}^{n} \frac{F_{t}}{(1+i)^{t}}=0
$$

5 Obtida a partir da análise de projeção do fluxo de caixa, sendo definida como a taxa de juros que torna nulo o VPL da alternativa analisada, ou seja, é a taxa de juros onde as receitas e as despesas se igualam. 
O significado das variáveis em (4.7) é o mesmo que o apresentado para a expressão (4.6). Normalmente a viabilidade de um projeto qualquer é assegurada se a TIR $>$ TMA.

Na avaliação econômica a seguir será apenas focado o caso de tarifa feed-in devido a que este, conforme mostrado anteriormente seria o mecanismo de incentivo mais favorável para viabilização do investimento em painéis fotovoltaicos.

Após a utilização das expressões (4.6) e (4.7), e considerando valores de $i=12 \%$ a.a., $t=25$ anos e $F=8604,0$ (investimento inicial), foram obtidos os valores apresentados na Tabela 4.4.

Como o valor do VPL é positivo, e o TIR é maior do que a TMA (Taxa Mínima de Atratividade), o investimento no painel solar residencial, para o caso analisado, seria viável (Tabela 4.4), visto que o retorno começaria a partir do $12^{\circ}$ ano, isto se a vida útil for de 25 anos. $O$ valor de reajuste de energia na Tabela 4.4 inclui a taxa de inflação.

\subsubsection{Análise dos Fatores Incidentes na Viabilidade Econômica}

\subsubsection{Incidência do Preço do Equipamento}

Atualmente existe uma tendência à diminuição dos custos ( $R \$ / W p)$ principalmente do painel solar, que é o componente de maior incidência no custo de aquisição do equipamento. Uma recente pesquisa de preços (2014) de painéis solares mostrou que houve uma queda destes em relação aos valores médios achados no inicio do estudo (2012). Acharam-se valores, por painel ${ }^{6}$, na faixa de $\mathrm{R} \$ 1.000$; assim, no caso dos quatro painéis considerados no exemplo ter-se-á $C_{\text {TOTAL_PAINEIS }}=4^{*} 1.000=\mathrm{R} \$ 4.000$; isto significa uma redução de $24,2 \%$ no preço dos painéis.

6 Produtos procedentes da Ásia, considerados como aceitáveis. 
Tabela 4.4. Cálculo do VPL baseado no Custo do sistema fotovoltaico.

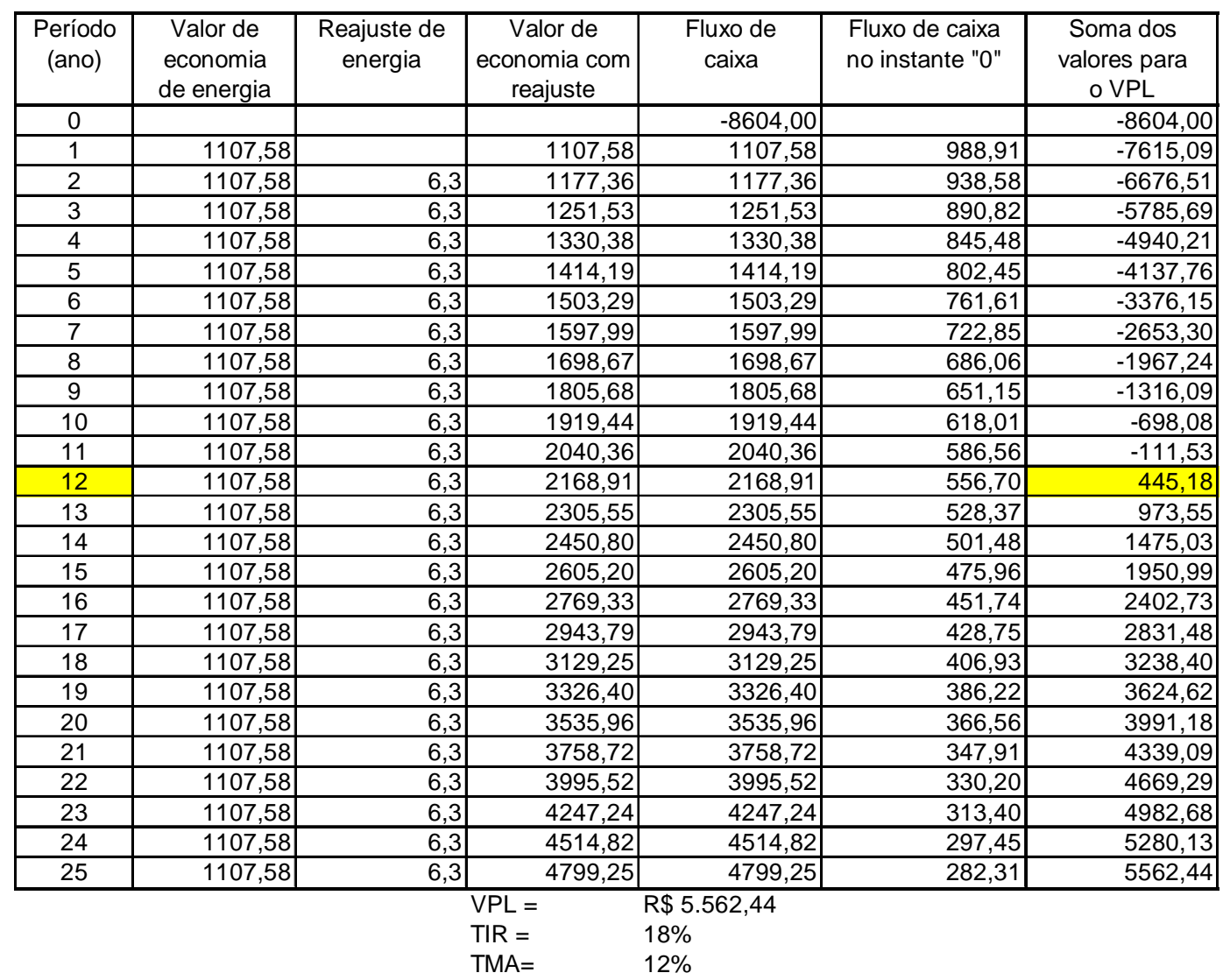

No caso dos inversores acharam-se valores na faixa de $R \$ 1.200$; redução de $20 \%$ em relação ao custo anterior. Isto poderia favorecer o custo total de aquisição do sistema solar. Ressalta-se que o custo devido a montagem e mão de obra ( $R \$ 1.824$ ), foi mantido constante em ambos os casos.

Assim, o custo inicial do investimento para esse caso será igual a $R \$ 7024,0$ com o qual se obtém os valores mostrados na Tabela 4.5 (mesma vida útil dos painéis, 25 anos).

Levando em conta estes preços, os novos valores do VPL e TIR resultaram em VPL=R $\$$ 7.142,44 (25 anos) e $\mathrm{TIR}=22 \%$ considerando a mesma TMA (12\%). O retorno do investimento, neste caso, começará a partir do $9^{\circ}$ ano. Ressalta-se que estes valores têm caráter exclusivamente ilustrativo, sendo relevante pontuar que uma análise mais precisa e exaustiva do caso poderia reduzir ainda mais o tempo de retorno do investimento. 
Tabela 4.5. Cálculo do VPL considerando custos recentes (2014).

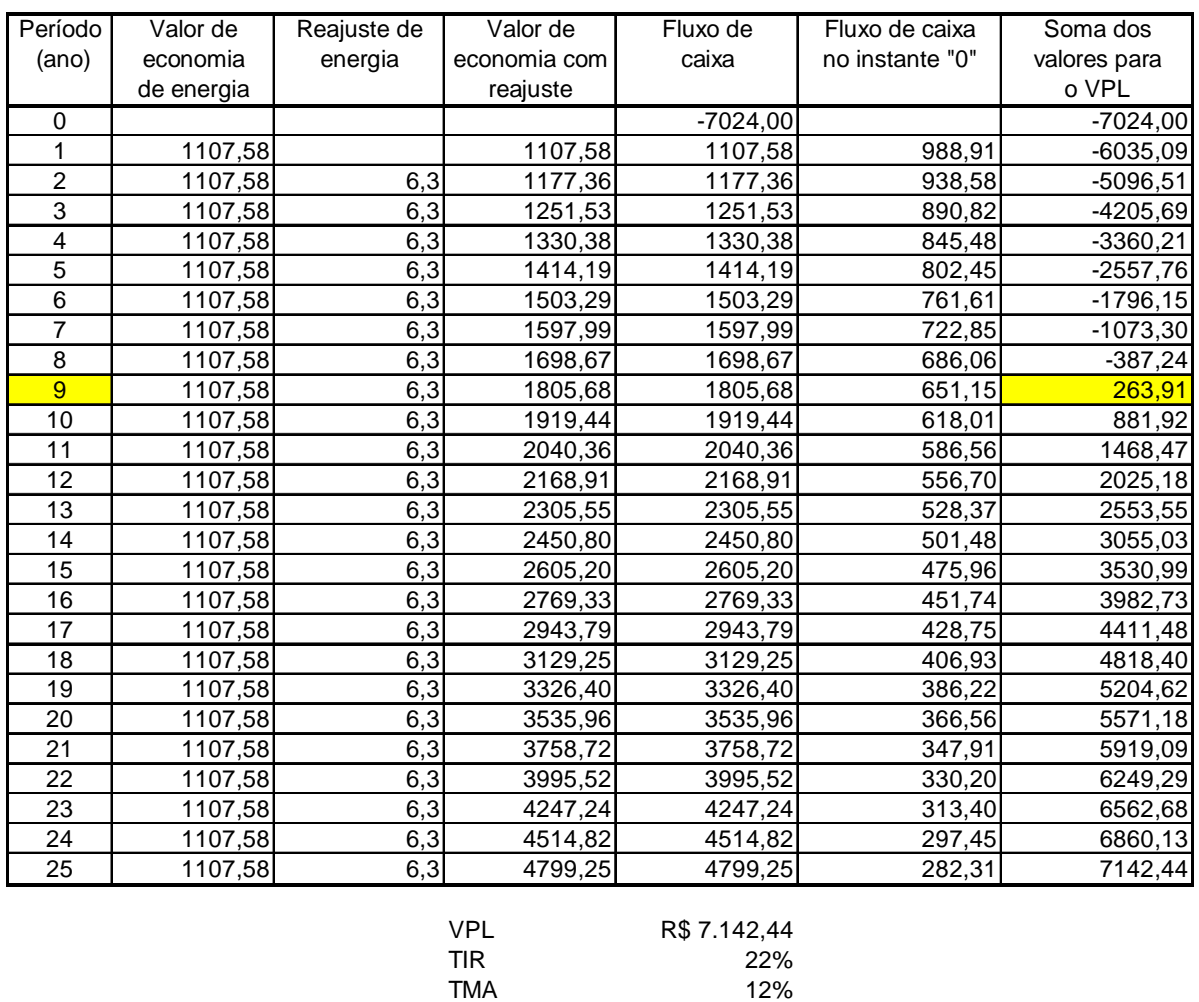

\subsubsection{Incidência dos Níveis de Radiação}

Foi também verificado que valores de radiação diferentes do considerado $(5,02$ $\mathrm{kWh} / \mathrm{m}^{2} / \mathrm{dia}$ ) não tiveram influência significativa na análise do retorno de capital, isto porque os valores de radiação de outros estados não são significativamente diferentes. O valor aproximado de radiação solar obtido para estas outras regiões [77], foi de: Recife $(P E)=5,50$; Belém $(P A)=5,06$; Rio de Janeiro $(R J)=4,49$; Florianópolis $(S C)=4,24$; e Brasília (DF) = 4,92 (kWh/m2/dia).

Deve também ser levado em conta que a vida útil do inversor, principalmente das chaves semicondutoras (IGBT - Insulated Gate Bipolar Transistor), é função do tempo de operação, isto é, quanto mais freqüente for sua operação menor será sua vida útil exigindo troca do equipamento antes da vida útil média.

\subsubsection{Incidência da Variação Tarifaria}

A recente aprovação da medida provisória MP-579 (2012), que previa uma redução das tarifas de distribuição em até $28 \%$ [81], pode afetar a viabilidade dos empreendimentos para geração de energia solar ${ }^{7}$. Assim, podem ser feitos os seguintes comentários:

7 Essa redução acabou não ocorrendo na prática e os valores das tarifas hoje vigentes, incluindo o montante relativo às bandeiras tarifárias, viabilizam muito mais o investimento em painéis solares. 
- No caso da tarifa net metering

A tarifa a ser paga, considerando o valor líquido de energia, conforme mostrado na Seção 4.1 .5 (ii), será $28 \%$ menor ao valor apresentado; isto é, $C_{E}=R \$ .41,60^{*}(1-0,28)$ $=\mathrm{R} \$$. 29,95. Ocorre que, implicitamente, a valorização da energia produzida pelos painéis será reduzida em $28 \%$, tornando ainda mais distante o horizonte de viabilização da energia fotovoltaica em nível residencial, quando aplicada a modalidade tarifária baseada na tarifa net-metering.

- No caso da tarifa feed-in

Devido a que este mecanismo de incentivo não está sendo considerado na regulamentação brasileira, o efeito da MP-579 sobre o retorno e viabilidade não será analisado. Apenas indicar que, como ocorre em alguns países Europeus, o custo da energia excedente de uma determinada instalação com fonte renovável, injetada na rede $\mathrm{CA}$ terá que ser maior que o custo unitário da energia da concessionária, o que favorece a viabilidade do projeto.

Assim, podem ser estabelecidos os seguintes pontos:

- Apesar da queda no preço dos painéis fotovoltaicos, esta forma de geração de energia é ainda relativamente cara, principalmente no referente ao custo do investimento inicial. Um fato favorável a esta forma de geração, assim como no caso da geração eólica, é que a fonte primária (radiação) não tem custo, mas que ainda assim o retorno financeiro, na maioria dos casos, não é tão imediato.

- Apesar dos avanços na tecnologia dos painéis solares, a eficiência destes é ainda baixa, em torno de 15\%. Assim, caso não sejam instalados em espaços sem uso (como é o caso dos telhados de residências, tetos de campos esportivos, etc.) a área a ser ocupada pelos painéis será relativamente grande e a energia gerada não será na mesma magnitude.

- Da avaliação econômica realizada pode-se ainda concluir que, sem os devidos subsídios e incentivos governamentais, o tempo de retorno pela instalação de painéis fotovoltaicos, por parte de consumidores residenciais, não é tão imediata. No caso avaliado, este tempo mínimo foi de nove anos utilizando a tarifa feed-in. 


\subsection{Viabilidade Econômica de uma Micro-Rede Híbrida em Sistemas Isolados}

Nos exemplos de micro-redes elétricas mostrados nos capítulos anteriores foram considerados sistemas de geração híbridos, isto é, sistemas com mais de um tipo de fonte de geração. Geralmente, estas micro-redes estão compostas por fontes renováveis de natureza intermitente. Em alguns casos, ditos sistemas consideram grupos geradores com motores a combustão (geralmente diesel), que servem de geração básica ou para suprir de energia nos períodos em que os recursos renováveis são insuficientes.

No Brasil, existem vários sistemas isolados principalmente nos estados da região Norte, como Acre, Amazonas, Pará, Rondônia, Roraima, Amapá e Matogrosso, onde a preservação do meio ambiente, aliada às grandes distâncias, torna impeditiva economicamente, a interligação com o Sistema Interligado Nacional (SIN) [82]. Atualmente, estes sistemas tem um grande número de pequenas unidades geradoras a diesel, devido ao baixo investimento inicial necessário para a implantação desta fonte, assim como à relativa facilidade logística para o suprimento de combustível. Segundo o Relatório do Plano Anual de Operação 2015 da EPE, a participação dos Sistemas Isolados na carga total de energia elétrica do país será inferior a 1\%, após a integração do Sistema Manaus e do Sistema Macapá ao SIN.

A geração nos sistemas isolados é prioritariamente térmica a óleo diesel, existindo em menor escala a geração à base de óleo combustível, gás natural e biomassa de cavaco de madeira. O sistema isolado da usina hidroelétrica Coaracy Nunes, no estado de

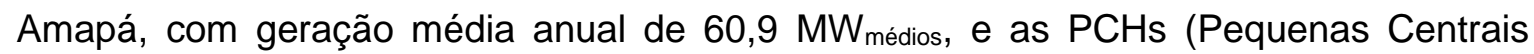
Hidroelétricas) Margarida (MT), Prata e Alto Jatapu (RO), com exceção deste último (Alto Jatapu) se encontram interligados ao SIN.

Devido ao alto custo econômico e ambiental da geração diesel nestes sistemas, ganha ênfase o estudo da substituição desta fonte energética (diesel) por fontes renováveis, com o objetivo de minimizar o custo global da operação e, ao mesmo tempo, implementar uma solução sustentável ao meio ambiente.

Assim, o principal objetivo deste estudo é, avaliar os custos de investimento das fontes renováveis, bem como o custo operacional da geração diesel durante os períodos em que a MR funciona no modo ilhado e quando está conectada à rede elétrica. 


\subsubsection{Desenvolvimento do Modelo para Simulação}

O Modelo em questão foi desenvolvido utilizando o programa Excel da Microsoft, no ambiente Visual Basic e tem como objetivo a análise elétrica e econômica de um subsistema isolado para suprimento de uma carga com a otimização de investimento em geração eólica, solar e hídrica, conforme mostrado na Figura 4.4. A otimização é realizada em intervalos horários, com base na potência do subsistema, possibilitando tratamento da carga com modulação distinta entre os meses do ano, bem como dos perfis de geração eólica e solar.

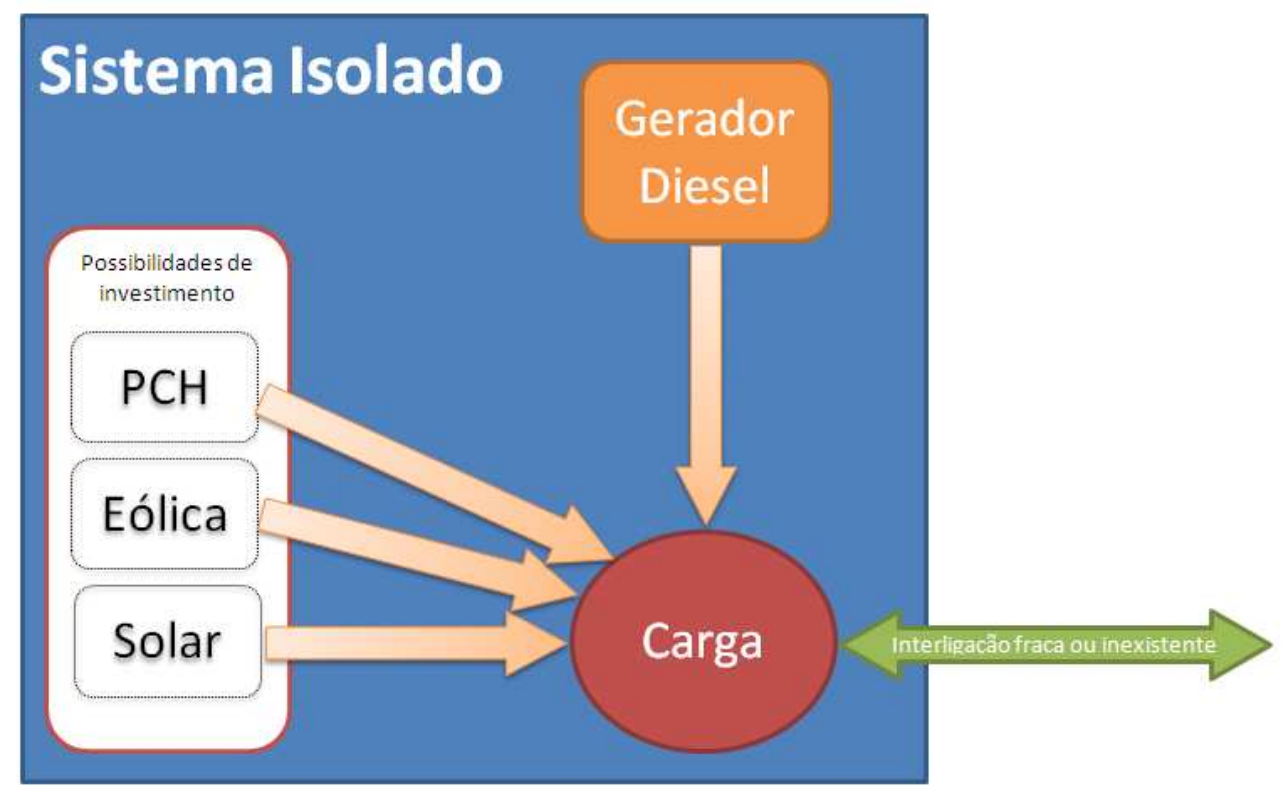

Figura 4.4. Simulador de sistemas isolados [82].

O modelo desenvolvido está estruturado em 4 blocos (Figura 4.5). No primeiro bloco é feita a leitura de todo o conteúdo da planilha, seguido do balanço energético no qual é feita a análise dos perfis de carga e da geração horária; no bloco análise econômica é feita a contabilização dos custos de investimento, custo de geração diesel e custos de déficit e finalmente o quarto bloco recorre aos anteriores para buscar a melhor alocação dos recursos utilizando método suportado por algoritmos genéticos.

Leitura dos dados de Entrada

Balanço Energético

Análise Econômica

Portfolio Ótimo

Figura 4.5. Estrutura do modelo. 
Uma das etapas importantes no desenvolvimento do programa refere-se ao balanço energético. A mesma segue a seguinte rotina:

a) Calcula-se a energia necessária para atender à carga em todos os cenários;

b) Calcula-se a geração solar e eólica para o abatimento da carga;

c) Calcula-se a geração hidroelétrica alocando a energia diária controlável nos horários de maior prioridade;

d) Calcula-se a geração diesel e a energia fornecida pela interligação considerando a priorização indicada na entrada do modelo;

e) Calcula-se o déficit ou a sobra de energia do sistema.

\subsubsection{Análise Econômica e Otimização dos Investimentos}

Nesta etapa do modelo avalia-se economicamente o sistema simulado através do Custo Esperado Total (CET), do Custo Médio Mensal (CMM) e do Valor em Risco Condicional ${ }^{8}$ (CV@R - Conditional Value at Risk) mensal, considerando todos os cenários de geração. O modelo desenvolvido tem, como principal função objetivo, a redução de custo de operação de um sistema isolado através da inserção de outras fontes renováveis, diminuindo o custo da geração diesel existente (Figura 4.6).

A utilização de cenários de geração como entrada para as três fontes possibilita a análise probabilística do custo de atendimento da carga. A análise da composição ótima das alternativas de investimento resulta na melhor configuração de investimento possível entre as três fontes estudadas, minimizando o custo e atendendo aos critérios de risco especificados [82].

\footnotetext{
${ }^{8}$ Refere-se à perda esperada do investimento a partir de um determinado valor em risco, ao invés do retorno.
} 


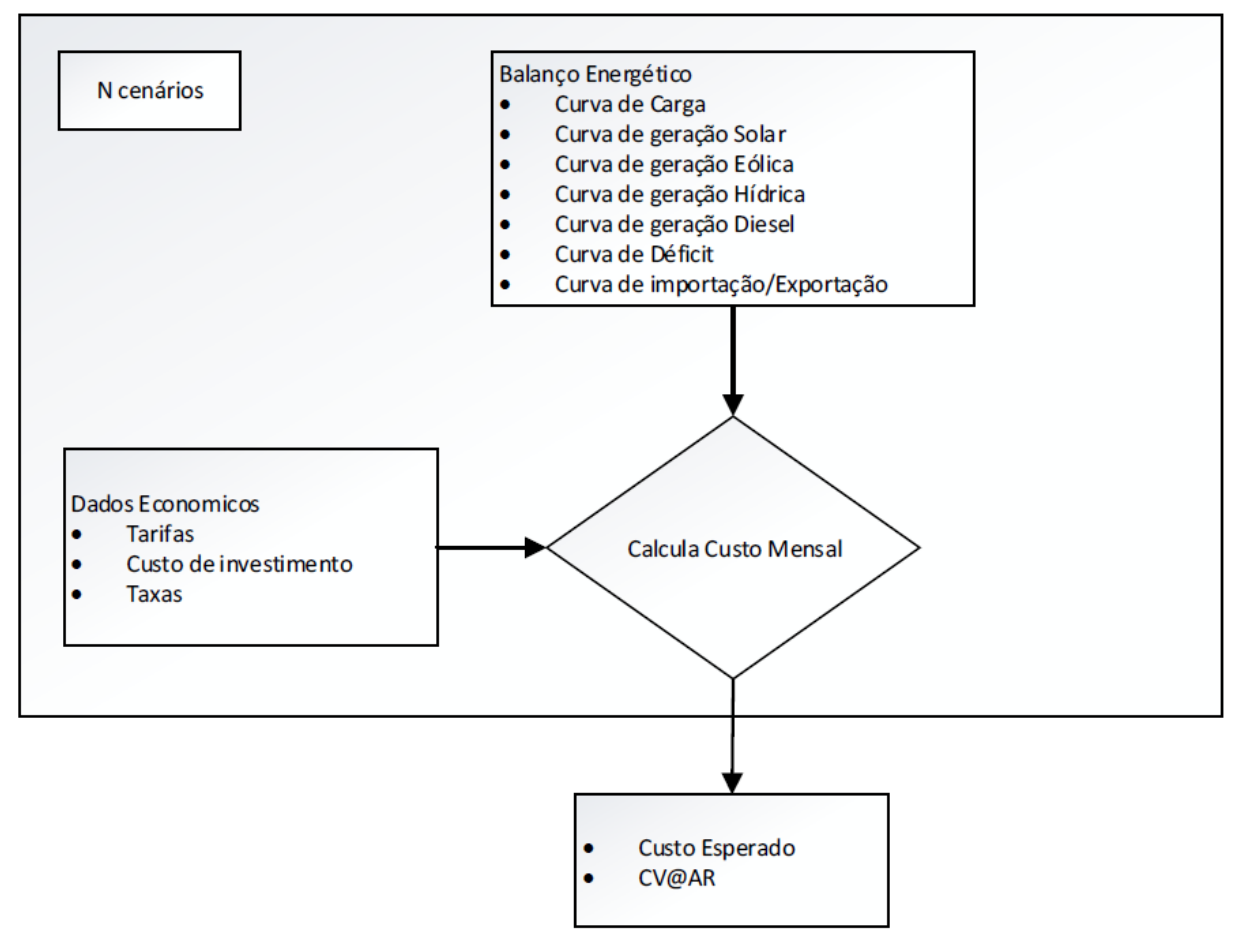

Figura 4.6. Fluxograma de entradas e saídas da análise econômica [82].

Uma sintese geral do modelo para o cálculo da otimização dos investimentos é apresentada na Figura 4.7.

Esta avaliação econômica será realizada em casos quando se tem participação apenas das fontes de geração alternativas e quando inclusive o gerador diesel estiver operando. No caso da operação da micro-rede no modo ilhado, deverá ser realizado o respectivo balanço energético (regime permanente) verificando que a carga não ultrapasse a capacidade das fontes presentes na micro-rede.

$\mathrm{Na}$ sua base de dados a planilha possui um histórico de 63 anos (de 1948 até 2010) chamado de ENA (Energia Natural Afluente) tanto para a geração solar, eólico e hidroelétrico. Apenas as séries ENA da PCH foram obtidas de um banco de dados, as outras séries (vento e radiação) correspondem a séries históricas reconstituídas a partir de modelos de mesoescala9 ${ }^{9}$.

Para a reconstrução das séries de ENAe (Energia Natural Afluente Eólica) e geração eólica, de 1948 a 2010, para as regiões de estudo, foi desenvolvida uma metodologia específica [99].

9 São aqueles fenômenos que têm duração entre 1 e 12 horas, ou uma extensão horizontal entre 1 e $100 \mathrm{Km}$, ou ainda uma altura entre 1 e $10 \mathrm{Km}$. Exemplo destes fenômenos são as tormentas convectivas, brisas marítimas, tornados, etc. 


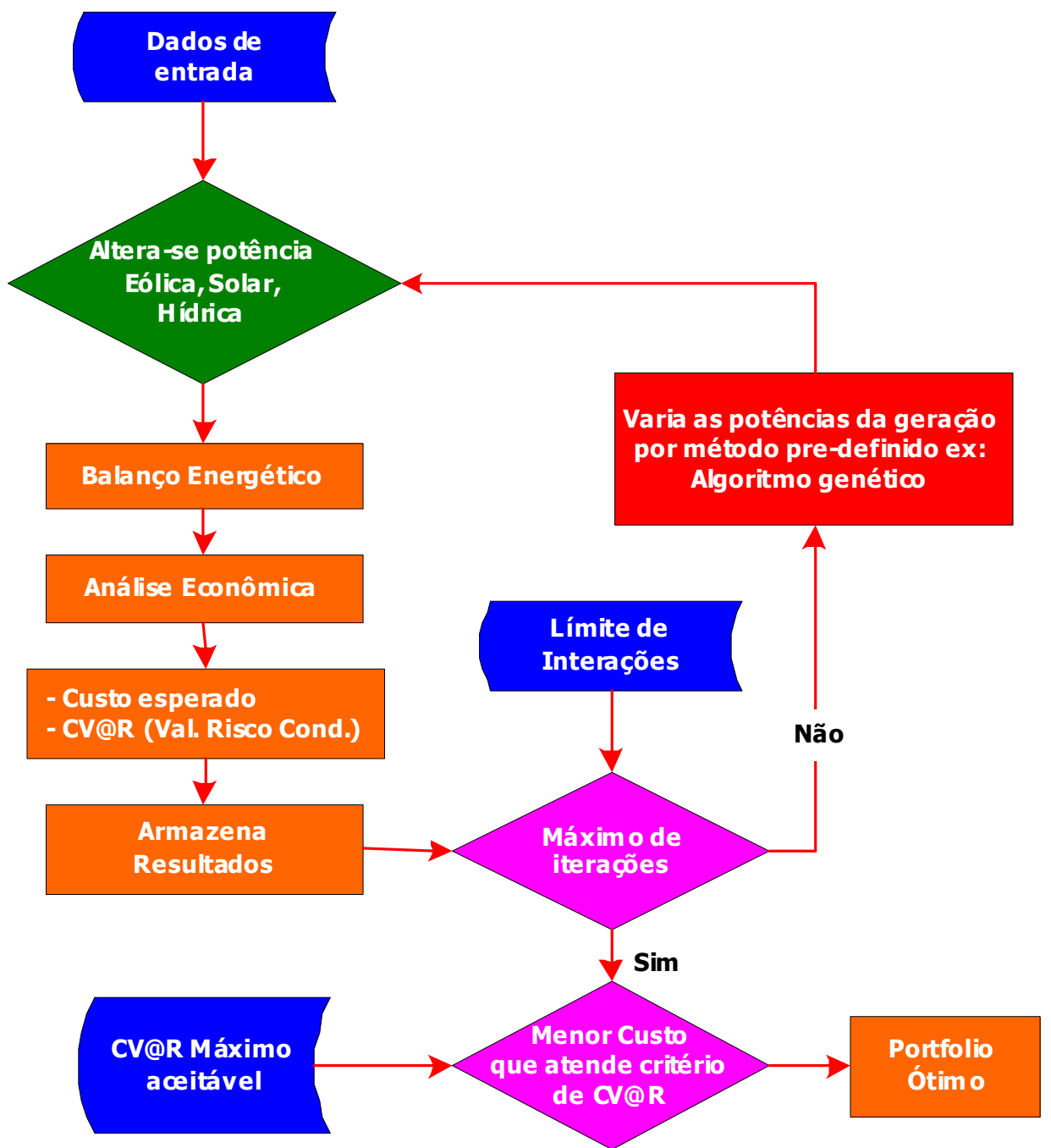

Figura 4.7. Fluxograma do modelo geral de otimização [82].

Para tanto, foram utilizadas séries de dados de vento, de uma mesma região, utilizando duas fontes diferentes: NOAA (National Oceanic and Atmospheric Administration) e VORTEX (Modelo atmosférico de Mesoescala on-line que fornece velocidades de vento estimadas para locais onde não existem medições de longo período). Assim, para uma determinada região de estudo, estas duas séries de dados de vento terão como características:

Série NOAA:

- Período: 1948 a 2010;

- Variável: Velocidade média diária;

Série VORTEX:

- Altura: Nível de superfície, 10m.

- Período: 1982 a 2014;

- Variável: Velocidade média horária;

- Altura: de 50 a 150m.

Utilizando modelos matemáticos, as duas séries são comparadas e, como critério de aceitabilidade de aderência, são adotadas como aceitáveis as séries que apresentam 
um coeficiente de correlação superior a 0,8. Essas serão as séries reconstituídas, utilizadas no programa, que foram utilizadas para simular a MR hibrida. Um estudo mais completo sobre a metodologia de reconstituição de dados para a série histórica do vento pode ser encontrado em [99].

As séries históricas de radiação solar foram também obtidas a partir de modelos de mesoescala. Assim, foi utilizada como premissa, para a reconstrução do histórico de geração, que exista uma correlação negativa entre a vazão, em uma determinada usina hidrelétrica, e a radiação solar em local próximo (períodos de chuva são em geral nebulosos e com níveis de radiação ao nível do solo muito inferiores aos dias ensolarados). A série de radiação solar disponível (1999 à 2013) é extrapolada para o histórico todo, obtendo-se 81 anos (1932 à 2013) correlacionados naturalmente com a geração hidrelétrica [100].

Ainda, segundo [100], durante a reconstrução do histórico de radiação, as ENAs hidráulicas são separadas em 2 grupos: Grupo 1, contendo as ENAs de 1932 à 1998, que são os anos que não tem histórico solar; e o Grupo 2, contendo as ENAs de 1999 à 2013, que são os anos coincidentes ao histórico de radiação solar. Logo, analisa-se a semelhança entre as ENAs do Grupo 1 com as do Grupo 2, e para cada ENA do Grupo 1 é assimilada uma ENA do Grupo 2.

Em seguida, utilizando a premissa de que anos de vazão semelhante tem comportamento de radiação solar semelhante, reconstrói-se o histórico com as séries de radiação ordenadas conforme o Grupo 2. Na Figura 4.8, mostra-se a seqüência da metodologia anteriormente descrita. Maiores detalhes sobre as séries reconstituídas de irradiação solar podem ser encontradas em [100].

Levando em consideração a combinação das três fontes de geração limpa utilizadas (solar, eólica e hídrica), a participação do gerador diesel, da concessionária, além dos dados mensais e sazonais para os 63 anos do histórico, pode-se inferir que os cenários existentes são inúmeros. Com o objetivo de reduzir este universo de casos existente, foi selecionado especificamente o Cenário 1 que teve um dos melhores desempenhos hidrológicos da série histórica. 


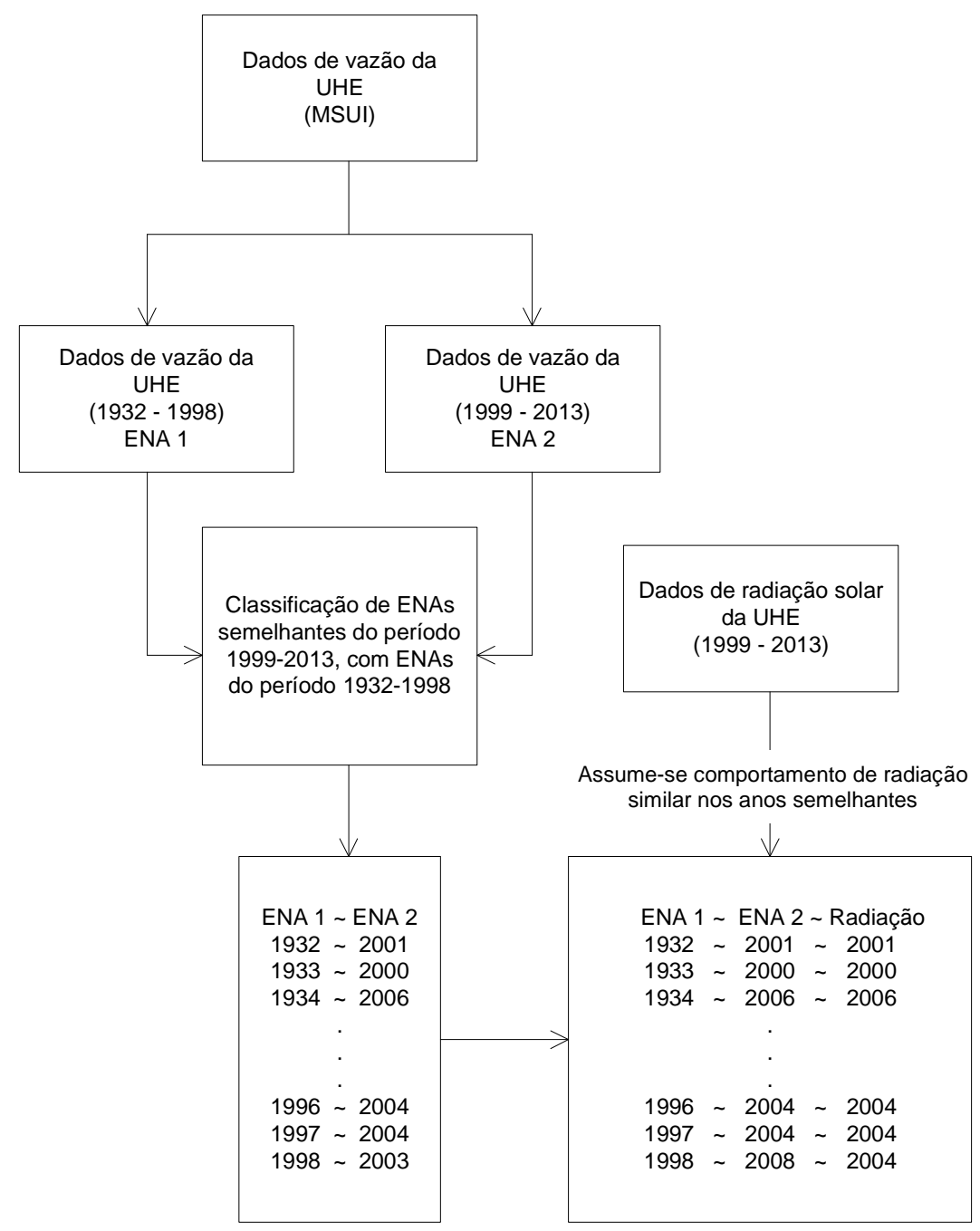

Figura 4.8. Fluxograma de reconstrução de histórico de radiação solar [100].

Para a análise e simulações apresentadas neste capítulo foram consideradas, além da concessionária de distribuição que alimenta a carga da micro-rede, um gerador diesel de 6,04 MW de capacidade, uma $\mathrm{PCH}$ de $4 \mathrm{MW}$, uma turbina eólica de 3,5 MW e um sistema de geração fotovoltaica de 0,30 MW, que juntos atendem uma carga de 6,04 MW, conforme apresentado na Figura 4.9.

$\mathrm{Na}$ avaliação econômica aqui apresentada, o custo de investimento da $\mathrm{PCH}$, painel solar e gerador eólico ainda devem ser pagos, enquanto que a do gerador diesel é considerado já amortizado. Assim, apenas o custo operacional deste (diesel) é incluído na avaliação e processamento na ferramenta computacional utilizada. A razão disto é que na maioria dos sistemas isolados na rede elétrica brasileira o gerador diesel já se encontra instalado no local. Assim, o objetivo será analizar a opção de reduzir ao máximo a dispendiosa geração a combustível fóssil. 


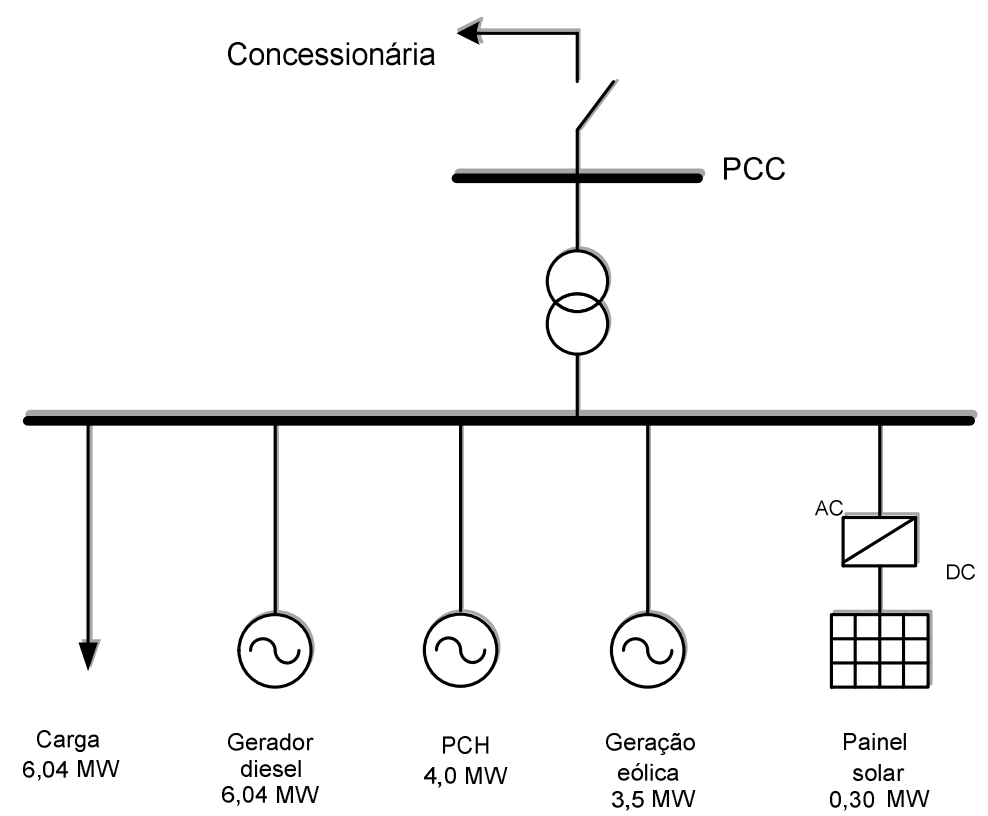

Figura 4.9. Micro-rede proposta para a análise de viabilidade econômica.

A carga da MR é caracterizada pela curva de carga típica de uma comunidade localizada na região norte do Brasil, cuja carga média e demanda máxima são iguais a 4,0 MW e 6,04 MW, respectivamente. Na análise e implementação do programa foi considerado que o gerador diesel sozinho consegue atender à demanda da comunidade já no primeiro ano, levando em conta a possível indisponibilidade das fontes renováveis caracterizadas pela intermitência na geração. A seguir são descritas as principais variáveis utilizadas nas telas de saída do programa utilizado:

Fonte:

Custo :

Período:

Prioridade de consumo:

Tempo:

Limite de importação:

Limite de exportação:

Custo esperado total (CET):

Custo médio mensal (CMM):
0 - OFF (desligado); 1 - ON (ligado)

Refere-se ao custo de investimento da fonte $\mathrm{PCH}$, solar ou eólica.

Define o período considerado para amortizar o investimento.

$0=$ Diesel; 1 = Interligado (concessionária). A escolha do valor $(0$ ou 1) não elimina a fonte que não for considerada, mas apenas indica a prioridade que terá a alternativa escolhida. Por exemplo, se for escolhida a opção 0 , primeiro será gasto o diesel e depois, caso o diesel não atenda à carga, será importada energia da concessionária.

É o tempo de simulação.

Define a potência máxima de importação pela interligação.

Define a potência máxima de exportação pela interligação. Quando a concessionária estiver desligada, aloca-se valor zero nestes limites.

É o valor correspondente aos 60 últimos meses trazidos a valor presente.

É o custo efetivo de determinado mês levando em conta as curvas de carga no mês, o tamanho da MR, o investimento nas fontes e todos os demais fatores. 
Tarifa de importação

(exportação) :

Preço de déficit:

Prioridade de despacho:

Cenário:

Mês :

Ano :
É dada pela parte positiva da curva de importação e valorada pela tarifa horária de compra (venda); informada pelo usuário.

Este valor é utilizado para valorar a falta de energia no lado da carga, por exemplo, para alocar um valor a itens (como produtos perecíveis estragados, etc) perdidos pela falta (déficit) de energia. Daí que toda vez que existe déficit os custos CMM e CET são maiores. No caso do programa utiliza-se um valor de 2000 $\mathrm{R} \$ / \mathrm{MWh}$.

Define a prioridade horária para o atendimento à carga, sendo $0 \mathrm{a}$ maior e 23 a menor prioridade

Número de cenário do histórico de 63 anos.

Mês para o qual será feita a simulação.

Período considerado para o crescimento da carga, entre 1 a 5 anos. De fato, a utilização do ano 1 traz menos risco para o déficit do que o ano 5, que também terá efeito sobre os custos CMM e CET calculados.

Vale destacar e esclarecer que nas respostas apresentadas a seguir os valores de Custo Médio Mensal (CMM) e Custo Esperado Total (CET) apresentam valores altos (da ordem de milhões) porque as capacidades dos geradores na MR considerada são também altas. O programa é sensível à capacidade instalada dos geradores, ao tamanho da carga atendida, à sobrecarga (decorrente das curvas de carga típicas existentes na base de dados) e ao déficit na geração. A função de minimização do custo, perdas e/ou risco na geração, não foi implementada na ferramenta utilizada nesta seção.

Por outro lado, simulações preliminares permitiriam estabelecer que:

- O melhor desempenho da PCH corresponde ao mês de Dezembro, caracterizado pelas freqüentes chuvas.

- O melhor desempenho do gerador eólico corresponde ao mês de Julho, caracterizado pelos ventos freqüentes.

- O melhor desempenho do gerador solar corresponde ao mês de Setembro, caracterizado pela elevada radiação solar.

O horizonte da previsão (para planejamento) considerado foi de cinco anos, enquanto que a taxa de crescimento conservativa da carga foi estabelecida em $3 \%$ a.a. No programa, este último valor pode ser modificado pelo usuário. Segundo informações do governo brasileiro, em 2014 a taxa de crescimento do consumo de energia elétrica nacional foi de $+3,5 \%$.

Na tabela 4.6 é possível observar os valores das variáveis utilizadas na análise dos diversos casos. 
Tabela 4.6. Valores das variáveis utilizadas nos casos analisados.

\begin{tabular}{|c|c|}
\hline \multicolumn{2}{|l|}{ PCH } \\
\hline Potência & $4 \mathrm{MW}$ \\
\hline Custo de Investimento $(\mathrm{X})$ & $\mathrm{R} \$ .5 .000 .000 / \mathrm{MW}$ \\
\hline Período de amortização & 14 anos \\
\hline Taxa de Interesse & $12 \%$ \\
\hline \multicolumn{2}{|l|}{ Painel solar } \\
\hline Potência & $0,30 \mathrm{MW}$ \\
\hline Custo de Investimento & $\mathrm{R} \$ .6 .500 .000 / \mathrm{MW}$ \\
\hline Período de amortização & 20 anos \\
\hline Taxa de Interesse & $12 \%$ \\
\hline \multicolumn{2}{|l|}{ Gerador eólico } \\
\hline Potência & 3,5 MW \\
\hline Custo de Investimento ${ }^{(X)}$ & $\mathrm{R} \$ .3 .700 .000 / \mathrm{MW}$ \\
\hline Período de amortização & 14 anos \\
\hline Taxa de Interesse & $12 \%$ \\
\hline \multicolumn{2}{|l|}{ Gerador Diesel } \\
\hline Potência & $6,04 \mathrm{MW}$ \\
\hline Preço (XX) & $\mathrm{R} \$ .1 .420,0 / \mathrm{MWh}$ \\
\hline \multicolumn{2}{|l|}{ Carga } \\
\hline Demanda de potência & $6,04 \mathrm{MW}$ \\
\hline Taxa de depreciação & $3 \%$ a.a. \\
\hline Custo do déficit & $\mathrm{R} \$ .2 .000,0 / \mathrm{MWh}$ \\
\hline
\end{tabular}

Os custos de instalação dos equipamentos, e de energia, acima utilizados podem variar de uma para outra região e/ou atualizados pelos fabricantes e pela ANEEL (ou órgão resposável), respectivamente.

\subsubsection{Casos Analisados}

Durante a avaliação e análise econômica foram considerados oito casos:

Caso 1. MR suprida apenas pelo gerador diesel (desconectada da concessionária).

Caso 2. MR conectada com a rede e simultaneamente com a $\mathrm{PCH}$, o gerador eólico e o gerador diesel: $(A)$ período mais chuvoso; $(B)$ período com maior vento. 
Caso 3. MR conectada com a rede e simultaneamente com a PCH e o Gerador eólico (sem a participação do gerador diesel): (A) período mais chuvoso; (B) período com maior vento.

Caso 4. MR "ilhada" constituída por um gerador diesel, a $\mathrm{PCH}$, o gerador eólico e o gerador solar; (A) período mais chuvoso; (B) período com maior vento; (C) período mais ensolarado.

Caso 5. Similar ao Caso 4, porém, conectada com a rede, com limite de exportação de 3,0 MW.

Caso 6. MR "ilhada" constituída por um gerador diesel, o gerador eólico, o painel solar (sem $\mathrm{PCH}$ ); (A) período com maior vento; (B) período mais ensolarado.

Caso 7. MR "ilhada" constituída apenas pelo gerador eólico e o painel solar (sem PCH e gerador diesel); (A) período com maior vento; (B) período mais ensolarado.

Caso 8. MR alimentada exclusivamente pela rede elétrica.

\subsubsection{MR suprida apenas pelo gerador diesel (Caso 1)}

O principal objetivo deste caso é mostrar os custos (CMM, CET e CV@R) a serem obtidos quando apenas o gerador diesel supre de energia à carga da micro-rede, sem a participação das fontes de geração renováveis e nem a concessionária.

- Observa-se, na Figura 4.10, que o CMM e CET atingem valores de $R \$ 4.345,7$ $x 10^{3}$ e $\mathrm{R} \$ 196.814,3 \times 10^{3}$, respectivamente. O valor de risco condicional (CV@R) é igual a $R \$ 4.753,3 \times 10^{3}$. Estes valores serão mais em frente comparados com os outros casos de operação estabelecidos neste estudo.

- O gerador diesel atende toda a demanda da carga na MR não havendo déficit na geração. Observa-se também que a carga está caracterizada pela sua curva típica, conforme mencionado anteriormente.

- Por ser este tipo de geração função do custo de combustível, este caso situa-se entre os resultados mais caros em termos de custo. 


\subsubsection{MR conectada com a rede e simultaneamente com a $\mathrm{PCH}$, o gerador eólico e o gerador diesel (Caso 2)}

O objetivo deste caso é observar o desempenho da micro-rede considerando as fontes alternativas conectadas. São dois os cenários a serem avaliados: (A) Período de maior chuva e, (B) período de maior vento.

\section{A. Período de maior chuva (Dezembro)}

Realizadas as simulações foi possível observar o seguinte comportamento (Figura 4.11):

- A concessionária (cor laranja) contribui suprindo pouca energia entre as 13:00 a 17:00 hr. Pode-se observar que em dois períodos ao longo do dia a MR exporta energia ao sistema principalmente por conta da geração da $\mathrm{PCH}$ (cor azul) que tem participação durante o dia todo.

- Nota-se que apesar do gerador diesel participar na MR, por conta da otimização de recursos e custos de energia gerada, este não participa de forma contínua na geração.

- O CMM da MR, para as condições estabelecidas, é igual a $\mathrm{R} \$ 1.632,3 \times 10^{3}$. Este custo (referente ao investimento nas fontes renováveis e combustível no gerador diesel) é a média do CET trazidos a valor presente. O CET é igual a $R \$$. 74.388,3 $\times 10^{3}$. Este custo corresponde a 60 meses (12 meses $\times 5$ anos) considerados no computo do programa, mesmo que será pago nos próximos 5 anos.

- Nota-se que a carga é em todo momento igual à soma dos valores da geração incluindo, se for o caso, o valor injetado pela concessionária (intercâmbio).

\section{B. Período de maior vento (Julho)}

No caso do mês com maior vento (mês 7), foi possível constatar que (Figura 4.12):

- A geração eólica (cor verde) gera durante o dia todo. A maior participação da PCH ocorre entre 06:00-23:00 hrs.

- O custo médio mensal (CMM) e CET (gasto pela micro-rede) não tiveram variação em relação ao caso anterior isto porque o cenário e ano especificados, foram mantidos constantes.

- Foi também simulado o caso da inclusão do painel solar. O resultado foi muito próximo ao aqui apresentado visto que a capacidade do painel solar é relativamente pequena em relação ao resto das fontes. 


\subsubsection{MR conectada com a rede e simultaneamente com a PCH e o Gerador eólico (Caso 3)}

Para a análise desta condição não foi considerada a participação do gerador diesel nem do painel solar. Neste caso foram analisados também dois cenários:
A. Período de maior chuva.
B. Período de maior vento.

\section{A. Período de maior chuva (Dezembro)}

Com base nos resultados apresentados na Figura 4.13 podem ser apontados os seguintes comentários:

- O CMM e CET da MR, para as condições estabelecidas, são iguais a $R \$ 1.692,4$ $x 10^{3}$ e $R \$ .77 .072,9 \times 10^{3}$. O CV@R é igual a $R \$ 3.107,8 \times 10^{3}$.

- A geração da PCH (cor azul) teve uma participação continua ao longo do dia.

- No período 13:00-17:00 existe déficit na geração e, portanto, há importação de energia da concessionária (cor laranja). Entre as 06:00-12:00 e 18:00-21:00 existe sobra (excesso) na geração.

B. Período de maior vento (Julho)

- Observa-se uma redução na geração da PCH e aumento da geração eólica (Figura 4.14).

- Os custos CMM, CET e CV@R são os mesmos ao do caso anterior (Caso 3A). Neste caso não existe intercâmbio e nem excesso na geração.

\subsubsection{MR ilhada constituída por um gerador diesel, a PCH, o gerador eólico e gerador solar (Caso 4)}

Neste caso foram analisados três cenários:
A. Período de maior chuva.
B. Período de maior vento.
C. Período mais ensolarado. 
A. Período de maior chuva (Dezembro)

- Neste caso (Figura 4.15), os respectivos custos foram: $C M M=R \$ 2.054,1 \times 10^{3}$, $\mathrm{CET}=\mathrm{R} \$ 93.588,1 \times 10^{3}$ e $\mathrm{CV} @ \mathrm{R}=\mathrm{R} \$ 4.444 .0 \times 10^{3}$.

- Por ser o período de maior chuva, a PCH contribue durante todo o dia gerando inclusive excesso de energia durante vários períodos ao longo do dia.

- O suporte pelo gerador diesel (cor rosa) ocorre entre 14:00-17:00 hr. Não existe déficit na geração, mas sim excesso no período 05:00-13:00. A geração solar contribue no período 06:00-16:00 hr.

B. Período de maior vento (Julho)

- Os custos CMM, CET e CV@R são os mesmos ao do caso anterior (Caso 4A). Neste caso não existe intercâmbio e nem excesso na geração.

- Devido à otimização da geração e dos custos envolvidos nesta, não existe contribuição do gerador diesel (Figura 4.16). Verifica-se que por se tratar do mês de meior vento o gerador eólico trabalha durante o dia todo.

- Devido às solicitações da carga neste mês, as três fontes de energia renováveis são suficientes para atender a carga.

C. Período mais ensolarado (Setembro)

- Os custos CMM, CET e CV@R são os mesmos ao do caso anterior (Caso 4A). Neste caso não existe intercâmbio, mas sim um leve excedente na geração entre 05:00-06:00 (Figura 4.17).

- A geração solar apresenta um valor levemente maior ao do caso anterior. Notase uma diminuição considerável na contribuição do gerador $\mathrm{PCH}$. Este gerador (PCH), por ser do tipo fio d'agua, depende diretamente dos câmbios de estação.

\subsubsection{Similar ao Caso 4, porém, conectada com a rede, com limite de exportação de 3,0 MW (Caso 5)}

Neste caso, além de ser imposto um limite de exportação (pelo excesso de geração) de 3,0 MW, foram analisados três cenários:
A. Período de maior chuva.
B. Período de maior vento.
C. Período mais ensolarado. 
A. Período de maior chuva (Dezembro)

- Neste caso (Figura 4.18), os respectivos custos foram: $C M M=R \$ 2.023,2 \times 10^{3}$, $\mathrm{CET}=\mathrm{R} \$ 92.142,2 \times 10^{3}$ e $\mathrm{CV} @ \mathrm{R}=\mathrm{R} \$ 4.444,0 \times 10^{3}$.

- De forma similar aos casos anteriores com maior chuva, a PCH contribue durante todo o dia. A geração excedentaria da $\mathrm{PCH}$, barras em cor azul acima da curva de carga, é exportada ao sistema (concessionária).

- Como o valor de exportação ao sistema está limitado a 3,0 MW, toda energia superior a este valor será catalogada como excesso na geração. É o que ocorre neste caso por volta das 07:00 hr.

- O suporte pelo gerador diesel (cor rosa), embora não significativo, ocorre entre 14:00-17:00 hr. Não existe déficit na geração. A geração solar contribue no período 06:00-16:00 hr.

B. Período de maior vento (Julho)

- Os custos CMM, CET e CV@R são os mesmos ao do caso anterior (Caso 5A). Neste caso não existe intercâmbio e nem excesso na geração.

- Verifica-se que o gerador eólico tem uma participação continua durante as 24 horas (Figura 4.19), desta forma otimizando a geração com o aproveitamento do vento neste mês. A participação do painel solar ocorre entre 06:00-16:00

C. Período mais ensolarado (Setembro)

- De forma análoga ao caso anterior, os custos CMM, CET e CV@R são os mesmos ao do Caso 5A.

- Apesar de ter sido considerado o mês com maior radiação solar, não é possível observar um acréscimo significativo da geração solar (Figura 4.20). Porém, o custo médio sazonal resultou maior aos dos casos $5 \mathrm{~A}$ e $5 \mathrm{~B}$, conforme mostrado na Tabela 4.7. 


\subsubsection{MR ilhada constituída por um gerador diesel, o gerador eólico, o painel solar, sem PCH (Caso 6)}

Neste caso foram analisados também dois cenários:
A. Período de maior vento.
B. Período mais ensolarado.

\section{A. Período de maior vento (Julho)}

- Neste caso (Figura 4.21), os respectivos custos foram: $C M M=R \$ 2.753,3 \times 10^{3}$, $\mathrm{CET}=\mathrm{R} \$ 125.084,3 \times 10^{3}$ e $\mathrm{CV} @ \mathrm{R}=\mathrm{R} \$ 4.624,3 \times 10^{3}$.

- Devido à desconexão da $\mathrm{PCH}$, a geração eólica assume o papel de geração básica na MR contribuindo praticamente durante todo o dia.

- O gerador diesel constitui-se na segunda fonte de maior participação. Por causa disso, conforme mencionado no primeiro item deste caso houve um aumento nos custos CMM, CET e CV@R.

B. Período mais ensolarado (Setembro)

- Os custos CMM, CET e CV@R são os mesmos ao do caso anterior (Caso 6A).

- Observa-se que a geração eólica ainda constitue-se na geração básica da MR (Figura 4.22). A participação do gerador diesel é também similar ao Caso 6A.

- Apesar de ser o mês mais ensolarado, o valor máximo da geração solar apresenta um valor ligeiramente maior ao caso anterior.

\subsubsection{MR ilhada constituída apenas pelo gerador eólico e painel solar (Caso 7)}

Este caso tem por objetivo observar especificamente a contribuição e custo de operação do gerador eólico e solar (sem PCH).
A. Período de maior vento.
B. Período de maior insolação. 
A. Período de maior vento (Julho)

- Neste caso (Figura 4.23), os custos foram: $C M M=R \$ 3.3 .690,4 \times 10^{3}, C E T=R \$$ $167.627,1 \times 10^{3}$ e $C V @ R=R \$ 6.325,7 \times 10^{3}$. Verifica-se que o gerador eólico tem uma participação continua durante as $24 \mathrm{hr}$ e o painel solar só entre 06:00-16:00.

- Pelo fato da MR estar alimentada apenas pelo gerador eólico e o painel solar, mantendo a carga nominal em 6,04 MW, estas fontes não são capazes de atender a carga. Na Figura 4.18 mostra-se de forma explicita o "déficit" na geração (cor cinza) que enfrenta a MR praticamente durante as $24 \mathrm{hrs}$.

- O déficit existente no sistema é o principal fator pelo qual os custos CMM, CET e CV@R aumentam consideravelmente.

- Embora não seja tão significativa, a taxa de crescimento da carga é outro fator que tem influência sobre os custos CMM e CET,. Em todos os casos rodados foi utilizada uma taxa de crescimento da carga igual a $3 \%$.

B. Período de maior insolação (Setembro)

- Apesar de ter sido considerado o mês com maior incidência solar, os resultados pertencentes ao CMM, CET e CV@R apresentam valores praticamente iguais aos do Caso 7A, isto porque estes custos são computados independentemente de se um mês é mais favorável a determinada fonte, mas sim de sua inclusão ou não na MR.

- A contribuição da geração solar ocorre entre 06:00-16:00 hr, conforme mostrado na Figura 4.24.

\subsubsection{MR alimentada exclusivamente pela rede elétrica (Caso 8)}

O principal objetivo deste caso é mostrar os custos CMM, CET e CV@R a serem obtidos quando apenas a concessionária supre de energia à carga da MR.

- Observa-se na Figura 4.25 que estes custos apresentam valores de $C M M=R \$$ $1.529,0 \times 10^{3}, \mathrm{CET}=\mathrm{R} \$ 69.255,1 \times 10^{3}$ e $\mathrm{CV} @ \mathrm{R}=\mathrm{R} \$ 1.673,7 \times 10^{3}$. Estes custos representam o quarto valor mais caro (vide Tabela 4.7).

- A potência contratada da concessionária pela MR é igual a 7,0 MW que garante o suprimento à carga nominal. Caso esta (potência contratada) for menor ao da 
carga haverá déficit na MR, aumentando assim os custos de interesse anteriormente mostrados.

Um resumo dos valores de CMM, CET, CV@R, apresentados anteriormente, além do Custo médio sazonal, está sendo mostrado na Tabela 4.7.

Tabela 4.7. Resumo dos custos CMM, CET, CV@R e custo médio sazonal.

\begin{tabular}{|c|c|c|c|c|c|c|c|}
\hline \multicolumn{2}{|c|}{ Caso } & \multicolumn{2}{|c|}{ Descrição } & \multirow{2}{*}{$\begin{array}{c}\begin{array}{c}\text { Custo } \\
\text { médio } \\
\text { sazonal }\end{array} \\
\left(10^{3} \mathrm{R} \$\right) \\
\mathrm{N} / \mathrm{A}\end{array}$} & \multirow{2}{*}{$\begin{array}{c}\begin{array}{c}\text { Custo } \\
\text { Esperado } \\
\text { Total } \\
\text { (CET) }\end{array} \\
\left(10^{3} \mathbf{R} \$\right) \\
196.814,3\end{array}$} & \multirow{2}{*}{$\begin{array}{c}\text { CV@R } \\
\left(10^{3} \mathbf{R} \$\right) \\
4.753,3\end{array}$} & \multirow{2}{*}{$\begin{array}{c}\begin{array}{c}\text { Custo } \\
\text { Médio } \\
\text { Mensal } \\
(\mathrm{CMM})\end{array} \\
\left(10^{3} \mathrm{R} \$\right) \\
4.345,7\end{array}$} \\
\hline 1 & & Diesel & $\mathrm{N} / \mathrm{A}$ & & & & \\
\hline \multirow{2}{*}{2} & $A$ & Diesel+PCH+Eólica+ & Maior chuva & $1.418,9$ & \multirow{2}{*}{$74.388,3$} & \multirow{2}{*}{$2.483,8$} & \multirow{2}{*}{$1.632,3$} \\
\hline & $\mathrm{B}$ & concessionária & Maior vento & 1422,2 & & & \\
\hline \multirow{2}{*}{3} & A & PCH+Eólica+ & Maior chuva & 1420,2 & \multirow{2}{*}{$77.072,9$} & \multirow{2}{*}{$3.107,8$} & \multirow{2}{*}{$1.692,4$} \\
\hline & $\mathrm{B}$ & concessionária & Maior vento & 1422.2 & & & \\
\hline \multirow{3}{*}{4} & $A$ & & Maior chuva & 1477,7 & \multirow{3}{*}{$93.588,1$} & \multirow{3}{*}{$4.444,0$} & \multirow{3}{*}{$2.054,1$} \\
\hline & $\mathrm{B}$ & Diesel+PCH+Eolico+S & Maior vento & 1479,0 & & & \\
\hline & $\mathrm{C}$ & & Mais ensolarado & 1413,5 & & & \\
\hline \multirow{3}{*}{5} & A & & Maior chuva & 1384,9 & \multirow{3}{*}{$92.142,2$} & \multirow{3}{*}{$4.444,0$} & \multirow{3}{*}{$2.023,2$} \\
\hline & $\mathrm{B}$ & Diesel+PCH+Eólico+S & Maior vento & 1444,4 & & & \\
\hline & $\mathrm{C}$ & & Mais ensolarado & 1310,4 & & & \\
\hline \multirow{2}{*}{6} & $\mathrm{~A}$ & Diesel_Fólico+Solar & Maior vento & 1740,0 & \multirow{2}{*}{$125.084,3$} & \multirow{2}{*}{$4.624,3$} & \multirow{2}{*}{$2.753,3$} \\
\hline & $\mathrm{B}$ & Diesel+Eolico+Solar & Mais ensolarado & 1286,4 & & & \\
\hline \multirow{2}{*}{7} & A & Fólico+Solar (ilhado) & Maior vento & 2263,2 & \multirow{2}{*}{$167.627,1$} & \multirow{2}{*}{$6.325,7$} & \multirow{2}{*}{$3.690,4$} \\
\hline & $\mathrm{B}$ & Eollco+solar (IInado) & Mais ensolarado & 1624,3 & & & \\
\hline 8 & & Concessionária & $\mathrm{N} / \mathrm{A}$ & $\mathrm{N} / \mathrm{A}$ & $69.255,1$ & $1.673,7$ & $1.529,0$ \\
\hline
\end{tabular}

De forma resumida pode-se estabeler que:

- Quando a MR está sendo suprida exclusivamente pelo gerador diesel ou pela concessionária (Caso 1 e Caso 8), o custo médio sazonal, que representa o valor médio de um determinado mês ao longo dos cinco anos de projeção dos custos, independe da sazonalidade e/ou condição climática. Daí que na Tabela 4.7 este custo é preenchido como N/A.

- O custo médio sazonal será diferente para cada caso analizado, isto porque o mesmo é calculado considerando um determinado mês na base de dados e suas características sazonais (mês com maior chuva, vento ou sol).

- O primeiro valor mais caro em termos de CET e CMM ocorre no Caso 1, quando a MR está alimentada apenas pelo gerador diesel. Isto devido ao preço do combustível 
considerado no programa. Pode-se assim dizer que este cenário é proporcional ao valor do custo do combustível.

- O segundo valor mais caro em termos de CET e CMM, assim como o custo médio sazonal, ocorrem no Caso 7, quando existe déficit na MR. Isto por causa da valoração (punição se cabe o termo) à falta de energia no lado da carga (vide opção Preço de déficit $=2.000 \mathrm{R} \$ / \mathrm{MWh}$ nos resultados apresentados).

- A participação das fontes renováveis na MR impõe valores de custo relativamente menores aos casos anteriores, isto porque com a utilização destas fontes (renováveis) o valor de combustível destas é praticamente nulo.

- O Caso 8, MR alimentada exclusivamente pela concessionária, apresenta valores de custo menores aos anteriormente mencionados, isto devido a que o valor de risco condicional com a concessionária é menor.

- Em um teste adicional foi aumentado o valor da carga em 10\% (crescimento da carga) ao Caso 1, mantendo o valor da capacidade do gerador diesel. Observou-se um aumento proporcional nos valores de CMM, CET, CV@R e custo sazonal. Isto porque a MR apresentou um déficit na geração, o que levou ao aumento destes custos.

- Similar teste adicional foi aplicado ao Caso 4 (diesel+PCH+eólico+solar) com um acréscimo na carga de 10\%. Com a adição de uma fonte renovável com esta mesma ordem de grandeza, os custos anteriormente referidos mostraram menores acréscimos, devido aos cenários de menor déficit presentes neste caso.

- Em resumo, quando a MR opera com fontes de geração alternativas os custos avaliados nesta seção resultaram relativamente menores comparados aos casos quando esta (MR) era alimentada exclusivamente pelo gerador diesel, o que mostra a vantagem em termos de custo destas fontes (alternativas) em relação ao uso do gerador diesel. 

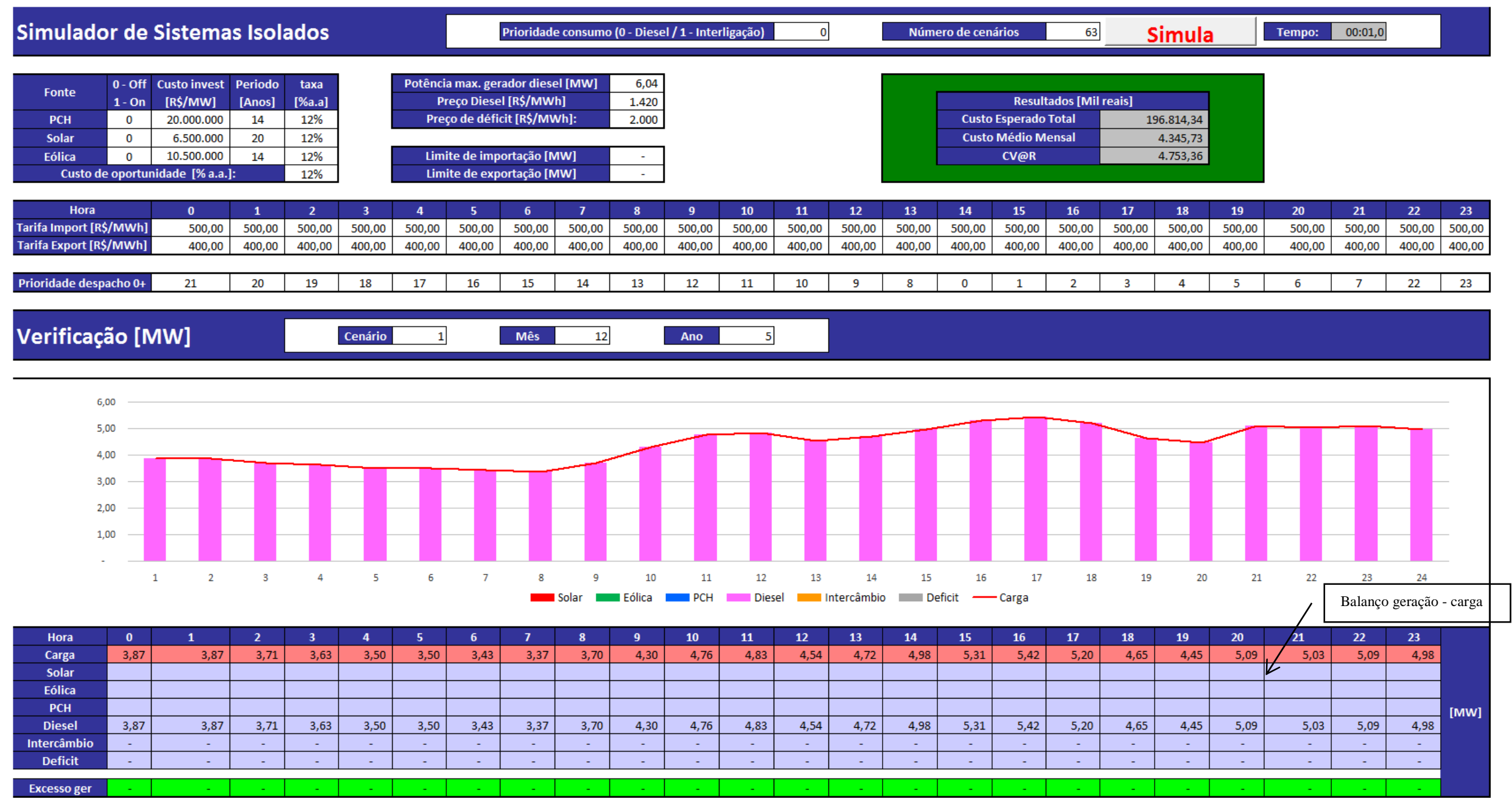

Figura 4.10. Tela principal mostrando a saída da simulação para o Caso 1. 

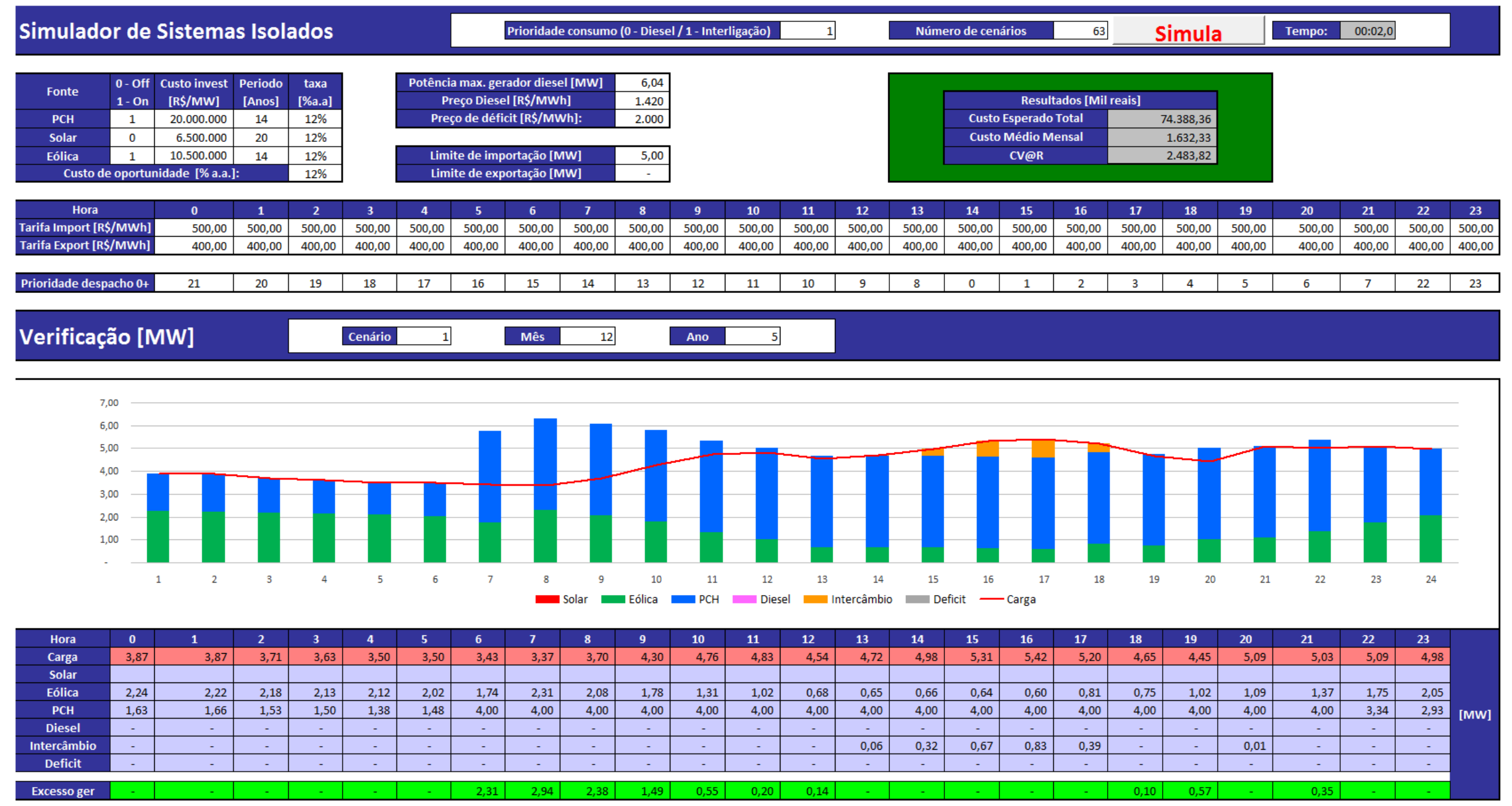

Figura 4.11. Tela principal mostrando a saída da simulação para o Caso 2A. 

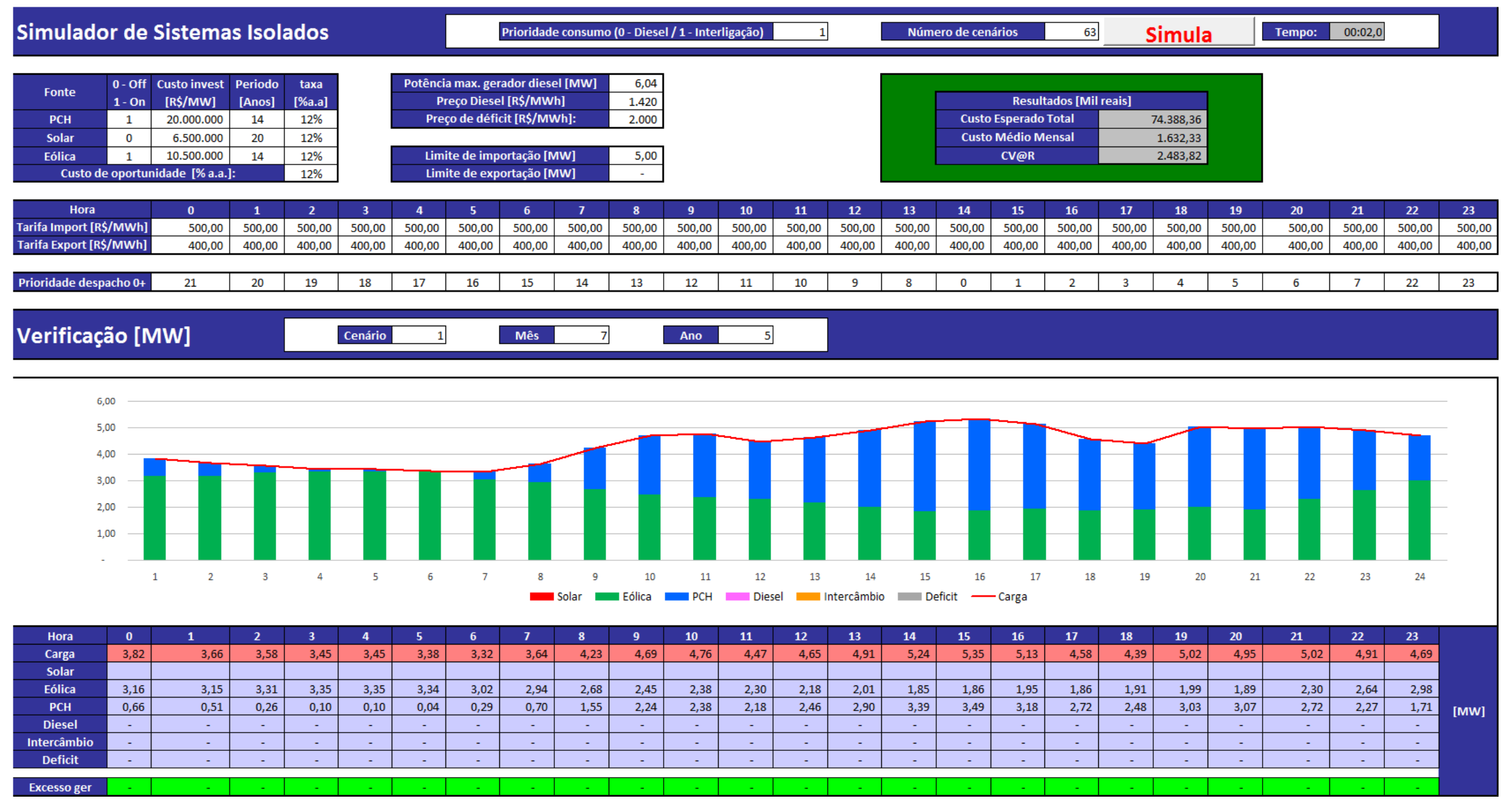

Figura 4.12. Tela principal mostrando a saída da simulação para o Caso 2B. 

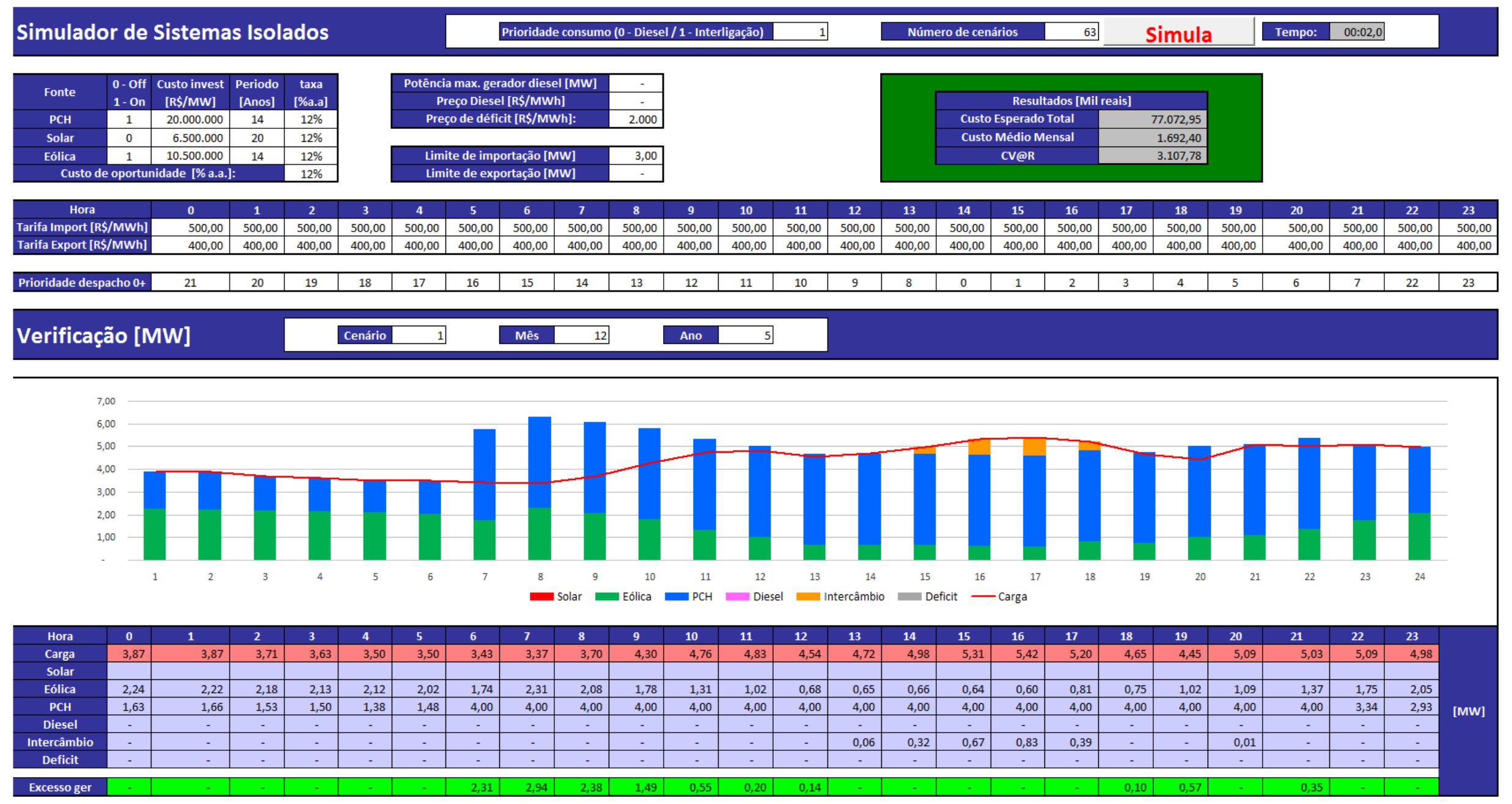

Figura 4.13. Tela principal mostrando a saída da simulação para o Caso 3A. 

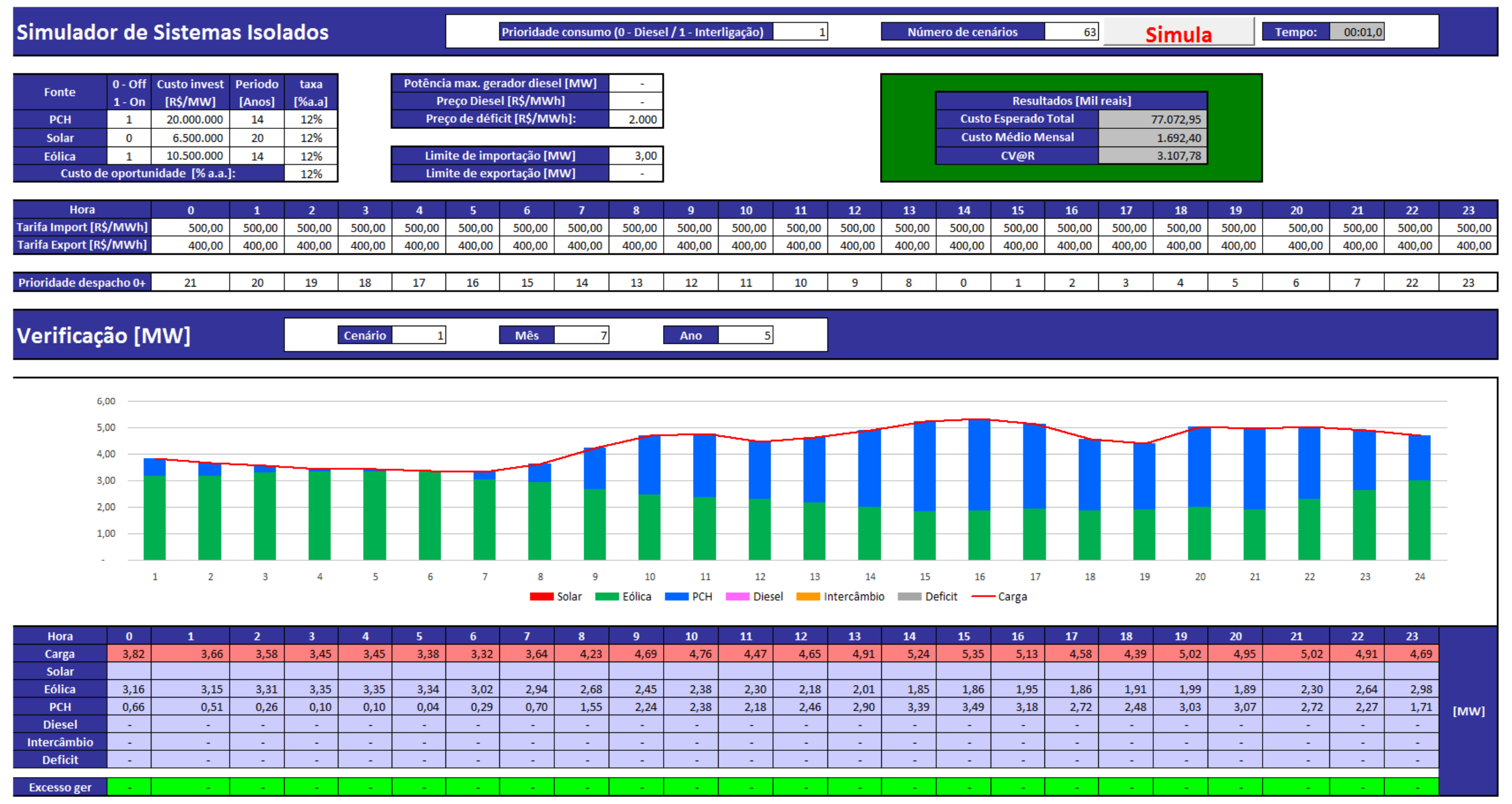

Figura 4.14. Tela principal mostrando a saída da simulação para o Caso 3B. 

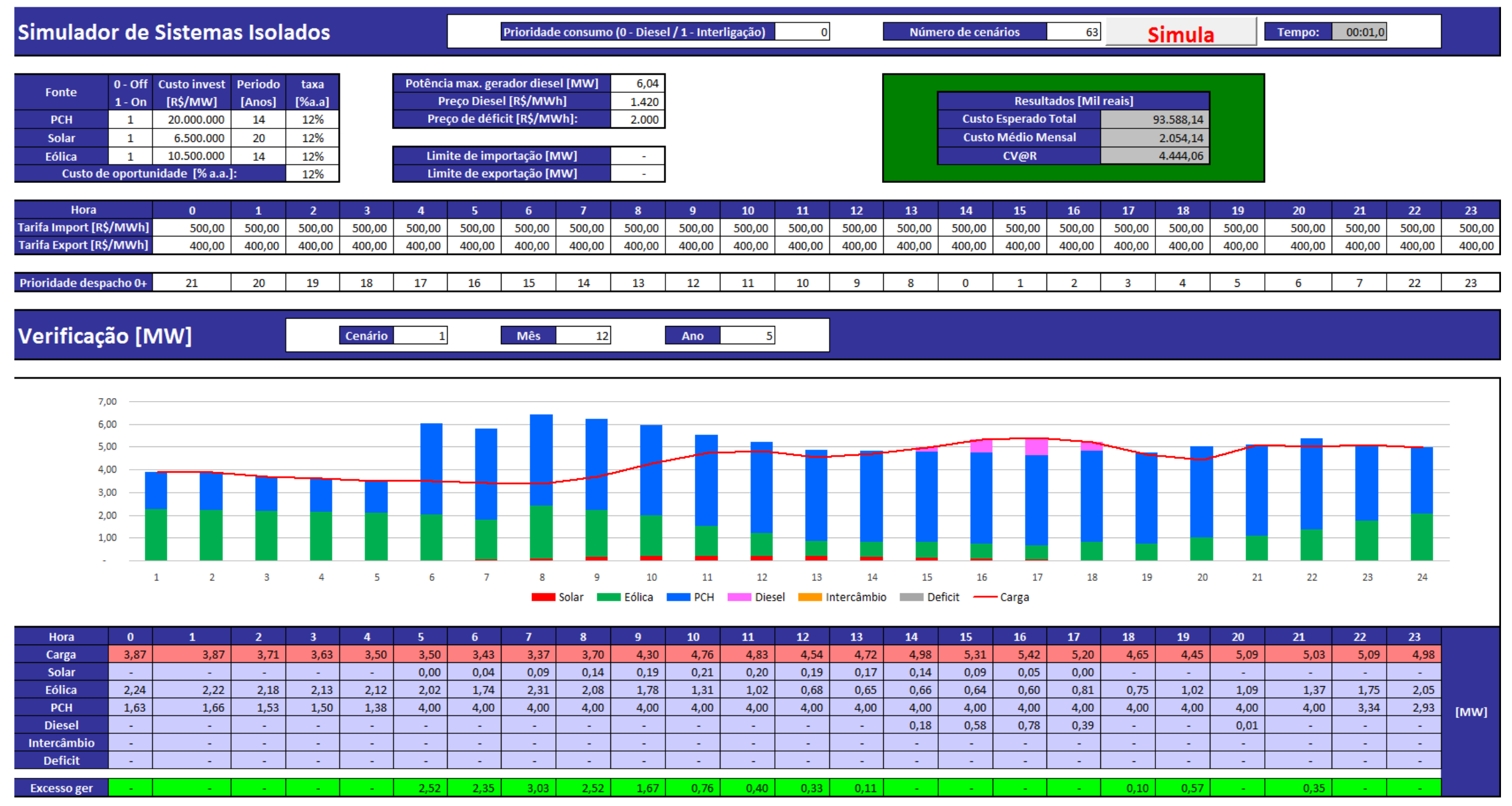

Figura 4.15. Tela principal mostrando a saída da simulação para o Caso 4A. 

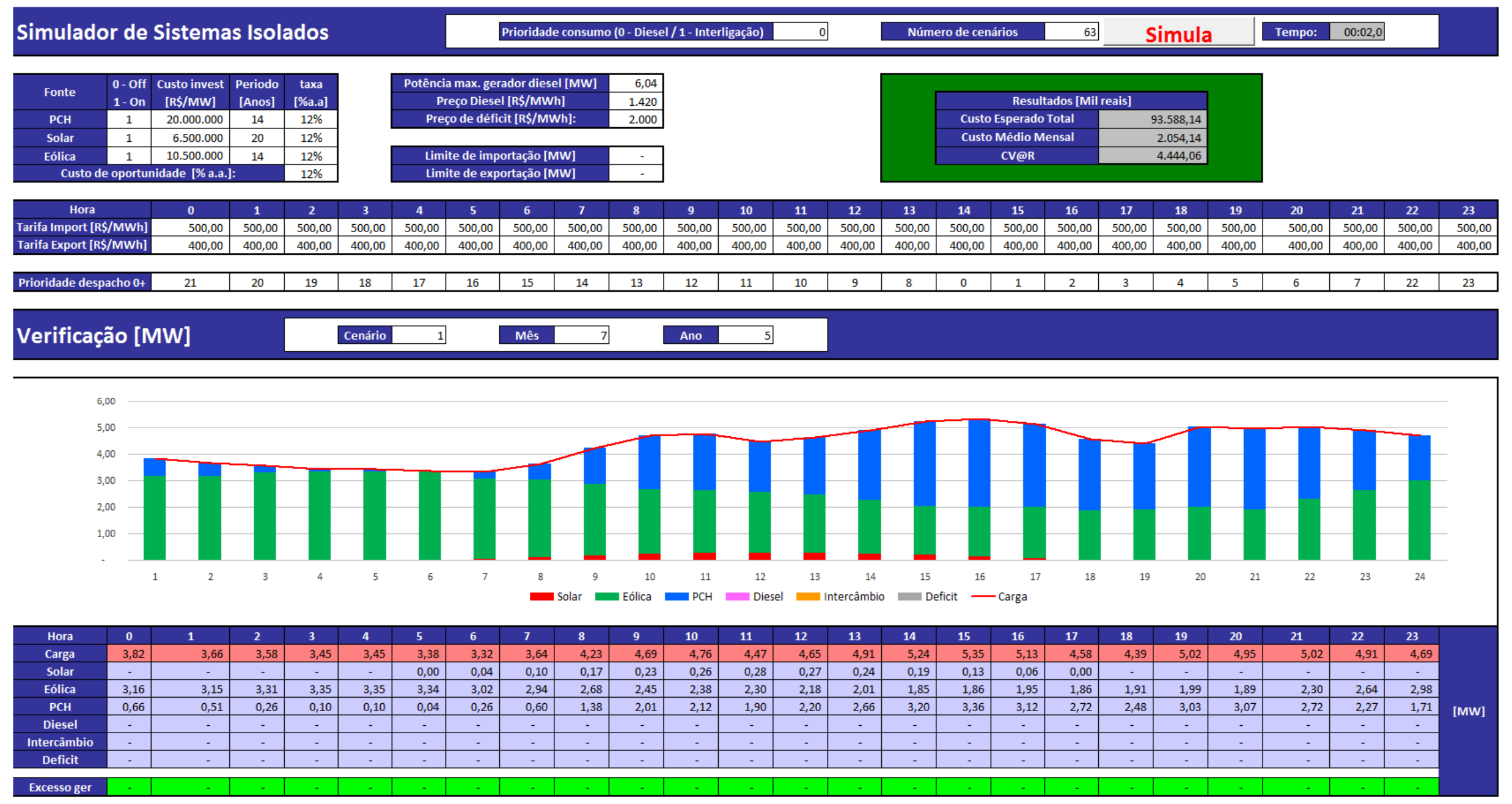

Figura 4.16. Tela principal mostrando a saída da simulação para o Caso 4B. 

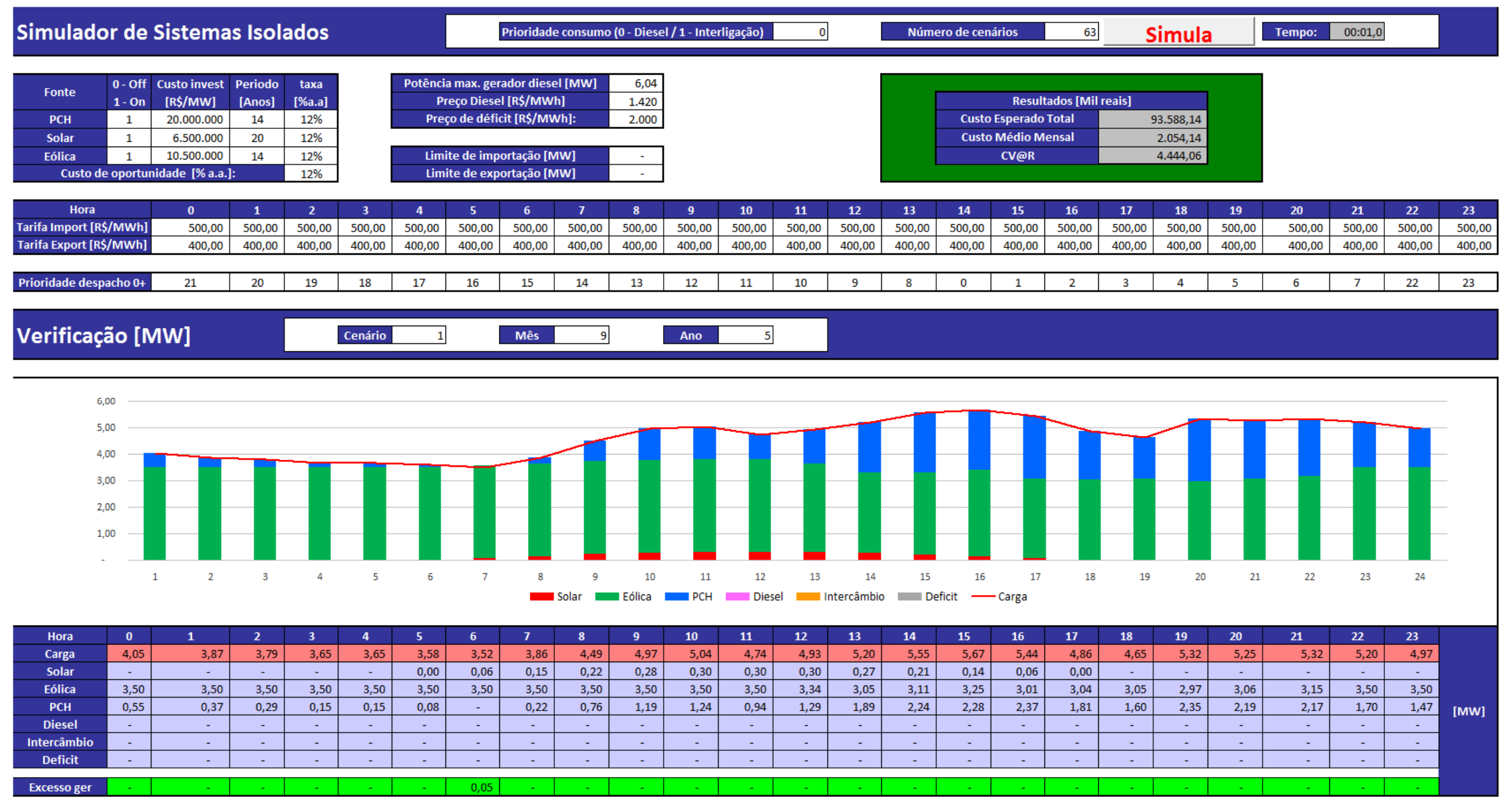

Figura 4.17. Tela principal mostrando a saída da simulação para o Caso 4C. 

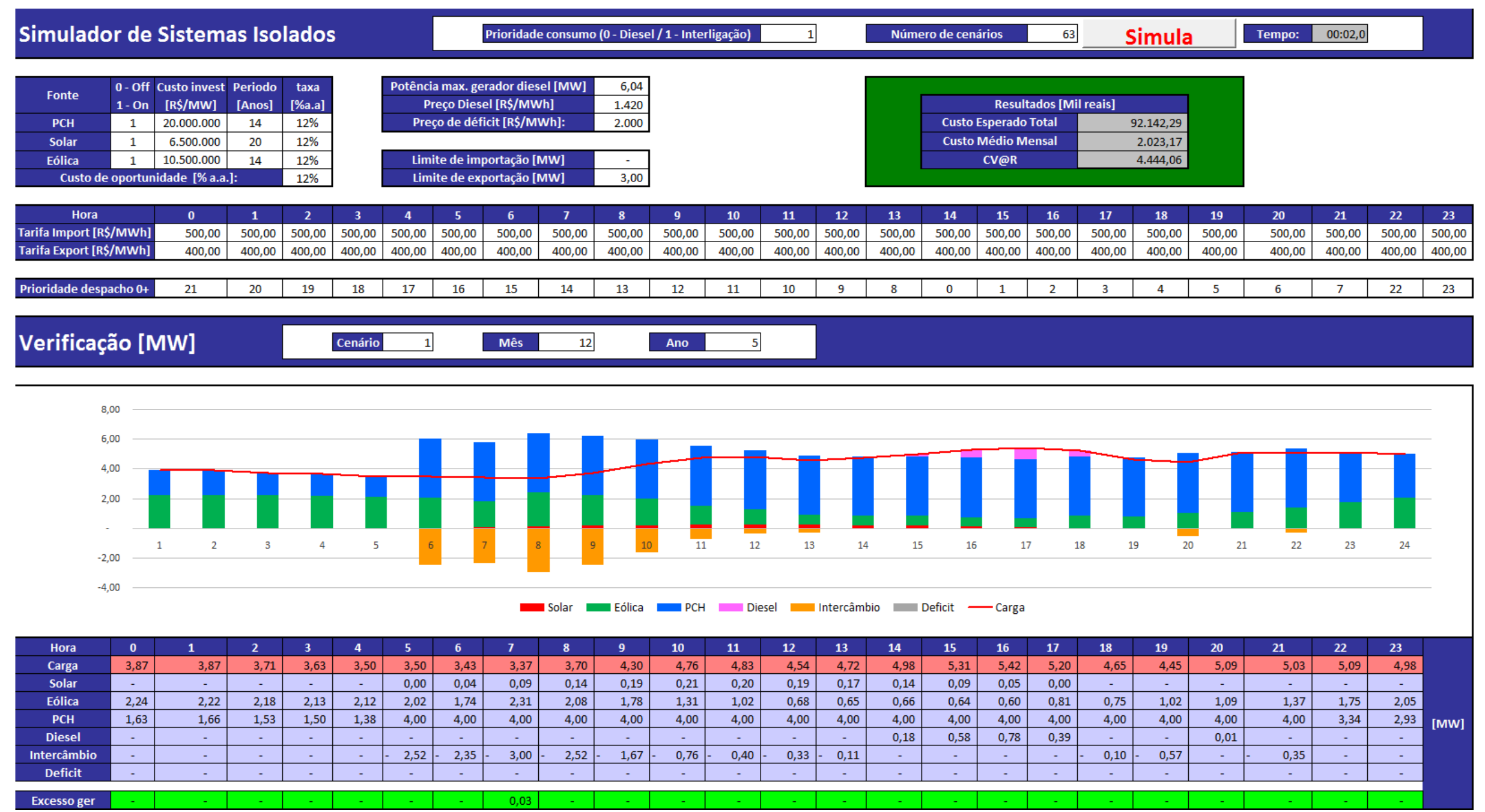

Figura 4.18. Tela principal mostrando a saída da simulação para o Caso 5A. 

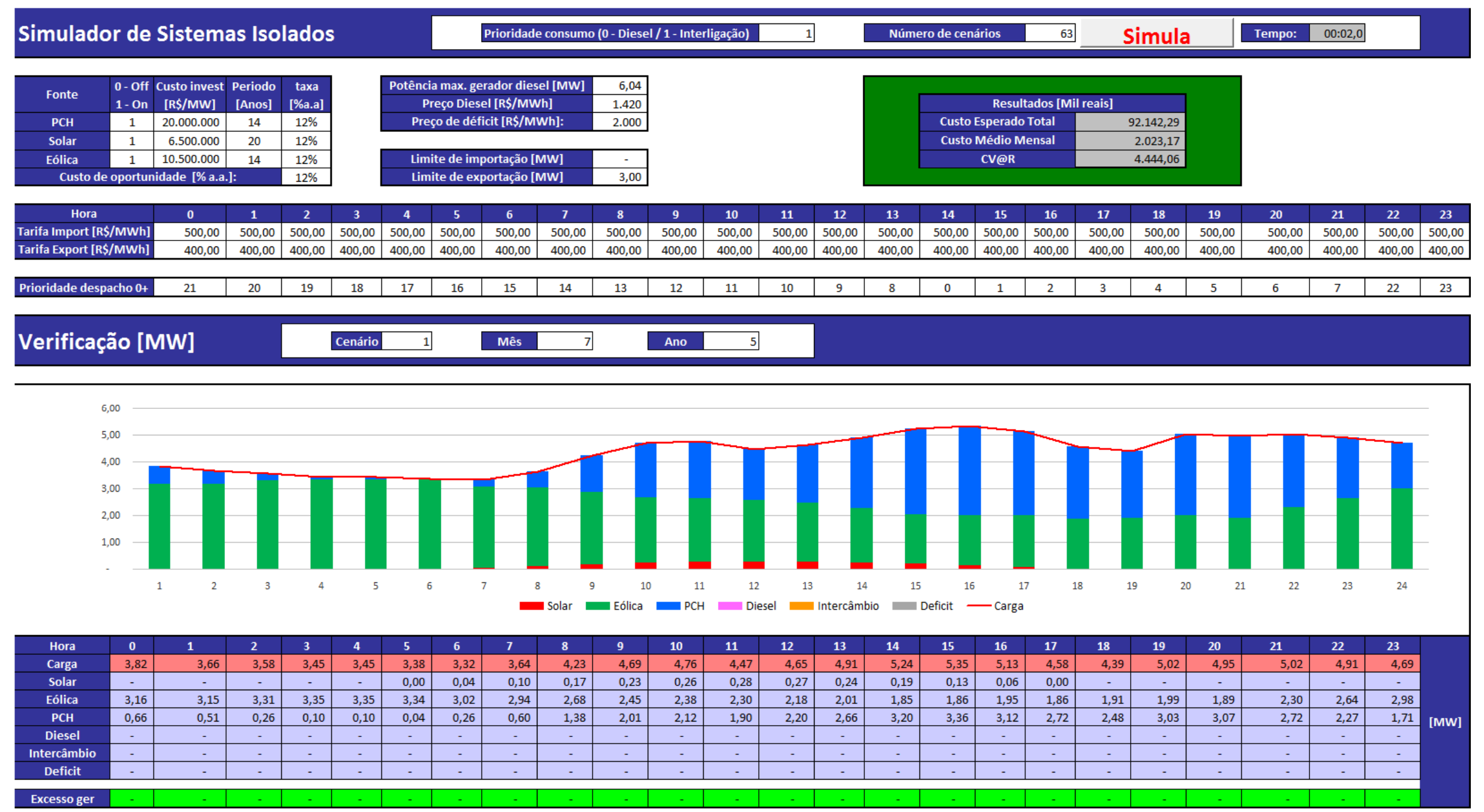

Figura 4.19. Tela principal mostrando a saída da simulação para o Caso 5B. 


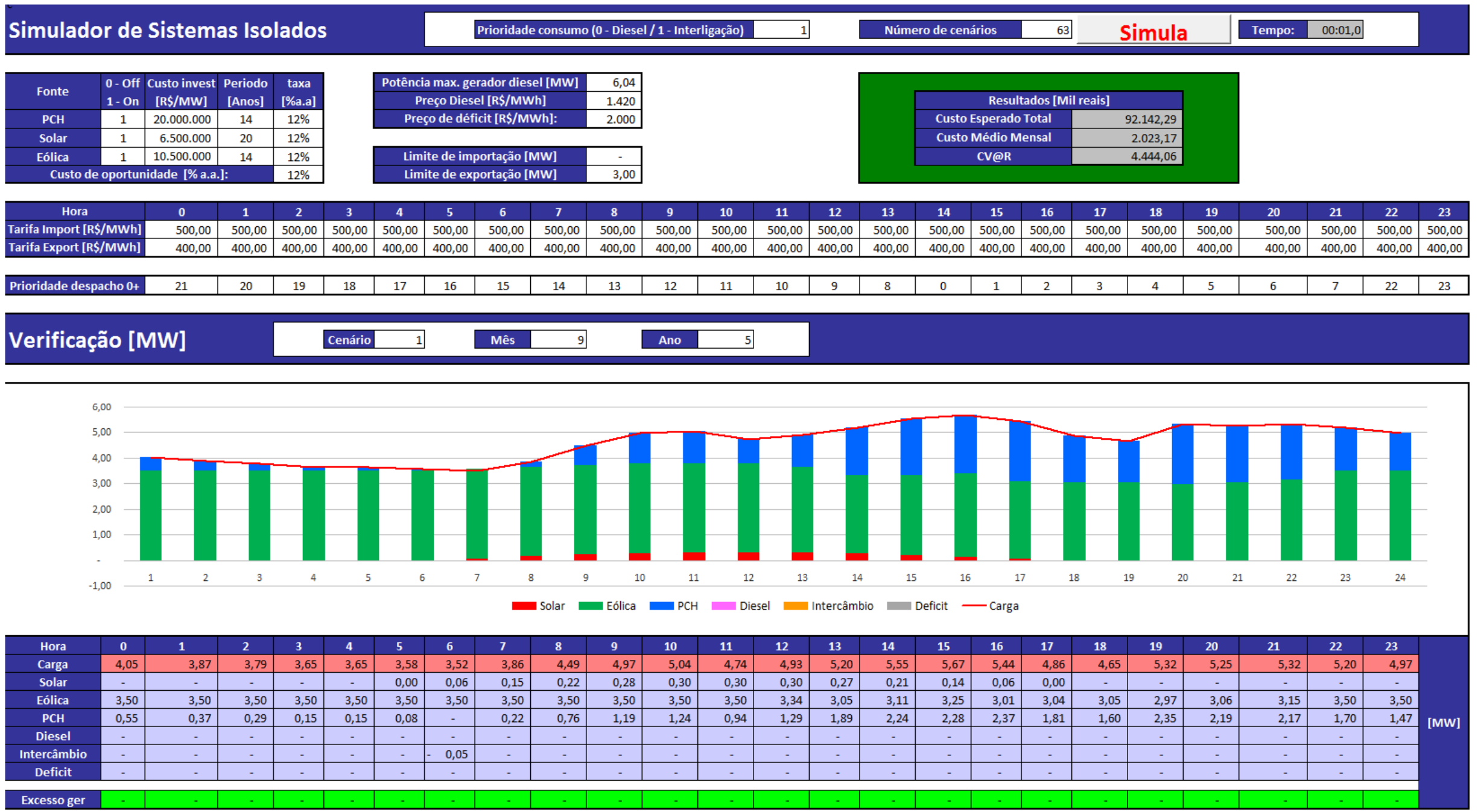

Figura 4.20. Tela principal mostrando a saída da simulação para o Caso 5C. 


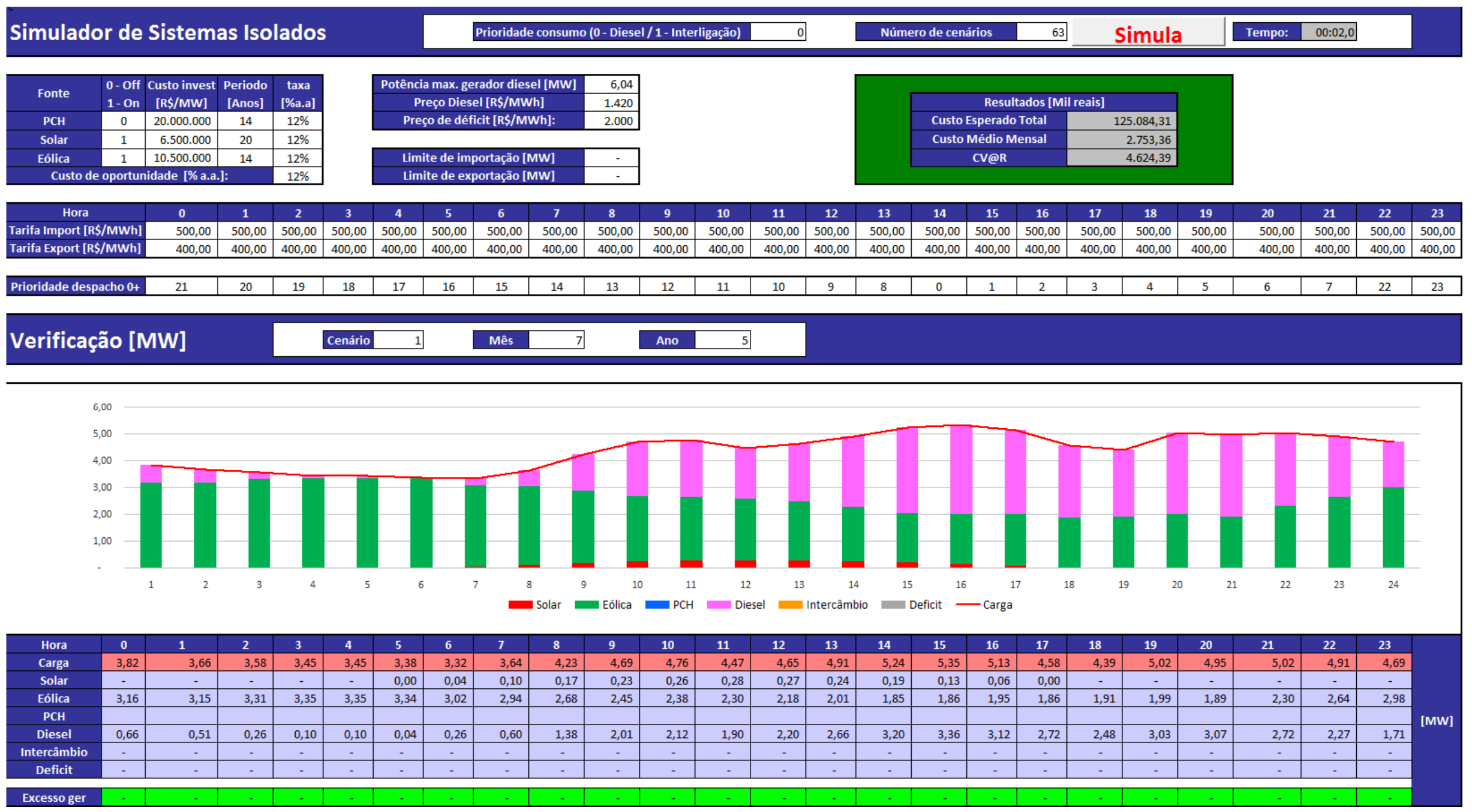

Figura 4.21. Tela principal mostrando a saída da simulação para o Caso 6A. 


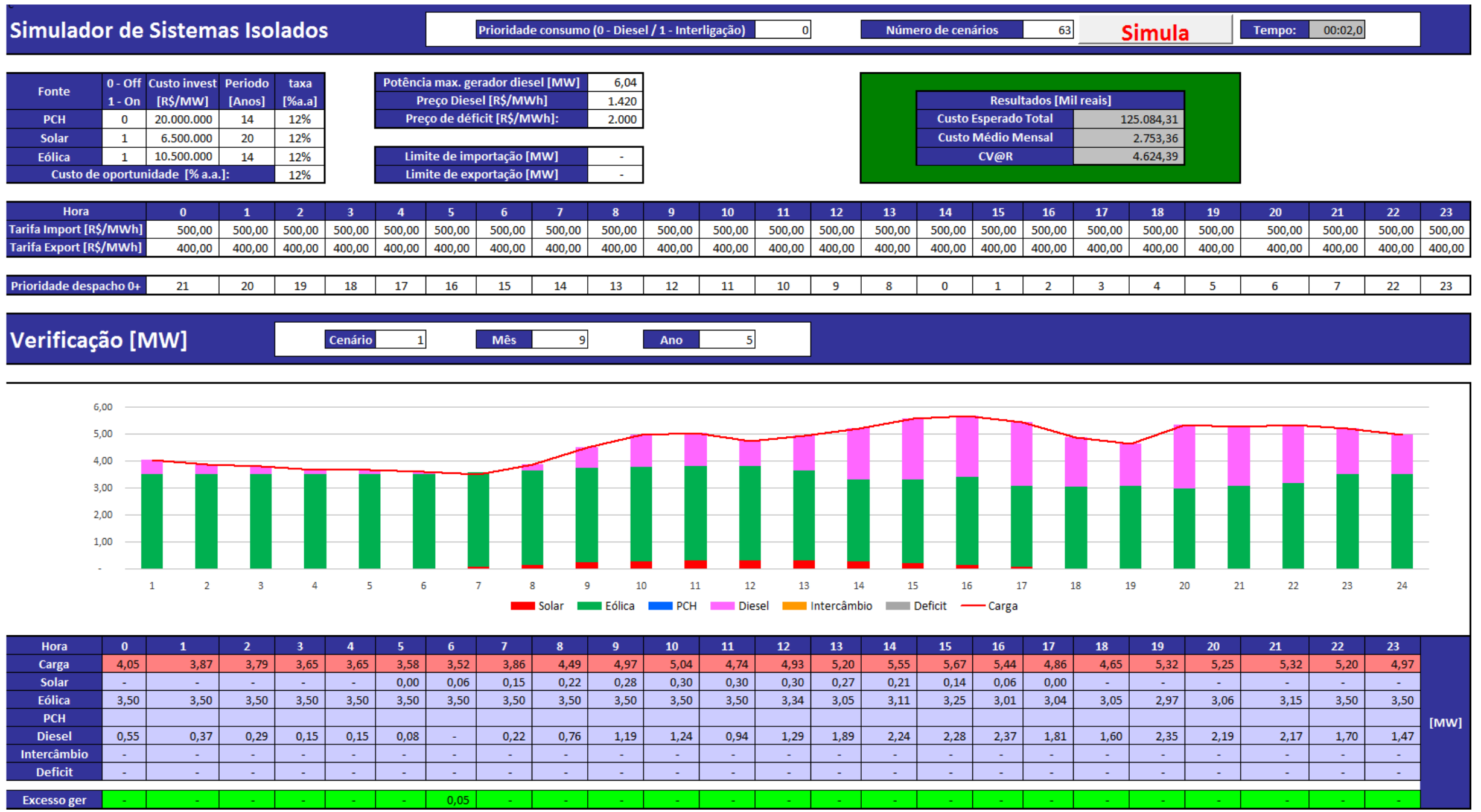

Figura 4.22. Tela principal mostrando a saída da simulação para o Caso 6B. 

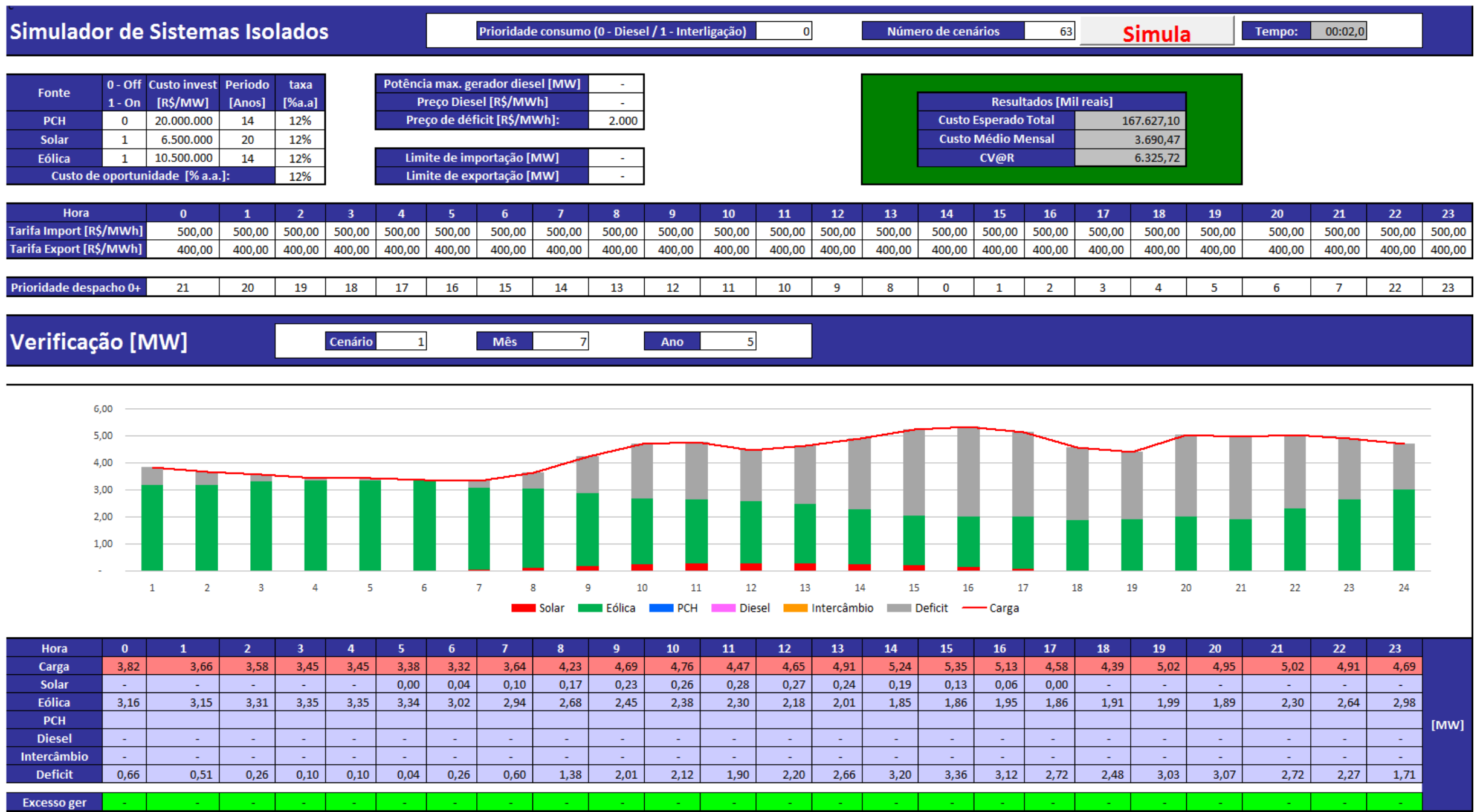

Figura 4.23. Tela principal mostrando a saída da simulação para o Caso 7A. 

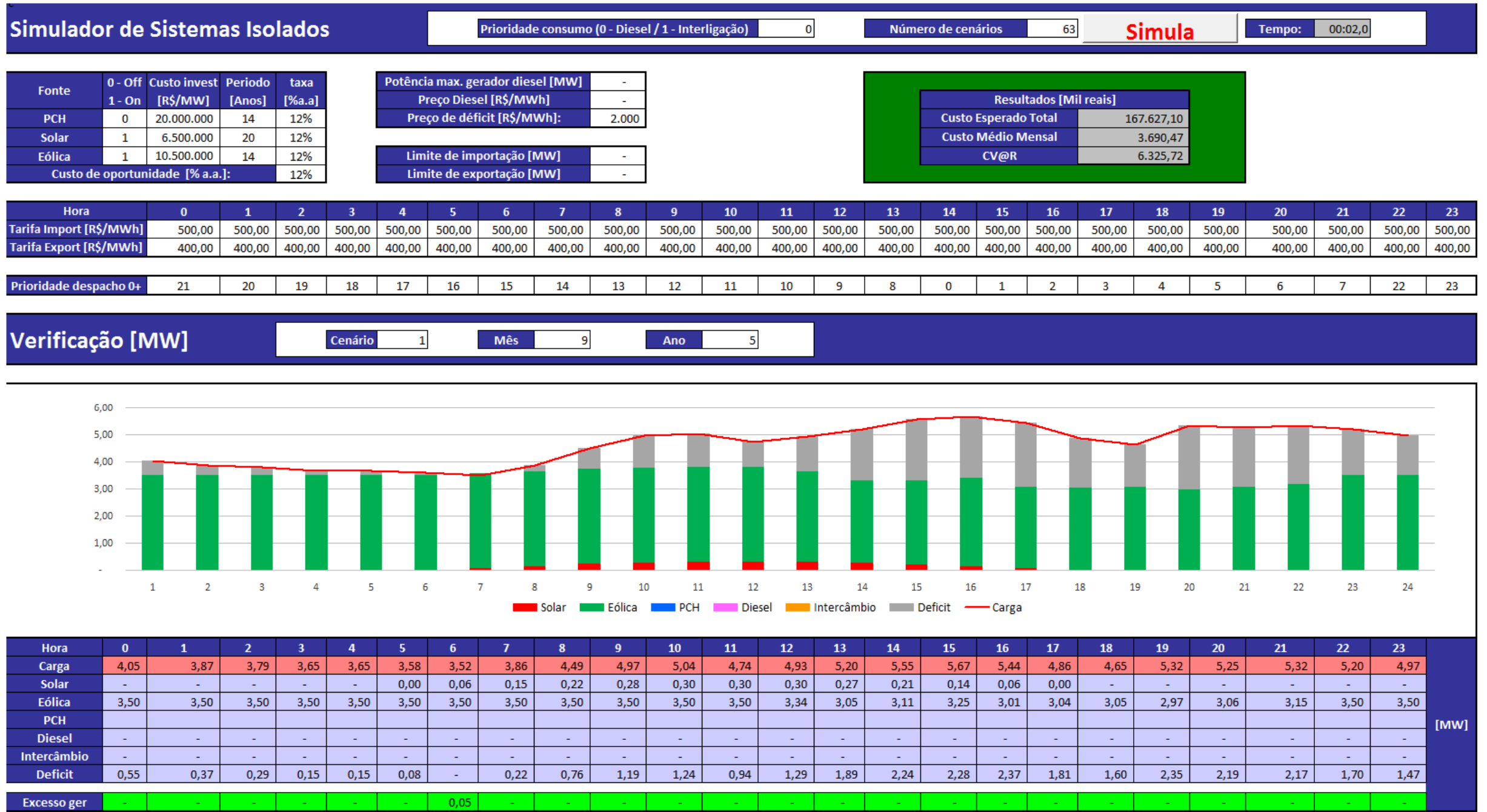

Figura 4.24. Tela principal mostrando a saída da simulação para o Caso 7B. 

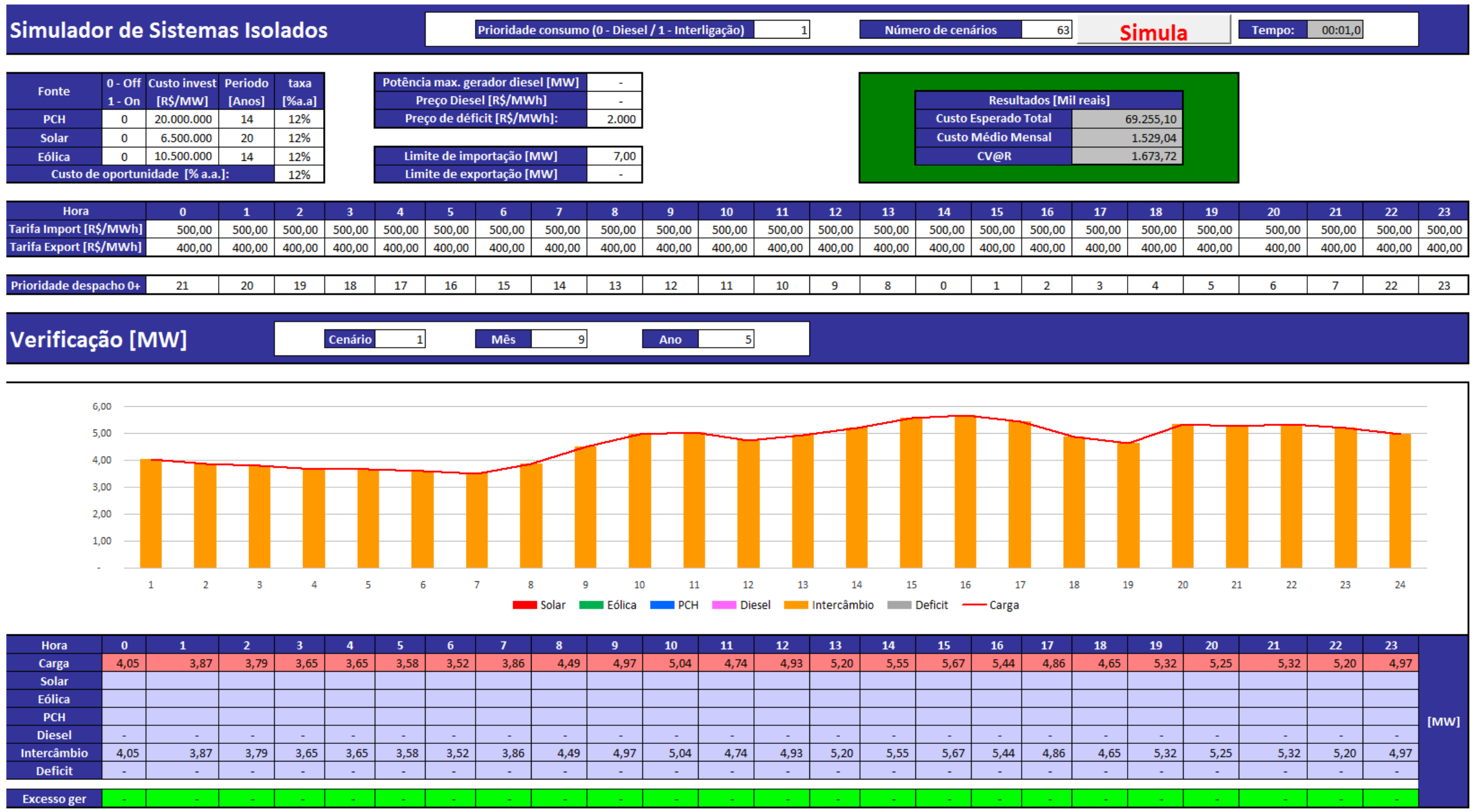

Figura 4.25. Tela principal mostrando a saída da simulação para o Caso 8. 


\subsubsection{Portfólio Ótimo (Caso Exemplo)}

Para determinar a melhor configuração de investimento possível entre as fontes alternativas consideradas, minimizando o custo e atendendo aos critérios de risco especificados, foi simulada, no programa anteriormente mencionado, a análise de otimização (via Algoritmos Genéticos), sendo que para o processamento de um cenário deve ser informado o valor limite da métrica de risco utilizada, o que, nesse caso, é representado pelo valor "limite" de CV@R.

A título de exemplo, apresentam-se a seguir os resultados correspondentes ao Caso 4 cujo CV@R, conforme mostrado na Tabela 4.7, era igual a $\mathrm{R} \$ 4.444,0 \times 10^{3}$. Pode-se observar (Tabela 4.8) que para diminuir (otimizar) os custos CET, CMM e CV@R, o algoritmo sugere manter as potências especificadas do gerador eólico e solar; porém, a potência da $\mathrm{PCH}$ poderia ser reduzida de $4 \mathrm{MW}$ para 3,89 MW sem comprometer o atendimento à carga. Observa-se também que os custos tiveram uma redução, embora leve, em relação aos custos apresentados na Tabela 4.7.

Tabela 4.8. Melhor configuração encontrada via Algorítmos Genéticos (Caso 4)

\begin{tabular}{|c|r|r|r|r|r|r|}
\hline \multirow{2}{*}{ Resultado ótimo } & \multicolumn{1}{|c|}{ Solar Pot } & \multicolumn{1}{c|}{ Eol Pot } & \multicolumn{1}{c|}{ PCH Pot } & \multicolumn{1}{c|}{$\begin{array}{c}\text { Custo } \\
\text { Total }\end{array}$} & $\begin{array}{c}\text { Custo médio } \\
\text { mensal }\end{array}$ & CVAR \\
\cline { 2 - 7 } & 0,30 & 3,50 & 3,89 & $93.562,83$ & $2.053,81$ & $4.443,00$ \\
\hline
\end{tabular}

Caso as capacidades das fontes alternativas fossem maiores às informadas na Tabela 4.6, com folga para atender à carga, o programa pode, além de escolher o "menor" custo e otimizar o CV@R, sugerir qual das fontes poderia ser reduzida na sua capacidade ou ainda ser dispensada. Para isso, foi considerado o CV@R do Caso 1 mostrado na Tabela 4.7 (só diesel, pior caso) igual a $R \$ 4.753,36 \times 10^{3}$. Com isso se garante que o otimizador não irá escolher casos menos custosos que possuam CV@R pior ao Caso 1. Em seguida, são especficadas as potências máximas das três fontes alternativas no sistema, neste caso igual a 8,00 MW, conforme mostrado na Tabela 4.9.

Observa-se (Tabela 4.9) que há uma redução nos custos CET, CMM e CV@R em relação ao Caso 4 que também prevê a utilização dos geradores eólico, solar e PCH. Para reduzir estes custos o programa de otimização propõe mudar a potência do gerador eólico para 4,86 MW, do solar para 3,95 MW e da $\mathrm{PCH}$ diminuir para 1,95 MW; sendo esta a melhor configuração encontrada pelo programa. 
Tabela 4.9. Melhor configuração encontrada via Algorítmos Genéticos (caso otimizado)

\begin{tabular}{|c|r|r|}
\hline \multicolumn{3}{|c|}{ Parâmetros } \\
\hline Limites Potência [MW] & Min & Max \\
\hline PCH & - & 8,00 \\
\hline Solar & - & 8,00 \\
\hline Eolica & - & 8,00 \\
\hline
\end{tabular}

\begin{tabular}{|c|c|c|c|c|c|c|}
\hline Tempo & $11: 11,0$ & & \multicolumn{2}{|c|}{ Cvar aceitavel [mil reais] } & \multicolumn{2}{|l|}{$4.753,00$} \\
\hline \multicolumn{7}{|c|}{ Melhor configuração encontrada } \\
\hline Resultado Ótimo & Solar Pot & Eol Pot & PCH Pot & $\begin{array}{l}\text { Custo } \\
\text { Total }\end{array}$ & $\begin{array}{c}\text { Custo médio } \\
\text { mensal }\end{array}$ & CVAR \\
\hline & 3,95 & 4,86 & 1,95 & $85.616,02$ & $1.879,23$ & $3.840,20$ \\
\hline
\end{tabular}

A aplicação desta ferramenta seria útil, por exemplo, em casos em que um stakeholder disponha de capital, conheça sua provável carga e, através do suprimento exclusivamente com gerador diesel a esta carga, conheça também seu CV@R, precisando fazer uma tomada de decisão sobre os tipos de fontes alternativas (incluindo suas capacidades) poderia investir, de forma a manter o gerador diesel apenas como "back-up", reduzindo em muito os custos operacionais da micro-rede.

Por outro lado, face à análise econômica apresentada neste capítulo, existe a necessidade de se realizar também um estudo técnico de MRs, pois a viabilidade de qualquer projeto envolve, e tem que satisfazer, ambos os estudos. A viabilidade econômica mede a conveniência geral do projeto em termos financeiros, enquanto que a análise técnica é normalmente insensível ao valor econômico do projeto.

Daí que no Capítulo 5 (próximo) apresentam-se as respostas dos geradores na MR diante de diversas perturbações que estes possam enfrentar durante sua operação. Durante este estudo (técnico), é muito importante observar se a rede restabelece sua condição normal, sem corte de carga, depois que a perturbação seja removida. Isto indica que, na sua concepção e posterior aprimoramento, o projeto é tecnicamente robusto. 


\section{CAPÍTULO 5}

\section{DIMENSIONAMENTO DE MICRO-REDES: ESTUDOS ELÉTRICOS}

\subsection{Introdução}

Neste capítulo serão apresentados os resultados das simulações realizadas com uma microrede elétrica nos vários modos de operação, especificamente quando a mesma está conectada com a concessionária e quando está ilhada desta. No caso do ilhamento da concessionária, serão apresentados os resultados do modo de ilhamento intencional (préplanejado) e ilhamento forçado, a fim de observar o desempenho dinâmico da micro-rede.

Objetiva-se também contribuir com as respostas que os geradores ofereceriam à micro-rede diante de condições críticas como a conexão inesperada de cargas (fora das programadas) na MR. Na maioria das referencias consultadas não são discutidas estas dificuldades. Além disso, com as respostas das simulações apresentadas pretende-se responder parte das questões levantadas pelo Departamento de Energia (DoE - Department of Energy) dos Estados Unidos referentes a problemas de sobrecarga e sub-freqüência em micro-redes elétricas, conforme estabelecidos em [83].

\subsection{Principais Conceitos Vinculados ao Controle de Aerogeradores}

Considera-se relevante, antes de se apresentar os casos de simulação da micro-rede, fazer uma revisão sucinta dos principais conceitos implicados nesta tecnologia. Entre os tipos de geração considerados estão: a geração eólica, um gerador diesel e uma pequena central hidrelétrica $(\mathrm{PCH})$. Nos dois primeiros tipos de geração é comum o uso de geradores de tipo síncrono e assíncrono. Já no terceiro tipo de geração tem sido comumente uilizados geradores síncronos. As diferenças e vantagens entre ambos os tipos de geradores (síncrono e assíncrono) estão bem estabelecidas além de serem facilmente encontradas na literatura.

\subsubsection{Métodos de Controle de Potência}

Uma das principais preocupações no caso dos aerogeradores refere-se ao controle da potência e proteção do aerogerador em situações de vento forte. Frente a esse problema tem sido proposto controles como o do stall, controle do pitch, e a combinação 
simultânea de ambos. Mediante estes tipos de controle "externo" modifica-se a velocidade de incidência do fluído (ár) impactando nas pás e, consequentemente na potência de saída do gerador. Estes tipos de controle serão descritos logo a seguir.

$\mathrm{Na}$ atualidade, o controle direto da potência mais utilizado em geradores assíncronos e que será utilizado em um dos exemplos de micro-rede utilizados, é feito através de conversores back-to-back, de pequena capacidade, conectados em paralelo com o rotor do gerador. Geradores controlados desta forma são chamados de DFIG (Doubly Fed Induction Generator) ou gerador de indução duplamente alimentado. Existem outras topologias de controle envolvendo conversores e arranjos especiais, como por exemplo: o gerador eólico com velocidade constante (fixed-speed wind turbine scheme), 0 gerador eólico com deslizamento variável (variable-slip wind turbine scheme), e a topologia do gerador eólico acoplado via conversor back-to-back de forma direta (full converter wind turbine scheme). Informações sobre estes arranjos de geração eólica, não utilizados neste trabalho, podem ser concontrados em [84].

Turbinas eólicas de tamanho relativamente pequeno, por exemplo, $80 \mathrm{~kW}$, têm em média velocidades de ingresso (cut-in speed), que é quando a turbina eólica começa a gerar energia, próximas a $4 \mathrm{~m} / \mathrm{s}$; velocidade nominal do vento (rated wind speed) que é quando a turbina atinge a sua potência nominal, de $13 \mathrm{~m} / \mathrm{s}$; e uma velocidade de corte (cut-out speed) que é quando a turbina é desligada do sistema, de aproximadamente 25 $\mathrm{m} / \mathrm{s}$.

\subsubsection{Controle do Stall}

No modo de controle da potência pelo stall, as pás são montados no rotor com um ângulo fixo, mas são projetadas de tal forma que as próprias turbulências criadas num lado da pá se comportem como freios (efeito stall) em situações de vento forte. Assim, as pás são as responsáveis pela redução da geração e eficiência durantes estas condições de operação (vento forte). Na Figura 5.1, está sendo ilustrada a condição de stall presente numa asa de aeroplano, assim como o ângulo de ataque para a sustentação. No caso das pás dos aerogeradores este efeito seria similar.

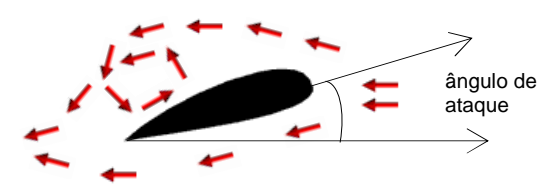

Figura 5.1. Efeito de freio (stall) devido à turbulência criada na própria pá. 


\subsubsection{Controle pelo Efeito Pitch}

O termo pitching se refere ao ato de girar as pás do rotor alguns graus em torno de seu eixo longitudinal, isto é feito a fim de também proteger a turbina durante ventos intensos ou para capturar a energia do vento de forma mais eficiente. O controlador do pitch faz com que a turbina opere com uma velocidade quase constante e consequentemente se tenha um melhor controle sobre a potência gerada. Em teoría, o ângulo de pitch poderia variar de 0 até 90 graus; porém, pesquisas referentes a instalações práticas mostraram valores na faixa de 0 até 30 graus. Na Figura 5.2, pode-se observar a forma de atuação do efeito pitch em turbinas eólicas.

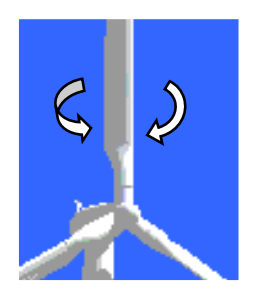

Figura 5.2. Controle pelo efeito pitch aplicado nas pás.

\subsubsection{Controle Simultâneo Pitch e Stall}

A vantagem do uso deste tipo de estratégia de controle é que, tanto em condições de vento forte e fraco, a velocidade da turbina eólica é mantida virtualmente constante. Até o advento de turbinas eólicas na ordem de MW, em meados dos anos 1990, a regulação utilizando a técnica stall era predominante. Hoje em dia, a regulação da velocidade pela estrategia pitch, em máquinas de grande porte, é a opção preferida. Atualmente, conforme informações disponíveis em [85], existem cerca de quatro vezes mais turbinas eólicas que utilizam a regulação de velocidade baseada na opção pitch do que aquelas baseadas na regulação pelo efeito stall.

\subsubsection{Necessidade de uma Carga Dissipadora}

Boa parte dos geradores eólicos são projetados para evitar a operação em vazio, especialmente quando estes não estão conectados à rede, onde seria exportada a geração excedente. Para lidar com esta condição é comum a instalação de uma carga dissipadora denominada como dumb (dummy) load. Este tipo de carga é também necessária quando o controle através do ângulo de pitch não é suficiente para proteger o gerador, por exemplo, em situações quando o banco de baterias alimentado pelo gerador eólico está carregado e este necessite ser desconectado. Nessas condições, se o aerogerador não tiver outra carga para alimentar, estará operando em vazio. Assim, a 
função da carga dissipadora é garantir, a todo instante, o balanço de energia no sistema, consumindo o exceso de energia e evitando que a energia gerada seja maior que a demanda. Outra razão importante para a conexão da carga dissipadora é a própria proteção da turbina, geralmente estas não são projetadas para operar em vazio; assim; especialmente na presença de ventos fortes, as pás poderiam alcançar velocidades muito elevadas que podem levar o aerogerador à sua autodestruição.

Micro-redes alimentadas com motor diesel, e inclusive usinas solares, podem também conter cargas dissipadoras, isto a fim de garantir que a geração opere com um nível de carga suficiente que otimize seu consumo de combustível e, no caso dos paineis solares, ofereçam proteção similar ao descrito para o aerogerador.

\subsubsection{Alívio de Carga em Micro-redes}

O alívio de carga em sistemas e redes de distribuição é um recurso operativo aplicado após a freqüência do sistema começar a cair a partir de seu valor nominal $(50 / 60 \mathrm{~Hz})$. Sabe-se que este procedimento normalmente ocorre de duas formas:

(a) Alívio de carga automático. No qual o sistema de proteção normalmente inicia o isolamento automático da carga na rede (conceito que pode também ser aplicado na micro-rede).

(b) Alívio de carga manual (ou seletivo). Cuja característica principal é a disponibilidade de tempo suficiente (geralmente até $30 \mathrm{~min}$ ) para a desconexão da carga selecionada.

Prevê-se que a introdução da tecnologia das redes inteligentes (smart grid) poderá diminuir substancialmente o alívio de carga forçado, já que os consumidores, informados pelos medidores inteligentes e/ou através da informação dinâmica do preço da energia de dispositivos inteligentes, tomarão determinadas decisões como a desconexão de cargas menos importantes, o que contribuirá na redução da demanda.

Conforme [86]-[87], os métodos de alívio de carga de maior uso, são:

(a) Alívio percentual de carga em função da queda de freqüência. Tipicamente, este esquema de alívio de carga é feito de três a seis etapas. Na Tabela 5.1, por exemplo, apresentam-se os valores percentuais da carga a ser aliviada para o caso de alívio em três etapas. 
Tabela 5.1. Carga aliviada em função da queda de freqüência.

\begin{tabular}{|c|c|c|}
\hline Etapa & $f(\mathrm{~Hz})$ & $(\%)$ da carga \\
\hline 1 & 59,3 & 10 \\
\hline 2 & 58.9 & 15 \\
\hline 3 & 58,5 & $\begin{array}{c}\text { conforme requerido a fim evitar } \\
\text { queda além de } 58,2 \mathrm{~Hz}\end{array}$ \\
\hline
\end{tabular}

(b) Uso combinado da taxa de variação da freqüência (ROCOF - Rate Of Change Of Frequency) e da porcentagem de carga a ser aliviada (Tabela 5.2). Neste método avalia-se a velocidade na qual a frequência vem caindo $(d f / d t)$, o que permite caracterizar o tipo de contingência que ocorre no sistema em diferentes instantes, proporcionando assim um alívio de carga mais adequado [87]. Por exemplo, para a mesma queda de frequência anterior de $59,3 \mathrm{~Hz}$, a derivada $d f / d t$ poderá ser fixada em:

Tabela 5.2. Carga aliviada em função do método RoCoF.

\begin{tabular}{|c|c|c|}
\hline$f(\mathrm{~Hz})$ & $\begin{array}{c}\text { RoCoF } \\
d f / d t\end{array}$ & $(\%)$ da carga \\
\hline $59,3 \mathrm{~Hz}$ & $0,4 \mathrm{~Hz} / \mathrm{s}$ & $10 \%$ do total da carga \\
$59,3 \mathrm{~Hz}$ & $1,0 \mathrm{~Hz} / \mathrm{s}$ & $25 \%$ do total da carga \\
$59,3 \mathrm{~Hz}$ & $2,0 \mathrm{~Hz} / \mathrm{s}$ & $35 \%$ do total da carga \\
\hline
\end{tabular}

Apesar destes métodos serem comumente utilizados pelas concessionárias de distribuição, no contexto deste trabalho será separada toda a carga excedente à potência nominal do gerador. Isto considerando a potência relativamente baixa, assim como a inércia, dos DERS envolvidos em sistemas de micro-redes.

Em geral, geradores diesel de pequeno e mediano porte não possuem capacidade de sobrecarga. Geradores acoplados a PCHs e turbinas eólicas de pequeno porte pode admitir, embora não seja recomendado, uma pequena porcentagem de sobrecarga temporária (até 10\%) [88], isto a fim de evitar o sobreaquecimento da máquina. Contudo, no trabalho, serão inclusos comentários referentes a qual seria a porcentagem de carga a ser desligada em um determinado exemplo, se forem aplicados os métodos de alívio de carga anteriormente descritos.

\subsection{Estudos de Estabilidade Transitória na MR}

Com o objetivo de estudar e analizar o desempenho de duas micro-redes elétricas, foram inicialmente simulados dois casos. No primeiro caso, orientado principalmente a avaliar as possibilidades de sucesso durante o ilhamento da micro-rede, são utilizadas duas fontes, um gerador diesel síncrono e um gerador eólico assíncrono. Esta micro-rede foi simulada utilizando o programa Matlab/Simulink. 
No segundo caso, foi analizada a resposta dinâmica da micro-rede, nos modos de ilhamento forçado e ilhamento pré-planejado, considerando sobrecarga imprevista na micro-rede e sua imediata aplicação de alívio de carga. Para o estudo deste segundo caso, simulado no programa PSCAD (Power System Computer Aided Design), foi utilizado um gerador diesel síncrono, uma $\mathrm{PCH}$ com gerador síncrono e uma turbina eólica com gerador de indução DFIG (Doubly Fed Induction Generator).

\subsubsection{Análise de Desempenho e Ilhamento da Micro-rede utilizando o Programa Matlab}

A micro-rede (MR) simulada está conectada à rede da concessionária através de um disjuntor (DJ-1) e de um transformador de 6 MVA $(13,8 / 2,4 \mathrm{kV})$, conforme mostrado na Figura 5.3 (vide também Anexo A). Durante a implementação deste sistema foram considerados os blocos e modelos disponíveis no programa Matlab/Simulink [89], amplamente utilizado no ambiente acadêmico. As fontes de geração consideradas são:

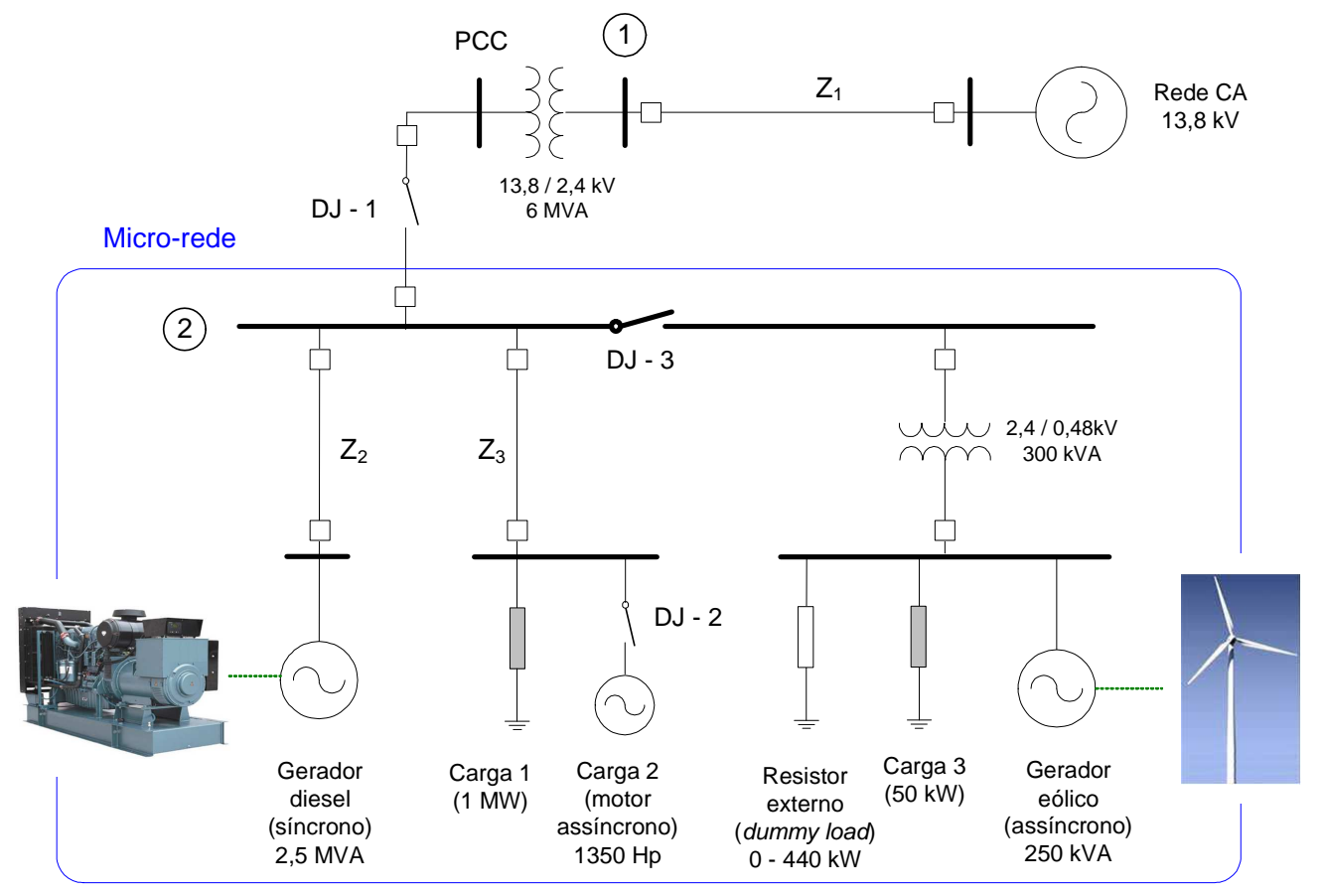

Figura 5.3. Micro-rede elétrica utilizada nas simulações [90].

(i) Um gerador diesel síncrono cujos valores nominais são: 2,5 MVA, 4,2 kV; que deverá fornecer energia a determinadas cargas críticas as quais são normalmente alimentadas pela rede. 
(ii) Um gerador eólico assíncrono (250 kVA, $480 \mathrm{~V}$ ) conectado à Barra 2 (PCC) através de um transformador de distribuição (300 kVA; 2,4/0,48 kV) que alimenta uma carga (com potência constante) de $50 \mathrm{~kW}$.

A carga do gerador diesel é composta por um motor assíncrono equivalente de 2 pólos $\left(1350 \mathrm{Hp}\right.$, isto é $0,746^{*} 1350 \mathrm{HP}=1007 \mathrm{~kW}$ ) conectado através do disjuntor CB-2 e uma carga resistiva $(1 \mathrm{MW})$. Ambas as impedâncias $Z_{2}$ e $Z_{3}$ tem valores semelhantes $(0,09416+j$ $0,09875 \Omega / \mathrm{km})$.

Convém lembrar que entre as principais características da máquina síncrona (gerador), para efeitos de simulação, estão:

- $\quad$ O gerador tem que operar numa velocidade que corresponde ao número de pólos da máquina e à freqüência do sistema ao qual está conectado. No caso simulado o número de polos foi de 4 , assim, $n_{s}=60^{\star} f /(2 p)=1800 \mathrm{rpm}$ (velocidade síncrona).

- A potência ativa gerada é controlada principalmente pelo regulador de velocidade. Neste exemplo, não foi implementado regulador de tensão que seria útil nos estudos de estabilidade.

- A potência reativa é controlada pelo nível de excitação do campo (tensão e corrente de campo) da máquina.

No caso do gerador eólico, boa parte dos aerogeradores que operam na atualidade estão baseados no uso de geradores assíncronos, isto devido às propriedades técnicas inerentes a este tipo de gerador. Uma destas propriedades refere-se a sua habilidade de gerar energia quando o rotor opera com velocidades diferentes da velocidade síncrona. Caso a velocidade do gerador seja incrementada acima da freqüência síncrona, o gerador estará fornecendo energia para o sistema. No entanto, o gerador assíncrono requer que seu estator seja previamente magnetizado pela rede, antes dele funcionar.

A análise do comportamento da micro-rede diante de vários cenários topológicos considera, conforme apresentado na Figura 5.3, uma micro-rede cujo grau de complexidade não é alto; isto porque considera-se de maior utilidade mostrar resultados com este tipo de sistema ao invés de usar sistemas mais complexos que pouco ajudem no entendimento de seu desempenho e reação diante da faltas na rede.

Assim, inicialmente serão avaliados os seguintes cenários: 
- $\quad$ Operação da micro-rede no modo normal, ou seja, conectada com a concessionária (DJ-1 fechado, DJ-2 e DJ-3 a ser fechados).

- $\quad$ Modo de ilhamento pre-planejado ou intencional (DJ-2 e DJ-3 fechados, DJ-1 a ser aberto).

- $\quad$ Modo de ilhamento forçado ou não-intencional (DJ-2 e DJ-3 fechados, DJ-1 a ser aberto).

- $\quad$ Ilhamento bem sucedido.

- $\quad$ Sucesso no ilhamento à custa de perder o motor assíncrono (Carga 2).

Colapso da micro-rede devido à sobrecarga (DJ-2 e DJ-3 fechados, DJ-1 a ser aberto).

\subsubsection{Operação da Micro-rede no Modo Conectado com a Rede}

Neste caso, a posição dos interruptores é a seguinte: DJ-1 fechado, DJ-2 e DJ-3 a serem fechados. O objetivo principal é mostrar que o gerador diesel pode ser utilizado para suportar a tensão na Barra 2 através do fornecimento de potência reativa, desta forma controlando a tensão nesta barra e nas barras nas quais estão conectadas as Cargas 1 e 3 . $\mathrm{Em} t=2 \mathrm{~s}$, o disjuntor DJ-2 é fechado conectando o motor assíncrono (ASSM) equivalente.

Como DJ-1 está normalmente fechado, boa parte da energia que o motor ASSM necessita é obtida da rede principal. Conforme esperado, o gerador diesel fornece pouca potência, aproximadamente $0,025 \mathrm{pu}$ (Figura 5.4a). Este valor equivale a $\mathrm{P}_{\mathrm{GD}}=0,025^{\star} 2,5=62,5 \mathrm{~kW}$ (sendo 2,5 o MVA BASE$_{\text {). }}$

A tensão nos terminais do gerador cai para aproximadamente 0,89 pu (Figura 5.4b); nesse instante o gerador diesel fornece potência reativa que, junto com a contribuição da rede principal, fazem que a tensão terminal na Barra 2 volte a seu valor normal (1,0 pu).

Na Figura 5.4(c) mostra-se variação da freqüência do gerador diesel. 


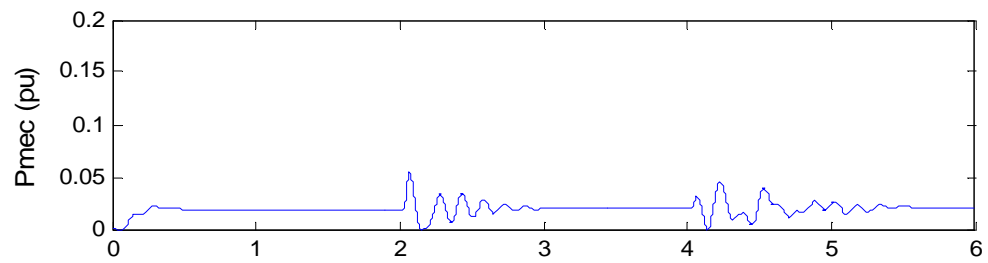

(a)

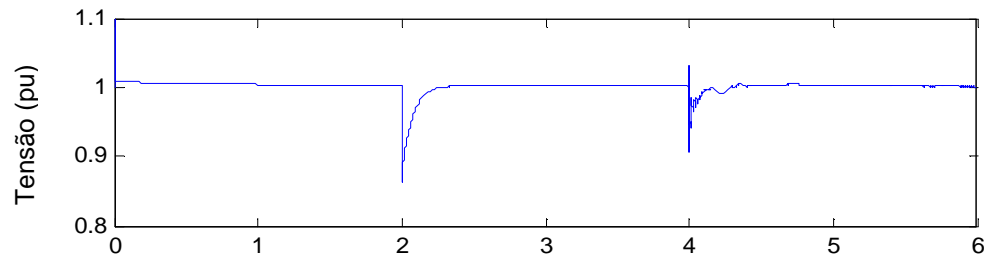

(b)

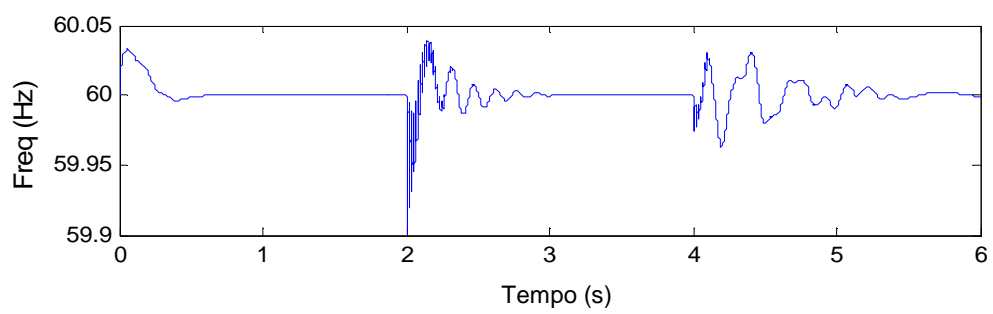

(c)

Figura 5.4. (a) Potência do gerador diesel, (b) Tensão na Barra 2, (c) Freqüência do gerador diesel.

Em $t=4 \mathrm{~s}$, o subsistema do gerador eólico, que já estava previamente em operação é conectado através do disjuntor DJ-3. Na Figura 5.5(a) mostra-se o efeito desta conexão sobre a potência do gerador eólico. Observa-se que durante todo o intervalo de simulação o aerogerador gera $50 \mathrm{~kW}$ para suprir a sua demanda local.

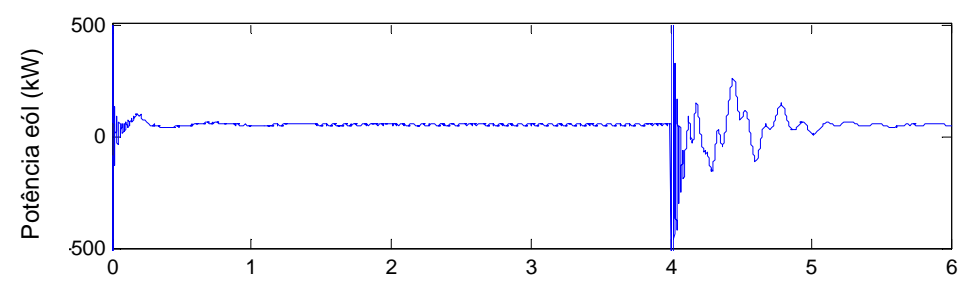

(a)

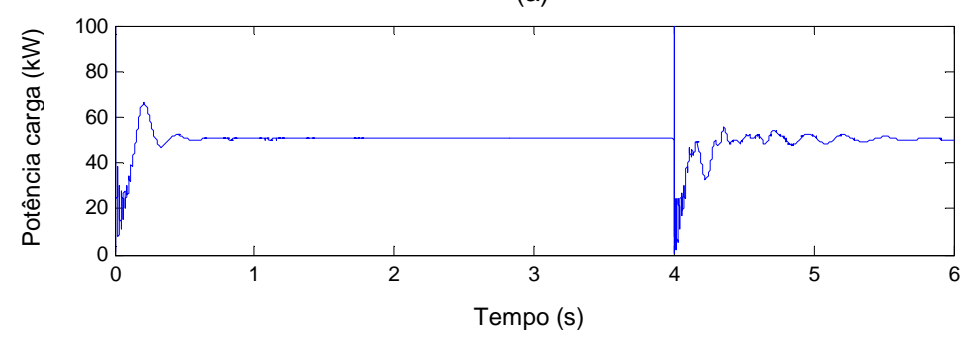

(b)

Figura 5.5. Potências: (a) do gerador eólico, (b) da carga no gerador eólico. 


\subsubsection{Modo de Ilhamento Planejado ou Intencional}

Neste caso, a posição dos interruptores é a seguinte: (DJ-2 e DJ-3 fechados, DJ-1 a ser aberto). Geralmente, este processo de ilhamento impõe transitórios com pouco efeito sobre a MR. Porém, ainda assim, a MR poderia enfrentar desbalanços entre a geração e a carga, sendo necessária a execução de recursos como o alívio de carga. O ilhamento préplanejado da MR ocorre em $t=1 \mathrm{~s}$. Entre as razões para a aplicação deste modo de operação podem estar: questões do custo da energia, manutenção do sistema, etc.

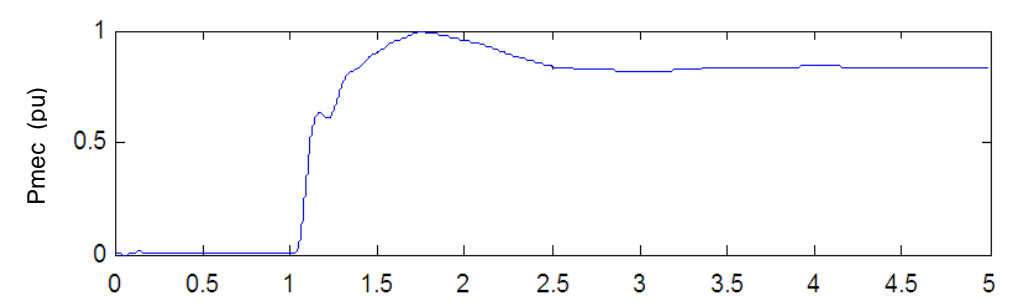

(a)

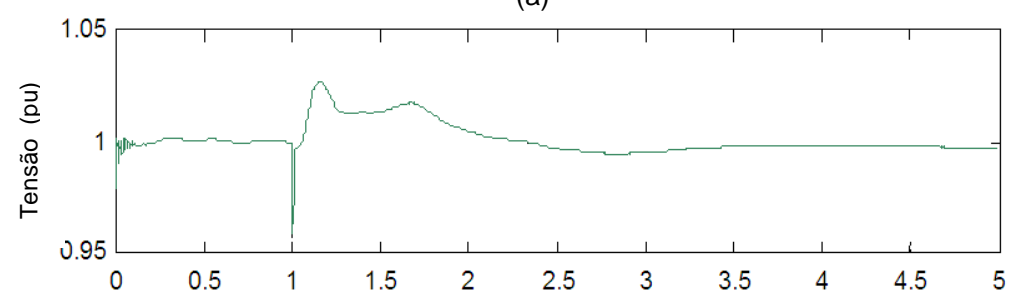

(b)

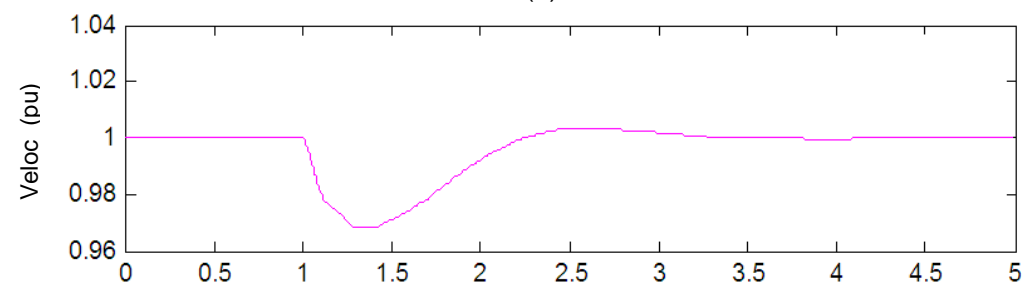

(c)

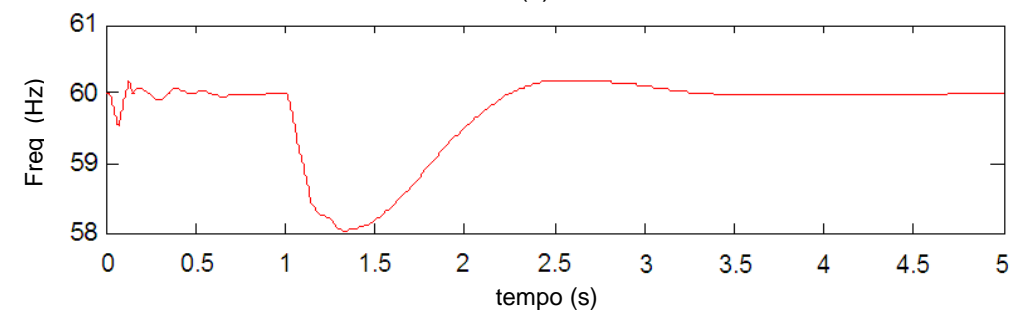

(d)

Figura 5.6. Ilhamento pré-planejado: (a) Potência do gerador diesel, (b) Tensão na barra 2, (c) Velocidade do gerador, (d) Freqüência do gerador eólico.

Nota-se que antes da abertura do DJ-1 as cargas da MR são alimentadas pela rede CA, daí que a potência que alimenta estas cargas por parte dos geradores na MR é muito pequena (Figura 5.6a). Após a abertura de DJ-1, os geradores da MR assumem a carga. A potência do gerador diesel aumenta até cerca de $0,8 \mathrm{pu}(\approx 2 \mathrm{MVA})$ de sua potência nominal. 
A tensão na barra 2 é levemente afetada atingindo um valor, em regime, de aproximadamente 0,998pu (Figura 5.6b). A velocidade do motor diesel (Figura 5.6c), que também reflete o comportamento da freqüência, cai até cerca de $(0.97 \mathrm{pu})$, porém uma rápida ação do regulador de velocidade, prevista no modelo, o restabelece a seu valor nominal (1,0 pu). O comportamento da freqüência do gerador eólico é mostrada na Figura 5.6(d). Nota-se que o ilhamento da rede CA faz que a mesma sofra uma queda momentânea até $58 \mathrm{~Hz}$, restabelecendo-se em cerca de 2,5 s.

\subsubsection{Modo de Ilhamento Forçado ou Não-Intencional}

A posição dos interruptores para este caso é a seguinte: DJ-2 e DJ-3 fechados, DJ-1 a ser aberto. O modo de ilhamento forçado pode ocorrer devido à presença de faltas no sistema ou devido a outras condições de chaveamento na rede. Antes de passar ao modo ilhado a MR pode estar fornecendo energia à concessionária. Durante este tipo de ilhamento a MR pode acabar em duas condições operativas: i) que o ilhamento seja bem sucedido, mantendo todas as cargas da MR e, ii) que para ter sucesso no ilhamento seja necessário desligar parte da carga atendida. Pode-se ter mais um caso no qual ocorre o colapso da $\mathrm{MR}$, por exemplo, devido à conexão de carga superior à capacidade dos geradores e mantida por um determinado período.

\subsection{Ilhamento Bem Sucedido}

Inicialmente, todos os disjuntores (DJ-1, DJ-2 e DJ-3) encontram-se fechados, com os geradores da MR já operando. Em $t=1 \mathrm{~s}$, ocorre uma falta (curto-circuito trifásico) entre a barra 2 e o disjuntor DJ-1 (Figura 5.3). Em $t=1,1 \mathrm{~s}$ o disjuntor DJ-1 é aberto. Quase que imediatamente ambos os geradores síncrono e assíncrono passam a alimentar as cargas da MR. Na Figura 5.7(a) mostra-se a transição no carregamento do gerador diesel a partir da condição quase zero de potência. Na Figura 5.7(b) mostra-se a queda da tensão na barra 2 (até aproximadamente 0,2 pu); voltando a seu valor nominal em aproximadamente 0,5 s. A recuperação da freqüência do gerador diesel (em $t=2,5 \mathrm{~s}$ ) é mostrada na Figura $5.7(\mathrm{c})$. Nas Figuras 5.7(d) e 5.7(e) mostram-se as respostas da potência do gerador eólico e sua freqüência após ter sido removida a falta. Particularmente, a potência deste gerador no instante de aplicação da falta atinge transitoriamente valores elevados. Apesar disso, o sistema consegue voltar a sua condição de pré-falta. 


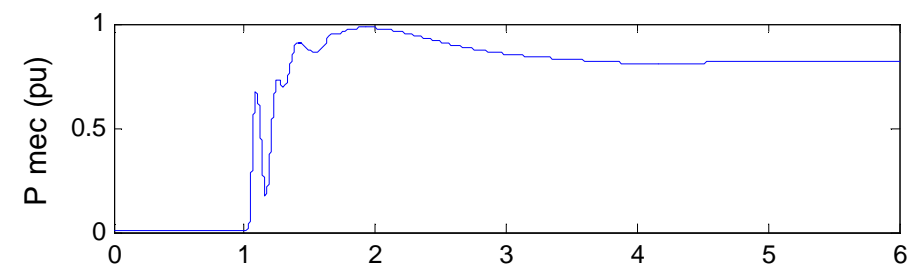

(a)

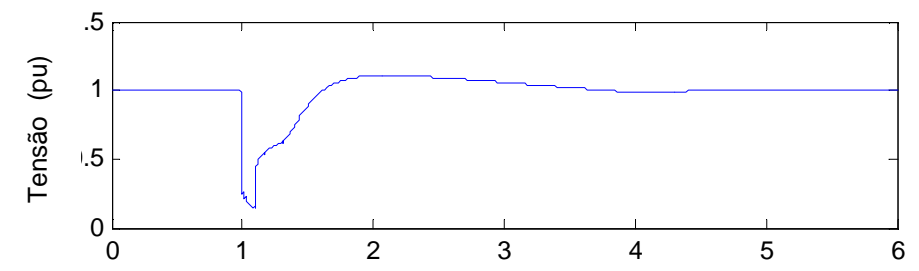

(b)

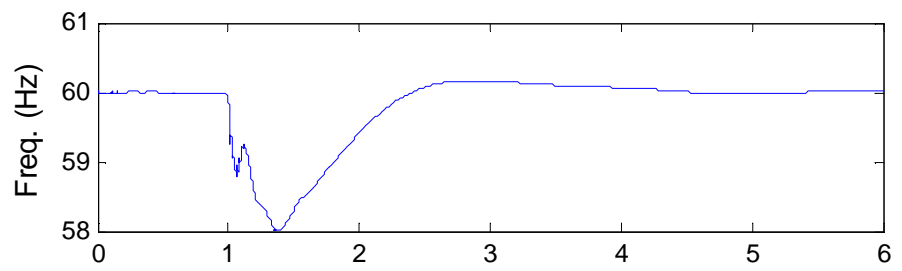

(c)

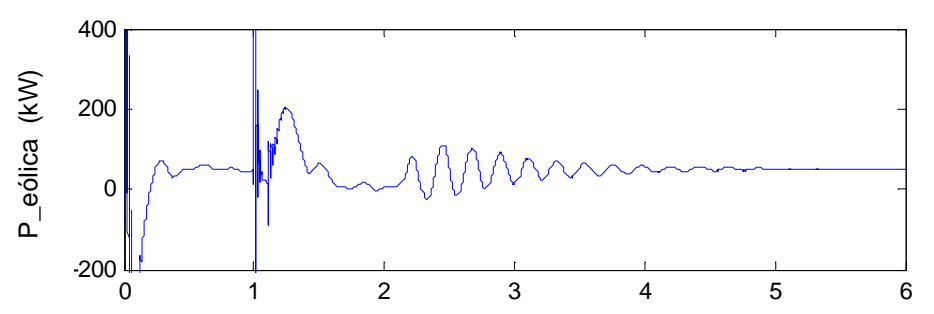

(d)

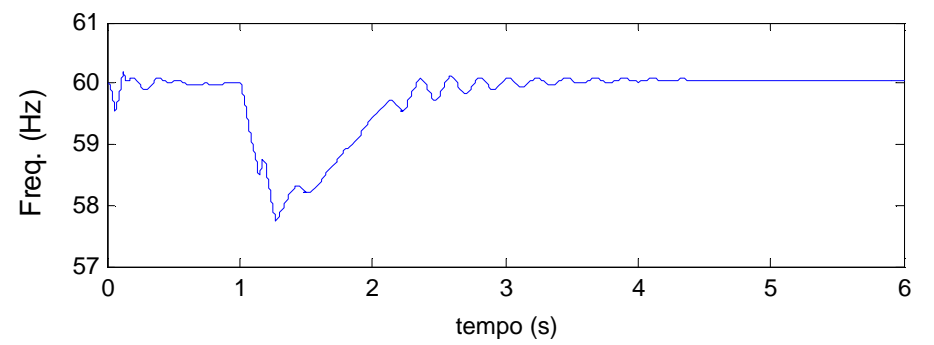

(e)

Figura 5.7. Illhamento forçado bem sucedido: (a) Potência do gerador diesel, (b) Tensão na barra 2, (c) Frequencia do gerador diesel, (d) Potência do gerador eólico, (e) Frequência do gerador eólico 


\subsection{Sucesso no Ilhamento devido à Saída do Motor Assíncrono}

A inclusão deste exemplo é para mostrar que o tempo de eliminação da falta pode ser crítico para manter a MR em operação. Após ser aplicada a falta trifásica descrita no item anterior, a abertura do disjuntor DJ-1 será realizada quando $t=1,2 \mathrm{~s}$ (100 ms a mais do que o caso anterior). Este atraso na eliminação da falta impõe um impacto negativo nos geradores.

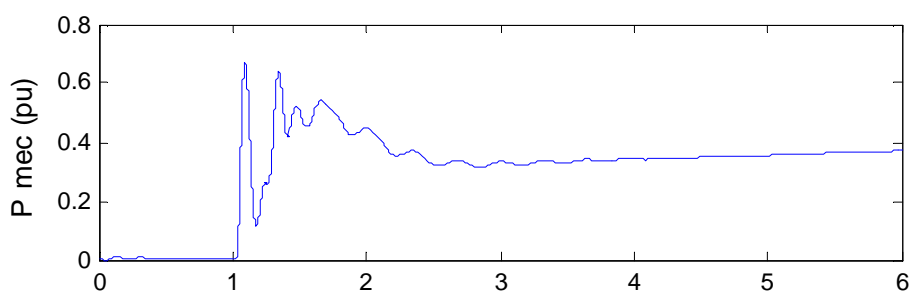

(a)

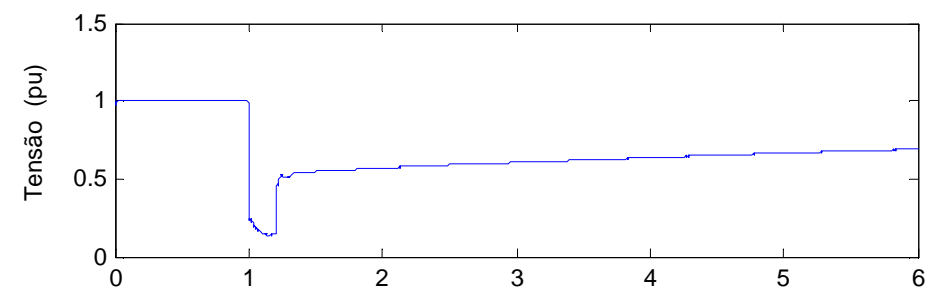

(b)

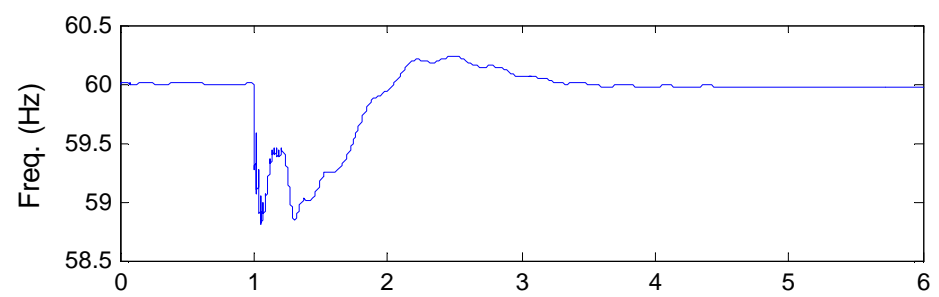

(c)

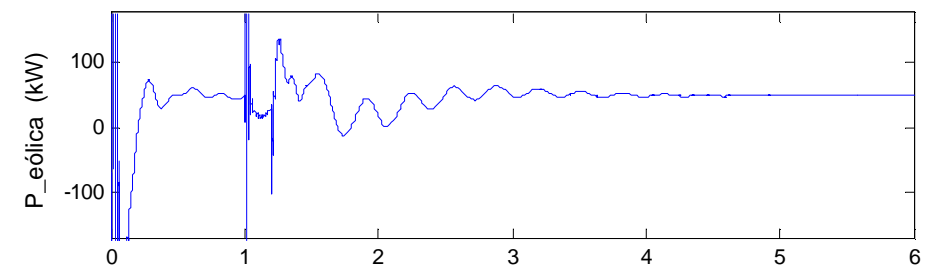

(d)

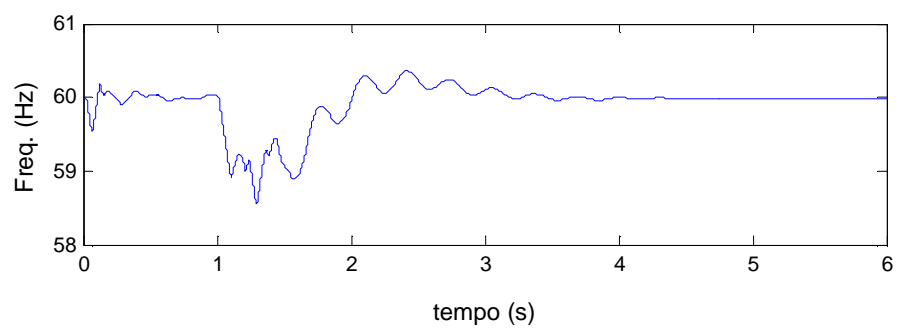

(e)

Figura 5.8. Illhamento forçado (com sucesso) graças a desconexão da carga 2: (a) Potência do gerador diesel, (b) Tensão na barra 2, (c) Frequência do gerador diesel, (d) Potência do gerador eólico, (e) Frequência do gerador eólico. 
Na Figura 5.8(a) mostra-se que, com a saída do motor ASSM (Carga 2) o gerador diesel entrega apenas a potência demandada pela carga (passiva) de $1 \mathrm{MW}$ (equivalente a aproximadamente $1 \mathrm{MW} / 2,5 \mathrm{MVA} \cong 0,4 \mathrm{pu}$ ).

O efeito do atraso na eliminação da falta pode também ser observado na tensão da barra 2 (Figura 5.8b). No momento da remoção da falta esta tensão sobe para aproximadamente 0,5 pu, após o qual apresenta uma recuperação gradativa e lenta. Já a freqüência do gerador diesel (síncrono) mostra uma recuperação relativamente rápida (Figura 5.8c). Nas Figuras 5.8(d) e 5.8(e) mostram-se a potência e freqüência do gerador eólico. Ambas as grandezas mostram uma boa recuperação apesar das oscilações presentes a partir da eliminação da falta até aproximadamente 3,0 s.

$\mathrm{Na}$ MR apresentada na Figura 5.3 foi também aplicada uma falta (curto-circuito) fase-terra no mesmo ponto da falta trifásica. Observou-se que a MR é capaz de suportar períodos mais longos (até $200 \mathrm{~ms}$ ) antes desta ser eliminada, sem perda de estabilidade.

\subsection{Colapso da MR devido a Sobrecarga}

A posição dos interruptores para este caso é a seguinte: DJ-2 e DJ-3 fechados, DJ-1 a ser aberto. O colapso da micro-rede pode ser resultado, por exemplo, da conexão acidental de carga maior à capacidade dos geradores após o ilhamento forçado ou até mesmo o ilhamento pré-planejado.

Nos resultados apresentados na Figura 5.9, o disjuntor DJ-1 é aberto em $t=1 \mathrm{~s}$, e de forma instantânea ambos os geradores assumem com sucesso a carga da MR. No entanto, em $t=$ 3 s uma carga excessiva igual a $4 \mathrm{MW}$ é conectada na barra 2. Na realidade, foram duplicados os valores existentes da Carga 1 (2x1 MW) e Carga 2 (2x1350 Hp).

Nos primeiros instantes o gerador diesel tenta assumir esta demanda colapsando logo na sua tentativa (Figura 5.9a). Na Figura 5.9(b) mostra-se o colapso da tensão na barra 2 após a sobrecarga. O impacto desta excessiva sobrecarga pode também ser observado no caso da freqüência de gerador diesel (Figura 5.9c). Observou-se que o gerador eólico, com capacidade bem menor ao do diesel, acaba também colapsando.

Em casos como este, não haverá controle de potência e frequência eficaz que possa ser utilizado para manter a MR operando. Contudo, uma forma de lidar com este problema seria a utilização de um sistema automático de alívio de carga (load shedding), que será apresentado a seguir. 


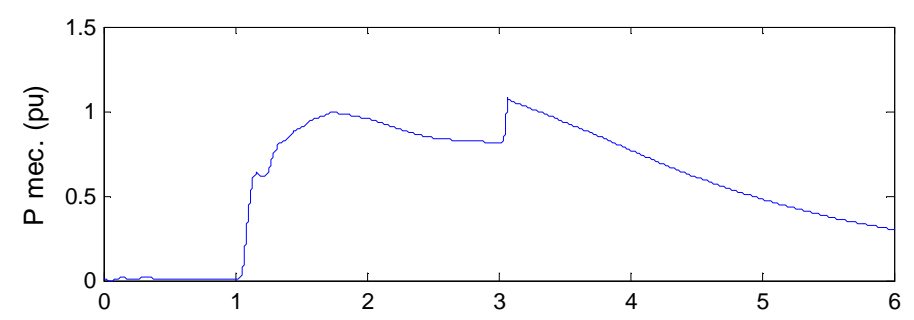

(a)

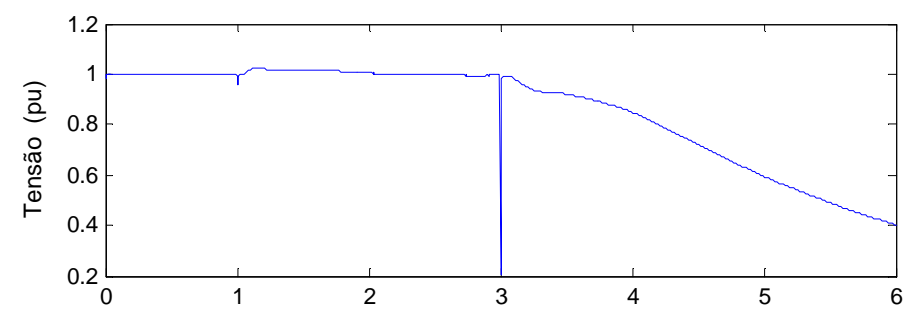

(b)

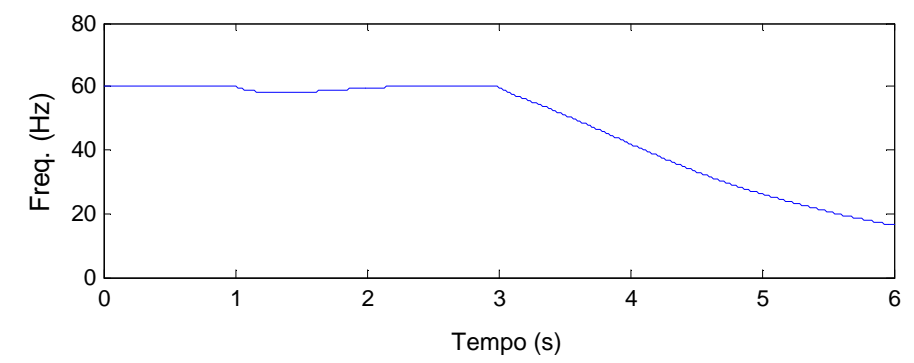

(c)

Figura 5.9. Colapso da MR devido à excessiva carga conectada: (a) Potência do gerador diesel, (b) Tensão na barra 2, (c) Frequência do gerador diesel.

\subsubsection{Avaliação de Condições Críticas de operação da MR utilizando o Programa PSCAD}

O caso de análise utilizado nesta seção tem certa semelhança com o anterior, porém com maior detalhe na construção de seus componentes. A MR está conectada à rede através do disjuntor DJ-P em série com um transformador de 6 MVA, 13,8/2,4 kV. A principal diferença está na utilização de mais uma fonte de geração ( $\mathrm{PCH}$ - Pequena Central Hidrelétrica) e o esquema DFIG (Doubly-Fed Induction Generator) no gerador eólico, conforme mostrado na Figura 5.10.

Não foram consideradas fontes que possuam elementos de armazenamento de energia como painel fotovoltaico e outros devido a que o objetivo destas simulações é analisar o comportamento dinâmico das fontes acima mencionadas.

Na Figura 5.10 estão também sendo mostradas as cargas (lineares) Carga 1, Carga 2 e Carga 3, normalmente alimentadas por cada DER, bem como as cargas suplementares (motores de indução equivalentes identificados como Carga 1A, Carga 2A e Carga 3A) que 
simularão a condição de sobrecarga. Estas últimas cargas estão conectadas a cada gerador por meio dos disjuntores DJ-4, DJ-5 e DJ-6, respectivamente. A simulação deste caso foi realizada no programa $\operatorname{PSCAD}^{\circledR}[91]$, também de uso comum em estudos de Sistemas de Potência.

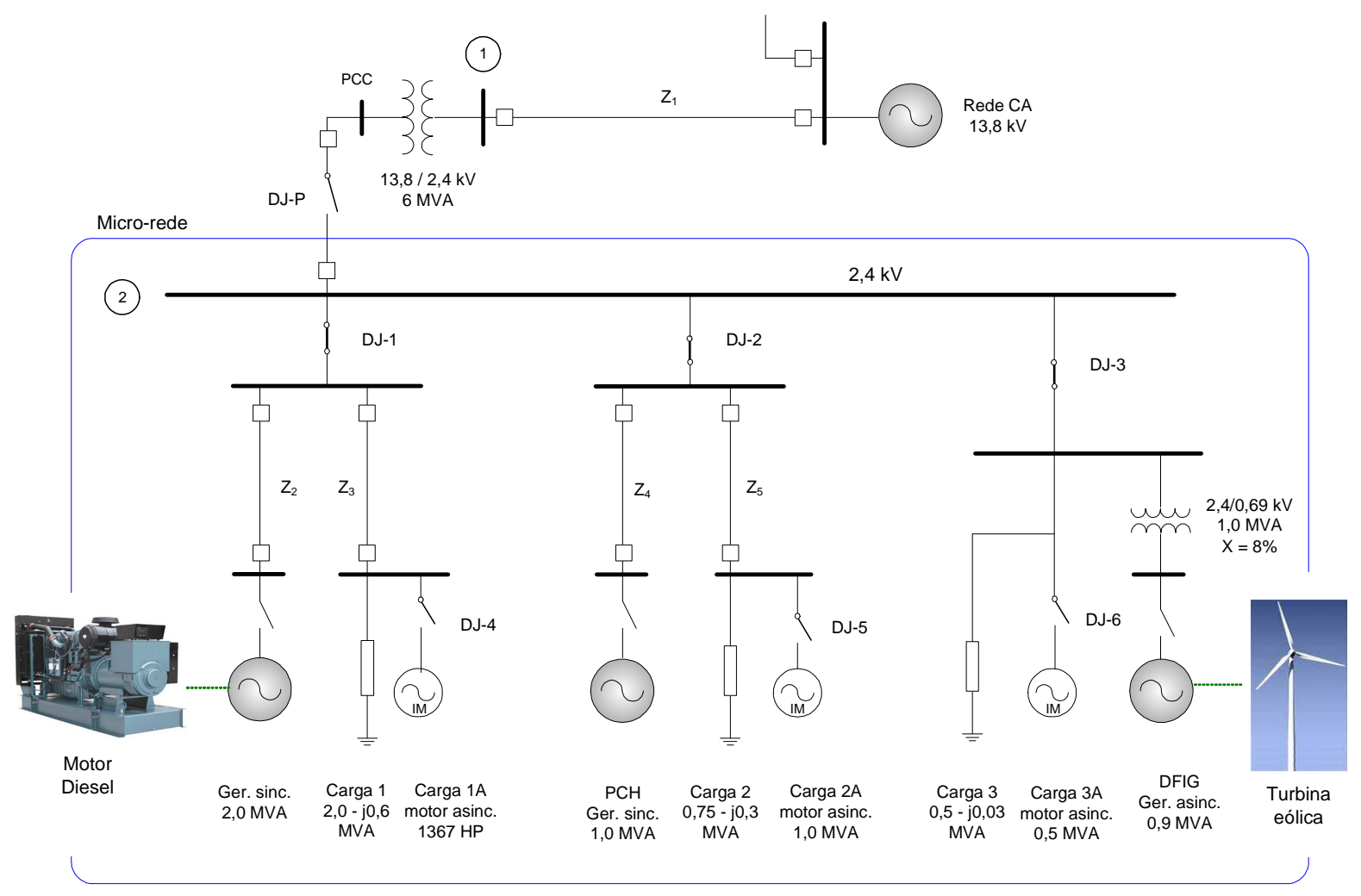

Figura 5.10. Micro-rede implementada no programa PSCAD [92].

O modelamento e equações das máquinas, já inclusas nos programas de simulação, não serão reproduzidos no trabalho visto que estes estão disponíveis na bibliografia referente a máquinas eléctricas. O gerador eólico (DFIG) está conectado à micro-rede através de um transformador de 2,4/0,69 kV.

A razão pela escolha de 2,4 kV na MR deve-se a que esta tensão é ainda popular em sistemas de média tensão e industrial em países como nos EUA e outros; assim, prefiriu-se fazer uso deste nível de tensão visando a publicação de alguns artigos técnicos a nível internacional. Adicionalmente, levando em consideração as potências das fontes utilizadas determinou-se que este sería um valor de tensão adequado.

Inicialmente, uma falta (curto-circuito trifásico) ocorre no trecho entre a Barra (2) e o disjuntor DJ-P fazendo que este (DJ-P) dispare, isolando assim a MR do sistema. Assume-se que, junto com CB os outros disjuntores (CB-1, CB-2 e CB-3) também serão abertos, evitando-se 
assim a condição de qualquer um dos geradores serem arrastados por outro, e porque previamente à interconexão destes é necessário realizar os devidos procedimentos de sincronização. Portanto, os DERS, e a própria micro-rede, estarão operando no modo ilhado. É nesta fase que os DERS podem ficar sobrecarregados. Adicionalmente, pode ser analisada a condição de sobrecarga dos DERs após estes estarem operando com sua carga nominal.

\subsubsection{Principais Caracteristicas dos Componentes Utilizados}

Alguns dos componentes utilizados no sistema simulado, como as fontes de geração e as cargas passivas e motores assíncronos (equivalentes), foram escolhidos da própria biblioteca do programa. Já os sistemas de controle, como o regulador de velocidade, regulador de potência (mecânica) constante, e o regulador de tensão dos geradores síncronos (diesel e PCH), tiveram que ser independentemente montados.

O objetivo disto foi dispor de reguladores de tensão e velocidade razoavelmente robustos capazes de lidar durante períodos envolvendo transitórios de sobretensão de subtensão. Os principais parâmetros destes geradores, tais como as reatâncias de eixo direto e em quadratura, assim como as constantes de tempo transitórias e sub-transitórias $\left(X_{q}, T^{\prime \prime}{ }_{d o}, X^{\prime \prime}{ }_{q}\right.$,

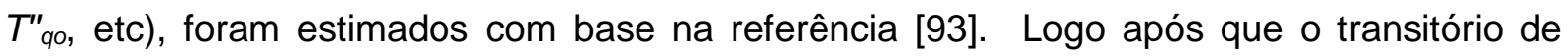
inicialização atinge a condição estável, os três modelos de geradores são chaveados da condição de máquinas ideais para "não ideais". Isto é, o modelo dinâmico das máquinas começa a ter validade.

\subsubsection{Modelo do Gerador Diesel}

$\mathrm{Na}$ Figura 5.11(a) estão sendo apresentadas as principais funções de controle do gerador diesel. Entre as funções de controle do gerador estão o regulador de tensão, regulador de velocidade e o regulador para manter a potência (mecânica) constante.

Basicamente, o regulador de tensão atua na tensão de exitação $\left(E_{f}\right)$, produzindo a corrente de campo $\left(I_{f}\right)$. Na Figura $5.11(\mathrm{~b})$, a tensão eficaz $\left(V_{r m s 1}\right)$ é medida nos terminais da máquina e comparada com a tensão de referência $\left(V_{\text {reft }}\right)$. A diferença entre estes valores é multiplicada pelo ganho e melhorada, caso houver uma resposta de frequência indesejável, por meio de um compensador do tipo avanço-atraso ${ }^{10}$ (lead-lag) de fase.

A fim de evitar o aparecimento de valores demasiado elevados ou extremamente baixos (por exemplo, valores negativos), é utilizado normalmente um limitador de tensão.

10 Frequentemente utilizado para melhorar a resposta da frequência em sistemas de controle. 
O sinal resultante é logo somado ao valor de tensão de campo inicialmente especificado $\left(E_{f 0}\right)$, a partir do qual se obtém $E_{f 1}$. Este valor $\left(E_{f 1}\right)$ é, então, corrigido por uma função adicional (função de pólo real ou real pole function utilizada para atenuar componentes de alta frequência, chattering, etc), para se obter, finalmente, a tensão de campo filtrada do controlador $\left(E_{f_{f} f t d}\right)$ que irá produzir a tensão controlada no regulador e corrigir a tensão terminal do gerador síncrono.

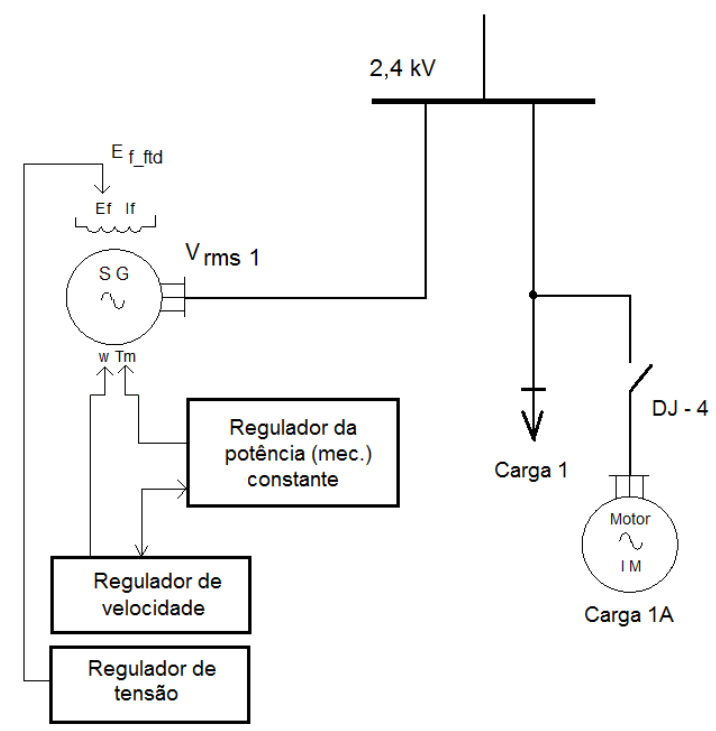

(a)

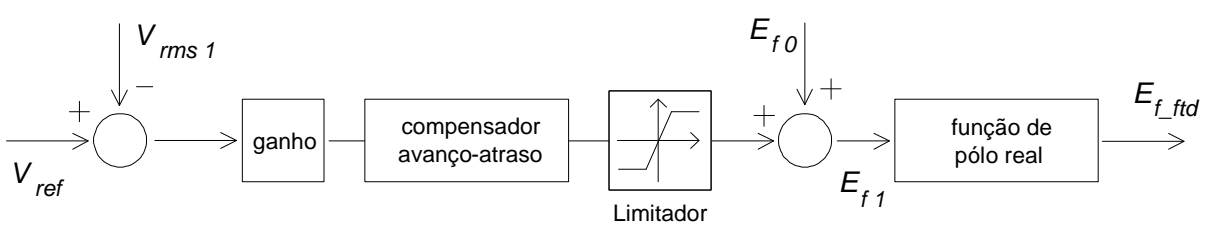

(b)

Figura 5.11. (a) Componentes de controle do gerador (síncrono) diesel, (b) Diagrama do regulador de tensão.

Onde,

$V_{\text {rms1 }}:$ Tensão medida nos terminais da máquina.

$V_{\text {ref }}:$ Tensão de referência.

$E_{\text {fo }}$ : Valor inicial da tensão de campo.

$E_{f \_ \text {ftd }}$ : Tensão de campo filtrada do controlador.

O regulador de velocidade atua sobre a velocidade do gerador $(w)$, que tem relação direta com a freqüência da máquina. Um componente adicional do regulador de velocidade é o torque mecânico $\left(T_{m}\right)$. A função do regulador da potência mecânica é manter $T_{m} \circ$ mais constante possível.

O torque elétrico $\left(T_{e}\right)$ deverá acompanhar o comportamento de $T_{m}$; assim, este poderá apresentar oscilações em torno de $T_{m}$. Apesar de este modelo apresentar a opção de 
simular a condição de falha na explosão de um dos cilindros (cylinder misfire) no motor diesel, o mesmo não foi incluso nos casos estudados.

\subsubsection{Modelo do gerador Eólico DFIG}

O gerador DFIG é basicamente uma máquina (de indução) de rotor bobinado no qual o rotor e o estator recebem alimentação via conversores VSC (Voltage Source Converters ou Conversores com Fonte de Tensão).

Atualmente, boa parte dos geradores eólicos de pequeno e mediano porte utilizam este esquema (DFIG) devido a sua versatilidade para operar sob condições de velocidade sub e super-síncrona [94]. A potência necessária para alimentar os conversores VSC é pequena, aproximadamente $30 \%$ da potência nominal do gerador. A regulação da velocidade estará também dentro desse intervalo.

$\mathrm{Na}$ Figura 5.12, os conversores (VSC) sob a configuração back-to-back estão sendo identificados como do lado do Rotor e do lado da Rede. O conversor do lado do Rotor é usado para controlar a velocidade e potência reactiva do gerador enquanto que o conversor do lado da Rede é usado para controlar a tensão CC e o intercâmbio de potência reactiva com a rede. Neste esquema é também utilizado o sistema chamado de crowbar cuja finalidade é a proteção dos conversores durante quedas de tensão.

O modelo de DFIG utilizado está disponível na biblioteca do programa PSCAD [91]. O nexo principal entre o gerador e a turbina eólica é o torque mecânico $\left(T_{m}\right)$ que deverá operar com um valor constante. Esta condição de $T_{m}$ constante deve-se a que tanto a velocidade do vento, assim como o ângulo de pitch (inclinação da pá) da turbina eólica, foram especificados para operar com valores constantes (por exemplo, $W_{S P}=8 \mathrm{~m} / \mathrm{s}$ e $11,5^{\circ}$, respectivamente). Foi considerado um coeficiente de potência $\left(C_{p}\right)$, que é a relação entre a potência mecânica disponível na turbina e a energia cinética incidindo nas pás, igual a 0,28.

Nota-se que entre os terminais do gerador (estator) e os conversores (VSC) existe um transformador intermediário com relação $0,69 / 0,5 \mathrm{kV}$; isto para garantir que as chaves semicondutoras operem com tensões relativamente baixas. Outros parâmetros adicionais adotados para este gerador, bem como para os outros, podem ser encontrados no Anexo B. 


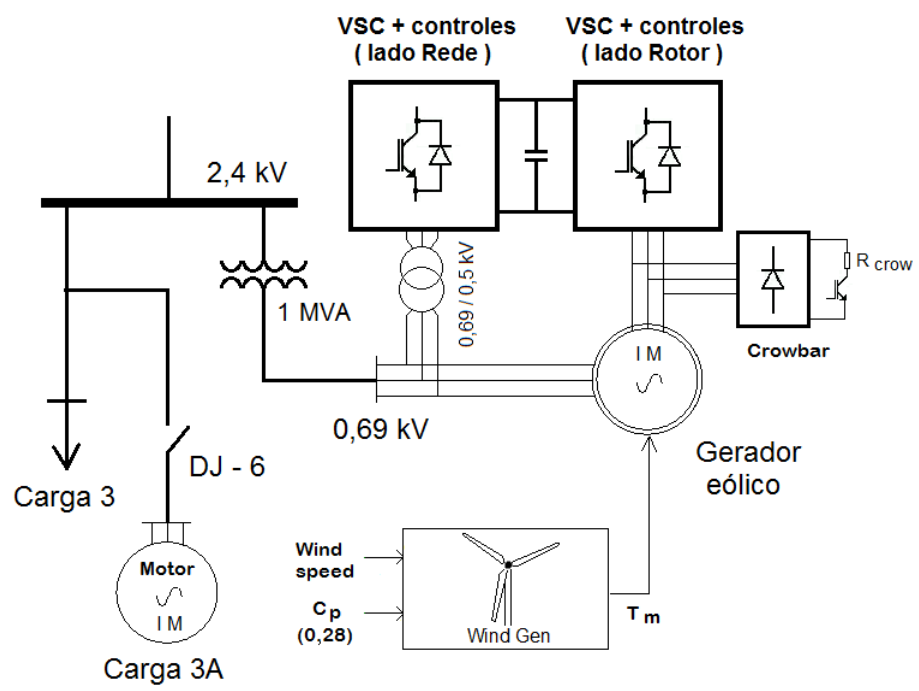

Figura 5.12. Gerador de indução duplamente alimentado (DIFG) utilizado.

Atualmente, alguns fabricantes já estão oferecendo sistemas de armazenamento (baterias) que fazem parte do pacote da turbina eólica, isto a fim de garantir o suprimento de energia ao sistema de controle da turbina, bem como alimentar algumas cargas consideradas críticas no sistema eólico, durante períodos de falta de vento.

\subsubsection{Modelo do Gerador na PCH}

$\mathrm{Na}$ Figura 5.13 estão sendo mostrados os principais blocos de controle assim como as cargas (normal, Carga 2, e não prevista, Carga 2A) consideradas no modelamento do gerador na $\mathrm{PCH}$. Devido à localização da fonte primária (pequenos reservatórios, rios, etc) a geração via $\mathrm{PCH}$ está às vezes localizada um pouco distante das cargas. Assim, será necessária a construção de linhas e a instalação de transformadores para a transmissão da energia gerada.

No trabalho está sendo assumido que a $\mathrm{PCH}$ está localizada a uma distância relativamente curta da carga. O modelo e dinâmica de inicialização durante a simulação da máquina síncrona, descrito previamente na Seção 5.3.2.2 (modelo do gerador diesel), são também válidas para este gerador na $\mathrm{PCH}$. 


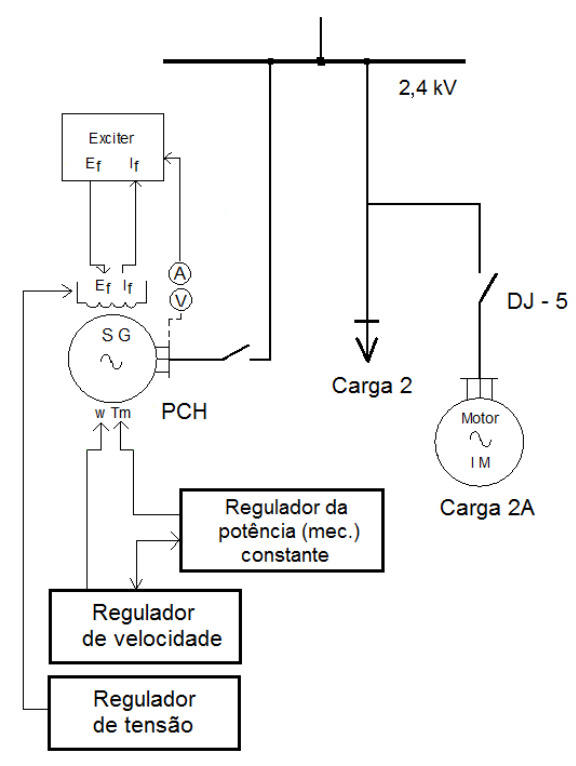

Figura 5.13. Principais blocos de controle implementados no gerador da PCH.

\subsubsection{Resultados das Simulações}

A seguir serão apresentados os resultados de algumas das condições operativas mais críticas que poderiam se apresentar em uma micro-rede, sendo estas:

- Ilhamento pré-planejado (sem a conexão de cargas não previstas).

- Alívio de carga durante o processo de ilhamento.

- Perda de um gerador.

- Falha na desconexão da carga não prevista durante o ilhamento pré-planejado.

\subsubsection{Ilhamento Planejado}

Inicialmente, a concessionária encontra-se alimentando tanto as cargas normais quanto as cargas adicionais (cargas extras). Em $t=15 \mathrm{~s}$, o disjuntor DJ-P é aberto ilhando de forma efetiva a MR. Assume-se que junto com DJ-P, os disjuntores das cargas extras (DJ-4, DJ-5 e DJ-6) são também abertos de forma efetiva. Portanto, apenas a carga normal de cada gerador estará sendo alimentada. Nota-se que a transição ao modo ilhado da origem a certas oscilações nos geradores. As constantes dos controladores P-I (Proporcional Integral) estabelecidos irão definir o grau de rapidez com que a máquina atinga a sua condição estável logo após a conexão da carga. 


\subsection{Gerador Diesel}

Na Figura 5.14(a), mostra-se a potência na saída do gerador diesel que alimenta a carga normal. Entre $t=5 \mathrm{~s}$ até $t=15 \mathrm{~s}$, a carga é alimentada pela concessionária. Após $t=15 \mathrm{~s}$, com a desconexão da concessionária, o gerador diesel começa a suprir de energia a Carga 1. Enquanto a carga estava sendo alimentado pela concessionária, o gerador diesel operava em vazio (potência zero). Durante o ilhamento a tensão terminal cai para aproximadamente $0,5 \mathrm{pu}$, antes de ser restabelecido para seu valor normal (Figura 5.14b). Na Figura 5.14(c), mostra-se a transição dos torques elétrico e mecânico da condição de vazio para plena carga.

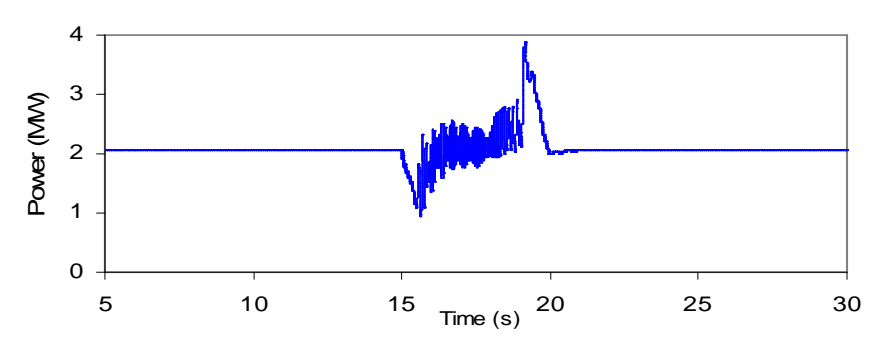

(a)

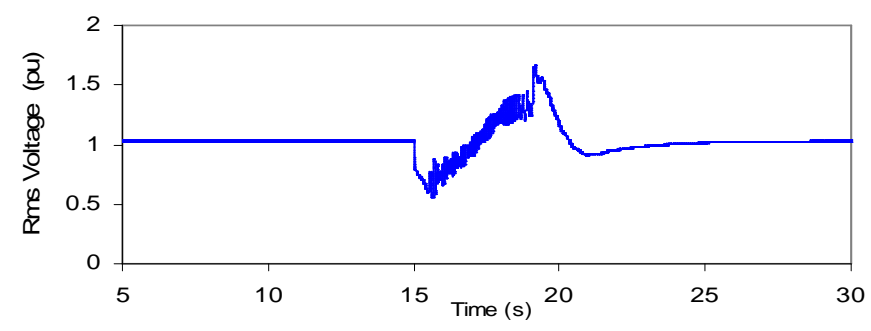

(b)

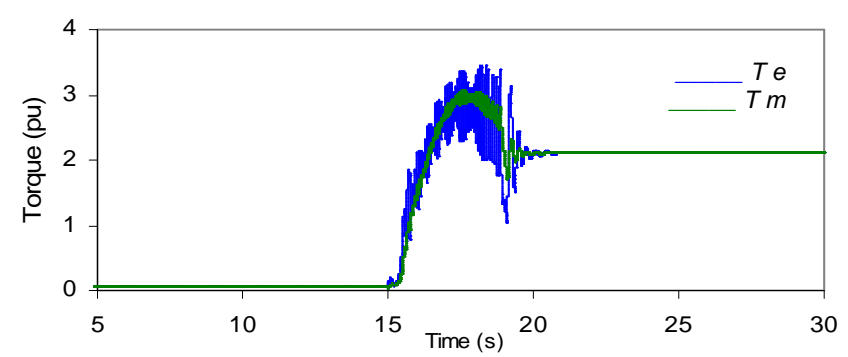

(c)

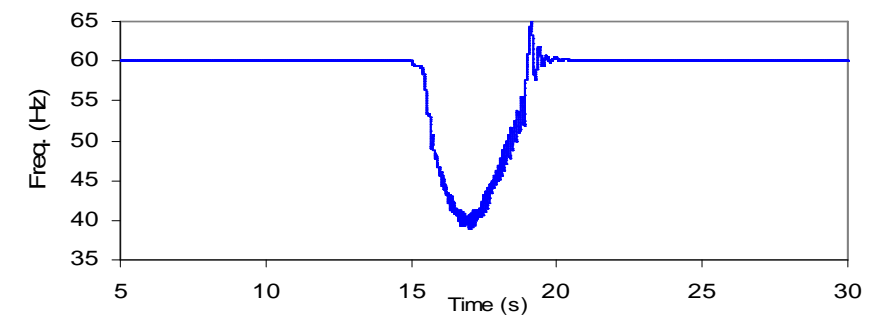

(d)

Figura 5.14. (a) Potência alimentada à carga do gerador diesel, (b) Valor eficaz (pu) da tensão, (c) Torque elétrico e mecânico, (d) Frequência do gerador diesel. 
A queda da freqüência (Figura 5.14d), cujo nível de tolerância varia de país para país, é de aproximadamente 33,3\% (cerca de $20 \mathrm{~Hz}$ ) em relação à freqüência nominal $(60 \mathrm{~Hz}$ ). Observa-se que a transição do gerador diesel a partir da condição de vazio para a plena carga é bem sucedida.

\subsection{Gerador PCH}

A separação da MR da concessionária também impõe uma perturbação significativa sobre o gerador da $\mathrm{PCH}$. Nota-se que durante essa transição a potência que alimenta a carga da PCH cai de forma instantánea para zero antes de ser restabelecida em aproximadamente 4,0s (Figura 5.15a). Antes desta transição, a potência do gerador da $\mathrm{PCH}$ também era quase zero (operação em vazio).

A tensão eficaz sofre uma queda momentânea (até $0,3 \mathrm{pu}$ ) antes de voltar a seu valor normal (1,0 pu), conforme mostrado na Figura 5.15(b). Quanto aos torques elétrico e mecânico, logo após algumas oscilações estes voltam à condição estável (Figura 5.15c).

A frequência do gerador da $\mathrm{PCH}$ cai para aproximadamente $56,5 \mathrm{~Hz}$ (queda de 5,83\%) conforme mostrado na Figura 5.15(d). Contudo, apesar das oscilações observadas o gerador da $\mathrm{PCH}$ consegue fazer a transição para a plena carga com sucesso.

\subsection{Gerador Eólico DFIG}

Na Figura 5.16(a) mostra-se a potência nos terminais do gerador DFIG após o ilhamento (em $t=15 \mathrm{~s})$. De forma análoga aos outros geradores, antes do ilhamento, o DFIG encontrava-se já operando (em vazio). Durante o ilhamento, antes da ação do regulador de tensão, a tensão nos terminais da máquina sofre uma queda considerável (Figura 5.16b).

A freqüência do DFIG apresenta também uma queda momentânea até aproximadamente $35,5 \mathrm{~Hz}$ (igual a 40,8\% da freqüência nominal), conforme ilustrado na Figura 5.16(c). Contudo, a ação do regulador de velocidade restabelece a mesma, e em consequência a freqüência, para seu valor nominal. 


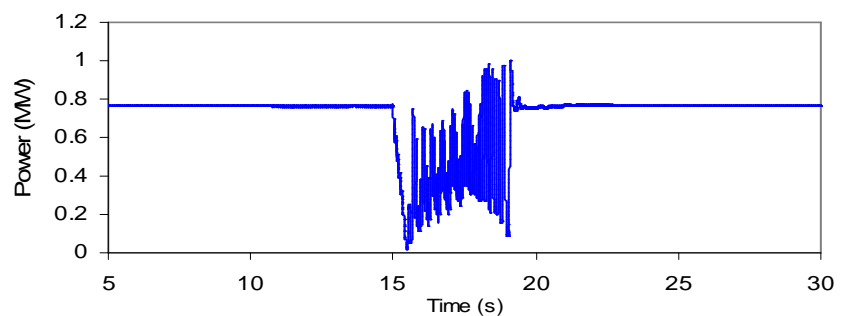

(a)

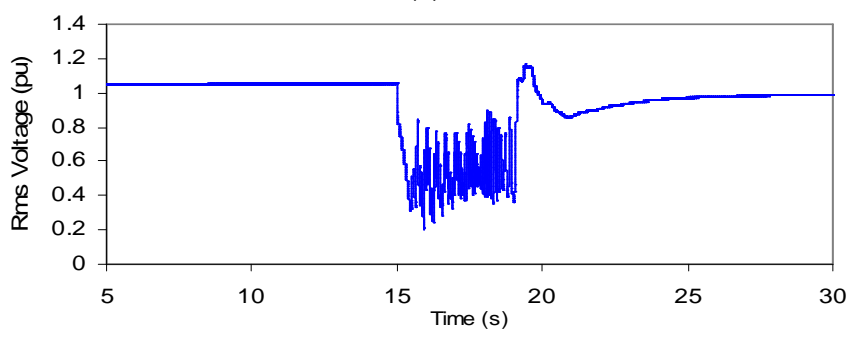

(b)

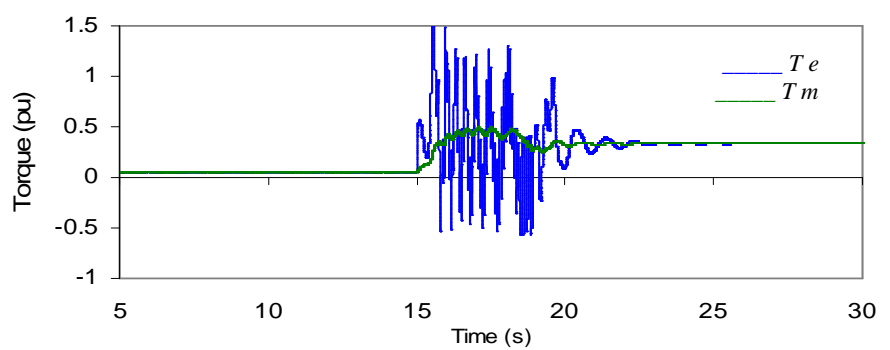

(c)

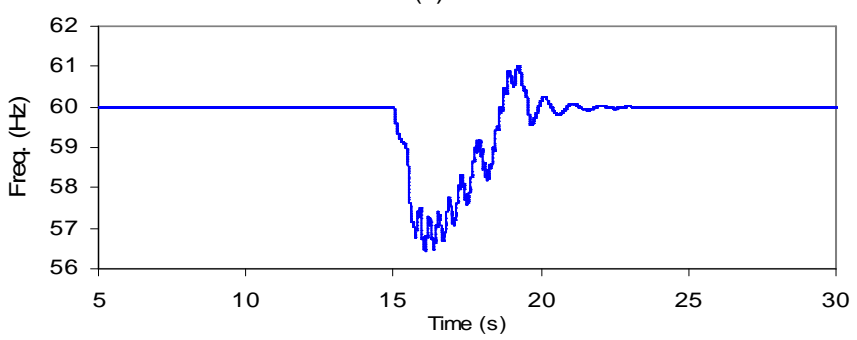

(d)

Figura 5.15. (a) Potência do gerador na PCH, (b) Valor eficaz (pu) da tensão, (c) Torque elétrico e mecânico, (d) Frequência do gerador. 


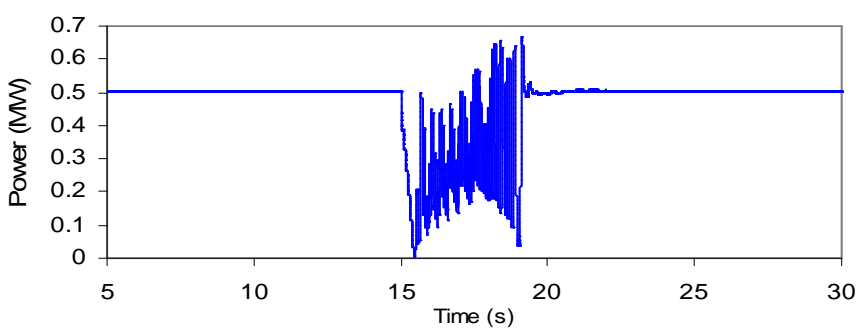

(a)

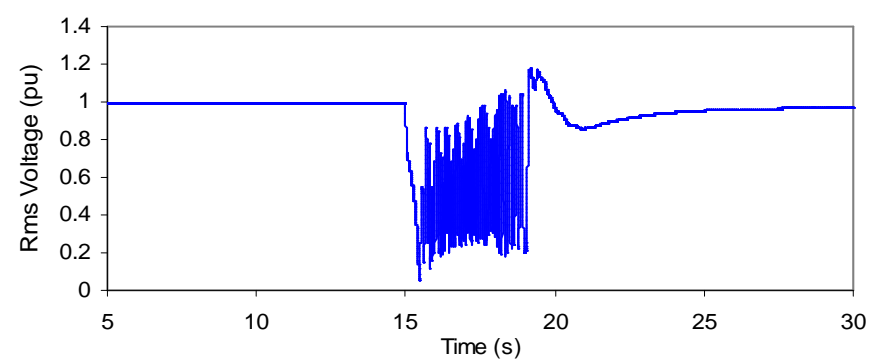

(b)

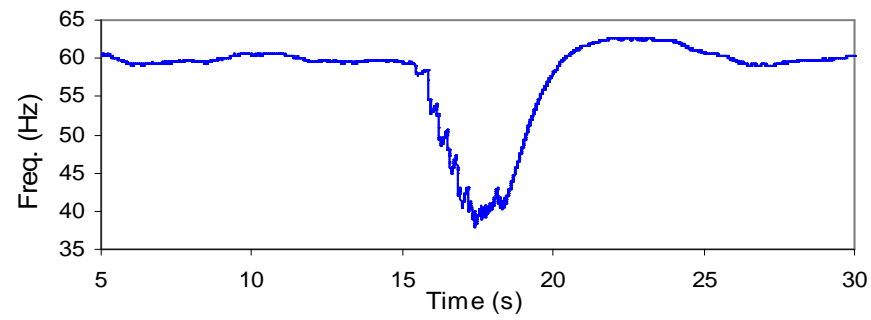

(c)

Figura 5.16. (a) Potência do gerador DFIG, (b) Valor eficaz (pu) da tensão, (c) Frequência do DFIG.

\subsubsection{Alívio de Carga logo após o llhamento}

Neste caso, considera-se que a MR encontra-se já no modo de operação ilhado alimentando as cargas normais. Em $t=15 \mathrm{~s}$, todas as cargas não previstas (Carga 1A, Carga 2A e Carga $3 A)$ são conectadas de forma inesperada. Estas cargas permanecem conectadas por $300 \mathrm{~ms}$ antes da abertura dos disjuntores DJ-4, DJ-5 e DJ-6, que desconectam as mesmas da MR. A seguir são apresentadas as respostas dos geradores na MR diante desta condição operativa.

\subsection{Gerador Diesel}

A carga não prevista conectada (motor de indução equivalente) é 50\% maior do que a carga normal. Inicialmente, o gerador tenta suprir esta carga, conforme mostrado nas respostas da potência e torque ( $T_{e}$ e $T_{m}$ ) das Figuras 5.17(a) e 5.17(c), respectivamente. No instante em que é aliviada a carga (abertura de DJ-4 em $t=15,3 \mathrm{~s}$ ) o gerador diesel volta em um tempo relativamente pequeno à sua condição de pré-sobrecarga. 
O regulador de tensão restabelece a tensão afetada em menos de um segundo (Figura 5.17b). A frequência cai para aproximadamente $58,7 \mathrm{~Hz}$ (equivalente a $2,17 \%$ do valor nominal), conforma mostrado na Figura 5.17(d).

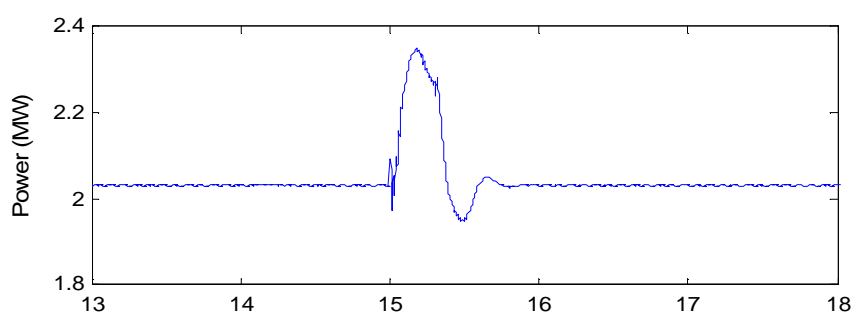

(a)

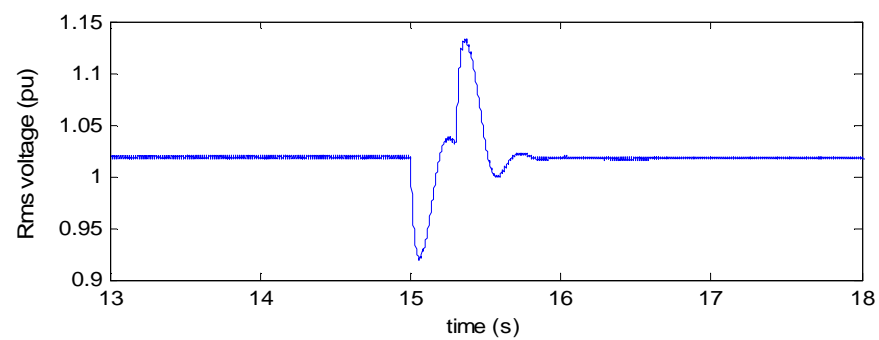

(b)

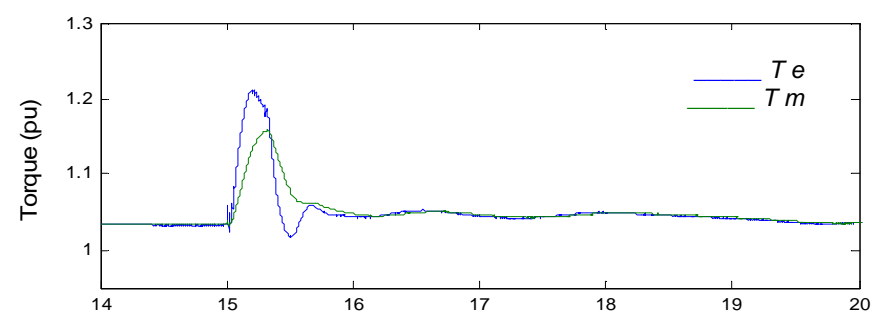

(c)

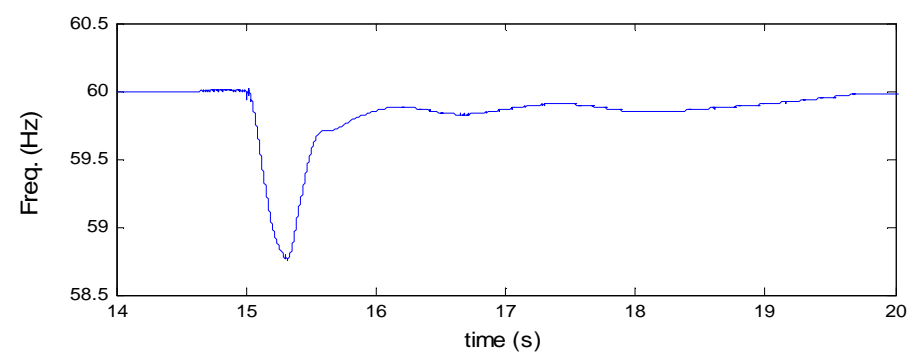

(d)

Figura 5.17. (a) Potência do gerador diesel, (b) Valor eficaz (pu) da tensão, (c) Torque elétrico e mecânico, (d) Frequência do gerador.

Caso fossem aplicadas as estratégias de alívio de carga apresentadas na Seção 5.2.3, o valor percentual de carga a ser removido sería o máximo especificado nas Tabelas 5.1 e 5.2. Por exemplo, segundo a Tabela 5.1, a carga a ser removida, considerando o valor mínimo de $58,7 \mathrm{~Hz}$, seria superior a $15 \%$, ou seja, a quantidade de carga necessária para evitar que a frequência diminua ainda mais. 
Já considerando a Tabela 5.2, a percentagem de carga a ser removida seria superior a 35\%. Isto porque o valor da RoCoF aproximado é $12 \mathrm{~Hz} / \mathrm{s}$, como pode ser observado na Figura $5.17(d)$.

Retomando a proposição inicial do trabalho, a desconexão da carga não prevista na sua integridade fez que a frequência volte a seu valor nominal em aproximadamente 1,0 s. Por outro lado, durante as simulações realizadas, verificou-se que o valor percentual de sobrecarga máximo admitido por este gerador foi de 0,8\% (em regime).

\subsection{Gerador PCH}

Neste caso, a carga não prevista conectada (1 MVA) é igual a $125 \%$ da carga normal $\left(\sqrt{0.75^{2}+0.3^{2}}=0,8 \mathrm{MVA}\right)$. As respostas da potência do gerador $\mathrm{PCH}$ e seus torques são mostrados na Figura 5.18(a) e Figura 5.18(c), respectivamente.

Observa-se certo grau de dificuldade deste gerador para voltar a sua condição estável após ser desligada a carga adicional. Isto acontece em virtude to tamanho da carga adicional e o tempo de permanência desta carga.

A tensão nos terminais da máquina cai para aproximadamente 0,85 pu (Figura 5.18b), enquanto que o valor da frequência durante esta condição reduz-se para $58,1 \mathrm{~Hz}$ (queda de $3,17 \%$ do valor nominal), conforme mostrado na Figura 5.18(d).

\subsection{Gerador Eólico DFIG}

A carga não prevista conectada ao gerador DFIG é o dobro da carga normalmente programada (2×0,5 MVA). O maior impacto ocorre na potência de saída do DFIG (Figura 5.19a), que tenta sem sucesso suprir com energia essa demanda.

Na Figura 5.19(b) pode ser observada a queda de tensão de 1,0 pu para aproximadamente 0,75 pu. Após ter sido removida a carga não prevista o gerador DFIG não apresenta oscilações significativas, isto por causa dos parâmetros otimizados especificados nos controladores após varias tentativas e erros nas simulações.

Turbinas eólicas, especialmente as de pequeno porte, geralmente não admitem sobrecarga. Para evitar essa condição, estas vêm munidas dos respectivos sistemas de protecção como o controle do àngulo de pitch e stall, e outros sistemas especificos. 


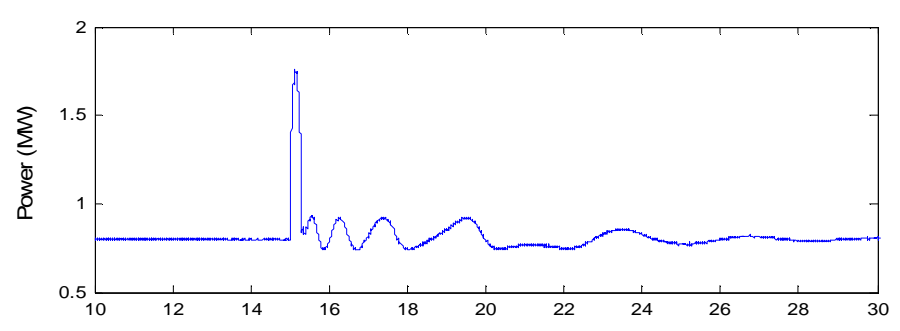

(a)

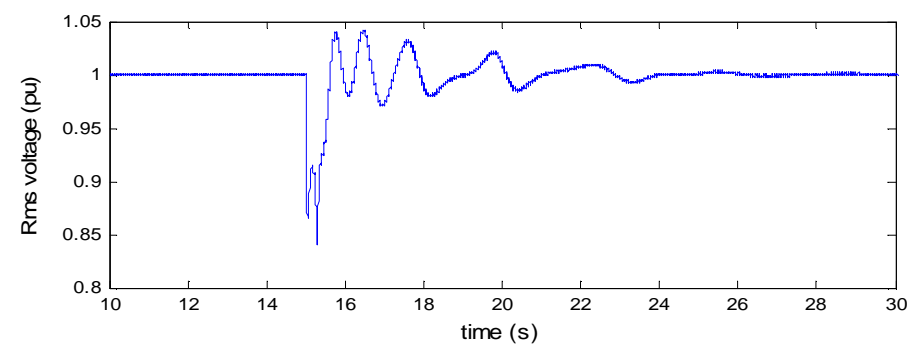

(b)

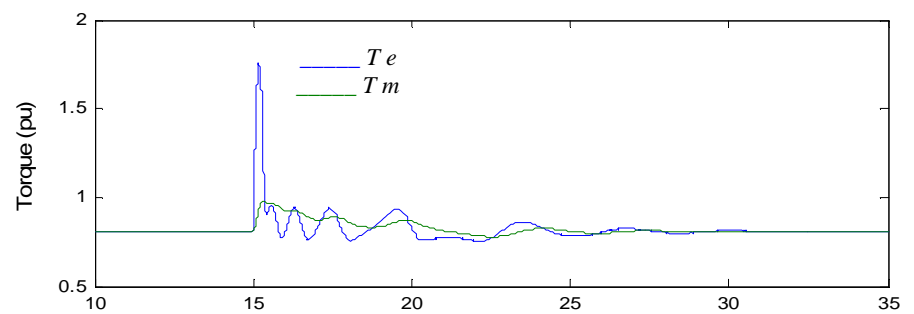

(c)

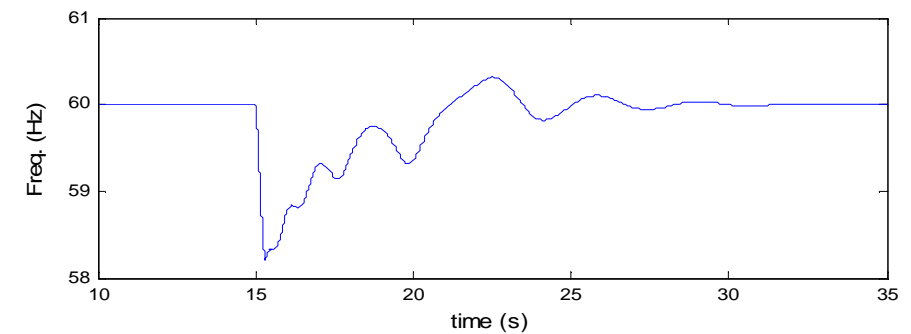

(d)

Figura 5.18. (a) Potência do gerador na PCH, (b) Valor eficaz (pu) da tensão, (c) Torque elétrico e mecânico, (d) Frequência do gerador.

O caso aqui apresentado é na realidade um caso de sucesso na desconexão da carga adicional. Pode haver situações de colapso da MR devidos à falha na desconexão desta carga. Foram também simulados casos de sobrecarga com tempos de permanência da carga maiores ao aqui especificado (maiores a $300 \mathrm{~ms}$ ) que levaram à instabilidade e colapso da MR. 


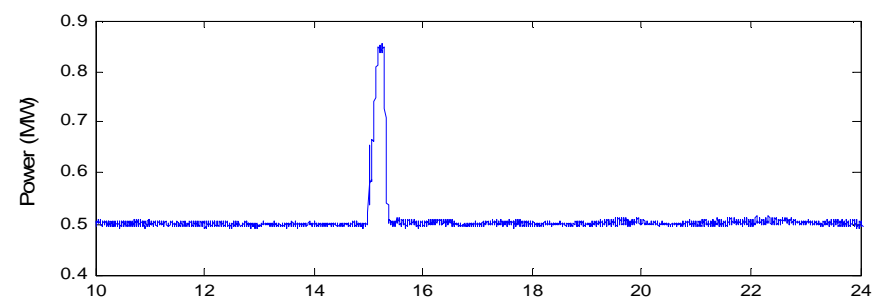

(a)

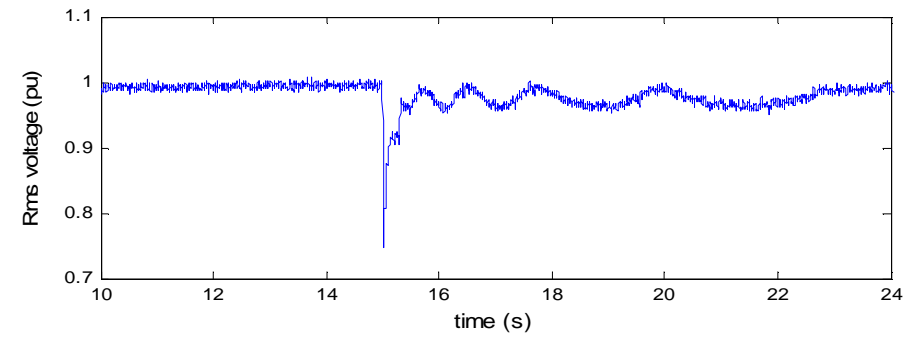

(b)

Figura 5.19. (a) Potência do gerador DFIG, (b) Valor eficaz (pu) da tensão.

\subsubsection{Perda de um Gerador}

Este caso de perda de um gerador pode representar um caso típico de sobrecarga. Entre as causas da perda de um gerador podem ser mencionadas a falta de vento, erros na comutação de circuitos, bloqueio mecânico do eixo do gerador, problemas de controle, etc. Inicialmente, o sistema se encontra operando normalmente quando em $t=10 \mathrm{~s}$ ocorre a perda de um dos geradores. Será assumido que o gerador DFIG é quem fica fora de serviço e que a carga normal correspondente ao mesmo (DFIG) permanece ligada durante 5 s antes de ser desconectada da MR. Sob essas considerações serão apresentados a seguir os efeitos desta perturbação sobre os geradores restantes (diesel e PCH).

\subsection{Gerador Diesel}

Devido a que o gerador diesel é o maior de todos, a saída do DFIG tem um efeito menor sobre ele. Como o gerador diesel esteve operando com sua plena carga, não pode fornecer energia para a carga deixada pelo DFIG. Esta resposta pode ser observada na Figura 5.20(a) na qual a potência do gerador diesel permanece praticamente constante. Assim também, tanto $T_{m}$ como $T_{e}$ são levemente afetados (aproximadamente 0,01 pu do valor normal), conforme mostrado na Figura 5.20(b).

No entanto, apesar de não ter sido aceita carga adicional alguma, a velocidade da máquina é afetada em virtude do leve aumento do torque. Este aumento no torque se traduz em uma (pequena) queda da freqüência (Figura 5.20c) de aproximadamente $0,1 \mathrm{~Hz}$ (cerca de 0,17\% do valor nominal, $60 \mathrm{~Hz}$ ). 


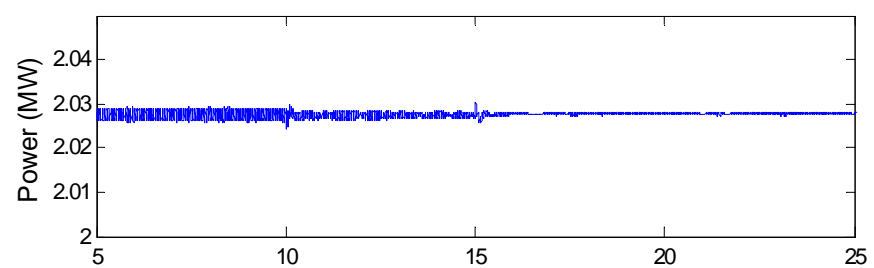

(a)

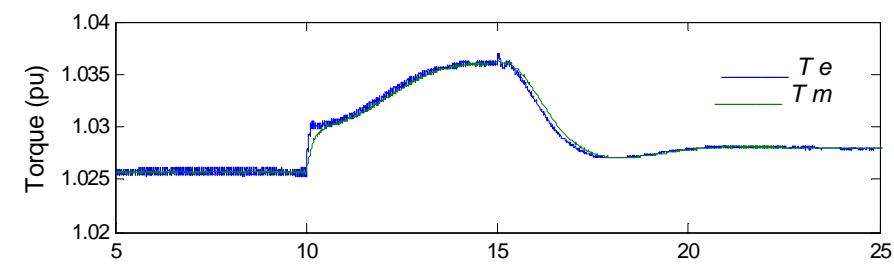

(b)

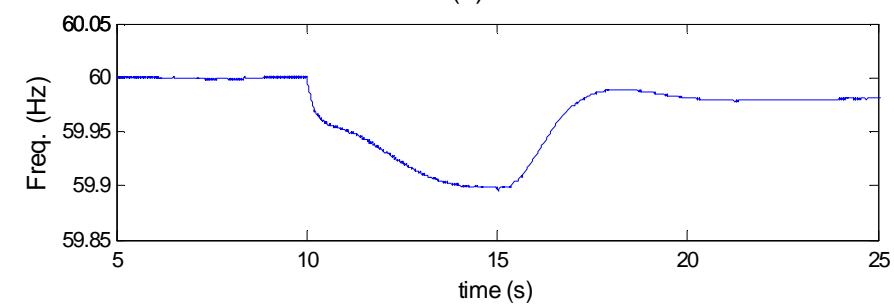

(c)

Figura 5.20. Gerador diesel: (a) Potência nos terminais, (b) Torque elétrico e mecânico, (c) Frequência do gerador.

\subsection{Gerador PCH}

$\mathrm{O}$ gerador da $\mathrm{PCH}$ tem que lidar com um impacto pouco maior em relação ao gerador diesel. Porém, a carga deixada pelo DFIG representa apenas uma pequena porção (menor a $18 \%$ ) da carga total (Figura 5.21a).

O regulador de tensão da $\mathrm{PCH}$ atúa rapidamente restabelecendo a tensão normal (Figura 5.21b). Tanto o torque elétrico quanto mecânico ( $T_{e}$ e $\left.T_{m}\right)$ voltam a seus valores normais após a desconexão da carga adicional (Figura 5.21c).

Finalmente, durante o período de sobrecarga, a frequência deste gerador (Figura 5.21d) apresenta uma queda de aproximadamente $0,14 \mathrm{~Hz}$ (cerca de $0,23 \%$ do valor nominal), valor este que está dentro dos limites de tolerância admitidos pela maioria dos países. 


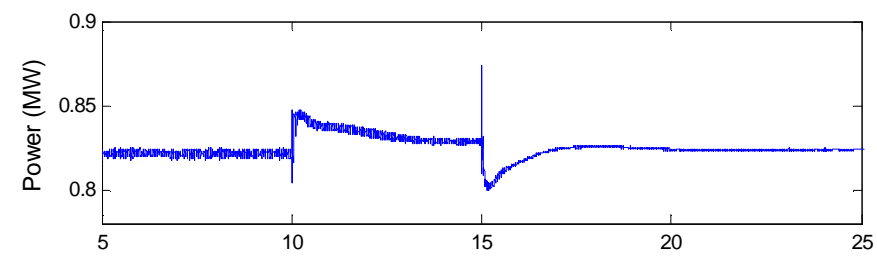

(a)

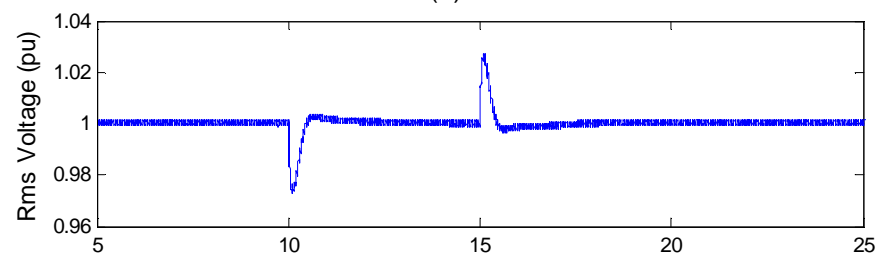

(b)

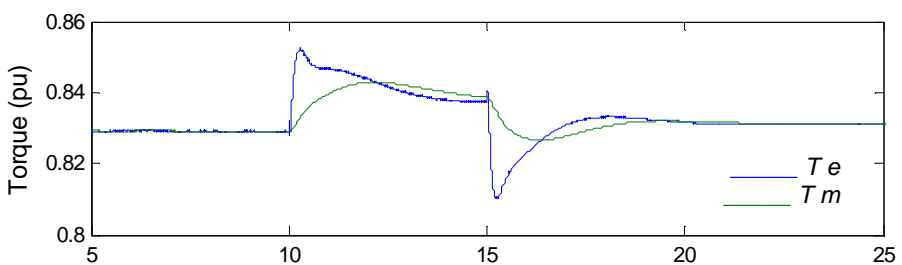

(c)

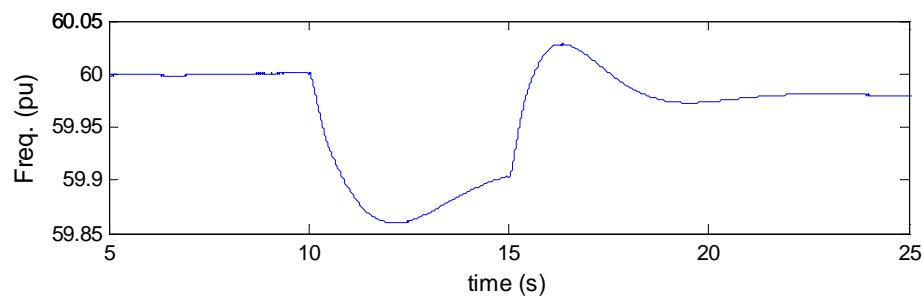

(d)

Figura 5.21. Gerador na PCH: (a) Potência nos terminais, (b) Valor eficaz (pu) da tensão, (c) Torque elétrico e mecânico, (d) Frequência do gerador.

\subsubsection{Falha na Desconexão da Carga não Prevista}

Observou-se que caso houver falha na desconexão das cargas não previstas, tanto no modo de ilhamento pré-planejado como forçado, os geradores da MR estarão diante um colapso iminente. Embora estes resultados não estejam inclusos na tese, foram mostrados na referência [94]. Por outro lado, apesar de uma pequena parcela de sobrecarga possa ser conectada aos geradores, na prática, esta deve ser evitada; isto por causa dos problemas de sobreaquecimento e desgaste que podem surgir devido a tais condições de operação.

Percebe-se que, ao longo do estudo, não foram feitas considerações relacionadas ao sistema de proteção contra sobrecarga comumente encontrada em geração. Sob estas condições (sobrecarga) a proteção de sobrecorrente deverá atuar após a corrente atingir um determinado valor, evitando assim que o gerador sofra qualquer dano. 
Em suma, neste capítulo foram apresentados os resultados das perturbações mais comuns em micro-redes elétricas. Especificamente foram analisados a resposta da MR durante os modos de ilhamento pré-planejado e forçado assim como do comportamento diante do alívio de carga, perda de um gerador e a falha na desconexão de cargas não previstas.

O ajuste adequado dos reguladores de tensão e velocidade de cada gerador fez que as oscilações de frequência sejam amortecidas e restabelecidas em periodos relativamente curtos.

A desconexão relativamente rápida de cargas "não previstas" mostrou que a estratégia de alívio de carga ainda é a alternativa mais comun para manter a operação da MR após essa perturbação. O tamanho da carga não prevista irá determinar, particularmente, o valor da queda de frequência e, portanto, o grau de resposta que o regulador de velocidade irá ter.

\subsection{Estudos de Sobretensão na MR}

Em um artigo recentemente submetido a um periódico internacional [101], foram analisadas às sobretensões que poderiam aparecer em uma MR produto de correntes de falta faseterra em uma MR ilhada. Para isso foi utilizada uma MR similar ao da Figura 5.10, exceto que neste caso foram removidas as cargas extras assim como inserida uma linha aérea, conforme mostrado na Figura 5.22.

Devido ao efeito das ondas trafegantes ao longo de cabos e linhas aéreas que compõem a micro-rede, essas sobretensões podem ser amplificadas comprometendo o nível de isolamento da MR como um todo. Grande parte dos trabalhos tratando o assunto de sobretensões está dirigido a sistemas de alta tensão, deixando uma lacuna para o estudo deste fenômeno em micro-redes.

Tanto os cabos e linhas aéreas que constituem o sistema de transmissão da MR foram caracterizados pelos seus parâmetros R-L-C. Segundo as Normas da ANSI e IEEE o mínimo BIL (Basic Impulse Insulation Level) e BSL (Basic Impulse Switching Level) para o nível de tensão de 2,4 kV são 20 kV e 10 kV, respectivamente. Assim, é importante verificar se as fases sãs onde comumente aparecem essas sobretensões (faltas fase-terra) não sejam ultrapassadas no seu nível de isolamento. 


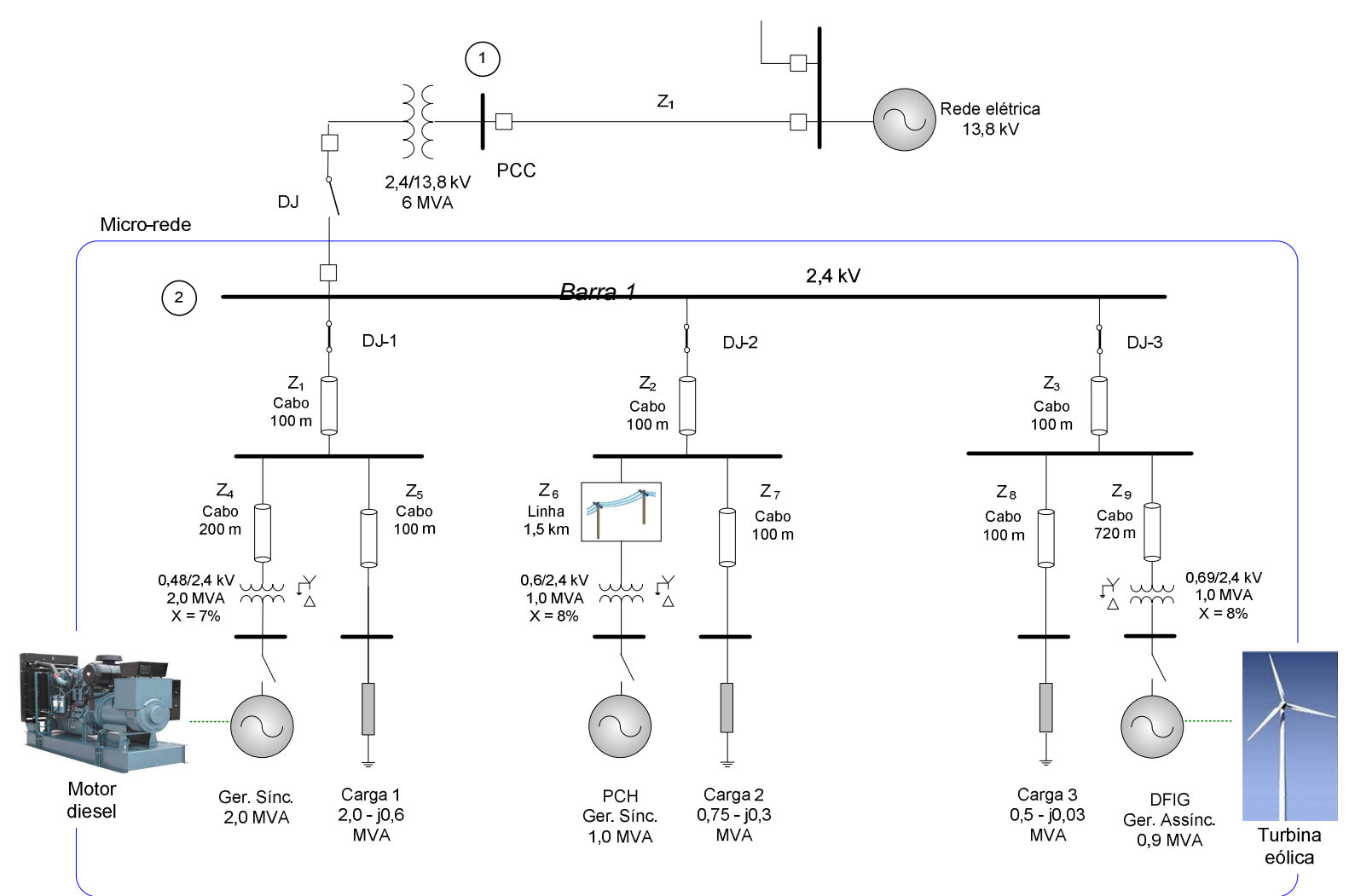

Figura 5.22. Micro-rede ilhada utilizada na análise de sobretensões.

Os tipos de faltas simuladas no programa ATP, que dão origem a estas sobretensões, são:

- Falta fase-terra

- Falta fase-fase

- Falta dupla fase terra

- Rompimento de condutor

Outros tipos de sobretensões (por exemplo, devido a ferrorressonância, energização de linha, manobra de disjuntores, etc) não serão considerados, pois estes precisam de uma abordagem diferente. Não são também abordadas sobretensões devidas a descargas atmosféricas. Neste tipo de faltas (fase-terra) a impedância de sequência zero da MR deve ser incluída na análise. Quase todos os parámetros dos diferentes componentes da MR (inércia das máquinas, reatâncias subtransitórias, etc) são similares aos da MRs utilizada na Seção 5.3.2.

Todos os cabos com impedâncias $Z_{1}$ até $Z_{9}$, exceto $Z_{6}$, foram considerados como tendo parâmetros similares, com exceção de seus comprimentos que podem ser diferentes, conforme mostrado na Figura 5.2.2. 
Para a obtenção destes parâmetros, assim como a impedância da linha aérea $\left(Z_{6}\right)$, foram utilizados dados de catálogos comerciais bem como sua geometria (Figura 5.23). O tipo do cabo utilizado corresponde ao 500MCM (cobre), cuja máxima corrente, no ducto, é de aproximadamente $470 \mathrm{~A}\left(90^{\circ} \mathrm{C}\right)$.

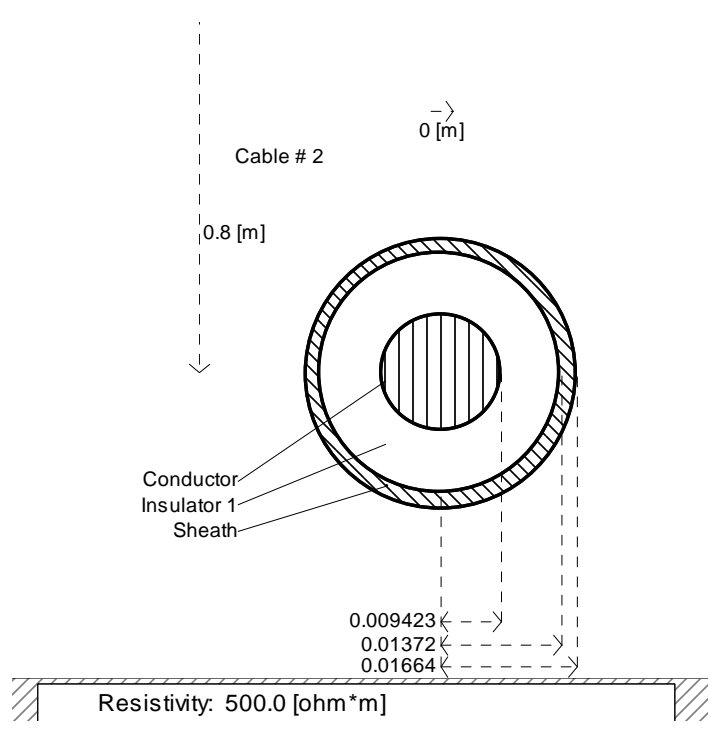

(a)

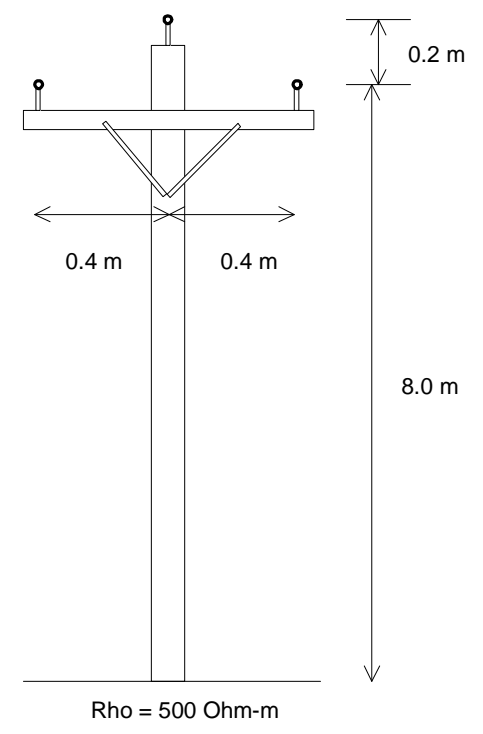

(b)

Figura 5.23. (a) Detalhe do cabo utilizado, (b) dimensões da linha aérea utilizada.

Da Tabela 5.3, retirada da referência [95], pode-se obervar que a suportablidade de curta duração (Norma IEC) para a tensão máxima do sistema de $3,6 \mathrm{kV}\left(V_{\text {nom }}=2,4 \mathrm{kV}\right)$ é igual a 10 kV rms (fase-terra), enquanto que o valor de crista do BIL está na faixa $20 \mathrm{kV}$ a $40 \mathrm{kV}$, dependendo do tipo de sistema. A Norma do IEEE não especifica estes valores para sistemas cujas tensões máximas sejam de $3,6 \mathrm{kV}$ a $12 \mathrm{kV}$. Assim, as sobretensões aqui calculadas serão comparadas com os valores dados pela Norma IEC.

Devido a que sistemas com tensões inferiores a $36 \mathrm{kV}$ são particularmente propensas a agressões externas no que se refer ao seu isolamento (encostamento de árvores e prédios, vandalismo, etc.) maiores valores de suportabilidade da tensão de curta duração e baixa freqüência são alocados (maior a duas vezes o valor da máxima tensão fase-fase, $V_{m}$ ). Assim, os valores do BIL para estas faixas de tensão são maiores, oferecendo proteção adicional ao BSL. Por outrol lado, em sistemas cuja tensão é superior a $245 \mathrm{kV}$ as sobretensões por BSL são um fator desicivo para o dimensionamento do nível de isolação, enquanto que em sistemas inferiores a $245 \mathrm{kV}$ o valor do BIL é mais importante do que o BSL (IEEE Std C62.82.1, 2010). 
Tabela 5.3. Tensões do BSL e BIL em sistemas de baixa tensão.

\begin{tabular}{|c|c|c|c|c|c|}
\hline \multicolumn{6}{|c|}{$\begin{array}{l}\text { IEC 71-1, 1993-12 Insulation coordination Part 1: Definitions, principles and rules. } \\
\qquad \text { Range } 1: 1 \mathrm{kV}<U_{m} \leq 245 \mathrm{kV}\end{array}$} \\
\hline \multicolumn{2}{|c|}{$\begin{array}{c}\text { Highest voltage } \\
\text { for equipment } \\
U_{m} \\
\end{array}$} & \multicolumn{2}{|c|}{$\begin{array}{l}\text { Standard short- } \\
\text { duration power frequency } \\
\text { withstand voltage }\end{array}$} & \multicolumn{2}{|c|}{$\begin{array}{l}\text { Standard lightning } \\
\text { impulse withstand } \\
\text { voltage }\end{array}$} \\
\hline \multicolumn{6}{|c|}{$\begin{array}{l}\text { IEEE 1313.1-1996 Insulation Coordination - Definitions, principles and rules, } \\
\text { Class 1: } 15 \mathrm{kV}<V_{m} \leq 242 \mathrm{kV}\end{array}$} \\
\hline \multicolumn{2}{|c|}{$\begin{array}{c}\text { Maximum } \\
\text { system voltage } \\
\text { (phase-to-phase) } V_{m}\end{array}$} & \multicolumn{2}{|c|}{$\begin{array}{l}\text { Low-frequency, } \\
\text { short-duration } \\
\text { withstand voltage } \\
\text { (phase-to-ground) }\end{array}$} & \multicolumn{2}{|c|}{$\begin{array}{c}\text { Basic lightning impulse } \\
\text { insulation level } \\
\text { (phase-to-phase) } \\
\text { BIL }\end{array}$} \\
\hline \multicolumn{2}{|c|}{$\mathrm{kV}$, rms value } & \multicolumn{2}{|c|}{$\mathrm{kV}$, rms value } & \multicolumn{2}{|c|}{$\mathrm{kV}$, crest value } \\
\hline IEC & IEEE & IEC & IEEE & IEC & IEEE \\
\hline 3.6 & & 10 & & 20,40 & \\
\hline 7.2 & & 20 & & 40,60 & \\
\hline 12 & & 28 & & $60,75,95$ & \\
\hline 17.5 & 15 & 38 & 34 & 75,95 & 95,110 \\
\hline 24 & 26.2 & 50 & 50 & $95,125,145$ & 150 \\
\hline 36 & 36.2 & 70 & 70 & 145,170 & 200 \\
\hline 52 & 48.3 & 95 & 95 & 250 & 250 \\
\hline 72.5 & 72.5 & 140 & $\begin{array}{l}95 \\
140\end{array}$ & 325 & $\begin{array}{l}250 \\
350\end{array}$ \\
\hline
\end{tabular}

\subsubsection{Simulações}

Foi assumido que as faltas anteriormente mencionadas ocorrem na Barra 1 (Figura 5.22). As mesmas (faltas) ocorrem em $t=22.5$ ms e são mantidas pelo resto da simulação. A fim de simular as piores condições, o valor da resistência da falta foi considerada igual a $0,001 \Omega$. A seguir são apresentados os resultados obtidos nas simulações.

\subsubsection{Falta Fase-Terra}

Uma das premissas da micro-rede considerada é que a sua corrente de curto-circuito seja limitada a valores relativamente baixos (menor a $4 \mathrm{KA}$ ). Assim, o lado conectado em estrela dos três transformadores foi aterrado através de uma resistência de 39,8 $\Omega$. A Figura 5.24(a) mostra que, com esta resistência de aterramento a corrente de falta na Barra 1 é limitada a $3,2 \mathrm{kA}$ (pico).

A redução desta resistência a um valor baixo (por exemplo, 0,398 $\Omega$ ) deu uma corrente de falta (valor de pico) igual a 8,74 kA (Figura 5.24b). A partir destas simulações preliminares pode-se afirmar que para valores baixos da resistência de aterramento a corrente de falta é alta, mas as sobretensões são relativamente baixas. Contrariamente, valores relativamente elevados desta resistência limitam a corrente de falta, mas as sobretensões nas fases sãs são maiores. 
Em todos os casos apresentados a seguir foi considerada a resistência de $39,8 \Omega$. Observase que ambas as correntes de falta na Figura 5.24 possuem a componente $\mathrm{CC}$ de offset.

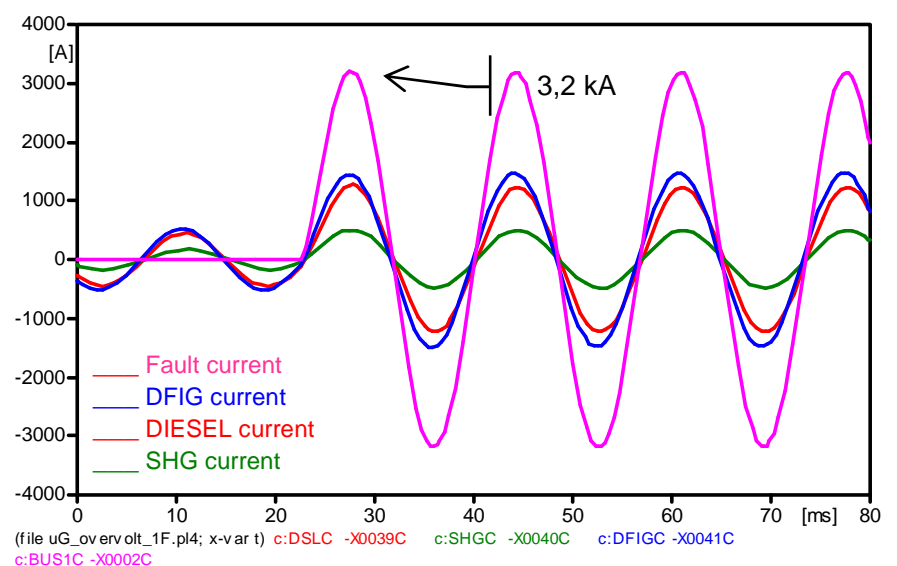

(a)

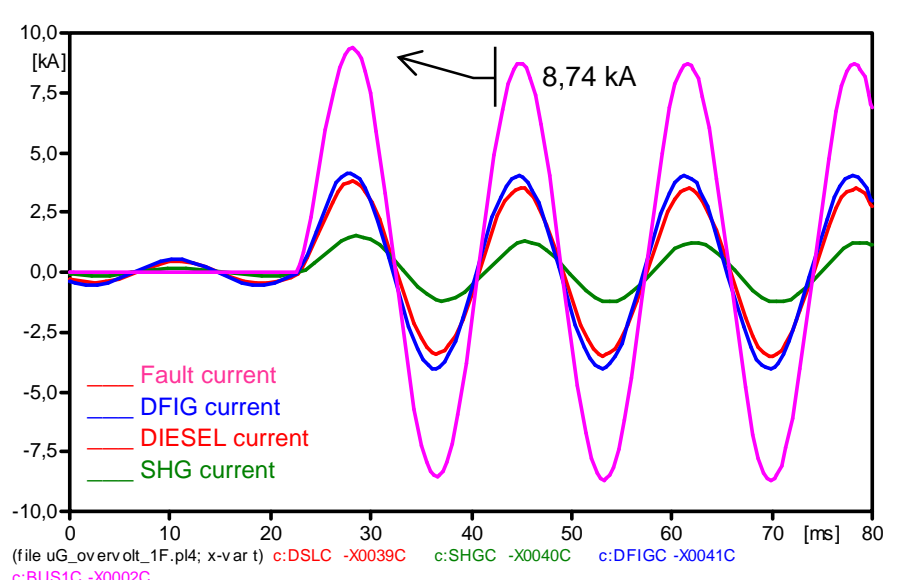

(b)

Figura 5.24. Correntes de falta medidas: (a) $R_{\text {Transf }}=39,8 \Omega$, (b) $R_{\text {Transf }}=0,398 \Omega$.

A tensão fase-terra das fases sãs ( $A$ e B) está sendo mostrada na Figura 5.25. O aumento da tensão (pico) nestas fases é de cerca de 1,7 vezes a tensão de pré-falta. Assim, a sobretensão fase-fase (valor eficaz) nestas fases ( $\mathrm{A}$ e B) será de aproximadamente $V_{\text {rms }}=$ $3,28 * \sqrt{ }(3 / 2)=4,02 \mathrm{kV}$. Este valor é inferior ao valor de suportabilidade considerado pela Norma IEC mostrada na Tabela $5.3(10 \mathrm{kV})$. 


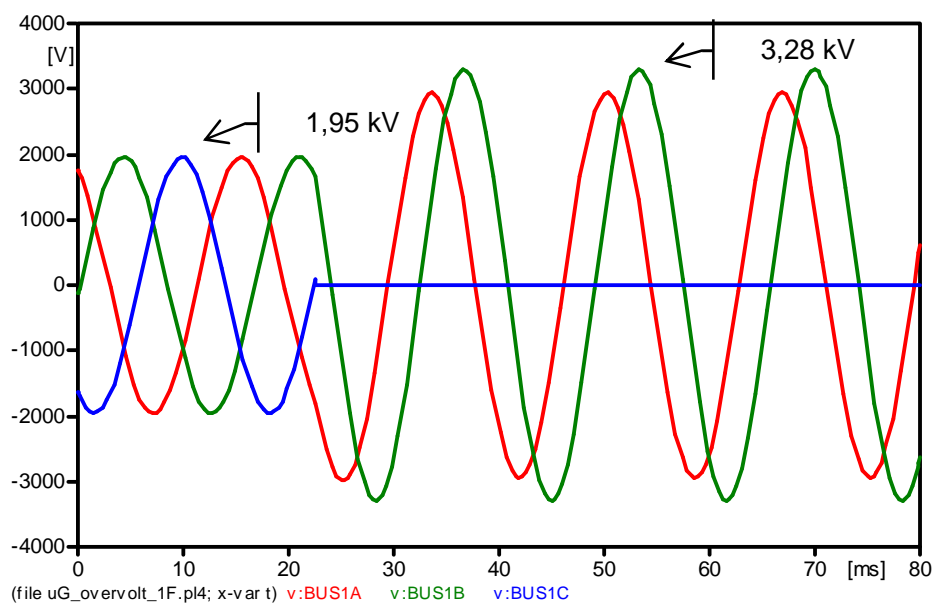

Figura 5.25. Tensões medidas na Barra 1 (fases A e B) durante a falta fase-terra.

\subsubsection{Falta Fase-Fase}

Conforme esperado, a corrente de falta nas fases em curto (fases B e C) mostraram valores elevados (15,4 kA no primeiro pico), mas a fase sã (fase A) não teve sobretensão alguma. Portanto, este tipo de falta, em termos de sobretensão, não oferece risco algúm para a MR.

\subsubsection{Falta Dupla Fase-Terra}

Foi considerado que as fases B e C fazem contato com terra. Embora a corrente de falta (pico) inicial atinge valores de até $15 \mathrm{kA}$, a sobretensão na fase sem falta ( $V_{\text {Barra } 1 A}=2,84 \mathrm{kV}$ ) não foi tão elevada como no Caso 5.4.1.1. A sobretensão fase-fase (eficaz) na fase $A$ foi de aproximadamente $V_{r m s_{-}}=2,84 * \sqrt{ }(3 / 2)=3,5 \mathrm{kV}$.

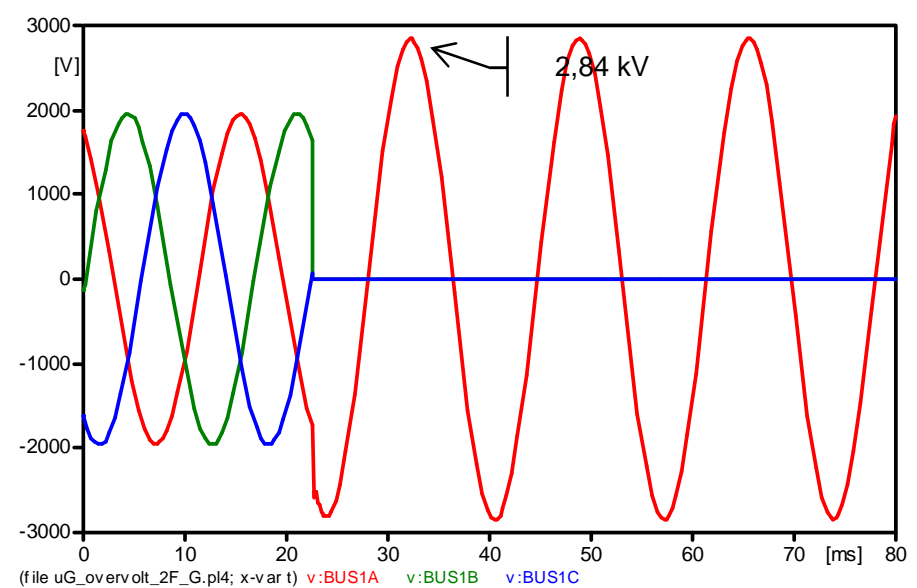

Figura 5.26. Tensões medidas na Barra 1 (fase A) durante a falta dupla fase-terra. 


\subsubsection{Rompimento de Condutor}

O rompimento de condutor em sistemas de baixa tensão pode ocorrer devido a várias causas, a título de exemplo podem ser mencionados: vandalismo, tentativa de roubo de condutor, rompimento por causa de caminhões que transportam cargas elevadas, etc. A corrente de falta, e a consequente sobretensão nas fases não afetadas, depende do tipo de solo sobre o qual o condutor cai. Solos com resistividade elevada (por exemplo, solo rochoso, asfalto seco, etc) darão origem a correntes de falta baixas. Contrariamente, solos com baixa resistividade como argila, e outros solos úmidos, darão lugar a correntes de falta elevadas.

Este tipo de falta foi aplicado no segmento onde foi colocada uma linha aérea (após o transformador da $\mathrm{PCH}$ e a linha LCC, na fase $\mathrm{C}$ ). Foi assumido que a resisitividade do solo é igual a $500 \Omega-\mathrm{m}$. Assumiu-se também que ambas as extremidades do condutor fazem contato com o chão simultaneamente. A tensão de pico obtida logo após a ocorrência da falta (fase B) foi igual a 3,27 kV (próximo ao valor obtido na Seção 5.4.1.1) o que dá um valor de tensão eficaz (fase-fase) de $V_{\text {rms } A}=3,27^{*} \sqrt{ }(3 / 2)=4,0 \mathrm{kV}$ (Figura 5.27). Da Figura 5.28, pode-se ver que a Barra 1 apresenta valores inferiores aos mostrados na Figura 5.27. Portanto, esta condição não apresenta níveis de tensão capazes de comprometer a suportabilidade dos componentes envolta da Barra 1.

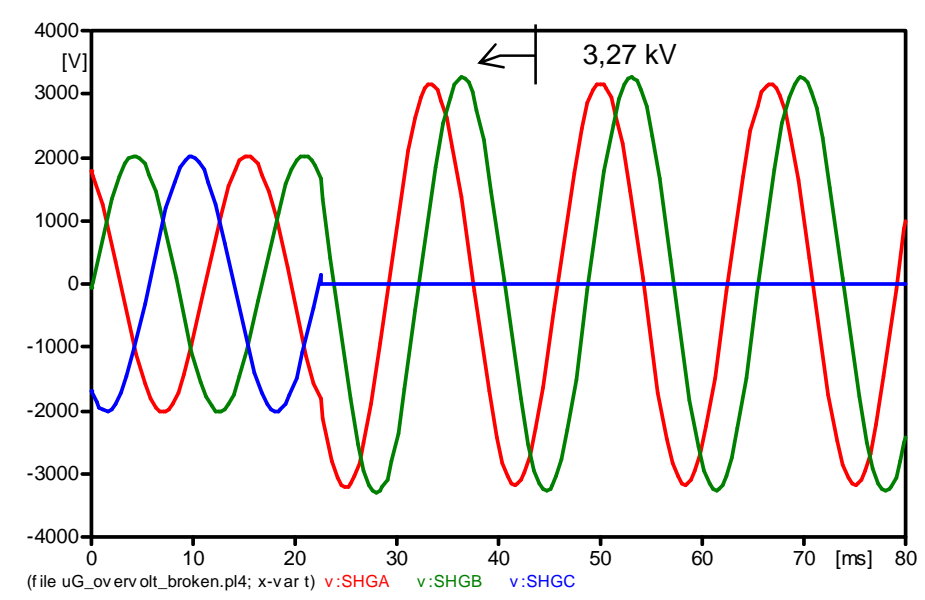

Figura 5.27. Tensões medidas próximas da linha aérea (rompimento de condutor). 


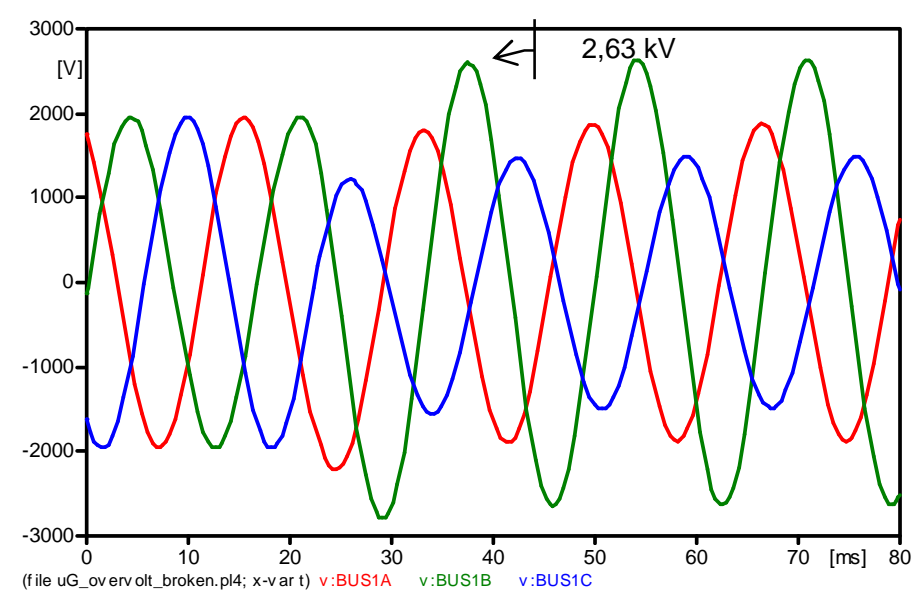

Figura 5.28. Tensões medidas na Barra 1 (rompimento de condutor).

\subsubsection{Falta Fase-Terra sem Carga}

Uma das condições mais desfavoráveis, em termos de criação de sobretensões, é a ocorrência de faltas quando a MR opera sem carga. Isso ocorre porque durante uma falta da carga (se não forem motores) absorve parte da corrente existente no sistema. Para isso, de forma análoga aos casos anteriores, a falta foi aplicada na fase $C$ (Barra 1) e removidas as todas as cargas passivas (cargas 1, 2 e 3).

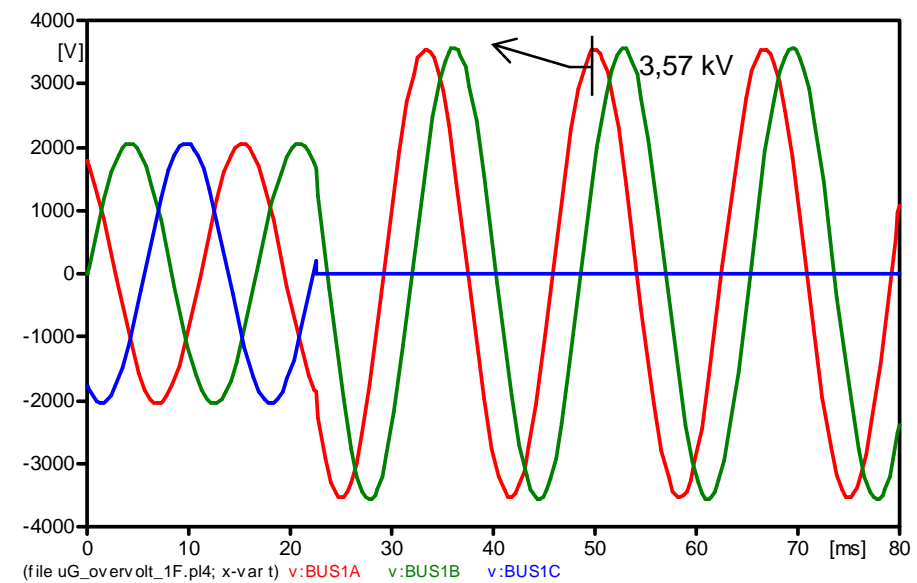

Figura 5.29. Tensões medidas na Barra 1 durante a falta fase-terra sem carga.

A tensão de pico medida na fase $B$ (Figura 5.29) foi igual a $3,57 \mathrm{kV}$, o que dá um valor de tensão eficaz (fase-fase) igual a $V_{r m s \_} A=3,57^{*} \sqrt{ }(3 / 2)=4,4 \mathrm{kV}$. 


\subsubsection{Substituição das Cargas Lineares por Motores Equivalentes}

Posteriormente, as cargas consideradas como potência constante (carga 1, 2 e 3) mostradas na Figura 5.22 foram substituídas por motores síncronos equivalentes com (quase) a mesma potência ativa. Devido à sua natureza intrínseca, a potência reativa do motor será um pouco maior ao da carga anterior (carga com potência constante). Lembrando que no caso de máquinas (motores), parâmetros como as reactâncias de eixo directo e em quadratura, constantes de tempo transitória e subtransitoria, entre outras variáveis, tem de ser especificadas no programa de simulação.

Durante uma falta a tensão do sistema cai; em um esforço para restabelecer esta tensão o campo magnético girante do rotor comporta-se agora como uma fonte extra; fornecendo corrente adicional ao estator, e em consequência para o sistema. De acordo com [96], a contribuição dos motores de indução, em função do seu tamanho e capacidade, tem duração tipicamente entre 1 a 4 ciclos após o inicio da falta. Já a contribuição de motores síncronos pode durar de 6-8 ciclos (tempo maior), daí a utilização de motores síncronos nesta análise.

Devido à semelhança das respostas estes resultados não serão incluídos no trabalho, mas apenas o valor de pico das sobretensões sustentadas (em regime). Na Tabela 5.4 apresentam-se estes valores assim como os resultados obtidos quando a MR tinha cargas especificadas como potência constante, isto para fins de comparação.

Tabela 5.4. Comparação das sobretensões medidas na Barra 1 para cargas com potência constante e substituídas por motores síncronos.

\begin{tabular}{|c|c|c|}
\hline \multirow{2}{*}{$\begin{array}{l}\text { Tipo de falta } \\
\text { (Barra 1) }\end{array}$} & \multicolumn{2}{|c|}{ Sobretensão de pico $(\mathrm{kV})$} \\
\hline & $\begin{array}{c}\text { com potência } \\
\text { constante (carga) }\end{array}$ & $\begin{array}{c}\text { com motores } \\
\text { síncronos (carga) }\end{array}$ \\
\hline F-T & $3,28^{(B)}$ & $3,83^{(A)}$ \\
\hline $\mathrm{F}-\mathrm{F}$ & $1,95(A)$ & $2,75^{(A)}$ \\
\hline F-F-T & $2,84^{(A)}$ & $3,85^{(A)}$ \\
\hline Rompimento cond. & $3,27^{(0)}$ & $3,61(0)$ \\
\hline F-T (sem carga) & $3,57^{(B)}$ & $3,57^{(B)}$ \\
\hline $\begin{array}{l}\text { (A) na fase } A \\
\text { (B) na fase } B \\
\text { (O) na fase } B \text { próxima }\end{array}$ & 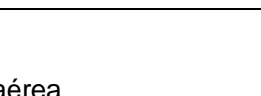 & \\
\hline
\end{tabular}

Observa-se que as sobretensões obtidas utilizando cargas dinâmicas são maiores às obtidas utilizando cargas modeladas como potência constante. Isto se deve à contribuição dos motores para a corrente de falta o que agrava a tensão nas fases sãs do barramento. 
Outra questão de interesse foi observar se a instalação de um pára-raios na Barra 1 ajudaria a reduzir estas sobretensões (caso com motores síncronos). A priori, devido às sobretensões relativamente baixas que foram obtidas, pode-se inferir o pára-raios não terá efeito algúm, mas isso deve ser confirmado após a realização das respectivas simulações. As características do pára-raios comercial instalado são apresentados na Tabela 5.5.

Tabela 5.5. Dados e curva $V$ - $I$ do pára-raios.

\begin{tabular}{|l|c|c|}
\hline \multirow{2}{*}{ Tipo de pára-raios } & $\begin{array}{c}\text { Onda de } \\
\text { impulso 30/60 } \\
(\mathrm{s}\end{array}$ & $\begin{array}{c}\text { Valores máximos da } \\
\text { tensão residual }\end{array}$ \\
\hline \multirow{3}{*}{$\begin{array}{c}\text { 3EL5 } 003 \\
\text { VNominal }=3 \mathrm{kV}\end{array}$} & $125 \mathrm{~A}$ & $6200 \mathrm{~V}$ \\
\cline { 2 - 3 } & $500 \mathrm{~A}$ & $6600 \mathrm{~V}$ \\
\cline { 2 - 3 } & $1000 \mathrm{~A}$ & $6800 \mathrm{~V}$ \\
\hline
\end{tabular}

Conforme antecipado, após realizar as respectivas simulações não foi observado efeito algum sobre essas sobretensões. A razão disto é que, para este pára-raios específico o menor valor da tensão fase-terra na curva $V$-I (onda de impulso de 30/60 (s, usada regularmente para enfrentar surtos de baixa freqüência) é igual a 6,2 kV. Portanto, tensões abaixo deste valor não serão cortadas pelo pára-raios. Contudo, este mesmo pára-raios será essencial no caso de sobretensões produzidas por descargas atmosféricas.

Em suma, pode-se afirmar que sobretensões decorrentes de faltas internas, na MR analisada, são inferiores ao valor de suportabilidade estabelecido pela Norma IEC para sistemas com tensão máxima igual a 3,6 kV (2,4 kV eficaz). 


\section{CAPÍTULO 6}

\section{CONSIDERAÇÕES FINAIS}

\subsection{Constatações e Contribuições da Tese}

Com base no estudo, na análise desenvolvida e nos resultados das simulações obtidas, podem ser estabelecidas as conclusões e destacadas as contribuições que se seguem.

Face às recentes mudanças nas redes elétricas e considerando eventos indesejados como a queda total dos sistemas elétricos de potência por diversas causas (black-outs), as microredes elétricas tem sido consideradas como uma das alternativas para minimizar os efeitos destes eventos.

Em anos recentes, a tecnologia das micro-redes tem mostrado um crescimento substancial para alimentar não só cargas críticas, mas também cargas regulares, principalmente residencial e comercial. Contudo, existem ainda desafios que esta tecnologia deve superar entre os quais podem ser mencionados os aspectos regulatórios e comerciais. Na tese, especificamente no Capítulo 2, estão sendo apresentadas as pesquisas sobre o atual cenário tecnológico, incluindo os principais projetos de MRs no mundo, material este que foi publicado no congresso da IEEE-Latin América, em 2010.

No que concerne às tendências comerciais em MRs, no atual cenário elétrico, foi possível constatar que entre as tarifas e incentivos governamentais de maior aplicação em MRs e produtores independentes de energia elétrica estão: a tarifa feed-in, a tarifa net metering, as políticas de quota (RPS) e os certificados de energia renovável (RECs). No ano de 2012 a ANEEL divulgou uma norma (ANEEL 482/2012) estabelecendo que no Brasil a tarifa net metering será a forma de compensação (econômica) pela energia gerada em sistemas de micro-geração e mini-geração, desde que esta (energia) provenha de fontes renováveis como a hidrelétrica, solar, eólica e biomassa, incluindo a co-geração.

Esta análise foi desenvolvida no Capítulo 3. No que se refere à comercialização de energia entre MRs, até agora existem apenas algumas propostas. O mercado ainda incipiente de MRs para a negociação de energia limita o desenvolvimento de métdos de negociação e suas aplicações práticas. Fatores como a distância geográfica entre MRs, alimentadas por fontes renováveis, devem ser considerados para a comercialização de energia, pois isto presupõe o estabelecimento de redes (linhas ou cabos) de interconecção. 
A comercialização de energia entre MRs próximas (por exemplo, entre predios vizinhos) sería mais vantajoso neste respeito. O estudo abordando os supracitados incentivos tarifários aplicados em diversos países, incluindo o Brasil, foi publicado na Revista IEEE Latin América, em 2014.

No Capítulo 4, foram estudados, inicialmente, a viabilidade econômica de um sistema fotovoltaico residencial, catalogado como uma MR, e logo a vibilidade técnico-económica de uma MR composta por fontes renováveis e um gerador diesel. No primeiro caso (sistema fotovoltaico residencial) foi possível constatar que esta opção é ainda cara e teria um tempo de retorno financeiro relativamente prolongado, se não for apoiada pelos incentivos tarifarios e subsidios governamentais.

No caso específico estudado, inicialmente foi obtido um período de retorno de 12 anos. Isto considerando preços de mercado padrão correspondente a 4 paineis solares do tipo monocristalino com vida útil de 25 anos, incluindo o inversor e mão de obra. Já considerando preços de paineis solares mais baixos, porém que poderiam comprometer a qualidade e vida útil destes, foi obtido um período de retorno igual a 9 anos. Não obstante, com a atual conjuntura energética (crise hídrica no SE do Brasil e o consequente incremento nas tarifas elétricas) este tempo de retorno poderia ser menor. $O$ estudo referente a esta análise foi publicado no congresso do IEEE (ISGT-Latin America), no ano 2013.

Por outro lado, da análise técnico-econômica e de viabilidade de MRs híbridas, também apresentada no Capitulo 4, no qual foram considerados um gerador diesel, uma $\mathrm{PCH}$, um gerador eólico e um sistema de geração fotovoltaico, pode-se concluir que o maior valor dos custos CMM, CET, CV@R, e custo médio sazonal, ocorrem quando existe déficit na MR. Isto por causa da valoração à falta de energia no lado da carga. Estes custos são também elevados quando a MR é suprida de energia apenas pelo gerador diesel (devido ao custo de combustivel) ou quando a MR está exclusivamente alimentada pela concessionária.

Nos outros casos analisados, ou seja com a inclusão de fontes de geração alternativa na $\mathrm{MR}$, estes custos apresentaram valores menores, havendo pequenas diferenças entre estes casos em função do tipo de fonte alternativa utilizada. Por exemplo, o período de maior chuva (Dezembro), favorável à $\mathrm{PCH}$, não é favorável à geração eólica cujo melhor desempenho é no mês de Julho, ou à solar, cujo melhor desempenho mostrou ser no mês de Setembro. O estudo referente a esta análise foi recentemente publicado no congresso da ATINER (2015). 
No Capítulo 5, dedicado específicamente à avaliação técnica de MRs, foram apresentadas as respostas e o desempenho dinâmico dos geradores especificados na MR. Foram realizados dois estudos. O primeiro teve como objetivo analisar e mostrar a resposta das fontes de geração na MR diante de condições como o ilhamento planejado e forçado (por exemplo por causa de faltas na rede), e o segundo considerando uma MR contendo alêm das fontes do primeiro estudo, um gerador eólico do tipo DFIG.

No primeiro caso, onde foi considerado um gerador diesel e um gerador eólico (assíncrono), foi possível observar que a MR pode enfrentar algumas dificuldades, até mesmo tentativas sem sucesso para alcançar a condição de ilhamento. Observou-se que o tempo considerado para abrir a falta (curto-circuito) e a magnitude da sobrecarga nos geradores na micro-rede são fatores que podem levar ao colapso da micro-rede. Os resultados deste estudo deram lugar à publicação de um artigo técnico no congresso IEEE-PES T\&D, em 2012.

No referente ao segundo estudo apresentado no Capítulo 5, simulações mais detalhadas de uma micro-rede no programa PSCAD considerando um gerador diesel, PCH (máquina síncrona) e gerador eólico (DFIG - Doubly Fed Induction Generator), mostraram que estes (geradores), apesar da pequena inercia, possuem boa recuperação diante de sobrecargas de consideração, seguidos do respectivo alivio de carga, desde que estes estejam providos dos respectivos reguladores de tensão e velocidade para lidar com estas condições no sistema. Os reguladores de tensão e velocidade para os geradores (síncronos) diesel e PCH tiveram que ser construidos, pois o programa PSCAD não possue estes reguladores na sua biblioteca de componentes. O gerador eólico DFIG foi implementado de forma detalhada, ajustando os conversores de realimentação, e seus controles, de forma que o gerador ofereça uma resposta rápida e robusta diante de perturbações na rede. Os resultados deste estudo foram publicados no Jornal Internacional Power and Energy Systems do Elsevier, em 2014.

Finalmente no Capítulo 5, foi realizada uma análise sobre as sobretensões devidas a faltas internas e a consequente suportabilidade (nível de isolamento) da MR frente a estas sobretensões. A conclusão deste estudo é que estas (sobretensões) são inferiores ao valor de suportabilidade estabelecido pela Norma IEC para sistemas com tensão máxima igual a 3,6 kV (2,4 kV eficaz). Assim, sob as considerações assumidas no trabalho não há sobretensões perigosas capazes de exceder o valor do BSL (Basic Switching Level) ou BIL (Basic Impulse Level) da MR. Os resultados deste estudo foram recentemente propostos para avaliação no Journal EPE/ SCIRP (2015). 


\subsection{Trabalhos Futuros}

Entre os tópicos que suscitam maior investigação podem ser mencionados os seguintes:

- $\quad$ Estudo detalhado para definir quem será o órgão ou ente que estará a cargo da operação e manutenção da micro-rede elétrica.

- $\quad$ Definição se o sistema de medição e proteção da micro-rede será independente ou estará a cargo da concessionária.

- Estudo da necessidade ou não de uma hierarquia ou arquitetura especial para a conexão da MR à rede da concessionária, de tal forma que não existam procedimentos contraditórios com as regras da própria concessionária ou com as estabelecidas pelo operador do sistema elétrico.

- Verificação da possibilidade de MRs que operem diretamente com CC, desta forma dispensando o uso de inversores CC/CA.

- $\quad$ Pesquisas referentes às usinas virtuais ou VPPs (Virtual Power Plants) são também necessárias dentro da tecnologia das MRs e geração distribuída. Neste modelo (VPP), geradores de pequeno porte distribuídos na rede podem ser vistos e operar dentro do mercado de energia como uma fonte unificada e flexível. Podem também disponibilizar e vender sua potência à rede em forma de "reserva" disponível. De forma similar ao conceito de internet das coisas, baseada no uso da internet para a operação de diversas aplicações no dia a dia, a tecnologia das VPPs é também considerada como uma aplicação da "internet da energia", pelo nexo desta com a internet para seu gerenciamento e operação.

- São também necessárias pesquisas referentes a condomínios inteligentes ou smart buildings, nos quais existe um gerenciamento otimizado do uso da energia através da tecnologia de medidores inteligentes incluindo, inclusive, a conexão de fontes alternativas de pequeno porte como painéis solares, geradores eólicos, etc.

- Seria interessante desenvolver um estudo referente à possibilidade de inserção, na MR, de sistemas de armazenamento capazes de injetar energia na rede elétrica durante períodos nos quais o preço da energia é favorável e atrativa à MR. 


\section{REFERÊNCIAS}

[1] MARNAY, C.; FIRESTONE R. Microgrids: An emerging paradigm for meeting buildingy and heat requirements efficiently and with appropriate energy quality. Califórnia: Berkeley National Laboratory. Disponível em: <http://der.lbl.gov/publications/microgrids>. Acesso em: 13 Abr 2011.

[2] HATZIARGYRIOU N.; Microgrids - Large scale integration of microgeneration. In: Conference on the Integration of Renewable Energy Sources and Distributed Energy Sources, Brussels, 2004.

[3] SOSHINSKAYA M, WINA H.J. et al. Microgrids: Experiences, barriers and success factors. Renewable and Sustainable Energy Reviews. Science Direct. v. 40, p. 659-672. Dez. 2014

[4] MARNAY, C.; ZHOU, N.; QU, M.; ROMANKIEWICZ J. International microgrid assessment: governance, incentives, and experience (IMAGINE). Lawrence Berkeley National Laboratory Publications, Jun. 2012. Disponível em: <http://eaei.lbl.gov/international-microgrid-assessment-governanceincentives-and-experience-imagine> Acesso em: 14 nov 2012

[5] SCHWAEGERL, C.; TAO, L.; LOPES J. P., et al. Advanced architectures and control concepts for more microgrids. STREP project funded by the EC under 6FP, SES6-019864, Erlangen, Germany, 2009. Disponível em: http://www.microgrids.eu/documents/668.pdf Acesso em: 13 abr 2011.

[6] HATZIARGYRIOU, N.; DIMEAS, A.; TSIKALAKIS, A. Centralized and decentralized control of microgrids. International Journal of Distributed Energy Resources, v. 1, p. 197-212, 2005.

[7] TSIKALAKIS, A.G.; HATZIARGYRIOU, N.D. Centralized control for optimizing microgrids operation. IEEE Transaction on Energy Convertion, v. 23, Mar. 2008. Disponível em:<ieeexplore.ieee.org/iel5/60/4453975/04454000.pdf> Acesso em 07 Abr 2011.

[8] DIMEAS, A.L.; HATZIARGYRIOU, N.D. Operation of a multiagent system for microgrid control. In: IEEE Power Engineering Society General Meeting, v. 1, 6-10 Jun. 2004. pp. 55-58.

[9] RASHEDUZZAMAN, M.; BHASKARA, S.N.; CHOWDHURY, B.H. Implementation of a microgrid central controller in a laboratory microgrid network. In: ABNorth American Power Symposium (NAPS), 9-11 Sept. 2012 .

[10] KING D.E., Electric power microgrids: Opportunities and challenges for an emerging distributed energy architecture. $186 \mathrm{pp}$. Tese (Doutorado). Universidade de Carnegie Mellon Pittsburgh, 2006.

[11] COSTA P. M, Regulação da Integração de Micro-geração e Micro-redes em Sistemas de Distribuição de Energia Eléctrica. 108 pp. Tese (Doutorado). Universidade de Porto, Portugal, 2008.

[12] LUBNA, M.; MALABIKA, B.; CONLON, M. A review of existing microgrid architectures. Journal of Engineering, p. 1-8, 2013. Disponível em:<http://dx.doi.org/10.1155/2013/937614> Acesso em: 18 Jun. 2013.

[13] HATZIARGYRIOU, N.; ASANO, H.; et al. Microgrids - an overview of ongoing research, development, and demonstration projects. In: IEEE Power \& Energy Magazine, Jul/Aug. 2007. Disponível em:< http://der.lbl.gov/sites/der.lbl.gov/files/LBNL-62937.pdf>, Acesso em: 13 Mar. 2010.

[14] USTUN, T.S.; OZANSOY, C.; ZAYEGH, A. Recent developments in microgrids and example cases around the world - a review. Renewable and Sustainable Energy Reviews Science Direct. v. 15, p. 4030-4041, out. 2011. 
[15] HOSSAIN E.; KABALCI E.; et. al.' Microgrid testbeds around the world: State of art. Energy Conversion and Management, Science Direct, v. 86, p. 132-153, out. 2014.

[16] AGENCIA NACIONAL DE ENERGIA ELÉTRICA (ANEEL), Resolução Normativa no 482, de 17 de abril de 2012. Disponível em: < www.aneel.gov.br/cedoc/ren2012482.pdf > Acesso em: 16 Mai. 2012.

[17] IEEE Std 1547.2-2008, IEEE Standard for Interconnecting Distributed Resources with Electric Power Systems, p. $1-207,2009$.

[18] IEEE Std 1547-2003, IEEE Standard for Interconnecting Distributed Resources With Electric Power Systems, p. $1-16,2003$.

[19] GAURAV, S.; SARKAR, S. Pricing games among interconnected microgrids. In: 2012 IEEE Power and Energy Society, General Meeting, 22-26 Jul. 2012. San Diego, CA.

[20] ALI M.S. Electricity Trading Among Microgrids. Diss. (Mestrado). p. 87. Universidade de Strathclyde, Escócia, 2009.

[21] SINHA, A.; LAHIRI, R.N.; NEOGI, S.; CHOWDHURY, S. Analysis of market price for distributed generators (DGs) in microgrids. In: $6^{\text {th }}$ International Conference on the European, Leuven, 27-29 Mai. 2009.

[22] KIM, H.; THOTTAN, M. A two stage market model for microgrid power transactions via aggregators. Bell Labs Technical Journal, v. 16, p. 101-107, 2011.

[23] SAWIN, J.L. Renewables 2013, Global Status Report, Ren 21. Paris, p. 178, 2013. Disponível em: http://www.ren21.net/REN21Activities/GlobalStatusReport.aspx Acesso em: 14 ago. 2013.

[24] NEW YORK STATE ENERGY RESEARCH AND DEVELOPMENT AUTHORITY, Microgrids: an assessment of the value, opportunities and barriers to deployment in New York state. Final Report 10-35, Sep. 2010. Disponível em: <http://www.nyserda.ny.gov/ /media/Files/ Publications/Research/Electic\%20Power\%20Delivery/1035microgrids.ashx?sc_database=web> Acesso em: 16 abr, 2012.

[25] MATAMOROS, J.; et al. Microgrids energy trading in islanding mode. Disponível em: <http://ieeexplore.ieee.org/stamp/stamp.jsp?arnumber=06485958> Acesso em: 18 Abr. 2013.

[26] YUAN LUO.; ITAYA, S. ; NAKAMURA, S. ; DAVIS, P. Autonomous cooperative energy trading between prosumers for microgrid systems. In: IEEE 39 th $^{\text {th }}$ Conference on Local Computer Networks Workshops, Edmonton, Canada, 8-11 Sept. 2014.

[27] LASSETER, R. H.; PIAGI P. Microgrid: a conceptual solution. In: Proc. $35^{\text {th }}$ Annual Power Electronics Specialists Conference (PESC'04), Aachen, Germany, 20-25 Jun. 2004. Disponível em: <http://scholar.google.com.br/scholar?q=Microgrid:+A+Conceptual+Solution \&hl=ptBR\&as_sdt=0\&as_vis=1\&oi=scholart > Acesso em: 13 Mar. 2010.

[28] TWAITE, K. Monopoly money: reaping the economic and environmental benefits of microgrids in exclusive utility service territories. Vermont Law Review, v. 34, 2010. Disponível em: <http://lawreview.vermontlaw.edu/articles/v34/4/twaite.pdf> Acesso em: 14 mar 2012.

[29] EL-KHATTAM W.; SALAMA M.M.A. Distributed generation technologies, definitions and benefits. Elsevier Electric Power Systems Research, v. 71, p. 119-128, 2004.

[30] WIKIPEDIA, Steam turbine. Disponível em: <http://en.wikipedia.org/wiki/Steam_ turbine> Acesso em: 24 out. 2011.

[31] SIEMENS, Combined cycle power plants. Disponível em: <http://www.siemens.com/ sustainability/en/environmental-portfolio/products-solutions/fossil-power-generation/combined-cycle-power-plants.htm> Acesso em: 04 jan. 2012. 
[32] ABE Eólica, Expansão de eólicas é de $216 \%$ em três anos. Disponível em: <http://www.abeeolica.org.br/site/zpublisher/materias/Noticias.asp?id=20321> Acesso em: 04 dez. 2012.

[33] UNICAMP, Sistemas fotovoltaicos conectados à rede elétrica no Brasil: Panorama da atual legislação, Relatório Final. Disponível em: <http://www.fem.unicamp.br/ jannuzzi/ documents/RELATORIO_PROJETO_2_FINAL.pdf> Acesso em: 30 mar. 2011.

[34] RENEWABLES FIRST. What is the difference between micro, mini and small hydro? Disponível em: <http://www.renewablesfirst.co.uk/hydro-learning-centre/what-is-the-difference-between-micro-miniand-small-hydro/> Acesso em: 24 jan. 2013.

[35] CERPCH - Centro Nacional de Referência em Pequenas Centrais Hidrelétricas. Disponível em:<www.cerpch.unifei.edu.br/> Acesso em: 26 abr. 2011.

[36] GUOJU, Z.; XISHENG, T.; ZHIPING, Q. Research on battery supercapacitor hybrid storage and its application in microgrid. In: Power and Energy Engineering Conference (APPEEC), AsiaPacific, p. 1-4, 2010.

[37] Wikipidea, Flywheel. Disponível em: <http://en.wikipedia.org/wiki/Flywheel> Acesso em: 24 out. 2011.

[38] ZHANG GUOJU, TANG XISHENG, QI ZHIPING, Research on battery supercapacitor hybrid storage and its application in microGrid. In: Power and Energy Engineering Conference (APPEEC), 2010 Asia Pacific.

[39] SCRIGNOLI, M. G. Sistemas elétricos híbridos eólico-fotovoltaicos: estudo de viabilização técnica e econômica em sistemas isolados - cargas individuais e minirredes. Projeto de formatura, Escola Politécnica da Universidade de São Paulo, 75 pp., 2010.

[40] J. ANDUAGA, M. BOYRA, I. COBELO, E. GARCíA, A. G.DE MURO, J. JIMENO, I. LARESGOITI, J. OYARZABAL, E. PEREA, R. RODRÍGUEZ, E. SÁNCHEZ, E. TURIENZO, E. ZABALA, La Microrred, una alternativa de futuro para un suministro energético integral, 142 pp.Tecnalia, 2008.

[41] J. J. JACKSON, F. MWASILU, J. LEE, J.-W. JUNG, AC-microgrids versus DC-microgrids with Distributed Energy Resources: A review. Renewable and Sustainable Energy Reviews Journal, v. 24, Aug. 2013. pp. 387-405. Disponível em: http://www.sciencedirect.com/science/article/pii/S1364032113002268

[42] D. CORNFORTH, T. MOORE, S. SAYEEF, Challenges and opportunities for inverters in microgrids. In: $37^{\text {th }}$ IEEE Annual Conference on Industrial Electronics Society (IECON 2011), Melbourne, 2011, pp. 3111-3116.

[43] HERMAN, D. EPRI project manager, investigation of the technical and economic feasibility of micro-grid based power systems. Disponível em: <http://www.epri.com/abstracts/Pages/ProductAbstract.aspx?Productld=000000000001009483>. Acesso em: 01 out. 2012.

[44] ZAMORA, R.; SRIVASTAVA, A.K. Controls for microgrids with storage: Review, challenges, and research needs. Renewable and Sustainable Energy Reviews, v. 14, n. 7, p. 2009-2018.

[45] HATZIARGYRIOU, N. Advanced architectures and control concepts for more microgrids. Disponível em: < www.microgrids.eu/documents/esr.pdf > Acesso em: 05 out. 2011.

[46] National Association of Regulatory Utility Commissioners (NARUC). Review of utility interconnection, tariff and contract provisions for distributed generation Disponível em: <www.distributed-generation.com/library/naruc_interconnection.pdf>Acesso em: 14 Out. 2013. 
[47] COSTA, P.M.; MATOS, M.A. Economic analysis of microgrids including reliability aspects. In: $9^{\text {th }}$ Int. Conf. on Probabilistic Methods Applied to Power Systems, Stockholm, Sweden, 1115 Jun. 2006.

[48] DEL ROSSO A., GHIA A. Hacia un diseño energético eficiente de una ciudad modelo, Resumen Ejecutivo, Cámara Argentina de la Construcción, Jul. 2008. Disponível em: <www.camarco.org.ar/File/GetPublicFile?id=881> Acesso em: 12 mar. 2013.

[49] KUECK, J. D.; STAUNTON, R.H. ; LABINOV, S.D.; KIRBY, B.J. Microgrid energy management system, CERTS Program Office Lawrence Berkeley National Laboratory, Jan. 29, 2003. Disponível em: <certs.lbl.gov/pdf/phase2-kueck.pdf> Acesso em: 26 nov. 2012.

[50] CHOWDHURY, S.; CHOWDHURY, S.P.; CROSSLEY, P. Microgrids and active distribution networks, p. 321. The Institution of Engineering and Technology, London, United Kingdom, 2009.

[51] C. MARNAY, N. ZHOU, M. QU, J. ROMANKIEWICZ, International microgrid assessment: governance, incentives, and experience (IMAGINE). Lawrence Berkeley National Laboratory Publications, Jun. 2012. Disponível em: <http://eaei.lbl.gov/international-microgrid-assessment-governanceincentives-and-experience-imagine-1.> Acesso em: 14 nov. 2012.

[52] SBI Energy, The world market for microgrids. Disponível em: <http://www.sbireports.com/Microgrids-2835891> Acesso em: 24 ago. 2011.

[53] BORGUETTI; A.; BOSETTI, M.; BOSSI, C.; MASSUCCO, S. An energy resource scheduler implemented in the automatic management system of a microgrid test facility. In: Int. Conf. on Clean Electrical Power, Capri, 21-23 mai. 2007.

[54] BARNES, M.; DIMEAS, A. Microgrid laboratory facilities. In: Int. Conf. on Future Power Systems, Amsterdam, 16-18 Nov. 2005. DOI: 10.1109/FPS.2005.204229

[55] QU, M.; MARNAY, C.; ZHOU, N. Microgrid policy review of selected major countries, regions, and organizations. Final Report, Ernest Orlando Lawrence, Berkeley National Laboratory, nov. 2011. Disponível em: <https://der.lbl.gov/publications/microgrid-policyreview-selected-major-countries-regions-organizations> Acesso em: 10 set. 2013.

[56] HIROSHI I. Sendai microgrid, introduction and use case. Disponível em: <WWW.e2rg.com/microgrid-2012/Sendai_Irie.pdf> Acesso em: 26 set. 2012.

[57] IEEE Spectrum, A microgrid that wouldn't quit. Disponível em: <http://spectrum.ieee.org/energy/the-smarter-grid/a-microgrid-that-wouldnt-quit> Acesso em: 26 set. 2012.

[58] REYES L. Huatacondo's microgrid and the social scada concept. Disponível em: <https://der.lbl.gov/sites/der.lbl.gov/files/jeju_reyes.pdf> Acesso em: 28 nov. 2012.

[59] VENKATARAMANAN, G., MARNAY, C. A larger role for microgrids. IEEE Power and Energy Magazine, v. 6, n. 3, p. 78-82, 2008.

[60] PLANAS, E.; GIL-DE-MURO, A.; et.al. General aspects, hierarchical controls and droop methods in microgrids: A review. Renewable and Sustainable Energy Reviews, Science Direct, v. 17, p. 147-159, jan. 2013.

[61] WIKIPIDEA. Electricity sector in Brazil. Disponível em: <http://en.wikipedia.org/wiki/Electricity _sector_in_Brazil> Acesso em: 03 jun. 2014.

[62] SMART GRID INSIGHTS, Microgrids: The BRICS opportunity, Ed. Zpryme Research \& Consulting, Jul. 2012. Disponível em: <http://etsinsights.com/reports/microgrids-the-brics-opportunity/> Acesso em: 07 mar. 2014. 
[63] ONS - Operador Nacional do Sistema Elétrico, Sistema interligado nacional. Disponível em: <http://www.ons.org.br/conheca_sistema/o_que_e_sin.aspx> Acesso em: 17 ago. 2014.

[64] PASCHOARELI, D. Microgrids in Brazil. 2011 Symposium on Microgrids, Jeju Island, Korea, 26-27 mai. 2011.

[65] CENTRO DE GESTÃO E ESTUDOS ESTRATEGICOS, Redes eletricas inteligentes: contexto nacional, Informe Tecnico p. 172, Brasília, 2012. Disponível em: www.cgee.org.br/atividades/redirect/8050 . Acesso em: 2 mar. 2013.

[66] BOCCUZZI. C.V. Smart Grid e a realidade Brasileira, Revista Smart Energy, Agosto de 2010

[67] AGENCIA NACIONAL DE ENERGIA ELETRICA (ANEEL), Consulta Pública (no 015/2010), Disponível em: http://www.aneel.gov.br/aplicacoes/consulta_publica/documentos/Nota Tecnica_0004_2011_ N015.pdf Acesso em 11 de Abril de 2012.

[68] AMBIENTE ENERGIA. Geração distribuída será beneficiada com a desoneração do PIS e Cofins. Disponivel em <https://www.ambienteenergia.com.br/index.php/2015/03/geracao-distribuida-serabeneficiada-com-desoneracao-pis-e-cofins/25671> Acesso em 24 mar 2015

[69] Y. ZOKA, A. SUGIMOTO, N. YORINO, K. KAWAHARA, J. KUBOKAWA, An Economic Evaluation for an Autonomous Independent Network of Distributed Energy Resources, In Electric Power Systems Research, v. 77, p. 831-838, 2007

[70] L. P. MENDONÇA, Introdução às Microredes e seus Desafios, Trabalho de formatura, Universidade Federal do Rio de Janeiro, p.78, 2011.

[71] J. YANG, J. ZHENG, L. WEI, S. ZHU, The experience and revelation from renewable portfolio standard in Texas for China. In: Int. Conf. Electrical and Control Engineering (ICECE), Yichang, 2011. p. 3236-3239.

[72] EPA United States Environmental Protection Agency, Renewable Energy Certificates (RECs). Disponível em: http://www.epa.gov/greenpower/gpmarket/rec.htm. Acesso em 25 jul 2012.

[73] T. E. DEL CARPIO-HUAYLLAS, D. S. RAMOS, R. L. VASQUEZ- ARNEZ, Feed-in and Net Metering Tariffs: An Assessment for their Application on Microgrid Systems. In: Sixth IEEE/PES LT\&D Latin America Conference and Exposition, 2012.

[74] NEW YORK STATE ENERGY RESEARCH AND DEVELOPMENT AUTHORITY, Microgrids: An Assessment of the Value, Opportunities, and Barriers to Deployment in New YorkState, Final Report 10-35, Sept. 2010. Disponivel em: http://www.nyserda.ny.gov/ /media/Files/Publications/Research/Electic\%20Power\% 20Delivery/ 1035microgrids.ashx?sc_database=web $>$.Acesso em: 16 Abr. 2012

[75] DEL CARPIO HUAYLLAS T.E., RAMOS D.S., Economic Evaluation of a Residential Solar Microgrid Connected to the Distribution System. In: 2013 IEEE PES Conference on Innovative Smart Grid Technologies Latin America (ISGT LA), São Paulo, 15-17 April 2013. pp. 1 - 6.

[76] CPFL Energia S.A. (Companhia Piratininga de Força e Luz), Relatório Final Projeto P\&D: Campanha Otimizada de Medição de Curvas de Carga Multiprocesso - PA0025 (1178-RTFINAL-R0-14)., Mar.2014.

[77] RETSCREEN INTERNATIONAL. Disponível em: http://www.retscreen.net/

[78] NEOSOLAR ENERGIA. Disponível em: http://www.neosolar.com.br/kit-gridtie-para-conexao-a-rede-1$2 \mathrm{kw}$.html.

[79] M. GRADELLA VILLALVA, J. RAFAEL GAZOLI, Energia Solar Fotovoltaica Conceitos e Aplicações: Sistemas Isolados e Conectados à Rede, Ed.Érica, p. 2012. 
[80] A.S. BOUAZZI. Feed-in Tariffs Ltd., The Information Site for the New Guaranteed Payments for Renewable Electricity in the UK. Disponível em:http:/www.fitariffs.co.uk/ Acesso em: 14 Mar. 2013.

[81] PRESIDÊNCIA DA REPÚBLICA, Medida Provisória no 579, Disponível em: www.planalto.gov.br/ccivil_03/_ato2011-2014/2012/../579.htm

[82] RAMOS D.S., BALAN M. Integração de Plantas Eólicas e Solares Fotovoltaicas a Usinas Hidrelétricas Existentes: Uma Abordagem via Complementação Energética com o suporte prático da instalação de plantas Piloto com diferentes tecnologias. Projeto de P\&D, CESP, MRTS Consultoria, USP, Relatorio 1, Dez. 2014.

[83] OFFICE OF ELECTRICITY DELIVERY AND ENERGY RELIABILITY, Smart Grid R\&D Program, Summary Report: 2012 DOE Microgrid Workshop. pp. C-2 \& E4. Disponível em <http://www.iitmicrogrid.net/event/2012\%20Microgrid\%20Workshop\%20Report\%2009102012.pdf?iframe=true\&width=9 80\&height $=780>$ acesso em

[84] S. CHAKRABORTY, M.G. SIMÕES, W. KRAMER, Power Electronics for Renewable and Distributed Energy Systems, Springer, London, 2013.

[85] WHITBY, B., UGALDE-LOO, C.E. Performance of Pitch and Stall Regulated Tidal Stream Turbines. In: IEEE Transactions on Sustainable Energy, v. 5, n 1, 15 Ago. 2013.

[86] ANSI/IEEE C37.106-1987 WG, Guide for Abnormal Frequency Protection for Power Generating Plants, New York, 1987. pp. 1-32. DOI: 10.1109/IEEESTD.1987.79552

[87] DELFINO B, MASSUCCO S, MORINI A, SCALERA P, SILVESTRO F. Implementation and Comparison of Different Under Frequency Load-Shedding Schemes. In: Power Engineering Society Summer Meeting, v. 1, pp. 308-312, 2001.

[88] MULJADI E, SAMAAN N, GEVORGIAN V, LI J, PASUPULATI S. Short Circuit Current Contribution for Different Wind Turbine Generator. In: IEEE Power and Energy Society 2010, GM, Minneapolis, Jul. 25-29, 2010.

[89] THE MATHWORKS INC., N.J. (USA), Student Edition of Matlab/Simulink, v. 7.12.0.635, 2011.

[90] DEL CARPIO HUAYLLAS, T.E., RAMOS, D.S., VASQUEZ ARNEZ, R.L., Microgrid Systems: Main Incentive Policies and Performance Constraints Evaluation for their Integration to the Network. IEEE Latin America Transactions (Revista IEEE America Latina), v. 12, No. 6, 08 Sept. 2014. pp. 1078 - 1085. DOI: 10.1109/TLA.2014.6894003

[91] PSCAD/EMTDC®, Manitoba HVDC Research Center, v.4.3.1.0 (x4), 2010

[92] R.L. VASQUEZ-ARNEZ, D.S. RAMOS, T.E. DEL CARPIO-HUAYLLAS, Microgrid Dynamic Response During the Pre-planned and Forced Islanding Processes Involving DFIG and Synchronous Generators. Int. Journal of Electrical Power \& Energy Systems (www.elsevier.com), v. 62, pp. 175-182, Nov. 2014. ISSN: 0142-0615, DOI: 10.1016/j.jjepes.2014.04.044

[93] SARMA MS. Electric Machines: Steady-State Theory and Dynamic Performance, Boston, MA, PWS Pub. Co., $2^{\text {nd }}$ Ed., 1994

[94] R.L. VASQUEZ-ARNEZ, D.S. RAMOS, T.E. DEL CARPIO-HUAYLLAS, Load Shedding Application within a Microgrid to Secure its Islanded Mode of Operation. In: Proc. 2013 Int. Conf. of Electrical and Electronics Engineering (ICEEE-WCE), London (U.K.), v. II, pp. 1127-1132, 3-5 July, 2013.

[95] HASE, Y., Handbook of Power System Engineering, John Wiley \& Sons Ltd, England, 2007. Pp. 451-452. 
[96] BROUSSARD, D.G., Understanding Short Circuit Motor Contribution, Vector, Jun. 2013. pp.45. http://www.ee.co.za/wp-content/uploads/legacy/Vector\%202013/vector_june2013_ge.pdf

[97] T.E. DEL CARPIO-HUAYLLAS., RAMOS D.S, VASQUEZ-ARNEZ R.L. Microgrid Systems: Current Status and Challenges. In: 2010 IEEE-PES Transmission \& Distribution Conference and Exposition Latin American, São Paulo, Nov. 8-10, 2010. pp: 7-12. DOI: 10.1109/TDCLA.2010.5762853.

[98] M. MENDONÇA, D. JACOBS, B.K. SOVACCOL, Powering the Green Economy: The Feed-in Tariff Handbook, 1st Ed., Earthscan Press, 2009.

[99] L.T. WITZLER; Metodologia para Reconstrução de Séries Históricas de Vento e Geração Eólica Visando a Análise da Complementariedade Energética no Sistema Interligado Nacional. Diss. de Mestrado. Escola Politécnica da Universidade de São Paulo, 2015. pp. 183, Cap. 4.

[100] Relatório Final de Projeto SEE no 61.215/2013, Estudo de Avaliação da Atratividade de Integração das Fontes Solar e Hidrelétrica contemplando definição de Metodologia e Modelo de Simulação, GEPEA/EPUSP, Abr. 2015.

[101] R.L. VASQUEZ-ARNEZ, D.S. RAMOS, T.E. DEL CARPIO-HUAYLLAS, Overvoltage Condition Assessment of a Microgrid due to Faults Occurring in the Islanded Mode of Operation. Submetido a: Energy and Power Engineering Journal (Scientific Research Open Access), under code: ID 6201850, 02 Jul. 2015. 


\section{Anexo A: Sistema Implementado no MATLAB/Simulink}

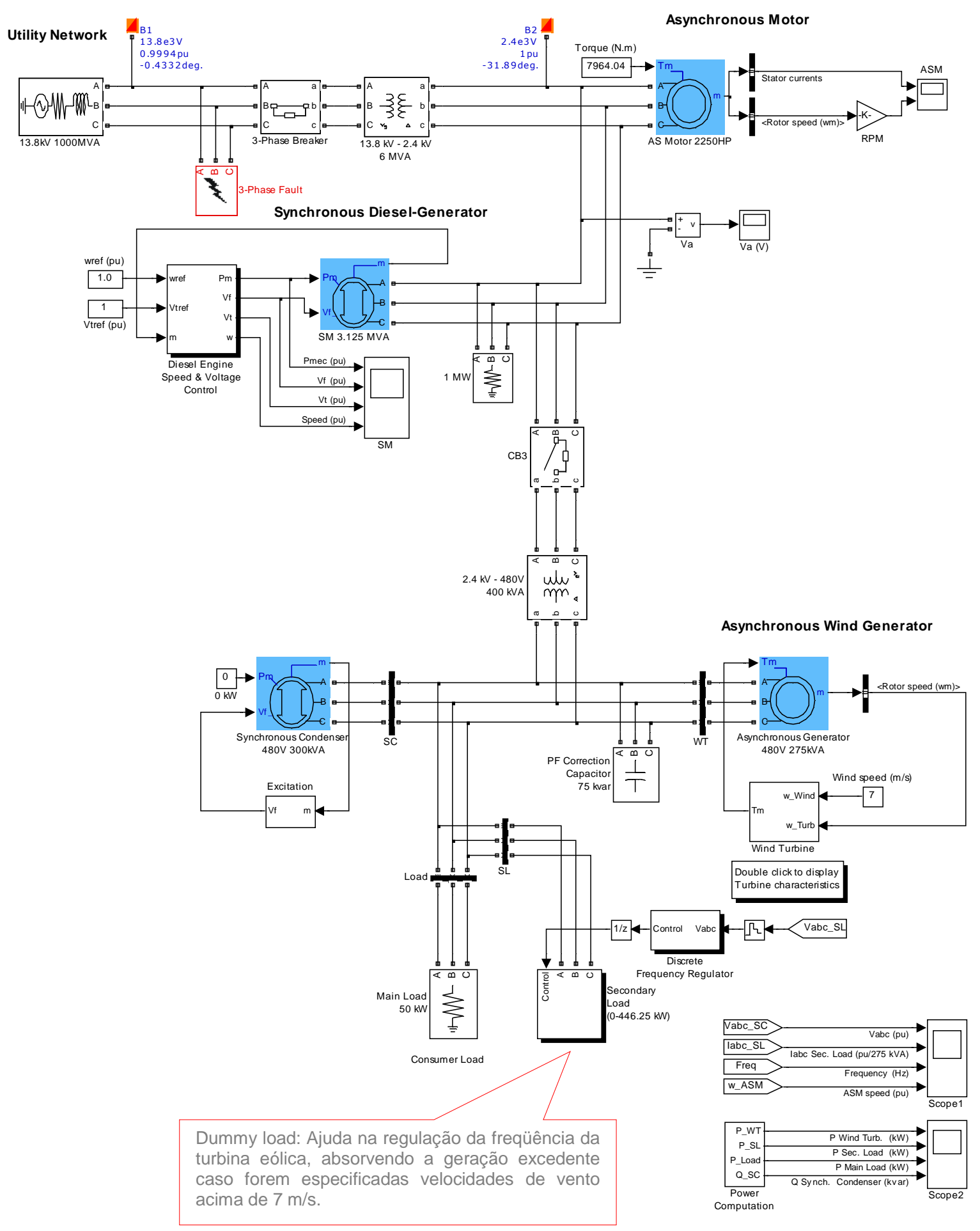

Figura A1. Sistema utilizado no Matlab/Simulink. 


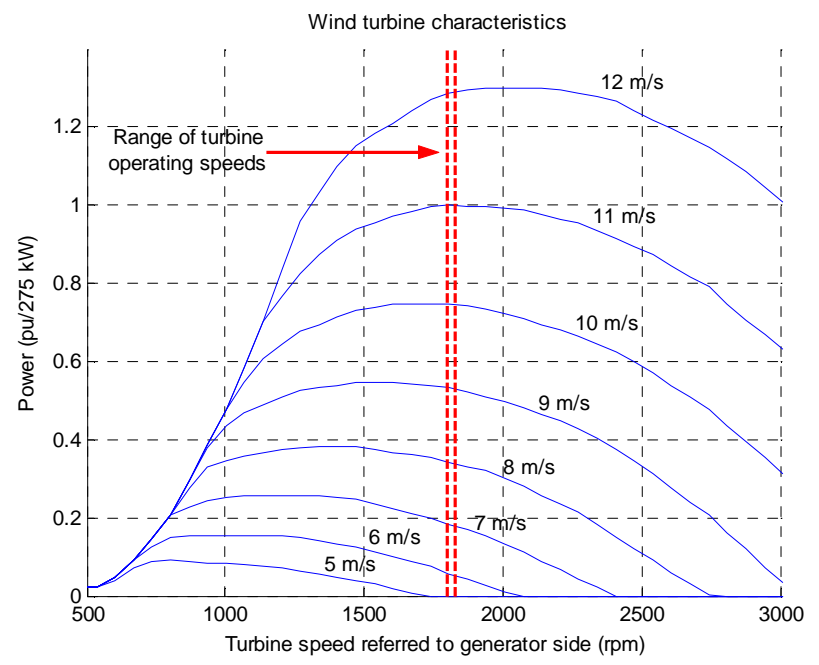

Figura A2. Relação potência x rpm do gerador eólico utilizado. 
Anexo B: Sistema Implementado no Programa PSCAD/EMTDC

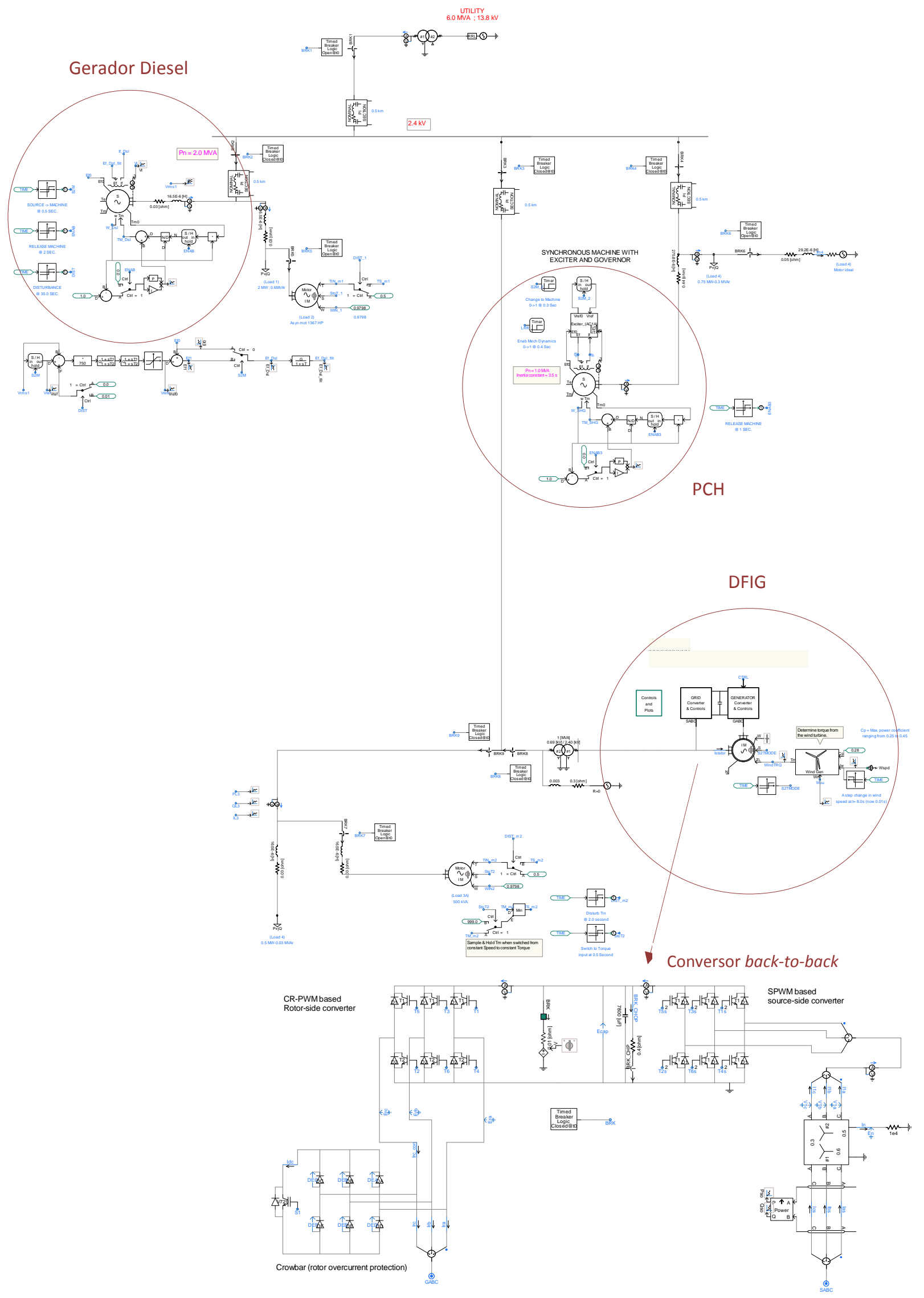




\section{PUBLICAÇÕES}

Resultado da pesquisa desenvolvida neste trabalho, foram publicados em periódicos e congressos internacionais e nacionais os seguintes artigos:

Periódicos:

[1] Vasquez-Arnez R.L., Ramos D.S., Del Carpio-Huayllas T.E., Microgrid Dynamic Response During the Pre-planned and Forced Islanding Processes Involving DFIG and Synchronous Generators. International Journal of Electrical Power \& Energy Systems (www.elsevier.com), Vol. 62, pp. 175-182, Nov. 2014. ISSN: 0142-0615, DOI: 10.1016/j.ijepes.2014.04.044

[2] Del Carpio Huayllas T.E., Ramos, D.S., Vasquez Arnez, R.L., Microgrid Systems: Main Incentive Policies and Performance Constraints Evaluation for their Integration to the Network. IEEE Latin America Transactions, Vol. 12, No. 6, 08 Sept. 2014. pp. 1078 - 1085. ISSN: 1548-0992. DOI: $\underline{10.1109 / T L A .2014 .6894003}$

[3] Ramos D.S., Del Carpio-Huayllas T.E., Vasquez-Arnez R.L., Load Shedding Application within a Microgrid to Assure its Dynamic Performance during its Transition to the Islanded Mode of Operation, Energy and Power Engineering Journal (Scientific Research Open Access), Vol.5, No.7, Sept. 03, 2013. pp. 437-445, ISSN 1949-243X. DOI: 10.4236/epe.2013.57047 http://www.scirp.org/journal/epe/

Artigos submetidos a periódicos:

[4] Vasquez-Arnez R.L., Ramos D.S., Del Carpio-Huayllas T.E., Overvoltage Condition Assessment of a Microgrid due to Faults Occurring in the Islanded Mode of Operation. Submetido a: Energy and Power Engineering Journal (Scientific Research Open Access), under code: ID 6201850, 02 Jul. 2015.

Congressos:

[1] Vasquez-Arnez R.L., Ramos D.S., Del Carpio Huayllas T.E., Load Shedding Application within a Microgrid to Secure its Islanded Mode of Operation. In: International Conference of Electrical and Electronics Engineering (ICEEE-2013), London (U.K.), Ago. 2013.

[2] Del Carpio Huayllas T.E., Ramos D.S., Economic Evaluation of a Residential Solar Microgrid Connected to the Distribution System. In: 2013 IEEE PES Conference on Innovative Smart Grid Technologies Latin America (ISGT LA), São Paulo, 15-17 April 2013. pp. 1 - 6. ISBN: 978-1-4673-5272-7, DOI:10.1109/ISGT-LA.2013.6554470. 
[3] Del Carpio Huayllas T.E., Ramos D.S., Vasquez-Arnez R.L., Feed-in and Net Metering Tariffs: An Assessment for their Application on Microgrid Systems. In: $6^{\text {th }}$ IEEE-PES Transmission \& Distribution Conference and Exposition Latin America, Montevideo, 3-5 Sept. 2012. ISBN:978-1-4673-2672-8, DOI: 10.1109/TDC-LA.2012.6319070

[4] Del Carpio Huayllas T.E., Ramos D.S, Vasquez-Arnez R.L., Microgrid Transition to Islanded Modes: Conceptual Background and Simulation Procedures Aimed at Assessing its Dynamic Performance. In: 2012 IEEE-PES Transmission and Distribution Conference and Exposition, Orlando, FL, 7-10 May, 2012. DOI: 10.1109/TDC.2012.6281422

[5] Del Carpio Huayllas T.E., Ramos D.S, Vasquez-Arnez R.L., Microgrid Systems: Current Status and Challenges. In: 2010 IEEE-PES Transmission \& Distribution Conference and Exposition Latin America, São Paulo, Nov. 8-10, 2010. pp: 7-12. DOI: ISBN 978-85-9991603-2. DOI: $10.1109 /$ TDC-LA.2010.5762853

[6] Balan M., Ramos D.S., Del Carpio-Huayllas T.E., Operational Cost Assessment of a Microgrid Generation Comprising Renewable and Non-renewable Generators. In: 2nd Annual Int. Conf. on Technology \& Engineering (ATINER), $22-25$ Jun. 2015, Atenas (Grecia). 